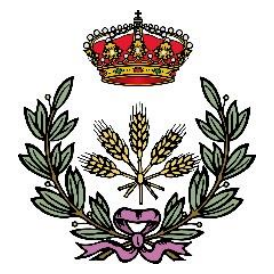

ESCUELA TÉCNICA SUPERIOR DE INGENIERIA AGRONÓMICA, ALIMENTARIA Y DE BIOSISTEMAS

\title{
EVALUACIÓN DE ALTERNATIVAS AGRICOLAS CON ESPECIES DE GRAMÍNEAS PERENNES PARA BIOMASA EN TIERRAS MARGINALES
}

\author{
TESIS DOCTORAL \\ CARLOS SIXTO CIRIA RAMOS \\ INGENIERO AGRÓNOMO
}



ESCUELA TÉCNICA SUPERIOR DE INGENIERIA AGRONÓMICA, ALIMENTARIA Y DE BIOSISTEMAS

UNIVERSIDAD POLITÉCNICA DE MADRID

\section{EVALUACIÓN DE ALTERNATIVAS AGRICOLAS CON ESPECIES DE GRAMÍNEAS PERENNES PARA BIOMASA EN TIERRAS MARGINALES}

CARLOS SIXTO CIRIA RAMOS

INGENIERO AGRÓNOMO

DIRECTORA:

Dra. Mํㅗ Pilar Ciria Ciria. Dra. Ingeniera Agrónoma 



\section{AGRADECIMIENTOS}

Una vez llegado este punto y echando la mirada atrás me gustaría agradecer a mucha gente que ha colaborado y me ha ayudado en la realización de este trabajo.

En primer lugar, me gustaría agradecer a mi directora Pilar todo el esfuerzo y dedicación empleado en mí durante estos largos años en los que siempre me ha guiado por el buen camino. También agradecer a mis coautores de publicaciones, Carlos, Ruth, Marina y Juan toda la ayuda y trabajo prestados. Además, me gustaría agradecer al Ciemat y especialmente a las personas que trabajan en el CEDER, desde su anterior director Miguel Latorre, a su actual directora Raquel Ramos, al personal de administración, taller, laboratorio, en especial a Ruth Barro y a Rocío Cortés, pretratamientos y combustión por ayudarme en todo lo posible. Agradecer a Juan Carrasco, jefe de la Unidad de Biomasa, su ayuda y confianza desde el primer momento y a Javier Pérez y Eva Sevillano su trabajo desinteresado para la consecución de los objetivos fijados.

También agradecer al personal de la Universidad Politécnica, Mª Dolores Curt, Carmen Dieguez y al personal de la biblioteca de la Escuela Técnica Superior de Ingeniería Agronómica, Alimentaria y de Biosistemas su ayuda durante estos años.

No me gustaría olvidar en los agradecimientos a la Dra. Marisol Berti y todo su equipo, Alan, Maciek, Dulan, Wenting y Bob por su ayuda tanto en lo profesional como en lo personal. Agradecer la posibilidad de realizar la estancia y los conocimientos adquiridos en ella, fueron meses de duro trabajo y esfuerzo, lejos de casa, en un lugar recóndito del Medio-Oeste Americano donde me hicieron sentir como si estuviera en casa.

Agradecer a toda mi familia la ayuda durante todos estos meses, en especial a mi tía Pilar de la que no tengo suficientes palabras de reconocimiento para agradecer toda su ayuda. A mis padres Sixto y Elena por darme siempre ánimos y el consejo adecuado, a mis hermanos Fernando y Eduardo por ayudarme en todo lo posible. A mi mujer, Laura, por iluminar mi camino, por aguantarme en los malos momentos y llenar mi vida de felicidad con Marcos y el pequeño que está por venir, los cuales hacen que te levantes cada mañana con ilusiones renovadas. Finalmente, me gustaría dedicar este trabajo a la memoria de mis abuelos Sixto y Alejandra que me enseñaron que la honradez, el trabajo duro y el apego a la tierra que alimenta a la familia son buenas actitudes para pasar por la vida, y dejar tranquilo este mundo cuando te llega la hora.

A todos ellos gracias. 



\section{ÍNDICE DE CONTENIDOS}

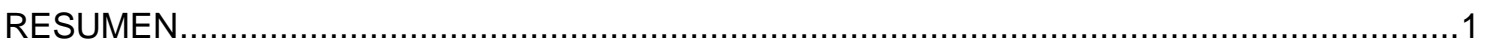

SUMMARY

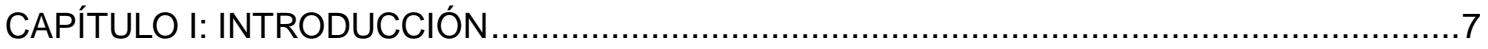

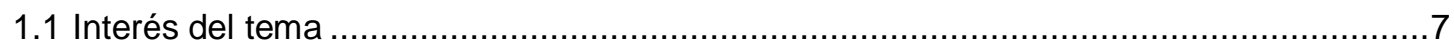

1.1.1 Situación general de la agricultura europea ................................................

1.1.2 Implicación de la PAC en el ámbito de la bioenergía .........................................

1.1.3 Principales amenazas de los sistemas agrarios europeos ................................ 8

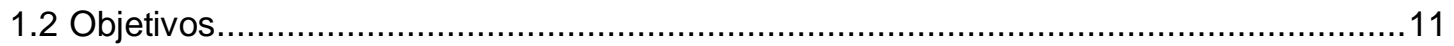

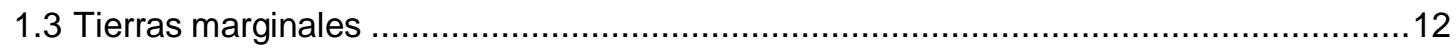

1.3.1 Definición de tierra marginal ................................................................12

1.3.2 Limitaciones biofísicas de las tierras marginales.............................................16

1.3.3 Limitaciones socioeconómicas de las tierras marginales ................................18

1.3.4 Limitaciones de sostenibilidad de las tierras marginales para su utilización con

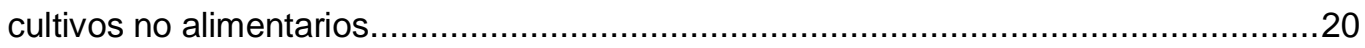

1.3.5 Cartografía de las tierras marginales ....................................................21

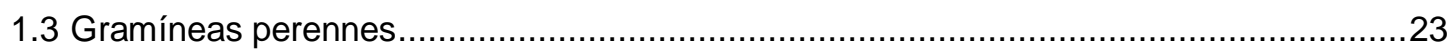

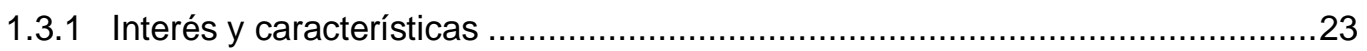

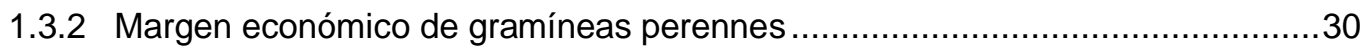

1.3.3 Análisis medioambiental de las gramíneas perennes........................................31

1.3.4 Análisis energético de las gramíneas perennes ............................................31

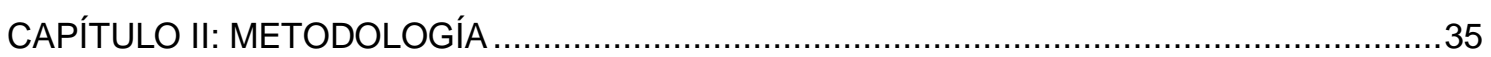

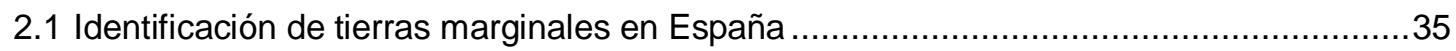

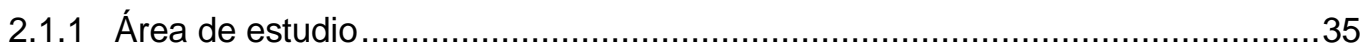

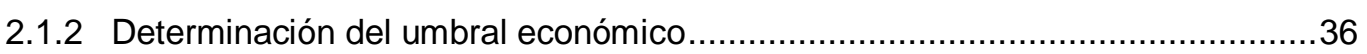

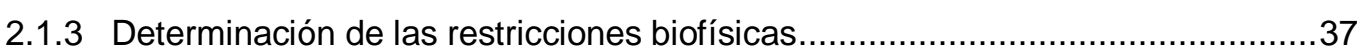

2.1.4 Fuentes de mapeo y gestión de datos .......................................................39

2.2 Ensayos de campo de gramíneas perennes del genero Agropyron...............................39

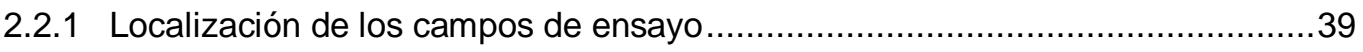

2.2.2 Diseño experimental y manejo de los cultivos..............................................41

2.2.3 Características químico-energéticas y métodos analíticos. ..............................43

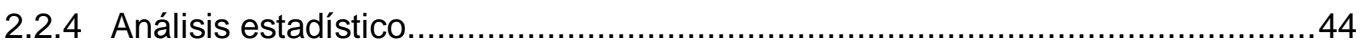

2.3 Comparación económica y medioambiental del agropiro alargado y el centeno en la tierra

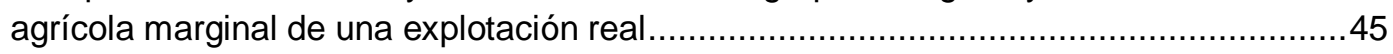

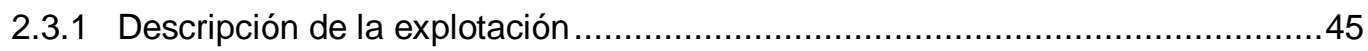

2.3.2 Gestión agrícola de la explotación .................................................................46

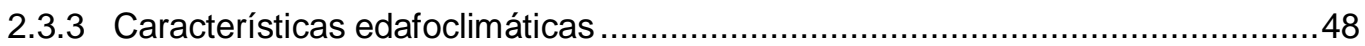




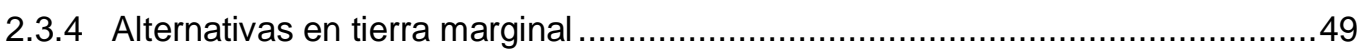

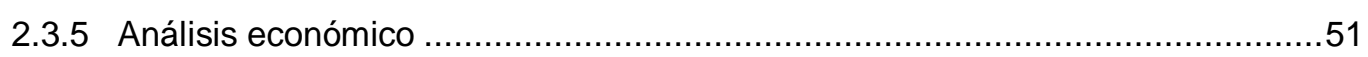

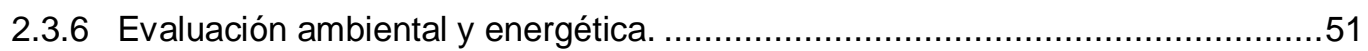

CAPÍTULO III: Artículo 1: Identificación de tierras arables marginales bajo condiciones de

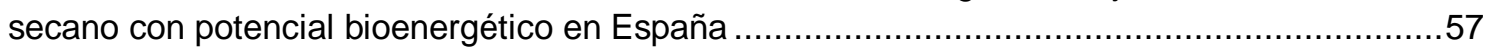

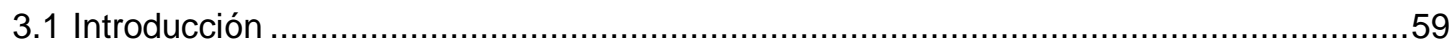

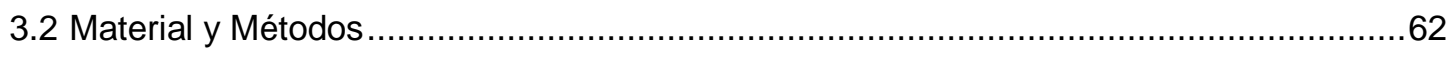

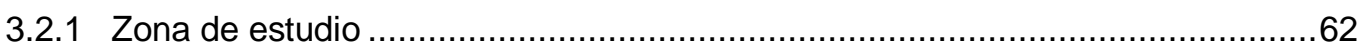

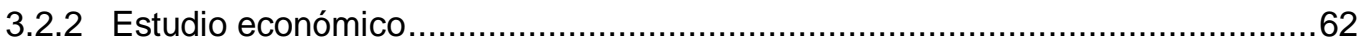

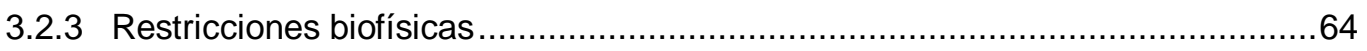

3.2.4 Fuente de mapas y herramienta informática utilizada ....................................66

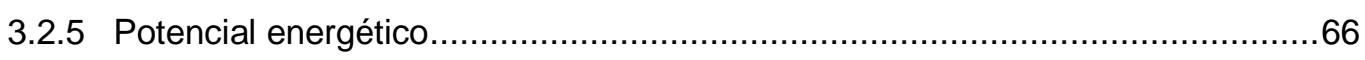

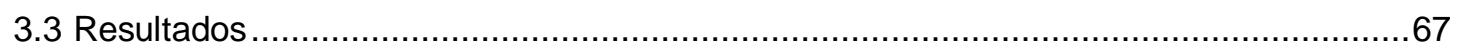

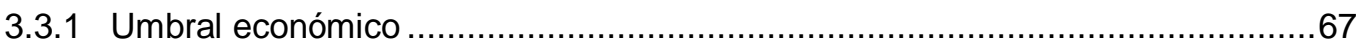

3.3.2 Identificación de las áreas marginales y áreas con limitaciones biofísicas.........67

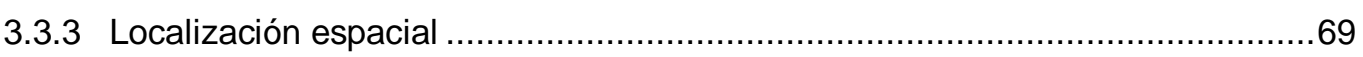

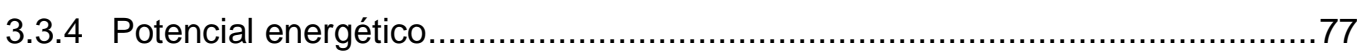

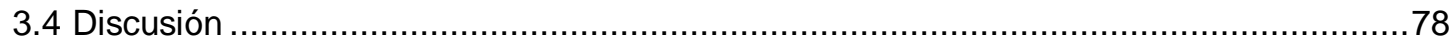

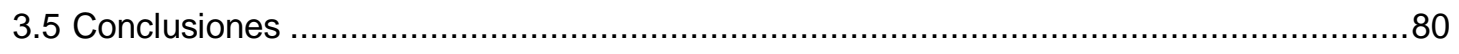

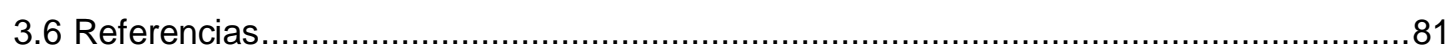

CAPÍTULO IV: Artículo 2: Rendimiento y calidad a largo plazo de especies perennes para

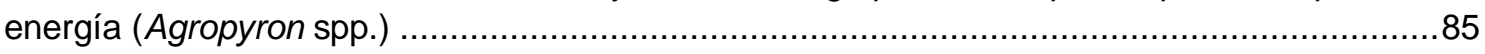

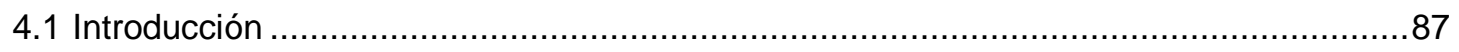

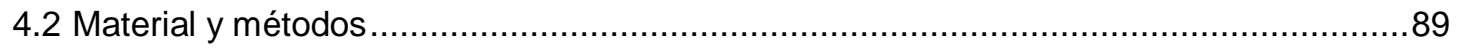

4.2.1 Localización y características edafoclimáticas de las parcelas experimentales 89

4.2.2 Diseño experimental y gestión de los cultivos ..............................................91

4.2.3 Características experimentales y métodos analíticos .....................................92

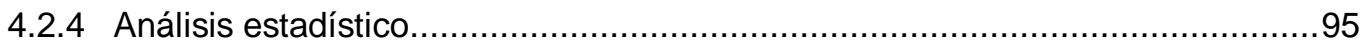

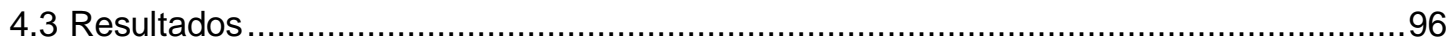

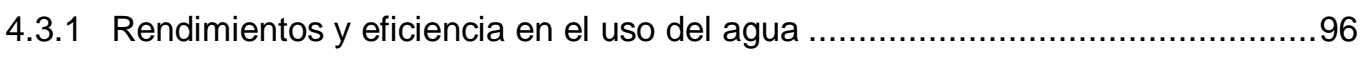

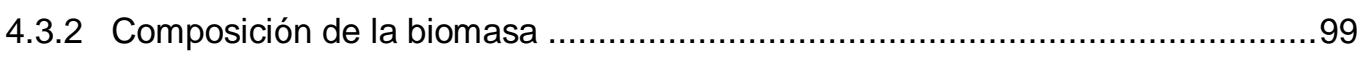

4.3.3 Índices de predicción de combustible .....................................................113

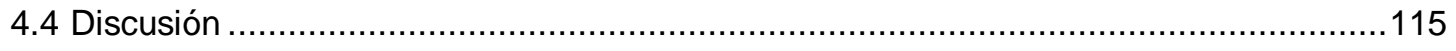

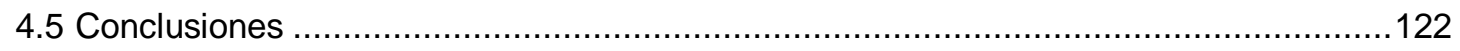

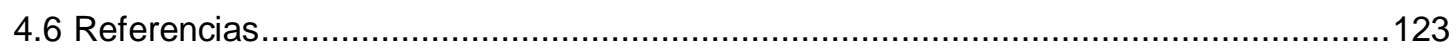

CAPÍTULO V: Artículo 3: Agropiro alargado (Thinopyrum ponticum (Podp) Barkworth \& D.R.Dewey) en el contexto de una explotación agrícola real, una alternativa sostenible comparado con el centeno (Secale cereale L.) en tierra marginal.

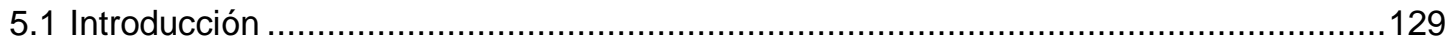




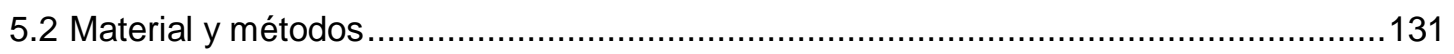

5.2.1 Descripción de la explotación estudiada ....................................................131

5.2.2 Manejo de los cultivos en la explotación .......................................................131

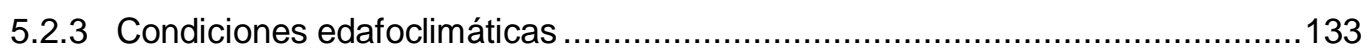

5.2.4 Gestión de la tierra marginal............................................................... 134

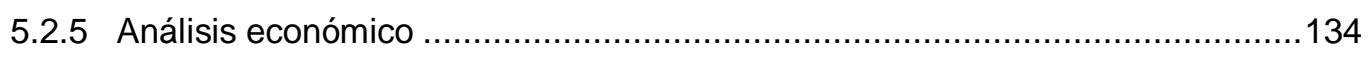

5.2.6 Evaluación energética y ambiental ........................................................ 135

5.2.6 Métodos de evaluación del impacto...........................................................138

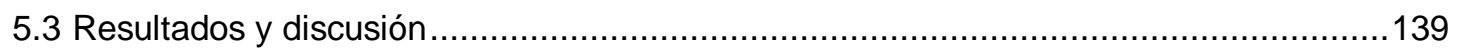

5.3.1 Balance económico de la explotación........................................................139

5.3.2 Evaluación del potencial de calentamiento global de la explotación y de la energía primaria consumida para las alternativas de cultivo en tierra marginal ..........141

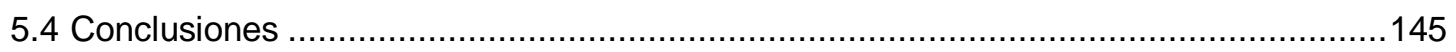

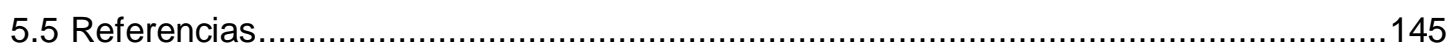

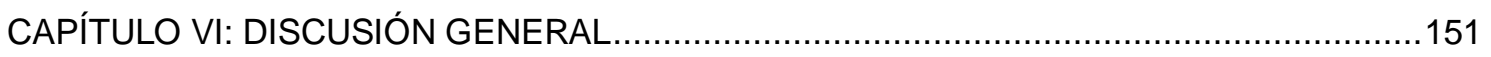

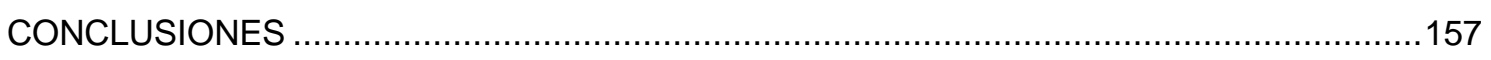

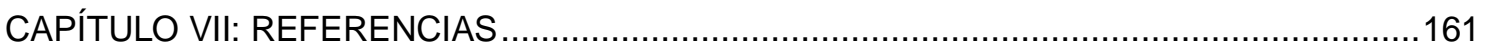

CAPÍTULO VIII: COLECCIÓN COMPLETA DE PUBLICACIONES ......................................177

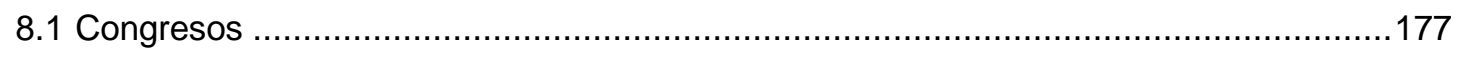

8.1.1 Sustainable Biomass Feedstock Options for Advanced Biofuels ....................177

8.1.2 Biomass Production and Feedstock Diversification for Advanced Biofuels: The

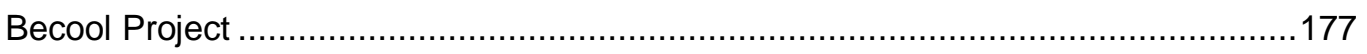

8.1.3 Perennial Grasses as feedstock for Bioenergy and Bio-Products ..................177

8.1.4 Estimation and Geographic Distribution of Marginal Agricultural Lands in Spain

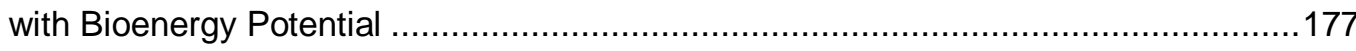

8.1.5 Sunn Hemp, a Promising Leguminous Energy Crop as Inter-Cropping System:

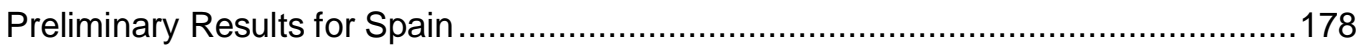

8.1.6 Effect of Harvest Time on the Composition of Tall Wheatgrass Biomass under

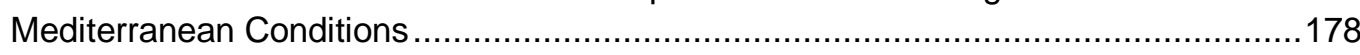

8.1.7 Perennial Grasses: Biomass Quality and Yield Comparison of Different Species in the Northern Great Plains of the United States ............................................... 178

8.1.8 Pure and Mixed Perennial Biomass Crops for a Constraint Marginal Land in

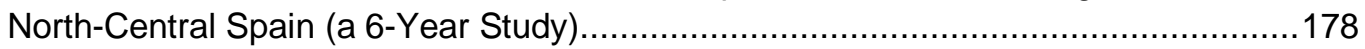

8.1.9 Strategies for Marginal Lands Management in Rain-Fed Agricultural Farms in

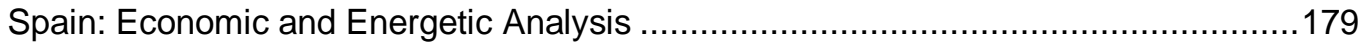

8.1.10 Varietal Response of Elytrigia Elongata under Semiarid Conditions in Spain:

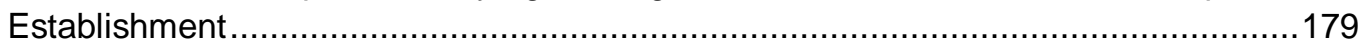

8.1.11 Energy Analysis of Agricultural Exploitations under Rain-Fed Continental Conditions in Central-Northern Spain .

8.1.12 Energy Balance for an Agricultural and Sheep Farming Exploitation under Extensive Conditions in a Semi-Arid Region of Spain. 
8.2 Revistas nacionales

8.2.1 Gramíneas perennes C3 con fines energéticos en sustitución de cultivos

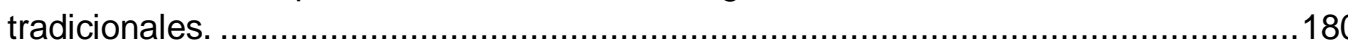

8.2.2 Gramíneas perennes destinadas a biomasa como alternativa en tierras marginales. 180

8.2.3 Balance energético de siete explotaciones agrícolas de secano. 180

8.3 Libros 180

8.3.1 Cultivos herbáceos perennes para producción de biomasa en España. 180

8.3.2 Análisis energético de explotaciones agrícolas de secano. 180 


\section{ÍNDICE DE FIGURAS}

Artículo 1: Identificación de tierras arables marginales bajo condiciones de secano con potencial bioenergético.

Figura 1. Distribución espacial de tierras arables de secano con rendimiento principal de cereales de invierno $\leq 1.5 \mathrm{Mg} \mathrm{ha}^{-1}$.

Figura 2. Tierra arable de secano con profundidad de suelo $<100 \mathrm{~cm} . \ldots \ldots \ldots \ldots .66$

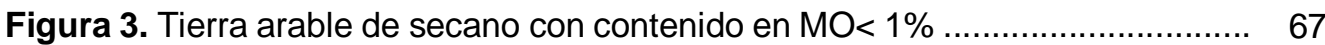

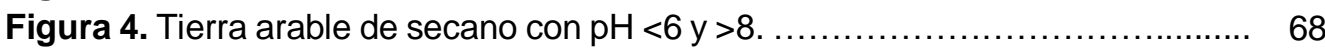

Figura 5. Tierra arable de secano con volumen de piedras $\geq 15 \%$. .................. 69

Figura 6. Tierra arable de secano con suelos tipo Entisol and Aridisol, de acuerdo con la clasificación TAXOUSDA ................................................... 70

Figura 7. Tierra arable de secano con concentración de sales $>4 \mathrm{dS} \mathrm{m}^{-1} \ldots \ldots \ldots . . .71$

Figura 8. Tierra arable de secano con precipitaciones anuales menores de 40072 $\mathrm{mm}$

Figura 9. Distribución espacial de la tierra arable de secano con alguna restricción considerada .........................................................................

Artículo 2: Rendimiento y calidad a largo plazo de especies perennes para energía (Agropyron spp.)

Figura 10. Diagrama ombrotérmico de las parcelas experimentales de Cubo de la Solana. Barras azules y blancas indican un año diferente.

Figura 11. Diagrama ombrotérmico de las parcelas experimentales de Alconaba. Barras azules y blancas indican un año diferente

Figura 12. $\mathrm{PCl}$, contenido en cenizas, $\mathrm{N}, \mathrm{P}, \mathrm{K}, \mathrm{S}, \mathrm{y} \mathrm{Cl}$ de las especies y años de la biomasa cultivada en CS. Medias y gráficas de interacción LSD de Fisher

Figura 13. Variación de $\mathrm{Si}, \mathrm{K}, \mathrm{Ca}$, y $\mathrm{Mg}$ de especies y años de las parcelas experimentales de CS (concentración y sus correspondientes óxidos en las cenizas). Medias y gráficas de interacción LSD de Fisher

Figura 14. $\mathrm{PCl}$, contenido en cenizas, $\mathrm{N}, \mathrm{P}, \mathrm{K}, \mathrm{Ca}, \mathrm{Si}$, y $\mathrm{Zn}$ de cultivares y años para la biomasa producida en los campos experimentales de AL. Medias y gráficas de interacción LSD de Fisher

Figura 15. Índices de combustible por especies y años para la biomasa cultivada en las parcelas de CS. Medias y gráficas de interacción LSD de Fisher

Artículo 3: Agropiro alargado (Thinopyrum ponticum (Podp) Barkworth \& D.R. Dewey) en el contexto de una explotación agrícola real, una alternativa sostenible comparado con el centeno (Secale cereale L.) en tierra marginal.

Figura 16. Descripción del sistema de evaluación ambiental y energética gráficamente. Incluye el diagrama de flujo con todos los procesos considerados, los límites del sistema, así como la unidad funcional especificada para las dos alternativas de cultivo en la zona de tierras marginales de la explotación en estudio

Figura 17. Potencial de calentamiento global para cada alternativa.

Figura 18. Energía primaria total consumida para el cultivo del agropiro alargado y el centeno en la explotación estudiada

Figura 19. Diferencias entre la energía primaria renovable y no renovable consumida para cada alternativa 



\section{ÍNDICE DE TABLAS}

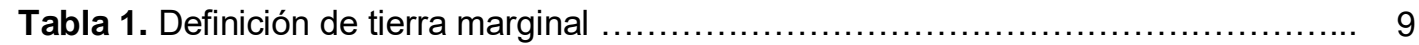

Tabla 2. Clasificación de la capacidad de la tierra (LCC) elaborada por el USDA ........ 12

Tabla 3. Coste horario de maquinaria y mano de obra para cada trabajo agrícola ....... 32

Tabla 4. Costes de materias primas y precio de venta del trigo y la cebada dependiendo de la producción .......................................................... 33

Tabla 5. Técnicas analíticas y estándares seguidos durante las pruebas ............... 40

Tabla 6. Inputs y dosis utilizadas en la explotación ......................................... 44

Artículo 1: Identificación de tierras arables marginales bajo condiciones de secano con potencial bioenergético.

Tabla 7. Costes horarios y mano de obra para cada tipo de trabajo agrícola ............... 59

Tabla 8. Inputs y outputs estudiados para rendimientos de trigo y cebada.................. 60

Tabla 9. Resultado de los inputs y outputs de los cultivos y margen económico calculado de acuerdo con la producción de grano esperada .......................................... 63

Tabla 10. Superficie de las diferentes restricciones biofísicas en municipios con una productividad media $\leq 1,5 \mathrm{Mg} \mathrm{ha}^{-1}$ en condiciones de secano

Tabla 11. Superficie con restricciones biofísicas en tierra arable de secano en España municipios con rendimientos $>1,5 \mathrm{Mg} \mathrm{ha}^{-1}$.

Tabla 12. Superposición de dos restricciones biofísicas (Valores expresados en \% de superficie)

Artículo 2: Rendimiento y calidad a largo plazo de especies perennes para energía (Agropyron spp.)

Tabla 13. Técnicas analíticas y normas seguidas durante las pruebas

Tabla 14. Análisis de varianza de los efectos fijos de especies $(S)$, cultivares $(C)$ y año (Y) de los rendimientos en MS de la biomasa y EUA de la biomasa producida....

Tabla 15. Rendimientos de biomasa de las parcelas experimentales de CS y AL. Datos proporcionados en Mg de MS.ha ${ }^{-1} \ldots$

Tabla 16. EUA de las parcelas de CS y AL. Datos reportados en $\mathrm{g} \mathrm{MS} \cdot \mathrm{L}^{-1} \ldots \ldots \ldots \ldots \ldots \ldots \ldots$

Tabla 17. Influencia de la especie, cultivar, y año en las propiedades y composición química de la biomasa en los dos campos de ensayo estudiados (CS y AL)

Tabla 18. Contenido en cenizas, poderes caloríficos y análisis inmediato de la biomasa de las diferentes gramíneas perennes recolectadas entre 2012 y 2018 en las parcelas de CS. Valores medios de tres repeticiones por especie, cultivar y año

Tabla 19. Elementos mayoritarios presentes en la biomasa de las diferentes especies perennes recolectadas en CS entre 2012 y 2018. Valores medios de tres repeticiones por especie y año

\section{.}

Tabla 20. Contenido de cenizas, poderes caloríficos y análisis inmediato de los cultivares de agropiro alargado recolectados en las parcelas de AL de 2014 a 2018. Valores medios para cuatro repeticiones por cultivar y año.....

Tabla 21. Elementos mayoritarios presentes en la biomasa de los cultivares de agropiro alargado recolectados en las parcelas de AL de 2014 a 2018. Valores medios para cuatro repeticiones por cultivar y año

Tabla 22. Índices empíricos de predicción de combustible para la biomasa cultivada en ambos lugares (CS y AL) y niveles de significación para los factores considerados 
Artículo 3: Agropiro alargado (Thinopyrum ponticum (Podp) Barkworth \& D.R. Dewey) en el contexto de una explotación agrícola real, una alternativa sostenible comparado con el centeno (Secale cereale L.) en tierra marginal

Tabla 23. Inputs y dosis utilizadas para cada cultivo durante los años de estudio

Tabla 24. Balance económico de los cultivos sembrados en la explotación de estudio (valores anuales medios ponderados en los 4 años) 


\section{ÍNDICE DE FOTOGRAFÍAS}

Foto 1. Espiga de agropiro alargado (izquierda), agropiro crestado (centro) y agropiro siberiano (derecha) (25 de junio de 2018).

Foto 2. Suelo del ensayo de Alconaba (izquierda, noviembre de 2014) y suelo del ensayo de cubo de la Solana (derecha, enero de 2011)

Foto 3. Croquis general del ensayo de Cubo de la Solana (izquierda) y del ensayo de Alconaba (derecha).

Foto 4. Agropiro alargado cultivar Alkar. Antes del abonado de cobertera (arriba izquierda); después del abonado de cobertera (arriba derecha); espigado (abajo izquierda) y floración (abajo derecha).

Foto 5. Microscopio electrónico de barrido con microanálisis de elementos (izquierda); calorímetro, prensa y reactivos para determinar el poder calorífico de las muestras (centro) y analizadores elementales CHNS (derecha).

Foto 6. Panorámica general de alguna de las parcelas de la explotación estudiada (julio de 2016)

Foto 7. Distintas labores agrícolas realizadas con la maquinaria de la explotación considerada (año 2015). Cultivar (izquierda), siembra de girasol (centro), cosecha de cereal (derecha).

Foto 8. Vista general de la parcela sembrada de agropiro alargado durante los años de estudio

Foto 9. Siega (arriba izquierda), empacado (arriba derecha), recogida de la biomasa (abajo izquierda) y vista general de la parcela de agropiro alargado después de recoger la biomasa (abajo derecha) (agosto de 2017).

Foto 10. Parcela de agropiro alargado (izquierda) y parcela adyacente de barbecho tradicional (derecha) después de una tormenta (agosto de 2018). 



\section{ABREVIATURAS}

Agencia Estatal de Meteorología

AEMET

Agencia Europea del Medio Ambiente

AEMA

Agropiro alargado

TW

Agropiro alargado cultivar Alkar

TWA

Agropiro alargado cultivar Bamar

TWB

Agropiro alargado cultivar Jose

TWJ

Agropiro alargado cultivar Riparianslopes

TWR

Agropiro alargado cultivar Szarvasi-1

TWS

Agropiro crestado

CW

Agropiro crestado cultivar Hycrest

$\mathrm{CWH}$

Agropiro siberiano

SW

Agropiro siberiano cultivar Vavilov II

SWV

Alconaba

$\mathrm{AL}$

Análisis de ciclo de vida

ACV

Análisis de la varianza de medias

ANOVA

Análisis de requisitos de energía acumulada

CERA

Áreas agronómicas homogéneas

$\mathrm{AAH}$

Base de datos histórica mundial del medio ambiente

HYDE

Base seca

bs

Centro común de investigación de la Comisión Europea

JRC

Centro de Sostenibilidad y de Medio Ambiente

SAGE

Clasificación de la capacidad del suelo-USDA

LCC

Comunidad Económica Europea

CEE

Consorcio de centros de investigación agraria

CGIAR

Cromatografía iónica

IC

Cubo de la Solana

CS

Cultivar

CV.

Departamento de agricultura de EE.UU

USDA

Desviación estándar

SD

Detección de conductividad térmica

TCD

Detección infrarroja

IRD

Mínima diferencia significativa

LSD

Digestion con microondas

MD

Eficiencia del uso del agua 
Environmental Research Institute

ESRI

Evapotranspiración de los cultivos en condiciones estándar

ETC

Fondo agrícola de desarrollo europeo

FEADER

Gases de efecto invernadero

GEI

Guía visual de evaluación de suelos

VSA

Índices de diferencias normalizadas de vegetación

NDVI

Instituto Internacional de Sistemas aplicados

IIASA

Materia orgánica

MO

Materia seca

MS

Nitrato amónico cálcico

NAC

Panel intergubernamental sobre el Cambio Climático

IPCC

Plasma acoplado inductivamente-espectroscopia de emisión óptica

ICP-OES

Poder calorífico inferior

$\mathrm{PCl}$

Poder calorífico inferior a presión constante

$\mathrm{PCl}_{\mathrm{p}, 0}$

Poder calorífico superior

PCS

Poder calorífico superior a volumen constante

$\mathrm{PCS}_{\mathrm{v}, 0}$

Política Agrícola Común

PAC

Potencial de calentamiento global

PCG

Sistema de Información de Ocupación del Suelo en España

SIOSE

Sistema de información geográfica

SIG

Sistemas agrarios de alto valor natural

SAVN

Temperatura de sinterización de las cenizas

TSC 


\section{RESUMEN}

El optimismo sobre el potencial de los biocombustibles como alternativa a los combustibles fósiles era elevado a principios del siglo XXI. Se esperaban beneficios tales como, la reducción de emisiones de gases de efecto invernadero, la descarbonización de la electricidad y el calor y un mayor desarrollo de las zonas rurales. Sin embargo, existía una creciente especulación sobre la controvertida contribución de los biocombustibles al aumento de los precios de los alimentos y al uso de agua dulce. Esto planteó cuestiones importantes sobre el uso de tierras arables para cultivos dedicados a la producción de biocombustibles y generó una disyuntiva entre la producción de alimentos o biocombustibles. En este contexto, las tierras marginales se han erigido como la principal alternativa de superficie para la producción de cultivos energéticos. Así pues, los agricultores necesitan encontrar alternativas fiables en zonas agrícolas marginales de secano donde la producción de cultivos alimentarios difícilmente es económicamente sostenible, y en las que el cultivo de gramíneas perennes destinadas a la producción de energía, podría ser una de las mejores alternativas.

El objetivo general de este estudio es identificar áreas donde los cultivos alimentarios tradicionales no son económicamente sostenibles debido a restricciones biofísicas, evaluar la introducción de diferentes especies de gramíneas perennes C3 del género Agropyron spp. en tierra arable marginal de secano desde un punto de vista agronómico $y$, evaluar la viabilidad de la introducción de las citadas especies en zonas marginales de explotaciones agrícolas reales comparando la respuesta de las nuevas especies con el cultivo sembrado tradicionalmente en esas zonas.

España tiene una superficie de 9,93 millones de hectáreas (Mha) de tierra cultivable de secano con limitaciones biofísicas y/o económicas, donde el bajo contenido de materia orgánica es la principal limitación. La evaluación de las diferentes alternativas de gramíneas perennes reveló que el agropiro alargado (Agropyron elongatum (Host) Beauv.) obtuvo las mejores producciones de biomasa $\left(4,8 \mathrm{Mg} \cdot \mathrm{ha}^{-1} \cdot \mathrm{año}^{-1}\right)$, y una calidad de la biomasa similar al resto de las especies estudiadas. La biomasa obtenida de las especies evaluadas mostró contenidos relativamente altos de cenizas, silicio y elementos alcalinos y poderes caloríficos inferiores entre 16,7 y $18,5 \mathrm{MJ} \cdot \mathrm{kg}^{-1}$ en base seca. Además, agropiro alargado mostró una sensible mejora en el balance económico (156 €·ha ${ }^{-1} \cdot$ año $^{-1}$ ), en comparación con el centeno (Secale cereale L.) (145 €·ha ${ }^{-1} \cdot$ año $^{-}$ $\left.{ }^{1}\right)$, el cultivo tradicional utilizado para la siembra de áreas marginales de una explotación agrícola real. La principal diferencia se obtuvo en la evaluación ambiental donde el 
agropiro alargado produjo un potencial de calentamiento global de $-1.9 \mathrm{Mg} \mathrm{CO}$ eq.ha' 1.año-1 versus $1.6 \mathrm{Mg} \mathrm{CO}_{2} \mathrm{eq} \cdot \mathrm{ha}^{-1} \cdot$ año-1 $^{-1}$ obtenido por el centeno.

De acuerdo con los resultados obtenidos se concluyó que sería de gran utilidad la implementación de este tipo de cultivo en terrenos marginales. El agropiro alargado es mejor opción que el cultivo tradicional desde el punto de vista ambiental y un poco mejor desde el punto de vista económico. Considerando estos resultados, la búsqueda de incentivos económicos debido a la reducción del $\mathrm{CO}_{2}$ eq. para el cultivo del agropiro alargado en comparación con el centeno es fundamental para mejorar su margen económico y así promover la implantación de este nuevo cultivo en las zonas marginales de las explotaciones agrarias. 


\section{SUMMARY}

The optimism regarding the potential of biofuels as an alternative to fossil fuels was high at the beginning of the 21 st century. Benefits, such as greenhouse gases (GHG) emission reduction, heat, electricity de-carbonization, and the development of rural areas, were expected for biofuel use. However, there is speculation regarding the contribution of biofuels to the increase of food prices and the use of freshwater. This raised important issues regarding the use of arable lands for growing crops dedicated to biofuel production and it created a conflict between food /feed and energy alternatives. In this context, marginal lands have revealed as the land available for energy crops production. Indeed, farmers need to find reliable alternatives in rainfed marginal agricultural areas where the production of food crops hardly ever is economically sustainable and the cultivation of perennial grasses for energy feedstock could be one of the most desirable alternatives.

The general purpose of this study is to identify areas where traditional food crops are not economically sustainable, as well as, the assessment of the introduction of different cool-season grasses (Agropyron spp.) from an agronomic and energetic point of view under marginal rainfed conditions, in addition to the study of the viability of the introduction of the cited species in marginal areas of real farms.

Spain has an extended area of 9.93 million hectares of arable land with biophysical and/or economic constraints under rainfed conditions where the low organic matter content is the principal biophysical constraint. The assessment of the different alternatives of perennial grasses revealed that the tall wheatgrass (Agropyron elongatum (Host) Beauv.) achieved the highest yields (4.8 Mg.ha- $\left.{ }^{-1} \cdot \mathrm{year}^{-1}\right)$ and similar biomass quality compared to the rest of the species tested. The biomass obtained from the tested grasses showed relatively high contents of ash, silicon, and alkali elements and the net calorific values ranged between 16.7 and $18.5 \mathrm{MJ} \cdot \mathrm{kg}^{-1} \mathrm{db}$. Moreover, the tall wheatgrass showed a slight enhancement of the profit margin $\left(156 € \cdot h \mathrm{~h}^{-1} \cdot \mathrm{y}^{-1}\right)$ from an economic point of view, compared to rye (Secale cereale L.) $\left(145 € \cdot \mathrm{ha}^{-1} \cdot \mathrm{y}^{-1}\right)$, the annual crop sowed traditionally in the marginal area of a real farm. The main difference achieved was in the environmental assessment where tall wheatgrass that produced a Global Warming Potential of $-1.9 \mathrm{Mg} \mathrm{CO}_{2}$ eq. $\cdot \mathrm{ha}^{-1} \cdot \mathrm{y}^{-1}$ versus $1.6 \mathrm{Mg} \mathrm{CO}_{2}$ eq. $\cdot \mathrm{ha}^{-1} \cdot \mathrm{y}^{-1}$ obtained for rye.

According to the results achieved it was concluded that it would be very useful the implementation of this type of crop in marginal land. Tall wheatgrass is better option than the traditional one from the environmental point of view and slight better option from the economic view. Considering these results, monetarization of the $\mathrm{CO}_{2}$ eq. reductions of 
tall wheatgrass compared to rye is essential to improve its profit margin and promote the implantation of this new crop in marginal areas of agricultural holdings. 


\section{INTRODUCCIÓN}




\section{CAPÍTULO I: INTRODUCCIÓN}

\subsection{Interés del tema}

\subsubsection{Situación general de la agricultura europea}

Según datos publicados por la Comisión Europea, actualmente en Europa, se utilizan para la agricultura unos 175 Mha entre cultivos herbáceos, leñosos y pastos. Esta superficie se divide en 10 millones de fincas, las cuales el 30\% están en Rumanía y el $13 \%$ en Polonia. Aproximadamente el $50 \%$ de la superficie agraria de la UE lo manejan el 3,1\% de las explotaciones agrícolas europeas. El tamaño medio de las explotaciones oscila entre las 3 ha por explotación en Rumanía y las 133 ha por explotación de la República Checa. Aunque la agricultura en los países de la UE es muy diversa, todos comparten algunas tendencias y retos importantes. Las zonas rurales se están despoblando, y las personas que permanecen en ellas tienden a ser mayores, aproximadamente el $28 \%$ de la población europea vive en el $83 \%$ del territorio, mientras que el $40 \%$ de esta población vive en el $4 \%$ del territorio. Hay pocos jóvenes agricultores, y a los futuros productores les resulta difícil adquirir sus propias tierras, el $50 \%$ de las tierras agrícolas de la UE son alquiladas. Las pequeñas y medianas explotaciones se están perdiendo, entre los años 2003 y 2013 se perdieron un $25 \%$ de las explotaciones totales de la UE de las cuales el $96 \%$ tenía menos de 10 ha, a la vez que las grandes explotaciones se hacen más grandes [1]. Este fenómeno es debido a que, con los bajos precios de los productos causados por la liberalización de los mercados entre otros motivos, no cubren los costes de producción, siendo sectores como la transformación y la comercialización los que obtienen mejores márgenes económicos. Muchos sectores están muy expuestos a estas condiciones de libre mercado lo que pone en riesgo su viabilidad económica [2].

Desde sus inicios la Política Agrícola Comunitaria (PAC) ha fijado como principal objetivo el mantenimiento de las rentas de los productores a cambio de unas medidas estrictas de producción que garantizan el abastecimiento y una seguridad alimentaria no vista en otras partes del mundo. En la actualidad, además de garantizar las rentas de los productores, la PAC fija otros objetivos a nivel europeo como son la transferencia del conocimiento y la innovación, la competitividad de las explotaciones en un mercado global, la organización de la cadena alimentaria, el bienestar animal, la gestión de riesgos causados por accidentes meteorológicos o por cualquier problema económico de otra índole, la conservación de los ecosistemas naturales y la mitigación del cambio climático [3]. En la reforma de la PAC vigente estos objetivos se financian a través de 
dos "pilares", el primer pilar dedicado a pagos directos a productores por superficie en el que el $80 \%$ de los pagos directos van a parar al $20 \%$ de las explotaciones y, el segundo pilar que financia el Fondo Agrícola de Desarrollo Europeo (FEADER) con tres objetivos principales que son la competitividad, la sostenibilidad y la mejora del medio ambiente y el clima que redundan en beneficio social para todos los ciudadanos europeos. La financiación de estos dos pilares le cuesta a cada ciudadano europeo aproximadamente $114 € \cdot$ año ${ }^{-1}[4]$.

\subsubsection{Implicación de la PAC en el ámbito de la bioenergía}

La implicación de la PAC actual en la bioenergía es muy escasa limitándose a financiar a través de ayudas al desarrollo rural (segundo pilar) proyectos de investigación relacionados con este ámbito. Las principales líneas de investigación que financia son plantas de biogás, repoblaciones forestales de ciclo corto para su uso energético, instalaciones y sistemas novedosos cuyo combustible son especies herbáceas o leñosas, utilización de aceites vegetales como combustibles, nuevas rotaciones de cultivo en el que las especies energéticas se intercalen con las alimentarias y estudio de nuevas especies de gramíneas perennes en tierra marginal para uso energético.

En este sentido, las gramíneas forrajeras perennes se han revelado como una de las mejores alternativas para producción de biomasa en zonas marginales con limitaciones biofísicas y socioeconómicas [5-10]. Estas especies tienen las mismas ventajas que otros cultivos energéticos entre las que se encuentran la disminución de la dependencia energética del exterior, la disminución de emisiones, la concentración de biomasa por unidad de superficie y el desarrollo rural local [11]. Además, tienen otras ventajas añadidas, son mejores que los cultivos tradicionales para mejorar la biodiversidad, son menos agresivos medioambientalmente, evitan la erosión del suelo, aumenta su fertilidad, reducen los costes de producción, sirven para cumplir los criterios fijados por la PAC, tienen capacidad de rebrote, más rusticidad que las especies anuales y su manejo es parecido al de las gramíneas anuales por lo que la explotación agraria no tendría que hacer ninguna inversión específica en su explotación [12-14].

\subsubsection{Principales amenazas de los sistemas agrarios europeos}

Numerosas son las amenazas que se ciernen sobre el medio ambiente y los

ecosistemas agrarios europeos, que tiene como principales amenazas la sobreexplotación de los recursos hídricos y la contaminación de los mismos, 
principalmente en los países mediterráneos, la pérdida de biodiversidad en los sistemas agrarios, el uso excesivo de sustancias químicas para la producción de alimentos y el cambio climático que tiene a la agricultura como una de las actividades más vulnerables [15].

La progresión de las zonas de regadío en los países de la cuenca mediterránea ha sido exponencial, los regadíos representan en la actualidad un $22 \%$ de la superficie agrícola total la cual genera 2/3 del empleo agrario, mientras que el descenso de la superficie de secano en esta área ha sido de un $23 \%$. Sólo en España el regadío representa el $80 \%$ de la demanda existente de agua dulce y, aunque la mayoría de los regadíos están modernizados, el uso del agua no ha disminuido, ya que, aunque el uso del agua en el cultivo es más eficiente hace falta un sistema más intensivo de producción para poder rentabilizar el coste derivado de la modernización del riego [16]. Además, estas infraestructuras ejercen un impacto ambiental negativo en ríos, humedales y aguas subterráneas. Otro problema asociado al uso del agua es la contaminación por nitratos que fue regulada por una directiva europea que mejoró la situación inicial. Un estudio realizado entre los años 2004 y 2007 detectó que en el 70\% de las estaciones se mejoraron o no empeoraron la concentración de nitratos en agua, aunque entre 2012 y 2015 se detectaron un $13 \%$ de estaciones con el nivel de nitratos por encima del umbral de $50 \mathrm{mg} \cdot \mathrm{L}^{-1}$ de agua [17]. La contaminación por nitratos de aguas subterráneas y superficiales es debido a una intensificación de la agricultura y la ganadería, así como un uso excesivo de fertilizantes inorgánicos.

La pérdida de biodiversidad en los sistemas agrarios es otra consecuencia de la forma de producción actual. Alrededor del $60 \%$ de las especies silvestres de los sistemas agrarios han visto disminuida su población afectando principalmente a aves e insectos, debido a la intensificación de las prácticas agrícolas que ligadas a la transformación de pastizales en tierras de cultivo, el aumento del uso de fertilizantes minerales y fitosanitarios, el monocultivo y la pérdida de vegetación natural reducen el alimento de las especies que habitan estos sistemas [18]. Para proteger esta biodiversidad la UE definió zonas de sistemas agrarios de alto valor natural (SAVN) con sus siglas en inglés (HNVS). Estos sistemas realizan un uso sostenible tanto del suelo como del agua donde la ganadería extensiva tiene un papel fundamental en el modelado del paisaje y además tienen, por otro lado, otros beneficios económicos asociados con el turismo. Estos sistemas se clasifican en tres tipos (I, II y III), siendo el tipo I los sistemas agrarios que tienen una proporción alta de vegetación seminatural, el tipo II son zonas que alternan áreas de vegetación seminatural con otras de usos agrícolas de 
baja intensidad y los de tipo III son zonas que albergan especies amenazadas. Un ejemplo de zonas de tipo I y II son zonas esteparias de secanos cerealistas muy importantes para la avifauna europea donde existe una buena rotación de cultivos y alta presencia de barbechos [19].

Las zonas SAVN tienen una gran importancia para preservar el equilibrio entre la producción de alimentos y el mantenimiento de los hábitats naturales ya que no tiene las desventajas de la agricultura intensiva como son la simplificación, perdida de paisaje y biodiversidad, problemas de regeneración y los problemas que puede llegar a crearse en áreas despobladas donde las áreas de cultivo se transforman en densos matorrales propicios para la propagación de incendios con todo lo que ello conlleva [19].

El uso generalizado de productos fitosanitarios es otro problema para el mantenimiento de la biodiversidad en los sistemas agrarios por los problemas que le acarrea a la flora y fauna silvestre limitando drásticamente la biodiversidad. En los últimos años, en Europa se han mantenido constantes el uso de productos fitosanitarios con excepciones como Dinamarca que ha reducido drásticamente su uso y Polonia que ha triplicado su uso desde la entrada de este país en la UE [20]. Los pastizales y los cultivos de secano son las zonas donde menos se usan este tipo de tratamientos [21]. Medidas aplicadas en la PAC, como las inspecciones de campo con importes elevados de sanción si se incumplen las prescripciones de los productos fitosanitarios y medidas como la obligación de cultivar tres especies diferentes en explotaciones de más de 15 ha ligadas al pago verde, favorecen la rotación de cultivos y controlan el uso desmedido de estos productos.

La lucha contra el cambio climático es una de las mayores amenazas que tiene el sector primario en la actualidad, afectando principalmente al centro y sur de Europa con periodos cada vez más marcados de sequías e inundaciones prolongadas que favorecen la aparición de plagas y enfermedades. Además, la agricultura genera emisiones principalmente de compuestos nitrogenados $\left(\mathrm{NO}_{\mathrm{x}}\right)$ procedentes de los fertilizantes y metano $\left(\mathrm{CH}_{4}\right)$ procedente de los procesos de digestión de la ganadería [22]. Para mitigar esta producción los reglamentos europeos integraron medidas para la lucha contra el cambio climático desde el sector primario a través de la PAC, estas medidas están basadas en la gestión de fertilizantes y rotación de cultivos principalmente. Además, existen iniciativas como la del "4 por 1000" promovidas por el Ministerio de Agricultura de Francia, el cual pretende aumentar cada año un 0,4\% el almacenamiento de Carbono orgánico en el suelo mediante la realización de cubiertas vegetales en cultivos permanentes en línea, siembra o plantación de cultivos con raíces 
profundas o el abonado orgánico con materiales como el estiércol de ovino o bovino y el compost.

En este contexto, es necesario buscar soluciones alternativas a los cultivos tradicionales en tierras marginales dentro de los sistemas agrarios del secano europeo e intentar que no se abandonen estos sistemas, evitando así posibles problemas a nivel social y ambiental. En base a todo ello, se han fijado los objetivos de este trabajo.

\subsection{Objetivos}

El objetivo general de este trabajo es la determinación de la viabilidad de diferentes especies y cultivares de gramíneas perennes sembradas en tierra marginal para fines energéticos.

Para ello se plantean los siguientes objetivos específicos:

Identificar las tierras arables marginales de secano en España de acuerdo a distintos criterios de marginalidad, las cuales pueden ser utilizadas para la implantación de gramíneas perennes para su uso energético sin crear conflictos con cultivos alimentarios, dando una nueva alternativa a esas tierras que están en riesgo de abandono.

Determinar mediante ensayos de campo las productividades, eficiencia de agua de lluvia y calidad de la biomasa de nuevas especies de gramíneas perennes en tierras marginales de secano: cinco cultivares y dos localizaciones de agropiro alargado, un cultivar de agropiro crestado (Agropyron cristatum (L.) Gaertn.) y un cultivar de agropiro siberiano (Agropyron sibiricum (Willd.) P. Beauv.).

Realizar un análisis de la viabilidad de estas especies en tierra marginal, comparando económica y medioambientalmente el agropiro alargado con el centeno, en el contexto de una explotación agraria real de secano, cuya parte de su superficie se encuentra localizada en tierra marginal cultivada tradicionalmente con centeno. Durante cuatro años se analizan las producciones, los márgenes económicos y el impacto medioambiental del agropiro alargado en una zona agrícola con restricciones biofísicas del secano español. 


\subsection{Tierras marginales}

\subsubsection{Definición de tierra marginal}

Son numerosos los estudios que definen el uso de tierras marginales para producción agropecuaria enfocado desde el punto de vista biofísico y socioeconómico.

En el siglo XIX se introduce el término "tierra marginal" en el campo de la investigación agraria. Ya en 1817 Ricardo [23] vinculó este término a su teoría de renta de la tierra y la perspectiva de baja productividad. En términos de restricciones de suelo y clima empezó a estar vinculada al concepto de tierras marginales a finales de siglo XX $[24,25]$.

En los últimos años este concepto ha presentado mayor interés científico y político bajo la creciente influencia de la presión demográfica sobre la tierra, el creciente consumo de carne y fibra y la demanda de biomasa para fines no alimentarios [26]. Según la Agencia Europea del Medio Ambiente (EEA) el término tierra marginal significa tierra cuyo valor de producción difícilmente alcanza sus costes de producción [27]; para la Agencia Estadounidense de Agricultura (USDA) tierra marginal es la tierra con bajo potencial agronómico, es la última tierra en ser cultivada y la primera en ser abandonada. Las tierras marginales se consideran como una fuente potencial de tierra que puede utilizarse de forma tradicional para la producción de alimentos, aunque cada vez más en desuso debido al margen económico ajustado de las explotaciones agrarias hoy en día, o para la producción de biomasa con fines energéticos y otros productos no alimentarios [28, 29]. Otros autores defienden que el término marginal depende del uso que tenga, ya que una tierra puede ser marginal para un uso, pero adecuada para otro [30].

Diferentes definiciones de tierra marginal hacen hincapié en las limitaciones biofísicas de las mismas, mientras que otras hacen hincapié más en las económicas y sociales. Estos diferentes puntos de vista son recogidos por Shortall (2013) [29], que muestra distintos puntos de vista recogidos en actas y documentos gubernamentales y de organizaciones sin ánimo de lucro (ONG). Shortall llega a la conclusión de que hay tres definiciones separadas del término tierra marginal la cual desde un punto más biofísico puede ser tierra no apta para la producción de alimentos, tierra ambigua de menor calidad y, desde un punto de vista más social puede ser tierra económicamente marginal. La tabla 1 muestra una serie de definiciones de tierra marginal desde diferentes puntos de vista. 
Tabla 1. Definición de tierra marginal.

\begin{tabular}{|c|c|}
\hline Definición & Fuente \\
\hline "...las tierras más pobres utilizadas..." & [24] \\
\hline "...tierra donde los ingresos equivalen al coste de producción" & [31] \\
\hline $\begin{array}{l}\text { "... Se utiliza para describir generalmente a tierras que están fuera del } \\
\text { mercado en contraste con tierras que producen un margen de beneficios" }\end{array}$ & [32] \\
\hline "... usos de la tierra al margen de la viabilidad económica" & [33] \\
\hline $\begin{array}{l}\text { "...área donde una producción rentable no es posible, bajo las condiciones } \\
\text { del lugar, tanto técnicas de cultivo, como políticas agrícolas y condiciones } \\
\text { macroeconómicas y legales" }\end{array}$ & [34] \\
\hline $\begin{array}{l}\text { "...se refiere a una tierra con utilidad limitada para cualquier función de } \\
\text { producción” }\end{array}$ & [35] \\
\hline $\begin{array}{l}\text { "...tierras no aptas para la producción de alimentos, por ejemplo con suelos } \\
\text { pobres o un ambiente de clima severo y que han sido degradadas" }\end{array}$ & [36] \\
\hline $\begin{array}{l}\text { "...definida como tierra donde la producción agrícola rentable no es posible } \\
\text { bajo un contexto determinado" }\end{array}$ & [27] \\
\hline $\begin{array}{l}\text { "tierras que tienen limitaciones severas para aplicaciones sostenidas de un } \\
\text { uso determinado. El aumento de insumos para mantener la productividad o } \\
\text { los beneficios solo será justificado marginalmente. Opciones limitadas de } \\
\text { diversificación sin aumento de insumos, manejo inadecuado pueden } \\
\text { producir riesgos de degradación irreversible". }\end{array}$ & [37] \\
\hline
\end{tabular}

También hay que tener en cuenta que muchos estudios se refieren a tierras marginales con sinónimos como tierras de cultivo abandonadas o tierras de baja producción agraria. La definición de tierras infrautilizadas, contaminadas, frágiles, vulnerables o degradadas, se solapan también en la definición de tierras marginales pero cada una tiene sus particularidades. A continuación, se comentan alguna de ellas:

- Tierras contaminadas: En estas tierras las restricciones biofísicas no tienen una causa natural, sino que son causadas por actividades industriales, mineras, extracción de hidrocarburos, plantas de energía, zonas afectadas por una guerra, zonas afectadas por derrames químicos o sitios nucleares, presentando un riesgo potencial para los seres humanos, el agua u otros ecosistemas [38].

- Tierra excedente: La tierra no se utiliza para la producción de alimentos, piensos, fibras y otras fuentes debido a la baja fertilidad del suelo o estrés abiótico o la tierra no se utiliza debido a que no es necesario actualmente debido a la racionalización de la producción. [26].

- Tierras agrícolas abandonadas: Tierras que se utilizaban anteriormente para la agricultura o el pastoreo, pero han sido abandonadas y no se han convertido en terrenos forestales o áreas urbanas. Las actividades agrícolas se han abandonado debido a razones económicas, políticas o ambientales [39]. Las expectativas sobre el grado de abandono de tierras agrícolas para 2030 para la UE oscilan entre el 1 y el 10\% [40] pero las expectativas de tierra en riesgo de abandono son mucho más elevadas [41]. 
- Tierras degradadas: Tierras con pérdida a largo plazo de la función y los servicios del ecosistema, causada por perturbaciones de las que el sistema no puede recuperarse sin ayuda comúnmente causada por el uso indebido del suelo [42].

- Tierras de desecho: Tierras con condiciones físicas y biológicas naturales que son per se desfavorables para las actividades humanas asociadas a la tierra. Se incluyen tierras sin cobertura vegetal o sin potencial agrícola apreciable, se incluyen dunas activas, salinas, afloramientos rocosos, desiertos y regiones montañosas áridas [42].

En muchos estudios también se reconoce que una tierra puede ser considerada como marginal temporalmente por lo que la marginalidad no tiene porqué ser un estado permanente [43]. Shujiang et al. [5] menciona ampliamente que existen dos factores que determinan la dinámica de las tierras marginales que constan, en primer lugar de procesos naturales en combinación con una gestión variada, haciendo referencia a los procesos en los que las tierras productivas se degradan debido al mal manejo y a la sensibilidad a la degradación de las mismas. Debido a este proceso, las tierras tienden a convertirse en marginales quedando fuera de uso. Bajo la influencia de la dinámica del manejo de la tierra también es posible que una tierra marginal se convierta en tierras productivas debido a inversiones realizadas para su mejora. En segundo lugar, por los cambios del mercado, los cambios de la demanda pueden disminuir los márgenes económicos haciendo que las tierras marginales sean abandonadas o utilizadas. Ambas dinámicas son posibles y dado que los mercados fluctúan rápidamente implica que el estado marginal de una tierra utilizada para el cultivo es dinámico y no permanente.

Hace 20 años, la Organización de las Naciones Unidas para la Alimentación y la Agricultura (FAO) encargó a un consorcio de centros de investigación agraria (CGIAR) un estudio para aumentar la salud alimentaria, mejorar la nutrición y reducir la pobreza rural del mundo, en el cual se abordaron los cuatro desafíos inherentes a la definición e identificación de tierras marginales desde el punto de vista agrario, excluyendo aéreas forestales y urbanas. Reconocieron que la perspectiva de lo "marginal" es diferente dependiendo del uso de las tierras, por lo que concluyen que "solo tiene sentido definir tierras marginales en términos de una situación específica claramente definida". También el CGIAR reconoce que la marginalidad está determinada por restricciones biofísicas y socioeconómicas, que pueden aplicarse por separado o simultáneamente y reconocen que hay diferentes términos utilizados que se refieren a tierras marginales. Por ello propusieron cuatro definiciones para cuatro tipos de categoría de tierra distinta con el fin de aclarar y evitar confusiones adicionales en las definiciones: 
- Tierras favorables: Tierra con pocas limitaciones de sostenibilidad o sin ellas bajo las condiciones de uso que tiene. Con el manejo actual el riesgo de daño irreversible es bajo. No tiene o tiene pocas restricciones biofísicas relacionadas con el suelo como la fertilidad, condiciones del terreno y climáticas como un adecuado régimen hídrico. Además de buenas condiciones biofísicas también tiene que tener buenas condiciones socioeconómicas como fácil accesibilidad a los 'inputs' (nomenclatura usada en todo el documento), facilidad de crédito o buen ratio output.input ${ }^{-1}$.

- Tierras marginales: Tierra que tiene limitaciones severas para la sostenibilidad del uso que se le esté dando. Tiene limitada diversificación sin el uso de inputs, es necesario aumentar inputs para mantener productividad o beneficios y con el manejo inapropiado corre el riego de una irreversible degradación. Tiene restricciones biofísicas en cuanto al suelo como baja fertilidad, escaso drenaje, salinidad, pendientes pronunciadas o condiciones climáticas desfavorables. Además, puede tener también restricciones socioeconómicas como ausencia de mercados o dificultad para acceder a los mismos, una infraestructura limitada en la explotación o tratarse de una explotación excesivamente pequeña, régimen de tenencia inadecuado, o desfavorable la relación output-input ${ }^{-1}$ por citar algunos.

- Tierras frágiles: Tierra muy sensible a la degradación, como resultado de un uso inapropiado por el ser humano. Las producciones sostenibles requieren unas prácticas específicas de manejo y los usos que se le pueden dar a la tierra son muy limitados. Suelos con baja fertilidad, erosionables, o con problemas de encharcamiento ocasional o continuado son algunos de las restricciones biofísicas que presentan este tipo de terrenos. Indisponibilidad o coste elevado de los inputs o competencia de la tierra con otros sectores son algunos de los factores socioeconómicos que también presentan estas tierras.

- Tierras degradadas: Tierra que ha perdido toda o la mayoría de su capacidad productiva como resultado de una intervención humana inapropiada. Puede que su grado de degradación sea reversible o irreversible y la recuperación de estos terrenos requieren de fuertes inversiones. Ausencia de fertilidad, terreno erosionado, ausencia de drenaje o elevada salinidad son factores biofísicos que tienen este tipo de tierras. Ausencia de un marco institucional, alto coste de rehabilitación o ausencia de inversión pueden ser algunos de los factores biofísicos que afectan a las tierras degradadas. 
Este estudio también enfatiza que estos tipos de tierra pueden cambiar con el tiempo y su clasificación puede ser dinámica en el tiempo.

\subsubsection{Limitaciones biofísicas de las tierras marginales}

Desde la primera visión general de las definiciones de tierra marginal queda claro que una de las características clave que aparece en la mayoría de las definiciones es la presencia de restricciones biofísicas. Estas restricciones según la FAO-CGIAR son la baja fertilidad, el drenaje deficiente, la profundidad del suelo, la salinidad, la pendiente del terreno y las condiciones climáticas desfavorables.

Existen varios estudios que se centran enteramente en las limitaciones biofísicas del suelo para clasificar las tierras que son adecuadas para cultivo, pastoreo o uso recreativo. Una de las más utilizadas es el Sistema de Clasificación de la Capacidad del Suelo (LCC) promovida por el USDA en la década de los 60. Esta clasificación consta de ocho clases de tierra (Tabla 2), la que distingue entre tierras no deterioradas para uso agropecuario y tierras que necesitan ser protegidas por el Programa de Conservación a través de la Ley de Seguridad Alimentaria.

Tabla 2. Clasificación de la capacidad de la tierra (LCC) elaborada por el USDA.

\begin{tabular}{cl}
\hline Clase & \\
\hline 1 & $\begin{array}{l}\text { Pequeñas limitaciones de uso } \\
\text { Moderadas limitaciones que restringen el uso de cultivos o requiere prácticas de } \\
\text { conservación especiales }\end{array}$ \\
3 & $\begin{array}{l}\text { Severas limitaciones que restringen el uso de cultivos o requiere prácticas de } \\
\text { conservación especiales o ambas }\end{array}$ \\
4 & $\begin{array}{l}\text { Muy severas limitaciones que restringen el uso de cultivos o requieren unas } \\
\text { prácticas de manejo muy cuidadosas o ambas } \\
\text { Baja o nula erosión pero tiene otras limitaciones imposibles de solucionar que } \\
\text { restringen su uso principal para pastos y pastizales, terreno forestal o hábitats } \\
\text { naturales } \\
\text { Limitaciones severas que generalmente hacen a la tierra inservible para su cultivo } \\
\text { y restringen su uso principal a pastos y pastizales, tierra forestal o hábitats } \\
\text { naturales } \\
\text { Muy severas limitaciones que hacen la tierra inservibles para cultivar y restringen } \\
\text { su uso para pastos y pastizales, terrenos forestales o hábitats naturales } \\
\text { Áreas variadas que tienen limitaciones para su explotación agraria y se restringe } \\
\text { su uso para el ámbito recreativo o hábitats naturales }\end{array}$ \\
&
\end{tabular}

De acuerdo con la clasificación del USDA de la clase 1 a la clase 4 es tierra que se considera capaz de producir cultivos con un buen manejo. Las clases 5-7 son más adecuadas para las especies vegetales perennes, pero pueden ser capaces de producir algunos cultivos especializados con un manejo intensivo. Los suelos de clase 8 no son adecuados para la producción agraria. La perspectiva adoptada por el USDA se basa en la capacidad de la tierra para ser utilizada para el cultivo de especies para 
alimentación o pastos, el área de distribución y el riesgo de degradación de la tierra. Esta clasificación principal se divide en otra subclasificación que describe más específicamente las restricciones biofísicas que son limitantes para la clase principal:

- Subclase e: Suelos cuyo problema dominante es la susceptibilidad a la erosión.

- Subclase w: Suelos para los cuales el exceso de agua es el peligro o limitación dominante que afecta a su uso.

- Subclase s: Constituida por suelos con limitaciones dentro de la zona de enraizamiento, como la superficialidad de la zona de enraizamiento, poca capacidad de retención de humedad, baja fertilidad difícil de corregir y salinidad o contenido en sodio.

- Subclase c: Suelos cuyo principal problema son las condiciones climáticas como la temperatura o la falta de humedad.

Además de estas clasificaciones, también hay varios enfoques para evaluar las limitaciones de la tierra, tomando como punto de partida la idoneidad de la tierra para la producción de cultivos dedicados a la alimentación.

En 1976, la FAO elaboró un marco flexible para la evaluación de tierras que indicaba las limitaciones para determinados cultivos. El marco flexible abarcaba los factores de calidad de la tierra como la disponibilidad de humedad, duración de la temporada de crecimiento, capacidad de drenaje del suelo, profundidad del suelo, disponibilidad de nutrientes y la salinidad [44]. Además, esta organización adoptó la Guía Visual de Evaluación de Suelos (VSA) que proporciona directrices sobre cómo hacer una evaluación visual de las aptitudes de suelo para los principales cultivos como olivos (Olea europea L.), viñedo (Vitis vinifera L.), huertos, trigo (Triticum aestivum L.) maíz (Zea mays L.), otros cultivos anuales y pastos. Estos indicadores que son medibles en campo incluyen la textura del suelo, estructura, porosidad, color, presencia de lombrices, profundidad de enraizamiento, formación de costra superficial y la erosión. Básicamente estos son los indicadores indirectos para los factores limitantes del suelo que influyen en la fertilidad y la operatividad de la maquinaria en el suelo. Sobre estas observaciones se desarrolla una puntuación según la cual se clasifican los suelos en pobres, clases moderadas y buenas. La tierra catalogada como "pobre" se superpone con la definición de tierra marginal, sobre todo cuando se obtienen resultados pobres para todo tipo de cultivos estudiados, lo que implica una baja probabilidad de uso para la producción de alimentos y cultivos industriales. 
El Instituto Internacional de Análisis de Sistemas aplicados (IIASA) hizo un enfoque de las evaluaciones agroecológicas fuertemente influenciado por Fischer et al [45], de cómo identificar la disponibilidad de suelo para la agricultura en diferentes zonas agroambientales y también para la producción de materia prima para biocombustibles. Según Fisher la idoneidad de la tierra para uso agrícola debe ser determinada por tres categorías de factores tales como, factores climáticos como la temperatura y el régimen de precipitación, especialmente haciendo hincapié a limitaciones como el déficit hídrico y el exceso de humedad en la época de crecimiento vegetativo; la baja productividad, los suelos pocos profundos, pedregosidad, acidez, salinidad y la topografía, particularmente pendientes demasiado pronunciadas y por lo tanto sensibles a la erosión e inaccesibles a la maquinaria. Esto no implica que las restricciones en todas las categorías deban aplicarse al mismo tiempo para clasificar la tierra en marginal y no marginal, pero sí implica que los factores biofísicamente restrictivos necesitan ser cubiertos para identificar las tierras marginales. Estas limitaciones biofísicas son similares también a las propuestas por el Centro Común de Investigación de la Comisión Europea (JRC) [46, 47] para la identificación de "áreas de restricciones naturales".

El trabajo del JRC define los criterios comunes para definir zonas de restricciones naturales para la agricultura. En Europa esta definición también tiene una motivación política que se especifica en el Reglamento 1305/2013 de la PAC para el periodo 20142020. En este Reglamento se requiere una revisión de las delimitaciones de las zonas menos favorecidas, que exige un marco que abarque toda la diversidad biofísica europea y que se aplique a la actividad agrícola en general y no a determinados cultivos o producciones. Así pues, el trabajo del JRC tiene por objeto proporcionar la base científica para evaluar y definir las limitaciones naturales de la agricultura en la UE. Todos los criterios para identificar áreas con restricciones naturales en Europa cubren limitaciones en las distintas categorías climáticas, edafológicas y topográficas. Los indicadores propuestos por el JRC coinciden con los propuestos por otros estudios anteriormente citados, sin embargo, se debe considerar que los valores umbral que distinguen entre marginal y no marginal deben ser elegidos de manera similar.

\subsubsection{Limitaciones socioeconómicas de las tierras marginales}

En la literatura sobre definiciones de tierra marginal y clasificaciones de tierras, generalmente hay un consenso sobre las limitaciones biofísicas que caracterizan las tierras marginales y que pueden identificarlas, mientras que para las limitaciones socioeconómicas hay menos consenso, ya que son indicadores más subjetivos. 
La definición de la FAO-CGIAR define los factores socioeconómicos limitantes como la ausencia de mercados, la difícil accesibilidad a los mismos, la tenencia de la tierra, el tamaño de la explotación, infraestructuras deficientes y ratios desfavorables de producción e ingresos.

Las ratios desfavorables output.input ${ }^{-1}$ es una característica reconocida ampliamente como típica en los análisis de tierra marginal. Ricardo [23] y más recientemente Barkley [31] y Strijke [33] citaron en sus estudios este término. Además mostraron que los rendimientos de las tierras marginales son dinámicos dependiendo de los contextos económicos bajo la influencia de factores como innovaciones, mercados, políticas y cambio climático [5].

La ausencia de mercado o difícil acceso a los mismos y la mala infraestructura de la explotaciones se define también en algún estudio [32]. La relación entre la accesibilidad en las oportunidades de desarrollo económico se explica ejemplificando que las tierras situadas más lejos de los grandes núcleos urbanos tienen más problemas para alcanzar usos más eficientes económicamente hablando debido al mayor coste en el transporte. Este factor es muy importante para explicar por qué muchas tierras marginales siguen siendo no utilizadas o abandonadas. Además se confirma en el estudio del JRC de identificar las tierras en riesgo de abandono, que confirma la relación entre una ubicación periférica y el riesgo de abandono de la tierra mediante la inclusión de baja densidad de población y lejanía como indicador [47]. Por otra parte, cabe preguntarse si el factor de distancia es una característica clave para todas las tierras marginales o un factor adicional para una parte de las tierras marginales. Las limitaciones biofísicas pueden ser una razón para abandonar las tierras también cuando están localizadas cerca de los grandes núcleos de consumo, mientras que las tierras que no tienen tantas limitaciones biofísicas localizadas en lugares aislados pueden ser utilizadas para la producción agrícola a pesar de su aislamiento. EI JCR también confirma este indicador sentenciando que la fertilidad del suelo se superpone a la localización de la tierra.

El factor de régimen de tenencia de la tierra y tamaño de las explotaciones se considera como se ha comentado anteriormente, un factor típico que define las limitaciones socioeconómicas de las tierras marginales. En el enfoque de la FAO-CGIAR sobre este tema, se indica que normalmente en los puntos donde más pobreza rural hay, también hay más tierras marginales. En esas situaciones de pobreza rural el acceso a la tierra también es más restringido y las explotaciones suelen ser más pequeñas. 
Esta cuestión es muy importante fuera de los límites europeos, pero no tanto dentro de la Unión Europea.

\subsubsection{Limitaciones de sostenibilidad de las tierras marginales para su utilización con cultivos no alimentarios}

La sostenibilidad para el uso de la biomasa no alimentaria en las tierras marginales es un tema de importante debate político y científico desde hace varios años debido a los efectos directos e indirectos sobre el uso de la tierra, la biodiversidad de los ecosistemas naturales y agrarios, el agua y los mercados.

Los efectos de la sostenibilidad de los cultivos en tierra marginal para fines no alimentarios, no solo no se consideran negativos, sino que hay muchos estudios que afirman que hay opciones sostenibles para utilizar las tierras marginales para satisfacer el aumento de la demanda de energía en la creciente bioeconomía europea [6-8, 12, 48-50]. En este sentido, Dauber y Miyake [38] cree en soluciones regionales para establecer sistemas sostenibles de producción de energía, incluyendo un uso de la tierra marginal que tendrá unos beneficios sociales, económicos y ecológicos. Los autores citados en las líneas anteriores demostraron que el uso de gramíneas perennes minimiza la erosión del suelo, incrementa la retención de agua del suelo con la consiguiente disminución de la escorrentía tanto de agua como de nutrientes, incrementa la fertilidad de los suelos y mejora la biodiversidad de las áreas donde se implantan entre otros beneficios.

El riesgo de pérdida de biodiversidad es un factor que sin duda necesita la atención específica en las áreas marginales europeas, especialmente porque se ha demostrado que las tierras agrícolas de alto valor natural coinciden con zonas de restricciones naturales que suelen superponerse con tierras marginales. Esta superposición es debida a que estas zonas de alto valor ecológico suelen encontrarse en zonas donde existe un manejo extensivo de la agricultura y la ganadería [51]. La intensificación de las labores agrarias en estas tierras puede ser contraproducente debido a la insostenibilidad y la degradación de la tierra. Existe una clara coincidencia entre los lugares donde se ha mantenido la biodiversidad de los sistemas de cultivo relativamente estable, donde los sistemas de agricultura tradicional han seguido existiendo y el cambio a sistemas agrícolas más intensivos y eficientes que disminuyen la biodiversidad [52]. Si las tierras marginales de cultivo tienden a abandonarse, la biodiversidad de estas zonas podrá perderse. 
En conclusión, se podría afirmar que la utilización de tierras marginales para cultivos no debe perderse ya que pondría en riesgo la biodiversidad.

\subsubsection{Cartografía de las tierras marginales}

Existen muchos estudios de escenarios que calculan las tierras marginales en el futuro próximo. Estos estudios cuantifican usualmente la cantidad de tierra necesaria bajo diferentes escenarios de mercados, políticas y tecnología. Para ello, primero toman cuantificaciones regionales de la categoría de tierras para la que quieren hacer el estudio basadas en conjunto de datos de satélites como Corine Land Cover o el Sistema de Información de ocupación del suelo en España (SIOSE).

Existen también otros estudios que tienen en cuenta un modelo más sofisticado que estiman los índices de capacidad de producción basados en distintos parámetros biofísicos y socioeconómicos [53]. Según Gibbs y Salmon [54], tales estudios tienden a sobreestimar los recursos, explican que es debido a la falta de datos precisos sobre condición y ubicación exacta de tierras degradadas. Ejemplo de esto es Eitelberg et al. [55], que estimó un rango de entre 1552 y 5131 Mha de disponibilidad de tierra a nivel global o Campbell et al. [39] que estimó un intervalo de 385 a 472 Mha a nivel mundial de tierras marginales.

En 1990 Oldeman et al. [56] identificaron a nivel mundial a través de un proyecto de la ONU las tierras degradadas consultando a expertos acerca del estado de la degradación de los suelos en relación con el tipo de suelo, extensión y grado de degradación. En 2008 se realizaron dos estudios enfocados a las tierras degradadas y a las tierras abandonadas. Bai et al [57] estudiaron las tierras degradadas con potencial para bioenergía a escala mundial. Para su estudio usaron un satélite que proporcionaba datos de los índices de las diferencias normalizadas de la vegetación (NDVI). Ese mismo año Campbell et al. [39] mapearon a nivel mundial las tierras abandonadas con potencial para bioenergía usando datos de History Database of the Global Environment 3.0 (HYDE) los cuales son mapas de cultivos y pastos para cada década entre el año 1700 y 2000. Las superficies abandonadas se determinaban en cada zona donde disminuía el área agrícola a lo largo del tiempo, además también comparó los valores usando datos de áreas abandonadas del Centro de Sostenibilidad y de Medio Ambiente (SAGE). En 2011 Cai et al. [58] mapearon tierras marginales, tierras cultivables degradadas y tierras abandonadas que podían ser potencialmente usadas para biocombustible a escala global. Para ello realizaron un modelado para evaluar la productividad de la tierra. Usaron una amplia selección de datos espaciales y generaron unos índices de 
sostenibilidad siguiendo las indicaciones del USDA. Este estudio tenía la intención de tratar de clarificar y ordenar los datos que había acerca de estas cartografías de acuerdo con múltiples criterios. Alcántara et al. en 2013 [59] realizaron un estudio en Europa Central y del Este acerca de tierras abandonadas y comparó los cultivos alimentarios y cultivos para energía con índices de vegetación normalizados, comparando vía satélite el cambio en la cubierta vegetal de estos terrenos abandonados entre 2003 y 2009. Ceausu et al. [60] mapearon en 2015 tierras marginales y tierras abandonadas para estudiar el potencial que tenían para volver a convertirse en hábitats naturales en Europa. Para realizar este trabajo utilizó el proyecto VOLANTE que contemplaba escenarios de abandono de tierras hasta 2040 y los superponía con cuatro indicadores para medir el grado de conversión en áreas silvestres. Liu et al. [61] también mapearon tierras marginales con potencial para la producción de cultivos energéticos en Canadá realizando una intersección de los mapas de cobertura del suelo locales con evaluaciones de los índices de capacidad de la tierra basados en el clima, suelo y factores agroecológicos limitantes.

En la actualidad dos proyectos europeos como son SEEMLA y MAGIC son los que cartografían áreas para la implantación de cultivos energéticos en tierra marginal en Europa incluyendo Ucrania. Gerwin et al. [48] focalizaron sus esfuerzos en utilizar para mapear tierras marginales los indicadores de la calidad del suelo y Van Eupen et al. [62] que utilizan QUICKScan, se propusieron cartografiar tierras marginales de acuerdo con terrenos con limitaciones que en su conjunto son graves para su uso en la producción agrícola debido a que es necesario incrementar los inputs para mantener la productividad, son zonas con baja fertilidad, escaso drenaje, poca profundidad, salinas, con pendientes elevadas del terreno y condiciones climáticas desfavorables. También busca superficies con difícil acceso a los mercados, donde se localizan gran número de pequeñas explotaciones con infraestructuras deficientes y opciones limitadas de diversificación. Además de estas zonas también mapean zonas contaminadas donde se ha confirmado la presencia de materiales contaminantes en el suelo que presentan un riesgo potencial para el ser humano, el agua u otros receptores.

El propósito de la cartografía en casi todos los estudios es identificar las tierras donde se puede producir materia prima para su uso energético, pero también hay estudios que toman la opción de conservación de la naturaleza. Los tipos de tierra mapeados en todos los estudios se superponen obviamente, pero en cada estudio se define de una manera diferente. Por ejemplo, para estudios similares como el de Oldeman et al. [56] y Bai et al. [57] que tienen como objetivo el estudio de la degradación 
de la tierra los resultados son dispares ya que uno utiliza opiniones de expertos y el otro se basa en datos obtenidos por satélite de índices de vegetación. Según Gibbs y Salmon [54] las evaluaciones por satélite son útiles para captar la degradación reciente o en curso mediante la medición de los cambios en la productividad, pero las evaluaciones por satélite no captan la imagen completa de todas las tierras degradadas, en particular las que se han degradado hace tiempo o diferencias muy pequeñas que hay entre zonas degradadas y no degradadas.

Los enfoques cartográficos que se centran más en identificar las tierras marginales como adecuadas a la definición de FAO-CGIAR de tierras marginales son los de Cai et al. [58] y Liu et al. [61]. Liu et al. se centran únicamente en las restricciones biofísicas de la superficie estudiada mientras que Cai et al. tiene en cuenta un amplio espectro de datos mundiales disponible sobre el suelo, el clima, la topografía y los combina en un modelo biofísico de productividad agrícola resultando tres categorías de productividad de la tierra como son baja, marginal y regular.

\subsection{Gramíneas perennes}

\subsubsection{Interés y características}

Las principales gramíneas perennes usadas para energía son Panicum virgatum L., Miscanthus giganteus Greef et Deuter, Arundo donax L. y Phalaris arundinacea L.

Panicum virgatum $\mathrm{L}$. es una especie con metabolismo $\mathrm{C} 4$ de crecimiento rápido originaria de Norte América, con rizomas delgados, largos y raíces fibrosas. Tallos erectos, recios normalmente sin ramificar, es posiblemente una de las especies más estudiadas para su uso energético. Cualidades a considerar son su productividad, adaptabilidad a distintos ambientes y alto rendimiento energético [63]. Su ciclo va desde finales de primavera a principios de otoño, la floración ocurre desde principios de junio a agosto, su fotoperiodo es muy marcado cuando desciende el número de horas de sol y tras la floración los tallos se lignifican y la planta entra en reposo [64]. Puede tener rendimientos aceptables durante al menos 10 años y suele tardar tres años en alcanzar su máximo rendimiento en una sola cosecha. Hay dos ecotipos claramente diferenciados que son "Upland” y “Lowland”, Upland es menos exigente en clima y suelo, pero también menos productivo. Puede llegar a alcanzar rendimientos de hasta $25 \mathrm{Mg}$ $M S \cdot h a^{-1} \cdot a n ̃ o^{-1}$ en cultivares Lowland en España [11] aunque en la bibliografía existen estudios de hasta 34,6 Mg MS $\cdot \mathrm{ha}^{-1} \cdot$ año-1 $^{-1}$ [65]. En general, este cultivo prefiere climas templados-continentales, inviernos fríos, veranos cálidos y precipitaciones entre 500 y 
$1000 \mathrm{~mm}$ anuales. En climas Mediterráneos donde hay elevado déficit hídrico solo se puede cultivar en regadío [64].

Es una especie que además de sus altos rendimientos, presenta un impacto positivo sobre el medio ambiente ya que fija carbono en el suelo. Un estudio realizado en Ohio (EE.UU) [66] notificó una ganancia de entre 9 y $35 \mathrm{~g}$ de $\mathrm{C} \cdot \mathrm{kg}^{-1}$ durante 5 años con enmiendas nitrogenadas entre 50 y $100 \mathrm{~kg}$ de $\mathrm{N} \cdot \mathrm{ha}^{-1} \cdot \mathrm{año}^{-1}$ y unos rendimientos de hasta $20 \mathrm{Mg} \mathrm{MS} \cdot \mathrm{ha}^{-1} \cdot \mathrm{año}^{-1}$ en un área con alrededor de $1000 \mathrm{~mm}$ de precipitación anual y $11^{\circ} \mathrm{C}$ de temperatura media. Existen un número significativo de estudios en una amplia gama de suelos y analizados con diferentes técnicas y a diferentes profundidades que encontraron una ganancia de $\mathrm{C}$ en el suelo después de implantar este cultivo en terrenos agrarios [67-74]. También existe un amplio número de estudios que ofrecen una mejora de la biodiversidad en zonas donde se establece sobre todo en la fauna silvestre y los microorganismos del suelo [63, 75-79], solo se encontró un efecto negativo sobre la biodiversidad, ya que afectó negativamente a las colonias de roedores en un estudio [80].

Miscanthus giganteus Greef et Deuter es un híbrido C4 estéril originario de regiones subtropicales de África y Asia [81]. Tiene rizomas sólidos, alargados, tortuosos y ramificados. Sus tallos pueden alcanzar los $4 \mathrm{~m}$ de altura y su inflorescencia es en panícula ramificada [82]. El rápido crecimiento, alto rendimiento en biomasa y bajo contenido en minerales hacen un cultivo adecuado para la producción de biomasa con fines energéticos. La propagación de esta especie se hace por rizomas siendo el establecimiento la etapa más complicada de su ciclo vegetativo. Llega a su máximo de producción al segundo o tercer año y la plantación puede tener una viabilidad de hasta 15 años. Sus rendimientos son superiores a los de Panicum virgatum $L$. aunque es muy exigente en agua [65]. La cosecha puede tener lugar desde Octubre hasta la primavera, ya que cuanto más se retrasa la cosecha la calidad de la biomasa recolectada es mejor [83]. Es un cultivo típico de regiones subtropicales y áreas templadas y no tolera temperaturas por debajo de $-3^{\circ} \mathrm{C}$. Prefiere suelos con gran capacidad de retención de agua pero con poco riesgo de encharcamiento [82].

Como en el caso de Panicum Virgatum L. hay numerosos estudios que certifican la mejora de materia orgánica del suelo después de establecer Miscanthus giganteus Greef et Deuter en terrenos agrícolas muy dispares en su textura [68, 72, 84-91]. La mayor ganancia de $\mathrm{C}$ en el suelo la muestra Beuch et al [85] que reportó 3,2 Mg C.ha${ }^{1}$.año $0^{-1}$ en un estudio de cuatro años y la menor ganancia la muestra Amougou et al [87] con una ganancia de $0,25 \mathrm{Mg} \mathrm{C} \cdot \mathrm{ha}^{-1} \cdot \mathrm{año}^{-1}$ en un estudio de tres años. En cambio, con 
el efecto de este cultivo sobre la fauna salvaje y del suelo hay división de opiniones. Por un lado, hay varios estudios que indican lo beneficioso que es su cultivo para la fauna salvaje y del suelo [77, 78, 92-95], pero también hay un estudio que desaconseja su cultivo en tierra marginal en Inglaterra porque es perjudicial para la fauna salvaje, la fauna del suelo, las aves y los insectos [96].

Arundo donax L., conocida en España como caña común, es una especie con metabolismo C3 nativa de regiones mediterráneas. Tiene gruesos rizomas por los que se propaga, de los que se descuelgan potentes raíces que penetran profundamente en el suelo, tallos robustos y con grandes hojas e inflorescencia en forma de panícula. La

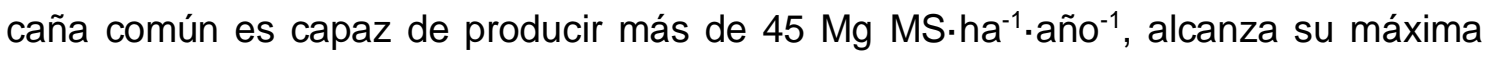
producción a partir del tercer año siendo el establecimiento la etapa más conflictiva para el éxito de la plantación. Esta especie tiene un importante grado de mejora debido a que las mayores producciones se han obtenido de cultivares silvestres [65]. Tiene buena adaptación a todo tipo de climas, aguanta bien heladas invernales y a principios de primavera. Aunque su gran desarrollo lo encuentra en zonas soleadas próximas a cursos de agua, prefiere suelos con la capa freática alta y es poco exigente en textura. Tiene gran resistencia a la sequía aunque la humedad atmosférica sea baja [97, 98].

Se han encontrado estudios que muestran resultados positivos en el $\mathrm{C}$ en el suelo en terrenos agrícolas después de la implantación de la caña común comparado con otras especies [99, 100]. Sus beneficios ecológicos están muy en duda ya que hay lugares en el mundo como EE.UU. donde está catalogado como especie invasora por lo que no se puede cultivar debido al alto riesgo de invasión [101].

Phalaris arundinacea L. es la cuarta gran especie usada para biomasa en el mundo. Especie con metabolismo $\mathrm{C} 3$ originaria de regiones templadas de Europa, Asia y América del Norte, actualmente se encuentra en zonas nórdicas de Europa y en climas de alta montaña. Tiene potentes rizomas, tallos erectos, que crean una masa de forraje densa, con panícula erecta y compacta. Crece bien en todo tipo de suelos, aguanta mejor que otras especies el encharcamiento prolongado, resiste bien a la sequía aunque sus mayores rendimientos los muestra en suelos orgánicos con alta humedad [65]. Un total de $15 \mathrm{Mg} \mathrm{MS} \cdot \mathrm{ha}^{-1} \cdot \mathrm{año}^{-1}$ han sido reportados por algunos autores durante dos cosechas [102].

Al igual que el resto de las especies comentadas, Phalaris arundinacea L. también es una especie que mejora la fijación de $C$ en el suelo [103] y la biodiversidad de la fauna salvaje y del suelo [104]. 
Las cuatro especies anteriormente descritas son las más utilizadas para biomasa debido su alta producción, calidad de biomasa y manejo de las mismas, pero todos estos cultivos tienen en común unas exigencias de clima y suelo que hacen muy difícil su producción en terrenos marginales de áreas Mediterráneas con bajo nivel de inputs. Por esta razón se necesitan especies que, aunque no alcancen tan altos rendimientos, tengan una producción económicamente viable para su cultivo en tierras marginales aportando bajo nivel de inputs y resistencias a condiciones bioclimáticas adversas. Estos cultivos que tradicionalmente han sido usados para forraje no han sido estudiados en profundidad para su utilización como biocombustible. Ejemplo de estos cultivos son las especies del género Agropyron spp.

El género Agropyron spp. incluye especies que guardan ciertas similitudes entre ellas, son originarias de zonas templadas del planeta y se han utilizado hasta la actualidad como especies forrajeras para alimentación animal. La especie más prometedora para su utilización para producción energética es el agropiro alargado ((Agropyron elongatum (Host) P. Beauv) (Elymus elongatus (Host) Greuter) (Elytrigia elongata (Host) Nevski) (Elytrigia pontica (Podp.) Tzvelev) (Thinopyrum elongatum (Host) D.R. Dewey) (Thinopyrum ponticum (Podp.) Barkworth \& D.R. Dewey) (Lophopyrum elongatum (Host) A. Löwe)), además existen otras especies prometedoras ampliamente contrastadas desde un punto de vista alimentario (forrajes) de las que aún se desconoce su comportamiento energético como el agropiro crestado (Agropyron cristatum (L.) Gaertn) (Agropyron aristatum Besser) (Agropyron barginensis Skvortsov) (Agropyron brandzae Pantu \& Solacolu) (Agropyron cristatiforme P.K. Sarkar) (Agropyron pectinatiforme Roem. \& Schult) (Cremopyrum pectinatum (M. Bieberstein) Schur) (Elymus pectinatus (M. Bieb.) Laínz) (Elytrigia praetermissa Nevski) (Triticum aragonense Lag.) cruzado o hibridado frecuentemente con Agropyron desertorum (K. Richt.) y el agropiro siberiano (Agropyron sibiricum (Willd.) P. Beauv) (Agropyron fragile (Roth) P.Candargy) [105].

Agropyron elongatum (Host) P. Beauv es una especie cespitosa con raíces fibrosas que pueden alcanzar una longitud de hasta $3 \mathrm{~m}$. Los tallos son robustos y lisos, pueden alcanzar una altura de hasta 2,5 m. [106]. La epidermis de los tallos está cubierta con una fina cutícula que le confiere resistencia a la sequía. Las células de protección estomática están a nivel de las células epidérmicas en el tallo y en la vaina de las hojas por lo que esta especie requiere un aporte moderado de agua [107]. Las hojas del agropiro miden de 2.5 a $5 \mathrm{~mm}$ de ancho, son planas y un poco retorcidas, se enrollan más en situaciones de estrés hídrico reduciendo así la transpiración, son de color verde 
o verde grisáceo y bastante veteada, la lígula es corta y membranosa, la presencia o no y la longitud de la aurícula varía dependiendo cultivares, en el haz y el envés de la hoja hay estomas pero se encuentran en mayor número en el envés, la epidermis tiene paredes celulares engrosadas y una gruesa capa de cutícula. El corte transversal de la hoja presenta una lámina basal ondulada debido a las venas marcadas que tiene, las cuales se extienden longitudinalmente marcando un patrón característico por la alternancia de haces pequeños y grandes [107]. La inflorescencia es en espiga erecta, larga y esbelta, el raquis es casi plano en el lado donde está enfrente de la espiguilla, generalmente es espinoso en los otros ángulos. Las glumas están veteadas, la lema del grano es obtusa, sin aristas, con cinco venas [108].

El agropiro alagado se propaga por semillas, con temperaturas de entre $15-20^{\circ} \mathrm{C}$ durante 7 días consecutivos y un periodo de oscuridad de al menos 16 horas, por estas razones, a principios de otoño es la mejor época para sembrar esta especie. La máxima producción de esta especie se alcanza a partir del segundo año, cuando el cultivo está ya bien implantado, la plantación puede durar por lo menos 10 años o más. Alrededor del décimo año la plantación empieza a decrecer. En zonas donde las condiciones bioclimáticas son menos adecuadas, la durabilidad de la plantación suele ser menor [107]. Requiere unos suelos con textura, contenido en agua y nutrientes similares a los de los cereales de invierno. En cuanto a textura se desarrolla mejor en suelos arenosos o franco-arenosos que, en suelos arcillosos, ya que la planta se desarrolla más rápidamente durante el primer año lo que es asociado con el éxito final de la plantación. Esta especie se desarrolla bien en pH entre 6,5 y 10, aunque su óptimo es entre 7,5 y 9, suelos con $\mathrm{pH}$ cercanos a 5,5 tienen efectos negativos sobre la producción. La resistencia a las inundaciones ocasionales es relativamente buena cuando el cultivo ya está bien implantado [107]. Es un cultivo bastante tolerante a la salinidad, siempre que el clima donde se encuentra tenga buen índice de pluviometría, además puede aguantar temperaturas extremas de entre $35^{\circ} \mathrm{C}$ y $-35^{\circ} \mathrm{C}$ si no son muy prolongadas en el tiempo [109].

La tasa fotosintética del agropiro alargado es de nivel medio bajo entre especies C3 con un rango de 10,3-19,2 $\mu \mathrm{mol} \cdot \mathrm{m}^{-2}$.s en invernadero, y 10,6-20,3 $\mu \mathrm{mol} \cdot \mathrm{m}^{-2}$.s bajo condiciones de campo sin restricciones bioclimáticas. En condiciones de sequía el intercambio de gases a través de la regulación de la conductancia estomática, tanto para el dióxido de carbono como para el vapor de agua tiene un efecto negativo [107].

Dado su amplia distribución alrededor del mundo y que el agropiro alargado solo se desarrolla bien en hábitats antropogénicos, no se multiplica por rizomas, es muy difícil 
que la introducción de estas especies en nuevos hábitats tenga riesgos asociados a la invasión de hábitats naturales, solo en algún estudio indican que cuando se implantan en praderas naturales compiten con la flora autóctona [110].

Agropyron cristatum (L.) Gaertn es también una especie cespitosa, de larga duración, resistente a la sequía y capaz de sobrevivir a inviernos de bajas temperaturas gracias a su potente sistema radicular. El tallo de porte erecto es más delgado que el del agropiro alargado. Las hojas son finas, planas y lisas por el haz, con ancho variable (2 a $6 \mathrm{~mm}$ ), dispuestas en el tallo longitudinalmente. Inflorescencia en espiguilla de 2 a $7 \mathrm{~cm}$ de largo de forma aplanada, superpuesta, orientada en un ligero ángulo sobre el raquis, la lema es lineal-lanceolada y se va estrechando hasta formar una arista corta $[111,112]$.

Esta especie está adaptada a zonas donde la precipitación media anual es de 250 $\mathrm{mm}$ y donde el período libre de heladas es generalmente inferior a 140 días, al igual que el resto de las especies de género Agropyron spp., el agropiro crestado es tolerante a las bajas temperaturas, puede aguantar inundaciones ocasionales en primavera y es muy tolerante al fuego. No tolera suelos mal drenados, encharcamientos prolongados 0 riego excesivo. Tiene buenas producciones en altitudes alrededor de $1000 \mathrm{~m}$. Puede crecer en suelos poco profundos, pero prefiere suelos profundos, de textura franca, bien drenados y con pH neutro, aunque resiste mejor en suelos moderadamente alcalinos. En condiciones de salinidad, la producción se reduce considerablemente, no se adapta bien a suelos limosos [112].

Agropyron sibiricum (Willd.) P. Beauv es también una especie cespitosa resistente a la sequía y duradera en el tiempo debido a su potente sistema radicular. Las plantas suelen medir entre 25 y $110 \mathrm{~cm}$ de altura. Los tallos son finos, huecos y lisos. Las hojas son aplanadas, lisas en el envés y profundamente estriadas en el haz, miden de 2 a 4 $\mathrm{mm}$ de ancho y de 8-15 cm de largo. Las hojas inferiores son más largas y cuanto más se acercan a la espiga se van acortando. La inflorescencia es en espiguilla, la cual es comprimida, diverge del raquis en menos de 35 grados; miden 7-10 mm de largo y poseen 4-9 flores [113].

Al igual que el agropiro crestado, el agropiro siberiano se desarrolla en secanos de escasa precipitación ( $\leq 250 \mathrm{~mm}$ ), en lugares con periodos libres de helada menores a 140 días. Se desarrolla bien en suelos poco profundos, aunque prefiere suelos profundos, de textura franca-arcillosa, bien drenados y de $\mathrm{pH}$ neutro. En condiciones de salinidad el vigor y la producción se reducen [114]. 
En la foto 1 se muestra un detalle de la morfología de la espiga de las tres especies del género Agropyron anteriormente citadas.
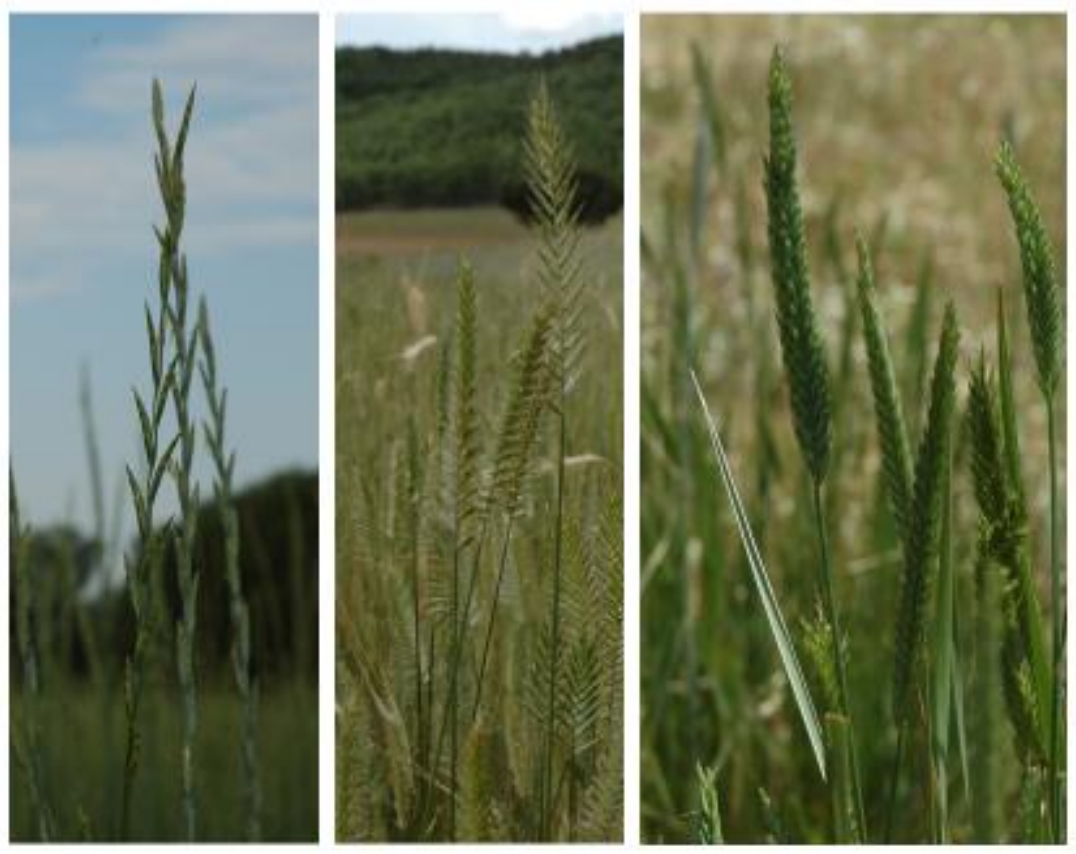

Foto 1. Espiga de agropiro alargado (izquierda), agropiro crestado (centro) y agropiro siberiano (derecha) (25 de junio de 2018).

Para la siembra de estas especies es necesario realizar labores similares a las que se le hacen a los cereales de invierno pudiendo usar la misma maquinaria en la preparación del suelo, siembra, abonado y tratamiento fitosanitario. Se realiza una labor principal de alzado y una labor complementaria de cultivador o conjunto (cultivador + rodillo); también se realiza un abonado de sementera entre las dos labores preparatorias con abonos inorgánicos comerciales cuya formulación se aproxime lo máximo posible a las exigencias en nitrógeno, fósforo y potasio que tenga el cultivo. Después de la siembra, a finales de invierno o principios de primavera se realiza un abonado de cobertera y el primer año se suele ayudar a la plantación con un tratamiento fitosanitario contra malas hierbas dicotiledóneas que no será necesario el resto de los años ya que, si se implanta bien, la competencia natural de la pradera sembrada no dejará que se propaguen las malas hierbas. La recolección se realiza como la de cualquier otro forraje con una segadora convencional y dependiendo de su destino y de la zona agraria donde se encuentre el cultivo se henifica y empaca para calor y/o electricidad o se ensila para biogás.

La diferencia con los forrajes sembrados para la alimentación del ganado es la fecha de recolección. Normalmente en la recogida para forraje no se espera hasta el 
estado fenológico de grano pastoso ya que, sino el forraje pierde cualidades organolépticas, en cambio en el forraje cuyo destino es la producción energética se prioriza el máximo rendimiento.

Además del estudio de las características morfológicas de estas especies, es necesario conocer también la viabilidad económica para su uso energético en el contexto actual, integradas en una explotación agrícola. Los parámetros económicos definirán si es viable su cultivo a gran escala para los agricultores.

\subsubsection{Margen económico de gramíneas perennes}

La importancia del estudio económico a nivel de explotación es indudable. El éxito de estas especies dependerá de la demanda que tengan en el mercado y la viabilidad económica de las mismas ya que en contadas ocasiones el productor antepone otros criterios al económico. El estudio económico de estas especies debe estar integrado en un estudio global de la explotación agrícola como unidad de producción, en el que el cultivo de gramíneas perennes en tierra marginal sea una alternativa que pueda competir con el cultivo por excelencia sembrado en tierras marginales o en tierras menos productivas de las explotaciones como es el centeno (Secale cereale L.).

De acuerdo con la Decisión 85/377 de la Comisión de la CEE de 7 de junio de 1985, se establece una tipología para el cálculo del margen bruto de las explotaciones agrarias. Se entiende por margen bruto el valor de la producción bruta de una explotación, del que se deducen determinados costes directos específicos como semillas (compradas y producidas en la explotación), abonos, productos fitosanitarios y otros gastos específicos de los cultivos. En la citada decisión se establece que no se incluirán en los costes directos los relativos a costes de maquinaria y mano de obra asalariada y familiar los cuales deben deducirse para calcular el margen bruto. Por esta razón la mayoría de los estudios agrarios solo contemplan el margen bruto dada la dificultad que tiene la imputación de los costes de maquinaria, mano de obra y otros costes indirectos [115]. No obstante, en este estudio se contemplan los costes de maquinaria y mano de obra y se repartirán de forma proporcional al coste horario de cada labor llevada a cabo en los diferentes cultivos. Existen otros estudios que realizan así el cálculo de los costes de maquinaria y mano de obra como el de Lloveras y Cabases [116] de diferentes cultivos en explotaciones del Valle del Ebro. Según EirizGervas et al en publicaciones del Ministerio de Agricultura de España [117] los principales costes de producción que tienen los agricultores de explotaciones de secano 
de cereales de invierno y leguminosas grano son la maquinaria y combustible (18\%), los fitosanitarios y fertilizantes inorgánicos (23\%), la mano de obra (10\%) y las semilla ( $9 \%)$.

Como ingresos las explotaciones agrarias de secano cuentan con la venta de su producción de grano y de paja y los pagos por superficie asociados a la PAC.

Hasta la fecha no se han encontrado estudios de costes de gramíneas perennes para biomasa a gran escala integrados en la rotación de explotaciones agrarias debido a que son cultivos que aún no gozan de la popularidad deseada y su cultivo no está generalizado.

\subsubsection{Análisis medioambiental de las gramíneas perennes}

Los métodos utilizados para las evaluaciones ambientales siguen los propuestos en el análisis de ciclo de vida (ACV) de los sistemas agrícolas [118]. El análisis de ciclo de vida es un método analítico empleado para la evaluación del uso y transformación de uno o varios recursos determinados. Su propósito es identificar y cuantificar los impactos que se generan en el medio ambiente durante todas las fases de existencia de un producto o actividad y de esta manera obtener información sobre su repercusión en la calidad ambiental. El ACV se estandariza a nivel mundial a través de las normas ISO 14040 y 14044 midiendo la carga ambiental y huella ecológica con una frase que define el proceso "de la cuna a la tumba" [119]. Para el estudio de ACV de gramíneas perennes se contabilizan los inputs utilizados para el cultivo y los trabajos de campo realizados a lo largo de un determinado periodo de tiempo realizando un inventario. Después se seleccionan los métodos de evaluación para transformar los elementos del inventario de ciclo de vida en impactos dependiendo de lo que se quiera medir. Por ejemplo, Frischknecht et al. [120] utilizan para la evaluación del potencial de calentamiento global del cultivo de una determinada especie el Panel Intergubernamental sobre el Cambio Climático (IPCC) 2013 para un horizonte temporal de 100 años y, para evaluar la energía primaria consumida para su producción usa el análisis del requisito de energía acumulada.

\subsubsection{Análisis energético de las gramíneas perennes}

Este análisis tiene por objeto definir unas características físicas, químicas y energéticas que permiten evaluar su comportamiento en las diferentes líneas de utilización. La caracterización de las gramíneas perennes se realiza determinando los componentes químicos y las características energéticas de la misma para luego pasar a una segunda fase de ensayos predictivos a escala de laboratorio, que indicarán la 
problemática en el comportamiento de las mismas en su posterior uso en la transformación termoquímica. Todos estos análisis están estandarizados por normas internacionales (ISO) como son ISO 14780:2017; ISO 14780:2017; ISO 18122:2015; ISO 16948:2015; ISO 16994:2016; ISO 18125:2017 o ISO 16967:2015.

La característica física de la biomasa de las gramíneas perennes más importante para determinar su utilización como combustible es la humedad, la cual se basa en la pérdida de masa de la muestra hasta humedad constante cuando se calienta a $105^{\circ} \mathrm{C}$. El contenido en humedad afecta tanto a la cantidad como a la calidad del producto obtenido.

Para su caracterización energética es necesario conocer el poder calorífico que se determina mediante la combustión con exceso de oxígeno bajo condiciones controladas de una muestra de la biomasa en un calorímetro.

En cuanto a su caracterización química hay que diferenciar dos análisis fundamentales para determinar su utilización como combustible. Es necesario realizar un análisis inmediato que determinará el contenido en cenizas y, volátiles y un análisis elemental que permitirá conocer el contenido de elementos tan importantes como el carbono, nitrógeno, hidrógeno y azufre relacionados con las posibles emisiones en procesos termoquímicos. El análisis elemental se basa en la combustión catalítica a temperatura variable. En las gramíneas perennes al ser especies herbáceas también es necesario conocer su contenido en cloro relacionado también con procesos de emisiones y corrosión. También se pueden realizar análisis de elementos minoritarios y trazas, así como análisis térmicos y de tendencia a la formación de escorias y sinterizados si su uso va destinado a combustión.

Si la biomasa de las gramíneas perennes se compara con combustibles como el carbón, que tradicionalmente se utilizan en procesos de conversión termoquímica, esta biomasa presenta una serie de ventajas con respecto a estos combustibles. Estas características son el bajo contenido en sulfuros y cenizas, además de su alta reactividad, que le reporta beneficios en los procesos de gasificación. Por el contrario, su baja densidad es un inconveniente para su utilización por lo que suele necesitar procesos de preparación cuya finalidad es dotar a estos productos de unas características requeridas para su utilización en diferentes equipos de conversión energética. 
METODOLOGÍA 


\section{CAPÍTULO II: METODOLOGÍA}

\subsection{Identificación de tierras marginales en España}

\subsection{1 Área de estudio}

Se analizó la tierra arable en condiciones de secano que se dedica a la producción de cultivos herbáceos en España, excluyendo las ciudades autónomas de Ceuta y Melilla. El área de estudio tenía una superficie aproximada de 10,5 Mha divididas en 8122 municipios.

Para determinar qué se puede considerar tierra agrícola marginal, se estudió el margen económico de los principales cultivos (trigo y cebada (Hordeum vulgare L.)) bajo condiciones de secano durante 6 años. Se tomaron estos dos cultivos debido a que la suma de las superficies de trigo y cebada representa el $80 \%$ de la superficie total de cultivos herbáceos sembrados en condiciones de secano anualmente [121], por lo que son los cultivos más representativos. El margen económico de estos cultivos ayuda a determinar cuál es la producción mínima que tienen que obtener los agricultores en el contexto actual para recuperar al menos los costes de producción de los cultivos. Es importante la identificación de estas áreas ya que son las primeras que se tienden a abandonarse por los agricultores debido a su baja rentabilidad [5].

Una vez que se ha determinado el umbral para cubrir los costes de producción, la ubicación espacial de las áreas se llevó a cabo cruzando datos de producción con una base de datos del Ministerio de Agricultura. Esta base de datos se compone de la producción media anual de cereales de invierno actualizada año a año en España (trigo y cebada, entre otros cultivos), para cada municipio en los últimos 39 años (1979-2018) [122].

Después de identificar los municipios que tienen como media anual producciones por debajo del umbral económico para cubrir costes de producción de los cereales de invierno considerados, el siguiente paso fue mapear y analizar las restricciones biofísicas en estas áreas para identificar cuáles son las principales restricciones biofísicas que puedan afectar a la producción. Esto también sirvió para identificar si estas restricciones biofísicas afectaban a municipios donde la producción promedio para cada cultivo estudiado era más alta que el umbral para cubrir costes de producción. Así, además de identificar zonas donde el estudio económico era negativo, también se identificaban aquellas áreas en las que pueden estar en peligro a corto plazo las producciones económicamente viables de los citados cultivos. 


\subsubsection{Determinación del umbral económico}

La metodología utilizada para determinar el margen económico de los dos cultivos de referencia está basada en la producción mínima por hectárea que los agricultores necesitan para recuperar los costes de producción. Para realizar este cálculo se tuvieron en cuenta los costes de la maquinaria (inversión, depreciación, costes de mantenimiento y combustible) y mano de obra (Tabla 3), además de los costes de adquisición de materias primas utilizadas para la producción (semillas, productos fitosanitarios y fertilizantes) (Tabla 4). Los costes de la maquinaria, las materias primas y los precios de producción en los años del estudio fueron obtenidos del Ministerio de Agricultura [117, 123].

Para el cálculo de los costes de maquinaria se consideró un sistema de laboreo tradicional, que es el más común en España, utilizando un tractor de 112 kW y el equipamiento agrícola adecuado. Con respecto a los trabajos agrícolas, se considera el coste horario para cada actividad agrícola, es decir, laboreo (alzado y labores preparatorias del terreno), fertilización tanto de fondo como de cobertera, siembra, tratamiento con herbicidas y cosecha, un precio de combustible de $0,89 € \mathrm{~L}^{-1}$ [123], así como un coste de mano de obra de $10 € \mathrm{~h}^{-1}$ [123].

Tabla 3. Coste horario de maquinaria y mano de obra para cada trabajo agrícola.

\begin{tabular}{lcccc}
\hline Labor agrícola & $\begin{array}{c}\text { Combustible } \\
\left(\mathbf{L} \cdot \mathbf{h a}^{-1}\right)\end{array}$ & $\begin{array}{c}\text { Horas por } \\
\text { labor }\left(\mathbf{h} \cdot \mathbf{h a} \mathbf{A}^{-1}\right)\end{array}$ & $\begin{array}{c}\text { Coste tractor + } \\
\text { apero }\left(\boldsymbol{\epsilon} \cdot \mathbf{h a}^{-1}\right)\end{array}$ & $\begin{array}{c}\text { Total } \\
\left(\boldsymbol{\epsilon} \cdot \mathbf{h a}^{-1}\right)\end{array}$ \\
\hline Alzado & 13,9 & 0,98 & 33,59 & 43,39 \\
Abonado de & 1,0 & 0,09 & 6,24 & 7,11 \\
fondo & 6,1 & 0,56 & 12,62 & 18,17 \\
Cultivado & 4,3 & 0,39 & 15,48 & 19,40 \\
Siembra & 0,7 & 0,07 & 5,24 & 6,11 \\
Abonado de & 2,7 & 0,21 & 3,61 & 5,71 \\
cobertera & 0,7 & 0,07 & 4,60 & 5,25 \\
Pase de rodillo & 17,1 & 0,44 & 39,60 & 44,00 \\
Pulverización & & & TOTAL & 149,14 \\
Cosecha & & &
\end{tabular}


Tabla 4. Costes de materias primas y precio de venta del trigo y la cebada dependiendo de la producción.

\begin{tabular}{|c|c|c|}
\hline & Trigo $\left(€ \cdot \mathbf{h a}^{-1}\right)$ & Cebada $\left(€ \cdot\right.$ ha $\left.^{-1}\right)$ \\
\hline \multicolumn{3}{|c|}{$\begin{array}{l}\text { Abonado de fondo para } \\
\text { diferente producción esperada: }\end{array}$} \\
\hline $1,0-1,5 \mathrm{Mg} \cdot \mathrm{ha}^{-1}$ & $50-63$ & $40-48$ \\
\hline $2,0-2,5 \mathrm{Mg} \cdot \mathrm{ha}^{-1}$ & $84-100$ & $60-80$ \\
\hline Semilla & 39 & 33 \\
\hline Herbicida & 23 & 22 \\
\hline \multicolumn{3}{|c|}{$\begin{array}{l}\text { Abonado de cobertera para } \\
\text { diferente producción esperada: }\end{array}$} \\
\hline $\begin{array}{l}1,0-1,5 \mathrm{Mg} \cdot \mathrm{ha}^{-1} \\
2,0-2,5 \mathrm{Mg} \cdot \mathrm{ha}^{-1}\end{array}$ & $\begin{array}{l}20-25 \\
30-41\end{array}$ & $\begin{array}{l}20-25 \\
30-41\end{array}$ \\
\hline Output & 190 & 161 \\
\hline
\end{tabular}

La fertilización de sementera se calculó estudiando las restituciones necesarias de las plantas dependiendo de la cosecha esperada [124], utilizando un abono complejo comercial NPK 8-24-8 para trigo y 8-15-15 para cebada, y el abonado de cobertera con Nitrato amónico cálcico (NAC 27\%). La dosis de siembra se estableció en $190 \mathrm{~kg} \mathrm{ha}^{-1}$ para trigo y $180 \mathrm{~kg} \mathrm{ha}^{-1}$ para cebada [125] y los precios de la semilla fueron los precios de venta de los outputs más el coste de tratamiento de selección de la semilla y el importe correspondiente del canon de royalties abonado a Geslive. El tratamiento con herbicida se calculó basado en la utilización de herbicidas de invierno para trigo y de primavera para cebada para la eliminación de malas hierbas monocotiledóneas y dicotiledóneas.

Las ayudas directas de la PAC, la renta de la tierra y los costes de oportunidad no se consideraron por diferentes razones. Aunque los pagos directos de la PAC y la renta de la tierra son ingresos y costes muy importantes que repercuten en el resultado económico final de cada explotación, tienen una gran variabilidad dentro de las explotaciones agrícolas españolas y no es posible comparar los promedios debido a la falta de datos fiables. El coste de oportunidad es un término comparativo, y no es un coste real incurrido por el cultivo.

\subsubsection{Determinación de las restricciones biofísicas}

Se consideraron siete factores de restricción biofísica siguiendo los mismos criterios y umbrales propuestos por el JRC, en las áreas donde el valor de producción no cubría los costes de producción, seis relacionados con el suelo: tipo, profundidad, pedregosidad, contenido de materia orgánica (MO), $\mathrm{pH}$ y salinidad, y uno relacionado con el clima como es la precipitación anual. 
La clasificación del suelo se basó en los cuatro tipos principales de suelo que se encuentran en España de acuerdo con la taxonomía del suelo del USDA: Inceptisol, Alfisol, Entisol y Aridisol. Inceptisol y Alfisol son suelos que no requieren riego para lograr rendimientos competitivos y tienen una retención adecuada de agua y nutrientes, a diferencia de las otras dos categorías, Entisol y Aridisol, que no son adecuadas para la agricultura de secano. Aridisol es representativo de las regiones áridas donde la evapotranspiración de los cultivos en condiciones estándar (ETc) es mayor que la transpiración durante la mayor parte del año, por lo tanto, el régimen de humedad suele ser árido. Entisol es un suelo con un desarrollo de perfil muy bajo y casi sin diferencias entre horizontes [126].

Se tuvo en cuenta la profundidad del suelo desde la superficie hasta el lecho rocoso, esta distribución tiene un impacto muy significativo en el rendimiento de los cultivos ya que influye en el desarrollo del sistema radicular [127]. Esto implica que una mayor uniformidad en la distribución de raíces podría mejorar el rendimiento económico de los cultivos. Los cereales de invierno debido a sus características, desarrollan el 90$100 \%$ del sistema radicular en los primeros $100 \mathrm{~cm}$ del suelo.

La pedregosidad es un factor importante para los cultivos, debido a su asociación con problemas de realización de labores agrícolas, su relación con la expansión de las raíces en el suelo y la retención de agua. El suelo se caracteriza como "pedregoso" cuando la concentración en volumen de piedras (fracción sólida del suelo cuyos componentes tienen un diámetro mayor a $2 \mathrm{~mm}$ ) es superior al $15 \%$ de la fracción del suelo [128].

El contenido de materia orgánica está directamente relacionado con la fertilidad del suelo. El nivel deseable de materia orgánica en los suelos agrícolas es, al menos, alrededor del $2 \%$, aunque es posible cultivar cereales de invierno con un contenido de MO superior al 1\% [129]. En consecuencia, las tierras con menos del $1 \%$ de contenido de $\mathrm{MO}$ fueron seleccionadas como tierras marginales.

El pH del suelo es un parámetro relevante en la productividad de la planta, porque la disponibilidad de nutrientes esenciales para las plantas depende de este valor. Si el $\mathrm{pH}$ del suelo no es adecuado, la producción puede reducirse hasta el punto de afectar el crecimiento del cultivo. La mayoría de las plantas necesitan un $\mathrm{pH}$ del suelo entre 5,5 y 7,5 para una absorción óptima de nutrientes. Por ejemplo, el pH ideal para los cereales de invierno es 6,5 [130], y aunque los cereales se pueden cultivar con un $\mathrm{pH}$ de 8 [131], no es lo más adecuado si se quieren obtener rendimientos competitivos en cereales de invierno. Un pH inferior a 6 podría afectar a la absorción de magnesio o nitrógeno, y un 
pH superior a 7 podría afectar la disponibilidad de manganeso [132]. Se han considerado como restricciones de $\mathrm{pH}$ valores menores de 6 y mayores de 8 .

Otro parámetro relevante es la salinidad. Cuando los cereales de invierno se siembran en terrenos sin pendiente, el límite de resistencia a la salinidad para el trigo y la cebada es de $4 \mathrm{dS} \mathrm{m}^{-1}$. Los valores de salinidad del suelo superiores a $4 \mathrm{dS} \mathrm{m}^{-1}$ tienden a afectar la productividad de la planta, aunque pueden resistir un contenido de salinidad de $6 \mathrm{dS} \mathrm{m}^{-1}$ [37]. Se ha tenido en cuenta como restricción una salinidad superior a $4 \mathrm{dS} \mathrm{m}^{-1}$.

Con respecto al clima, los cereales de invierno necesitan al menos $400 \mathrm{~mm}$ de precipitación en España para completar el ciclo de crecimiento [133]. Por lo tanto, el hecho de que la precipitación anual sea inferior a $400 \mathrm{~mm}$ plantea un problema.

\subsubsection{Fuentes de mapeo y gestión de datos}

Se utilizó la herramienta informática del Environmental Reseach Institute (ESRI. Inc.) y ArcMAPTM Spatial Analyst. ArcGIS versión 10.5 fue el software de sistemas de información geográfica (SIG) utilizado para organizar, agregar y representar los datos cartográficos.

Los mapas característicos del suelo se utilizaron como un sistema para el mapeo automatizado del suelo basado en una compilación global de datos del perfil del suelo y datos de detección remota disponibles públicamente llamados SoilGrids.

Los conjuntos de datos para establecer las restricciones de precipitación fueron la precipitación anual promedio acumulada durante 30 años, de 1975 a 2005 [134].

\subsection{Ensayos de campo de gramíneas perennes del genero Agropyron}

\subsubsection{Localización de los campos de ensayo}

El estudio se llevó a cabo en dos lugares diferentes de la provincia de Soria, situados en la meseta norte española, una de las áreas más extensas de agricultura de secano en el sur de Europa. Los campos experimentales se ubicaron en los municipios de Cubo de la Solana $\left[41^{\circ} 36^{\prime} \mathrm{N}\right.$ y $2^{\circ} 28^{\prime} \mathrm{O}$ ] a $1010 \mathrm{~m}$ sobre el nivel del mar, y Alconaba $\left[41^{\circ} 42^{\prime} \mathrm{N}\right.$ y $\left.2^{\circ} 22^{\prime} \mathrm{W}\right]$ a $1000 \mathrm{~m}$ sobre el nivel del mar.

Las dos localizaciones presentaban severas limitaciones biofísicas. En ambas zonas experimentales, los suelos tenían características similares, con textura arenosa (81\% arena en Cubo de la Solana y $86 \%$ arena en Alconaba), con un contenido de 
elementos gruesos (> $2 \mathrm{~mm}$ ) superior al $15 \%$ en volumen de suelo (Foto 2), bajo contenido de materia orgánica $(\leq 1 \%)$ y bajas retenciones de agua y nutrientes, lo que indica pérdidas potenciales altas por lixiviación. Tenían un $\mathrm{pH}$ neutro y no presentaban problemas de salinidad. El contenido del suelo en macronutrientes previo al experimento era nitrógeno $0,06 \%$ en las parcelas Cubo de la Solana y $0,05 \%$ en Alconaba; fósforo $\left(\mathrm{P}_{2} \mathrm{O}_{5}\right), 10,2$ y $10,0 \mathrm{mg} \cdot \mathrm{kg}^{-1}$ en Cubo de la Solana y Alconaba, respectivamente; y en potasio $\left(\mathrm{K}_{2} \mathrm{O}\right)$ de $152,5 \mathrm{mg} \cdot \mathrm{kg}^{-1}$ en los ensayos de Cubo de la Solana y $150 \mathrm{mg} \cdot \mathrm{kg}^{-1} \mathrm{en}$ las parcelas de Alconaba. Para el análisis del suelo, se tomaron muestras de suelo de la capa superior $(0-30 \mathrm{~cm})$ como se indica en la norma ISO 10381-1 y se analizó de acuerdo con las normas ISO: textura (ISO 11277), pH (ISO 10390), conductividad eléctrica (ISO 11265), materia orgánica (ISO 10694), fósforo (ISO 11263), potasio (ISO 11260), y amonio y nitratos (ISO / TS 14256-1 EX).

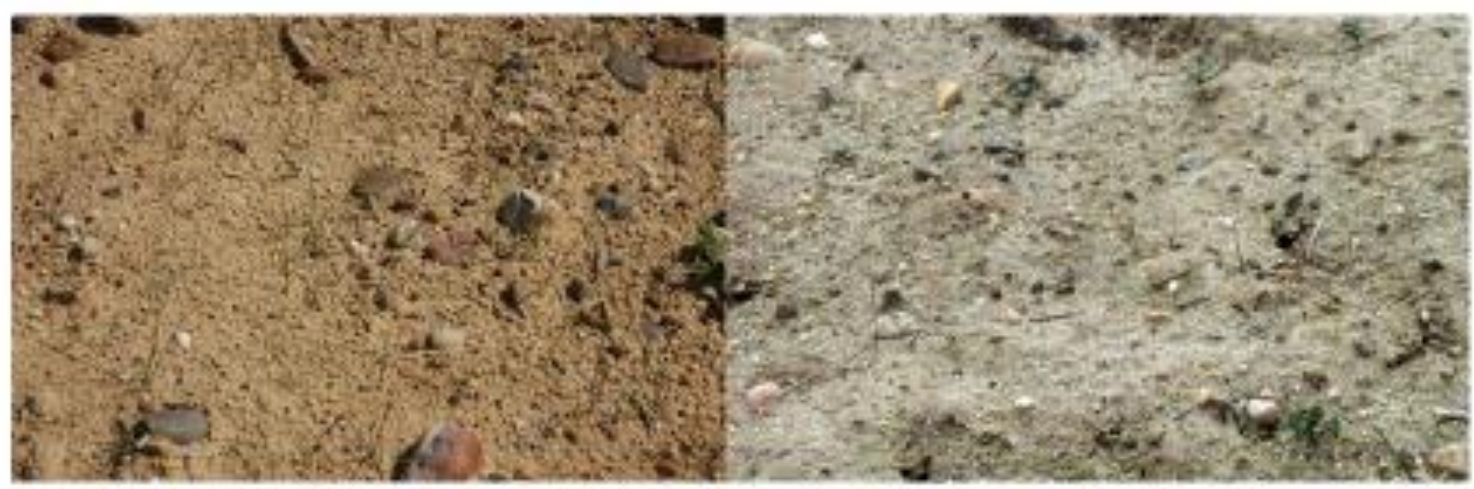

Foto 2. Suelo del ensayo de Alconaba (izquierda, noviembre de 2013) y suelo del ensayo de cubo de la Solana (derecha, enero de 2011).

El clima en ambas parcelas de ensayo era mediterráneo-continentalizado, caracterizado por inviernos fríos, veranos cálidos y bajas precipitaciones. Los datos climáticos se tomaron de las estaciones meteorológicas más próximas a la zona de la Agencia Estatal de Meteorología (AEMET) localizadas en las coordenadas $41^{\circ} 36^{\prime} \mathrm{N}$ y $2^{\circ} 30^{\prime} \mathrm{O}$ para los ensayos de Cubo de la Solana y $41^{\circ} 46^{\prime} \mathrm{N}$ y $2^{\circ} 29^{\prime} \mathrm{O}$ para las parcelas experimentales de Alconaba. La precipitación anual promedio durante el período de estudio fue de 502,7 mm en los ensayos de Cubo de la Solana, siendo 2018 el año más lluvioso (524 mm) y 2017 el más seco (315 mm). La cosecha apenas fue posible en 2017 debido a la producción de biomasa extremadamente baja obtenida como consecuencia de la baja precipitación anual registrada, particularmente entre marzo y junio (123 mm). La temperatura promedio anual fue de $10,6^{\circ} \mathrm{C}$, con temperaturas absolutas mínimas y máximas de $-11,9^{\circ} \mathrm{C}$ en enero de 2011 y $37^{\circ} \mathrm{C}$ en agosto de 2012 , respectivamente. El período libre de heladas fue desde finales de mayo hasta principios 
de octubre, y las condiciones de sequía generalmente se dieron durante los meses de verano.

El ensayo de Alconaba registró $437 \mathrm{~mm}$ de precipitación promedio anual, siendo 2018 el año más húmedo (524 mm) y 2017 el más seco con 351 mm. La temperatura promedio anual fue de $10,5^{\circ} \mathrm{C}$, y las temperaturas absolutas mínima y máxima fueron de $-10,5^{\circ} \mathrm{C}$ en enero de 2017 y $36,0^{\circ} \mathrm{C}$ en julio de 2015 , respectivamente. En los campos de ensayo de Alconaba se observaron similares períodos de heladas y sequías que en Cubo de la Solana.

\subsubsection{Diseño experimental y manejo de los cultivos}

Los ensayos de campo de Cubo de la Solana se estudiaron durante 8 años agrícolas (octubre de 2010 a septiembre de 2018). El experimento se diseñó sembrando tres repeticiones en un diseño de bloques completos al azar en parcelas de $300 \mathrm{~m}^{2}$ (3 $\mathrm{m}$ de ancho $\times 100 \mathrm{~m}$ de largo) para cada unidad experimental. Las especies sembradas fueron agropiro alargado (cultivares Alkar, Jose y Riparianslopes), agropiro crestado (cultivar Hycrest) y agropiro siberiano (cultivar Vavilov II) (Foto 3).

En los ensayos de Alconaba, se sembraron 3 cultivares de agropiro alargado con 4 repeticiones durante 5 años (octubre de 2013 a agosto de 2018) en parcelas con una superficie, forma y diseño similares al ensayo de Cubo de la Solana. Los cultivares sembrados en Alconaba fueron Alkar (coincidiendo con el ensayo de Cubo de la Solana) originario de EE.UU., Bamar originario de Polonia y Szarvasi-1 originario de Hungría (Foto 3).
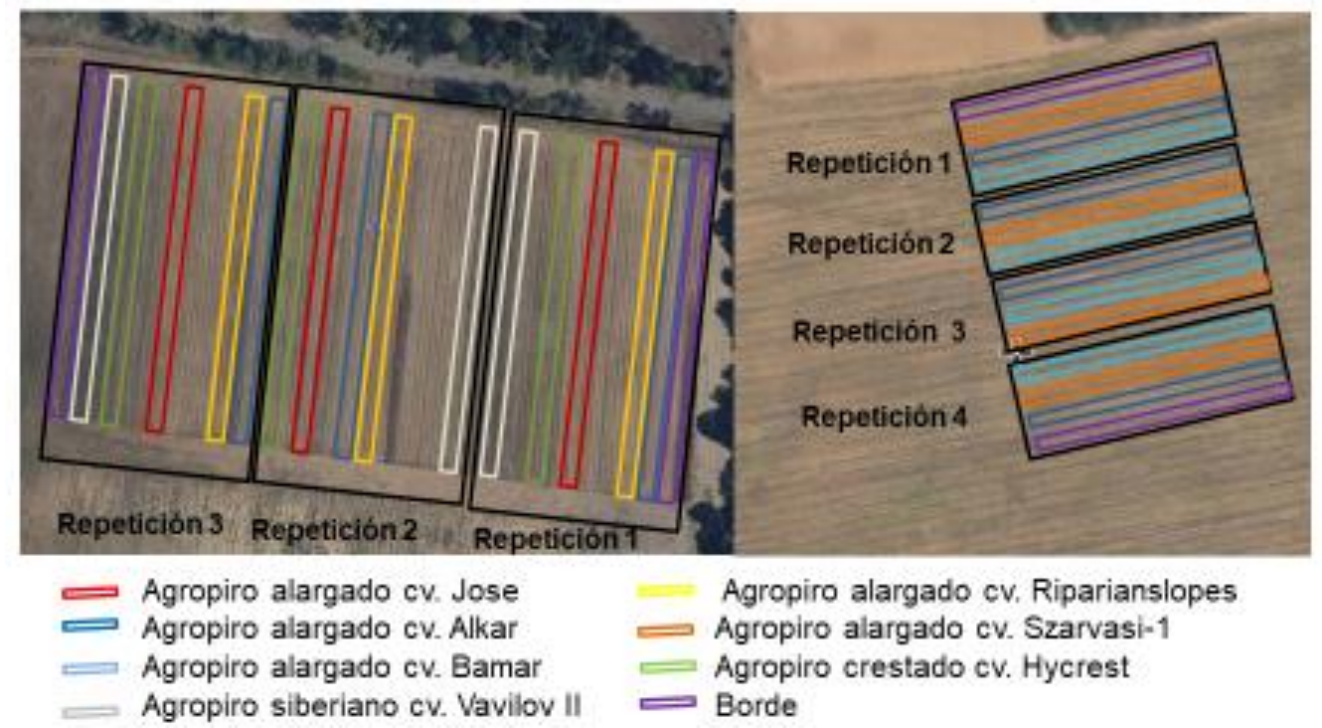

Foto 3. Croquis general del ensayo de Cubo de la Solana (izquierda) y del ensayo de Alconaba (derecha). 
El cultivo previo en ambos ensayos fue barbecho. La cronología para la realización de las labores fue el siguiente: una labor principal de alzado con arado de vertedera siete meses antes de la siembra, una labor complementaria de pase de cultivador en verano y la siembra en octubre (2010 en Cubo de la Solana y 2013 en Alconaba). La dosis de siembra fue de $20 \mathrm{~kg} \cdot \mathrm{ha}^{-1}$ para cultivares de agropiro alargado y $15 \mathrm{~kg} \cdot \mathrm{ha}^{-1}$ para agropiro crestado y agropiro siberiano. La máquina empleada fue una sembradora de chorrillo convencional con $13 \mathrm{~cm}$ de separación entre hileras. Se aplicó un abonado de fondo del complejo NPK 8-24-8 (300 kg $\left.\cdot \mathrm{ha}^{-1}\right)$ en el año de implantación de los cultivos dos días antes de la siembra y se envolvió con un pase de cultivador. Además, las parcelas se rodillaron a mediados de marzo del año de implantación para favorecer labores agrícolas como la siega y el empacado, antes de la aplicación de la fertilización de cobertera. Todas las parcelas se pulverizaron a finales de abril para controlar malas hierbas dicotiledóneas con 1 L.ha-1 de ácido 2,4-D 34,5\% + ácido 2-metil-4clorofenoxiacético 34,5\%. La fertilización nitrogenada se aplicó entre mediados y finales de marzo de cada año utilizando NAC $27 \%$ a $300 \mathrm{~kg} \cdot \mathrm{ha}^{-1} \cdot \mathrm{año}^{-1}$. La recolección se realizó mediante siega con una segadora acondicionadora de rodillos entre mediados de julio y principios de agosto, dependiendo del año, siempre y cuando los cultivos estuviesen en estado fenológico de grano pastoso y dejando unos $10 \mathrm{~cm}$ de rastrojo para favorecer el rebrote. Después de 5 o 6 días de secado en el campo, la biomasa fue empacada en pacas prismáticas ( $<10 \%$ de humedad).

El principal factor limitante para el crecimiento de estos cultivos en condiciones de secano es la disponibilidad de agua. La producción de biomasa de los cultivos depende de su eficiencia en el uso del agua. Por lo tanto, los cultivos con mayor eficiencia también logran un mejor margen económico. Se expresa como eficiencia del uso del agua (EUA) o eficiencia del uso de la lluvia, y se mide en términos de producción de cultivos por unidad de aporte de agua. Específicamente, EUA es el resultado de dividir el

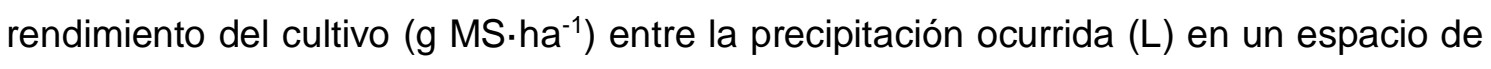
tiempo determinado [135]. Aunque la EUA se ha evaluado principalmente en cultivos agronómicos tradicionales, también interesa evaluarla en los cultivos destinados a biocombustibles [136]. La EUA se calculó para evaluar las diferencias entre cultivares y especies. El período de cálculo se realizó en los meses con la mayor actividad vegetativa (marzo a junio), que es cuando se considera que la lluvia es de vital importancia para la producción de biomasa en especies C3 en condiciones de secano, como informaron otros autores $[135,137]$. 
En la foto 4 se puede observar un detalle del ensayo de Alconaba del agropiro alargado cultivar Alkar en diferentes meses y etapas de crecimiento el año de implantación.

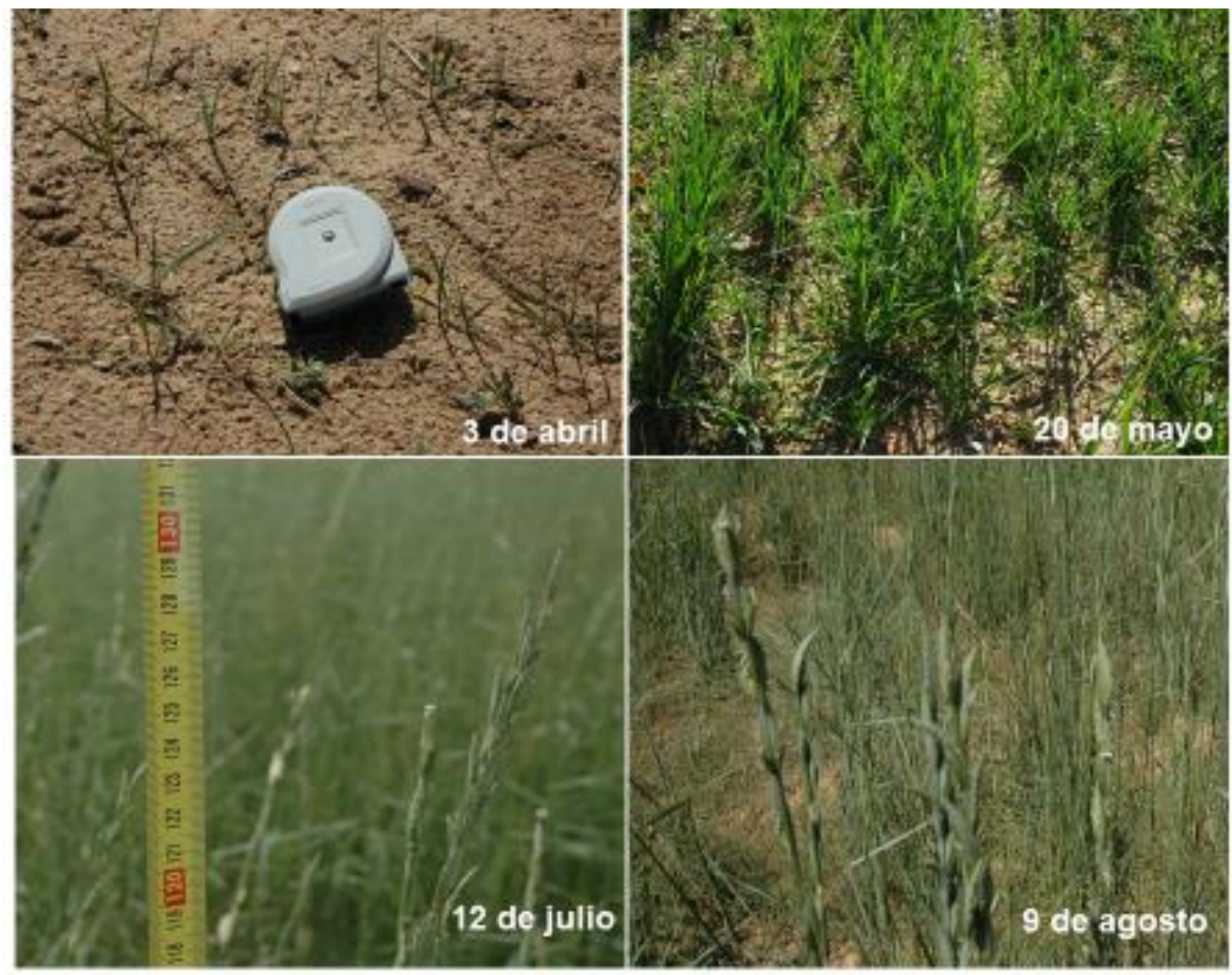

Foto 4. Agropiro alargado cultivar Alkar. Antes del abonado de cobertera (arriba izquierda); después del abonado de cobertera (arriba derecha); espigado (abajo izquierda) y floración (abajo derecha).

\subsubsection{Características químico-energéticas y métodos analíticos.}

Antes de empacar, se tomó una muestra de biomasa por subparcela, cultivar, especie y año para determinar cenizas, poder calorífico inferior y composición química de la biomasa con fines energéticos. Cada muestra se formó recolectando manualmente 3 submuestras de diferentes ubicaciones escogidas aleatoriamente en cada repetición y dejando la misma altura de rastrojo que la segadora. La biomasa del ensayo de Cubo de la Solana se analizó durante 7 años, desde la cosecha de 2012 hasta 2018 sin analizar la biomasa del año de implantación. La biomasa de las parcelas de Alconaba se analizaron anualmente entre 2014 y 2018.

La preparación de la muestra se realizó de acuerdo con ISO 14780: 2017 y los análisis de prueba se llevaron a cabo siguiendo los estándares internacionales correspondientes para biocombustibles sólidos (Tabla 5). 
Tabla 5. Técnicas analíticas y estándares seguidos durante las pruebas.

\begin{tabular}{lcc}
\hline \multicolumn{1}{c}{ Propiedad } & Técnica analítica & Norma \\
\hline Preparación de muestras & Muestreo y molienda & ISO 14780:2017 \\
Cenizas & Calcinación a 550C & ISO 18122:2015 \\
$\mathrm{C}, \mathrm{H}, \mathrm{N}$ & Análisis elemental & ISO 16948:2015 \\
$\mathrm{S}, \mathrm{Cl}$ & Bomba de combustión & ISO 16994:2016 \\
Poder calorífico & Calorímetro & ISO 18125:2017 \\
Elementos mayoritarios: Al, Ca, & Digestor de microondas y & ISO 16967:2015 \\
$\mathrm{Fe}, \mathrm{K}, \mathrm{Mg}, \mathrm{Mn}, \mathrm{Na}, \mathrm{P}, \mathrm{Si}, \mathrm{Ti}, \mathrm{Zn}$ & espectroscopia de emisión óptica & \\
\hline
\end{tabular}

El contenido de humedad se midió secando submuestras en una estufa a $105^{\circ} \mathrm{C}$ hasta peso constante. Los rendimientos de materia seca se calcularon teniendo en cuenta el área de la parcela, así como el peso y el contenido de humedad de los pacas.

En la foto 5 se muestran alguno de los equipos utilizados para el análisis de la biomasa.

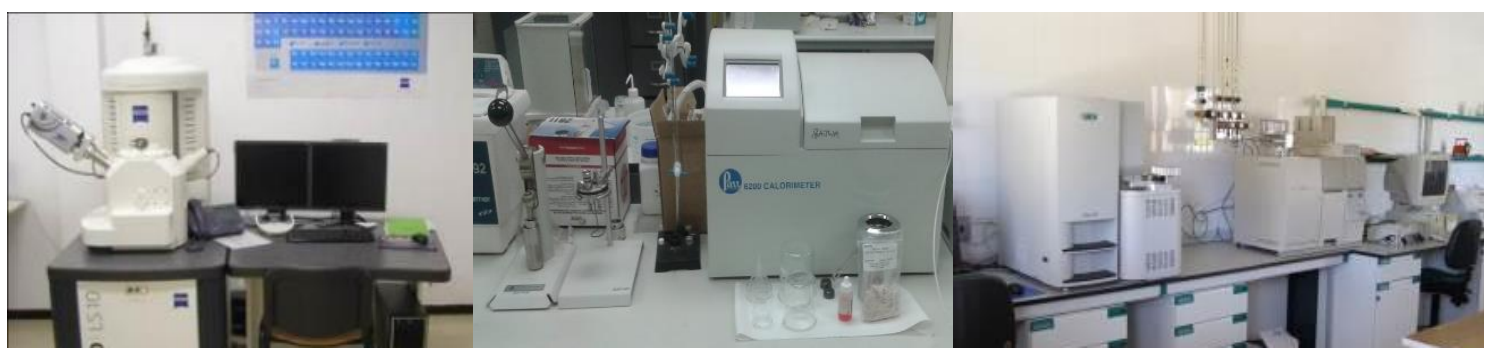

Foto 5. Microscopio electrónico de barrido con microanálisis de elementos (izquierda); calorímetro, prensa y reactivos para determinar el poder calorífico de las muestras (centro) y analizadores elementales CHNS (derecha).

\subsubsection{Análisis estadístico}

Los análisis estadísticos se realizaron con el software Statgraphics Centurion XVII (Statpoint Technologies INC, 2017, The Plains, Virginia, EE. UU.). Mediante el análisis de varianza (ANOVA) se evaluaron los efectos de las diferentes especies, cultivares y años en la producción y composición de biomasa. Se utilizó ANOVA multifactorial bidireccional (sumas de cuadrados de tipo III) con una interacción de orden máximo de 2. Todas las razones $\mathrm{F}$ se basaron en el error cuadrático medio residual. La normalidad de los datos y la homocedasticidad de las variaciones se verificaron utilizando la asimetría estandarizada entre curtosis y la prueba de Levene, respectivamente. No se consideraron necesarias transformaciones de datos. En el ensayo de Alconaba el cultivar y el año y la interacción entre ambos factores se consideraron efectos fijos. En Cubo de la Solana, se realizaron dos tipos de análisis a medida que se probaron diferentes especies y cultivares. Por un lado, un análisis de varianza con especie, año y especie por año como efectos fijos, con las tres especies como tres niveles factoriales (agropiro alargado, agropiro crestado y agropiro siberiano). Por otro lado, un análisis de 
varianza con especies por cultivares, años, y su interacción como efectos fijos, y considerando cinco niveles para el factor especie dividido por cultivar (agropiro alargado cultivar Riparianslopes, agropiro alargado cultivar Alkar, agropiro alargado cultivar Jose, agropiro crestado cultivar Hycrest, y agropiro siberiano cultivar Vavilov II). El bloque (parcelas replicadas) fue un efecto aleatorio en ambos sitios. Las diferencias entre medias de especies, cultivares y años se evaluaron mediante pruebas de rango múltiple de acuerdo con la prueba de diferencia menos significativa (LSD) de Fisher. Se observaron efectos significativos a valores de $p \leq 0,05$ (95\% del nivel de confianza). Las interacciones entre los factores (especies y años o cultivares y años) se representaron utilizando los medios y las gráficas de interacción LSD de Fisher. Las medias, las desviaciones estándar (SD), los percentiles del 75\% (P75), así como los valores individuales mínimos y máximos obtenidos para cada propiedad también se incluyeron en sus tablas correspondientes.

\subsection{Comparación económica y medioambiental del agropiro alargado y el centeno en la tierra agrícola marginal de una explotación real}

\subsubsection{Descripción de la explotación}

La explotación objeto de estudio es una explotación típica de la meseta norte española concretamente en la comarca del Campo de Gómara (Soria), situada en una de las zonas de cultivo de cereales de invierno más extensas del sur de Europa (Foto 6), pero fuertemente afectada por factores marginales tanto edafoclimáticos como socioeconómicos. Está dedicada al cultivo de cereales de invierno y girasol (Helianthus annus L.) en secano con prácticas de laboreo tradicional principalmente. EI JRC la define como una tierra de cultivo con intensidad media-baja y limitaciones severas, con bajas tasas de productividad [138].

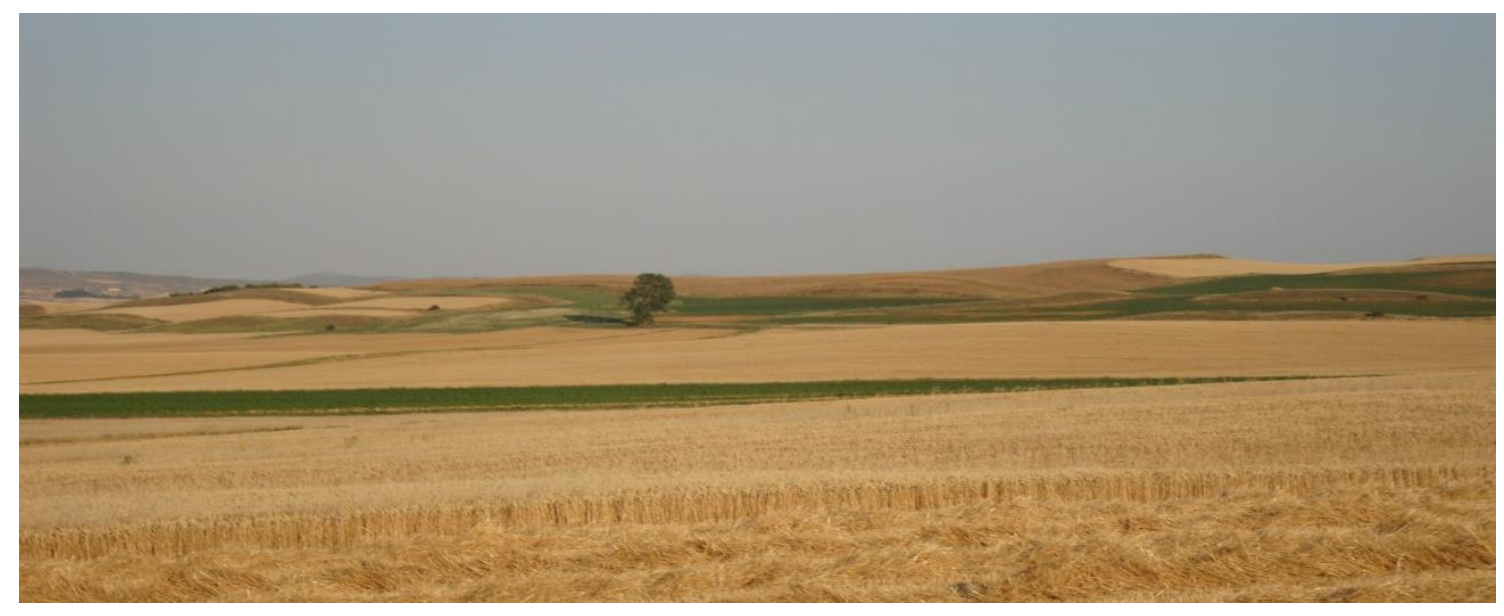

Foto 6. Panorámica general de alguna de las parcelas de la explotación estudiada (julio de 2016). 
En las fechas del estudio, la explotación tenía una extensión de 302 ha distribuidas en 38 parcelas con un área promedio de 7,9 ha (la superficie máxima era de 37 ha y la mínima de $1 \mathrm{ha}$ ) por parcela. La distancia máxima entre parcelas era de $15 \mathrm{~km}$. Un total de 40 hectáreas de su superficie se consideraron marginales debido a las restricciones económicas (baja productividad de cereales de invierno sostenida en el tiempo) y debido también a las restricciones biofísicas (bajo contenido de $\mathrm{MO}(\leq 1 \%)$ y pedregosidad ( $\geq 15 \%$ en volumen de suelo).

La explotación poseía sus propios medios mecánicos para realizar todas las labores culturales, y además tenía $2000 \mathrm{~m}^{2}$ de instalaciones donde almacenaba el grano recolectado y protegía a los equipos agrícolas de las inclemencias meteorológicas cuando no estaban trabajando.

\subsubsection{Gestión agrícola de la explotación}

El objetivo principal de la explotacion agraria era la producción de cereales de invierno de los que además, obtenía como subproducto la paja la cual también vendía. Las especies sembradas fuera del área de tierra marginal durante los cuatro años estudiados fueron cereales de invierno, principalmente, y girasol. Los cereales de invierno fueron trigo blando, que era el cultivo principal (un promedio de 111 ha de ocupación), cebada con una superficie media anual de 62 ha, triticale (Triticosecale $x$ Wittmack) con promedio anual de 32 ha. La distribución anual de girasol era 30 ha y la tierra en barbecho 27 ha. Para la siembra, el agricultor usó semillas comerciales multiplicadas los años anteriores en la propia explotación, excepto las semillas híbridas de girasol que compraba cada año. El cultivo tradicional sembrado en las parcelas de tierra marginal que tenía la explotación era el centeno.

La metodología llevada a cabo por el agricultor para sembrar los cereales de invierno consistía en una labor principal de alzado con el arado de vertedera mayoritariamente o con el chisel y una labor complementaria de pase de cultivador, además de una aplicación de fertilizante en otoño (principios de octubre a diciembre) de abonos complejos antes de la siembra. Después de la siembra realizaba un rodillado a principios de primavera (mediados de marzo), aplicaba la fertilización de cobertera con NAC $27 \%$, y una pulverización de productos fitosanitarios para el control de malas hierbas en abril o principios de mayo a cebada, triticale y centeno y a finales de otoño, a trigo. El período de siembra de cereales era de octubre a principios de diciembre. 
El girasol se sembró a fines de mayo y se cosechó a mediados de octubre. Las parcelas de girasol eran labradas los primeros días del invierno y luego, se les pasaba cultivador dos veces antes de sembrar en primavera además de una aplicación de glifosato antes de la siembra.

La tierra que se dejaba en barbecho era labrada a finales de la primavera y cultivada en verano para prepararla para el próximo período de siembra.

A mediados de octubre de 2013 se sembró parte de la superficie marginal de la explotación con agropiro alargado. La preparación de la tierra fue similar a la de los cereales de invierno con la misma fertilización. Se aplicó un tratamiento fitosanitario en el año de establecimiento para las malas hierbas dicotiledóneas. La fertilización de cobertera en primavera, la siega y el empacado en los primeros días de agosto fueron los únicos trabajos de campo realizados cada año.

La tabla 6 muestra los inputs y dosis usadas en la explotación durante el periodo de estudio. 
Tabla 6. Inputs y dosis utilizadas en la explotación.

\begin{tabular}{|c|c|c|c|c|c|c|}
\hline & \multicolumn{4}{|c|}{ Tierra no marginal } & \multicolumn{2}{|c|}{ Tierra marginal } \\
\hline & Trigo & Triticale & Cebada & Girasol & Centeno & $\begin{array}{l}\text { Agropiro } \\
\text { alargado }\end{array}$ \\
\hline Cultivar & Berdún & Verato & Cometa & Krisol & Petkus & Szarvasi1 \\
\hline $\begin{array}{c}\text { Dosis siembra } \\
\left(\mathrm{kg} \cdot \mathrm{ha}^{-1}\right)\end{array}$ & 200 & 200 & 180 & 4 & 150 & 20 \\
\hline $\begin{array}{c}\text { Fertilizante } \\
\text { Dosis abonado }\end{array}$ & $8-24-8$ & $8-24-8$ & 8-15-15 & - & $8-24-8$ & $8-24-8$ \\
\hline $\begin{array}{l}\text { de fondo } \\
\left(\mathrm{kg} \cdot \mathrm{ha}^{-1}\right)\end{array}$ & 300 & 250 & 300 & - & 200 & 300 \\
\hline $\begin{array}{c}\text { Fertilizante } \\
\text { Dosis abonado }\end{array}$ & NAC 27\% & NAC $27 \%$ & NAC $27 \%$ & - & NAC 27\% & NAC $27 \%$ \\
\hline $\begin{array}{l}\text { cobertera } \\
\left(\mathrm{kg} \cdot \mathrm{ha}^{-1}\right)\end{array}$ & 300 & 200 & 300 & - & 150 & 150 \\
\hline Herbicida & $\begin{array}{c}\text { Clorsulfuron } \\
75 \%+ \\
\text { Clortoluron } \\
50 \%\end{array}$ & $\begin{array}{c}2,4-D \\
\text { acido } \\
60 \%\end{array}$ & $\begin{array}{c}\text { Metsulfuron } \\
\text { metil } 11,1 \% \\
\text { Tribenuron- } \\
\text { metil } 22,2 \%+ \\
2,4-D \text { acido } \\
34,5 \%+ \\
\text { MCPA } 34,5 \%\end{array}$ & $\begin{array}{c}\text { Glifosato } \\
45 \%\end{array}$ & $\begin{array}{c}2,4-\mathrm{D} \\
\text { ácido } 60 \%\end{array}$ & $\begin{array}{c}2,4-D \\
\text { ácido } \\
60 \%\end{array}$ \\
\hline $\begin{array}{c}\text { Dosis } \\
\text { herbicida } \\
\left(\text { ud. } \cdot \text { ha }^{-1}\right)\end{array}$ & $20 \mathrm{~g}+2 \mathrm{~L}$ & $0,8 \mathrm{~L}$ & $45 g+1 L$ & $2,5 \mathrm{~L}$ & $0,8 \mathrm{~L}$ & $1 \mathrm{~L}$ \\
\hline
\end{tabular}

MCPA: ácido 2-metil-4-chlorophenoxyacetico.

Los cereales se cosechaban a mediados de julio y el girasol a mediados de octubre. Una vez que terminaba la cosecha de los cereales se procedía al empacado de la paja. Por otro lado, el agropiro alargado se segaba a finales de julio o principios de agosto, dejando el forraje 4 o 5 días en la parcela para la su henificación y posterior empacado.

En la foto 7 se muestra alguna de las distintas labores agrícolas realizadas en la explotación.

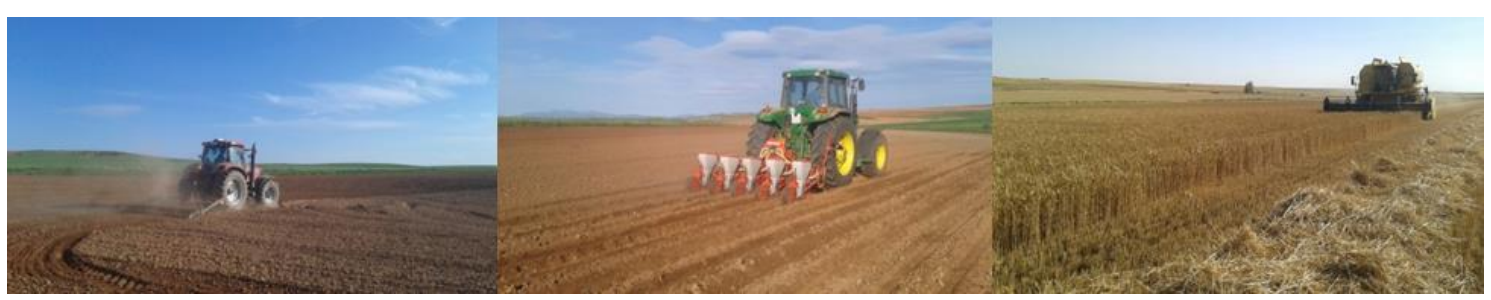

Foto 7. Distintas labores agrícolas realizadas con la maquinaria de la explotación considerada (año 2015). Cultivar (izquierda), siembra de girasol (centro), cosecha de cereal (derecha).

\subsubsection{Características edafoclimáticas}

El clima de la zona considerada se caracterizó por inviernos fríos, veranos cálidos y bajas precipitaciones. Los datos meteorológicos se tomaron en la estación 
meteorológica perteneciente al AEMET $\left(41^{\circ} 44^{\prime} \mathrm{N}\right.$ y $\left.2^{\circ} 4^{\prime} \mathrm{O}\right)$ más cercana a la explotación. La temperatura media anual durante el periodo estudiado fue de $11,0^{\circ} \mathrm{C}$, con una temperatura máxima absoluta en julio de 2015 de $36^{\circ} \mathrm{C}$ y una temperatura mínima absoluta en enero de 2017 de $-11,7^{\circ} \mathrm{C}$. La precipitación anual promedió $513 \mathrm{~mm}$, siendo el año más húmedo 2014 (595 mm) y el más seco 2017 (315 mm). El período libre de heladas fué desde principios de mayo hasta primeros de octubre, y el periodo de sequía fue generalmente los meses de verano julio y agosto.

La tierra marginal agrícola de la explotación se caracterizaba por suelos arenosos pobres ( $88 \%$ de arena, $8 \%$ de limo y $4 \%$ de arcilla), $0,54 \%$ de contenido de materia orgánica, $0,03 \%$ de contenido de nitrógeno, $6,73 \mathrm{mg} \cdot \mathrm{kg}^{-1}$ de fósforo asimilable y 58,19 $\mathrm{mg} \cdot \mathrm{kg}^{-1}$ de potasio, con una densidad aparente de $1,37 \mathrm{Mg} \cdot \mathrm{m}^{-3}$ y un contenido en elementos gruesos (>2 mm) de $29,58 \%$ en volumen. Estos suelos presentan un alto drenaje, en consecuencia, baja retención de agua, bajo contenido de nutrientes, altas pérdidas por lixiviación. En general, es un suelo de baja productividad para los cultivos alimentarios más comunes.

Para el análisis de suelo se tomaron muestras de la capa superior $(0-30 \mathrm{~cm}) \mathrm{de}$ acuerdo a la norma ISO 10381-1 y se analizó siguiendo las normas de estandarización establecidas para textura (ISO 11277), pH (ISO 10390), conductividad eléctrica (ISO 11265), contenido en MO (ISO 10694), contenido de fósforo Olsen (ISO 11263), contenido de potasio (ISO 11260) y contenido de amonio y nitratos (ISO / TS 14256-1 EX.).

\subsubsection{Alternativas en tierra marginal}

Para estudiar la alternativa más adecuada para la tierra marginal de la explotación, se establecieron dos parcelas experimentales, una sembrada de centeno (el cultivo alimenticio tradicional en este tipo de tierra) todos los años y la otra sembrada de agropiro alargado, como cultivo alternativo. Ambas parcelas tenían dos hectáreas cada una y se sembraron en la tierra marginal de la explotación. El análisis económico, energético y ambiental de los dos cultivos se realizó monitorizando los datos durante cuatro años (octubre de 2013 a septiembre de 2017).

En la foto 8 se muestra una vista general de la parcela de agropiro alargado durante los distintos años del estudio y en la foto 9 se muestran las labores de recolección de la citada parcela. 


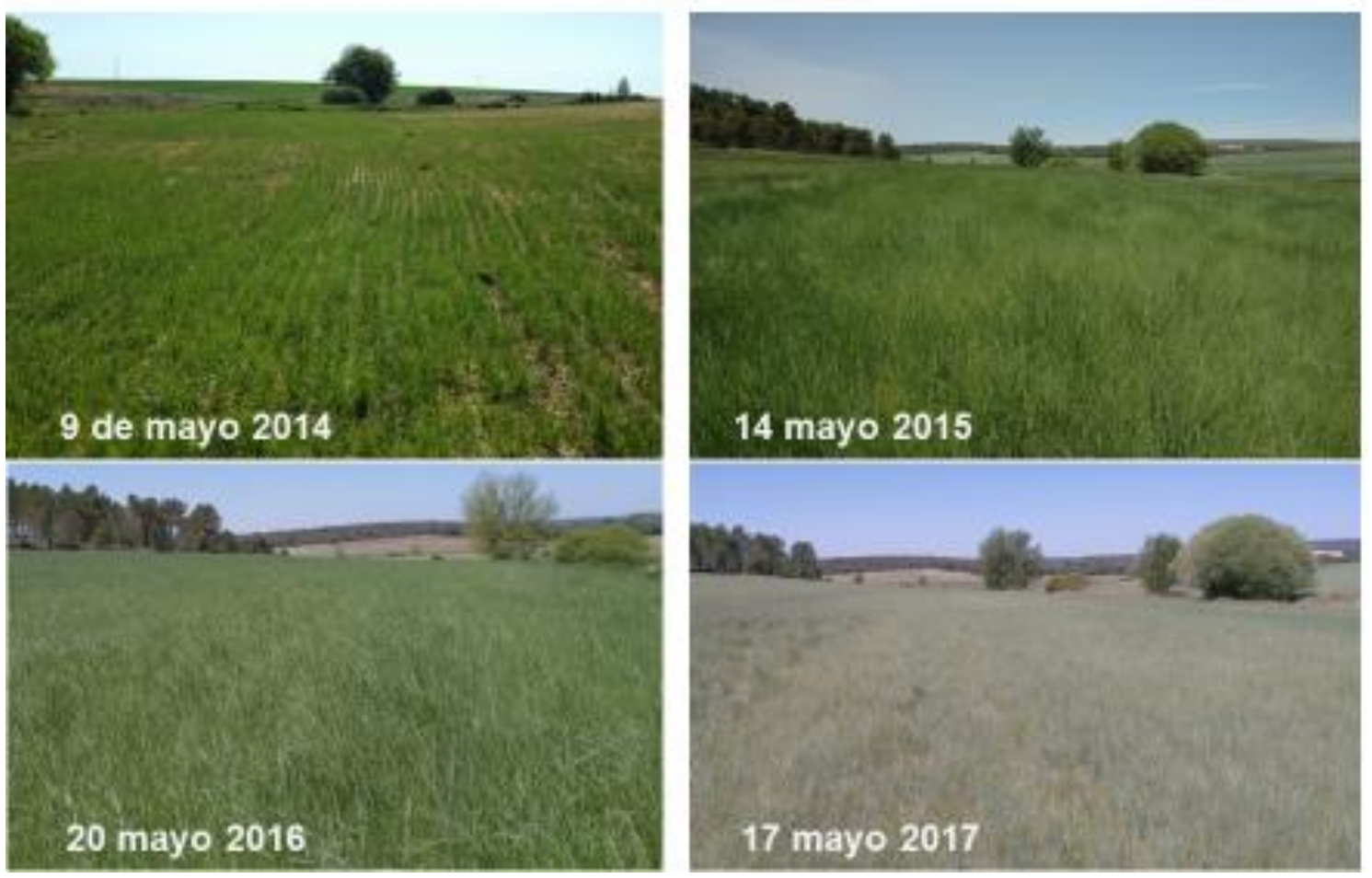

Foto 8. Vista general de la parcela sembrada de agropiro alargado durante los años de estudio.
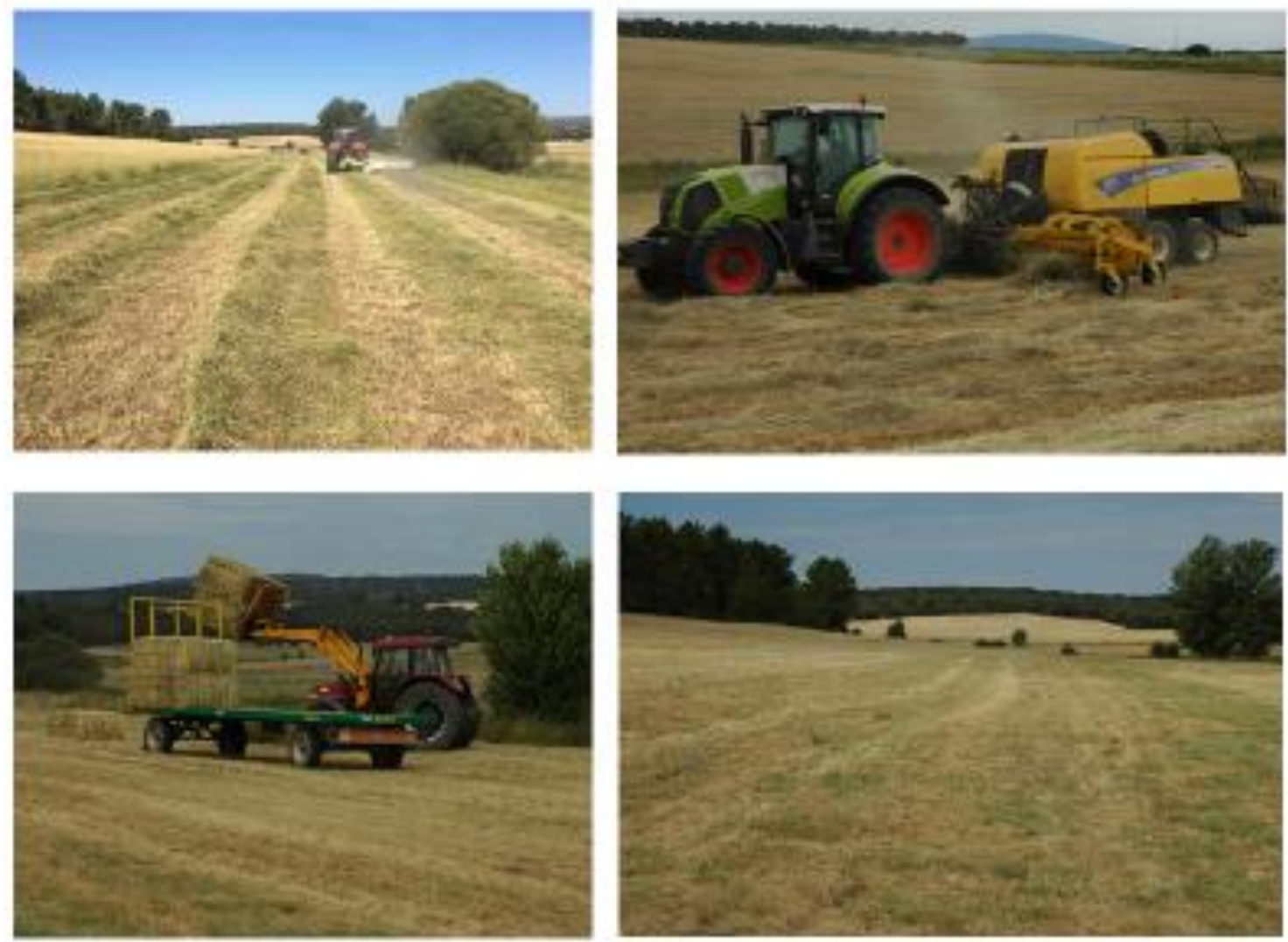

Foto 9. Siega (arriba izquierda), empacado (arriba derecha), recogida de la biomasa (abajo izquierda) y vista general de la parcela de agropiro alargado después de recoger la biomasa (abajo derecha) (agosto de 2017). 


\subsubsection{Análisis económico}

El análisis del margen neto de la explotación agraria de las dos alternativas en el área marginal descrita en la sección 2.3.4, se realizó teniendo en cuenta los precios de las materias primas (semillas, fertilizantes, herbicidas, combustibles) y maquinaria utilizada por el agricultor durante el período de estudio anteriormente descrito. Los costes de mano de obra y maquinaria, incluyendo los aperos agrícolas utilizados para cada actividad agrícola, se calcularon de acuerdo con las características técnicas, la capacidad real para llevar a cabo su trabajo, los costes de utilización y las condiciones de la explotación, como por ejemplo el tipo de suelo. El cálculo se realizó utilizando la base de datos online proporcionada por el Ministerio de Agricultura [123]. El balance económico se obtuvo de la diferencia entre los costes de producción y las ventas totales sumadas a la ayuda de la PAC.

El estudio económico de la parte no marginal de la explotación se realizó calculando la media ponderada de los inputs y outputs de los diferentes cultivos sembrados en la explotación durante los años de estudio con el precio real antes de impuestos obtenido de las facturas proporcionadas por el agricultor. En la superficie marginal, los cálculos de costes se realizaron de la misma manera, extrapolando los resultados de las parcelas experimentales ( 2 ha cada una) a toda la superficie de tierra marginal (40 ha) de la explotación, ya que esta presentaba restricciones biofísicas similares.

Los costes de implantación del agropiro alargado se repartieron durante los cuatro años del estudio.

El precio de venta de la biomasa obtenida en la producción de agropiro alargado se consideró igual que el que el agricultor percibe por la paja de cereal, debido a la falta de mercado para este producto en la actualidad.

\subsubsection{Evaluación ambiental y energética.}

El objetivo de la evaluación fue determinar y comparar los consumos de energía y los impactos ambientales de las dos alternativas de cultivo propuestas en la tierra marginal, desde la perspectiva del ciclo de vida. EI ACV es la herramienta de gestión ambiental, regulada por la norma ISO 14040 e ISO 14044, seleccionada para realizar las evaluaciones. 
El tipo de ACV realizado fue atribucional. Los límites del estudio incluyeron: a) la producción y el transporte de materias primas consumidas; b) la fabricación y uso de maquinaria, incluido el consumo de diésel, así como las emisiones de gases de escape que afectan al potencial de calentamiento global (PCG), y c) la aplicación de fertilizantes y las emisiones de campo asociadas que afectan al PCG. Para realizar los ACV se utilizaron la herramienta de software Simapro 9.0 y la base de datos europea Ecoinvent 3.5.

La modelización del inventario se hizo coherente con los análisis económicos. Los trabajos de campo y materias primas utilizadas considerados fueron los mismos cada año. Como en el estudio económico, las materias primas y los trabajos de campo adicionales del año de implantación se distribuyeron durante los años de estudio para obtener un promedio representativo. Los procesos de fondo para modelar todos los inventarios se tomaron de Ecoinvent 3.5.

Las emisiones de gases procedentes de la utilización de la maquinaria agrícola se consideraron de acuerdo con el consumo de diésel de esta maquinaria [118]. También se contabilizaron las emisiones de $\mathrm{N}_{2} \mathrm{O}$ [139] debido a la aplicación de fertilizantes, la descomposición de residuos de cultivos y la conversión de $\mathrm{NH}_{3}$ en $\mathrm{N}_{2} \mathrm{O}$. Las emisiones anuales promedio de $\mathrm{N}_{2} \mathrm{O}$ fueron de $0,000817 \mathrm{Mg} \cdot \mathrm{ha}^{-1}$. año-1 $^{-1}$ para agropiro alargado y de $0,01757 \mathrm{Mg} \cdot \mathrm{ha}^{-1} \cdot$ año $^{-1}$ para centeno.

Debido a que el laboreo convencional no aumenta la materia orgánica del suelo [140] se consideró que el contenido de materia orgánica $(0,540 \%)$ y el contenido de carbono orgánico $(0,313 \%)$ obtenido de los análisis iniciales del suelo $(0-30 \mathrm{~cm})$ fue estable y corresponde a un punto de equilibrio. En la literatura hay estudios que argumentan que el centeno mejora la materia orgánica del suelo en condiciones de laboreo convencional solo cuando se usa como cultivo de cobertura [141], pero no hay evidencia que sugiera que el centeno mejore la materia orgánica del suelo cuando se cosecha y se recoge el grano y la paja. Por lo tanto, la alternativa que consideró el cultivo de centeno fue una continuación de las prácticas comunes descritas y, por lo tanto, esto no cambió el equilibrio de la composición del suelo. Debido a este hecho, no se consideró el crédito o la deuda de $\mathrm{CO}_{2}$ debido a los cambios en la materia orgánica del suelo y el carbono orgánico para el sistema de cultivo de centeno. Sin embargo, en el caso del agropiro alargado se esperaba un incremento de la materia orgánica del suelo y de carbono debido a su carácter perenne, con la acumulación de biomasa en el suelo y la ausencia de operaciones de laboreo [142]. Esta ausencia de labranza también contribuye a mantener la calidad de la materia orgánica debido a la menor actividad del 
microorganismo del suelo que ayudará a mantenerla más estable [143]. Estos incrementos fueron confirmados por análisis de suelo de las parcelas realizados después de tres años de implantación del cultivo que revelaron un aumento de hasta $0,677 \%$ y $0,393 \%$ de la materia orgánica del suelo y el contenido de carbono orgánico, respectivamente. El aumento del carbono orgánico del suelo correspondió a una fijación anual de 0,765 Mg C.ha-1 equivalente a 2,805 $\mathrm{Mg} \mathrm{CO}_{2} \cdot \mathrm{ha}^{-1}$. Estas cifras se obtuvieron usando la densidad aparente del suelo $\left(1,370 \mathrm{Mg}\right.$ suelo $\left.\cdot \mathrm{m}^{-3}\right)$ de la capa superficial (0-30 $\mathrm{cm})$ y considerando la influencia de elementos gruesos (>2 mm) $(29,58 \%$ en volumen) que se eliminaron previamente de las muestras utilizadas para determinar el contenido de materia orgánica. 
RESULTADOS 
CAPÍTULO III: Artículo 1: Identificación de tierras arables marginales bajo condiciones de secano con potencial bioenergético en España

Ciria, C.S.; Sanz, M.; Carrasco, J.; Ciria, P. Identification of Arable Marginal Lands under Rainfed Conditions for Bioenergy Purposes in Spain. Sustainability 2019, 11, 1833. https://doi.org/10.3390/su11071833 ISSN: 2071-1050

Sustainability: Q2 in Environmental Sciences. Factor de Impacto (2019) 2.576 
Resumen: La producción de cultivos energéticos puede considerarse sostenible; sin embargo, su uso en tierras fértiles entra en conflicto con la producción de alimentos. El propósito general de este estudio es identificar áreas en España donde los cultivos alimentarios tradicionales no son económicamente sostenibles, pero donde podrían ser sustituidos por cultivos energéticos sin cambiar el uso del suelo. Se estudió el margen económico de los principales cultivos con más superficie cultivada del país, que son el trigo (Triticum aestivum L.) y la cebada (Hordeum vulgare L.), la ubicación de estas áreas y las limitaciones biofísicas que hacen estas tierras marginales. España tiene una superficie de 9,93 Mha, con limitaciones biofísicas y/o económicas en las zonas agrícolas de secano. Los rendimientos $\leq 1,5 \mathrm{Mg} \cdot \mathrm{ha}^{-1}$ marcan la rentabilidad de los cultivos anteriormente citados; el bajo contenido de materia orgánica es la principal limitación biofísica. Los resultados mostraron un potencial energético de 83,33 GJ.ha${ }^{1}$ sembrando triticale (x Triticosecale) y 174,85 GJ.ha-1 sembrando cardo (Cynara cardunculus L.) en tierras arables marginales. La producción de biomasa en esta zona serviría para cubrir entre un 3\% y un 5\% de las necesidades de energía primaria en España para triticale y cardo respectivamente. En este sentido, la implantación de cultivos energéticos en tierras marginales podría ser un instrumento para mejorar el desarrollo rural, impulsar la bioeconomía y alcanzar objetivos ambientales.

Palabras clave: Agricultura de secano; cultivos herbáceos; limitaciones económicas; limitaciones biofísicas; biomasa

\subsection{Introducción}

La agricultura en la actualidad se enfrenta a múltiples desafíos. Por un lado, es necesario producir más alimentos y fibra para alimentar a una población en continuo crecimiento [1] y, por otro lado, se necesita más materia prima para abastecer nuevos mercados emergentes como el de la bioenergía y los bioproductos con gran potencial. Teniendo en cuenta que los residuos y subproductos presentan un potencial energético limitado, los cultivos específicamente desarrollados para la producción de biomasa lignocelulósica podrían proporcionar una materia prima segura, sostenible y autóctona para una futura producción descarbonizada de electricidad y calor [2,3]. Así pues, el sector agrícola tiene que adoptar métodos de producción más eficientes y sostenibles para cubrir las crecientes y más diversas demandas futuras, además de las exigencias de adaptarse al cambio climático [1]. Sin embargo, el uso de cultivos energéticos en tierras arables utilizadas para otros fines crea cada vez mayor conflicto y plantea problemas importantes sobre la sostenibilidad de esta opción [4-6]. 
En el contexto descrito, el concepto de tierra marginal tiene gran interés tanto científico como político, considerándose como una alternativa potencial para producir bioenergía y otros productos no alimentarios a partir de biomasa [4,6], al tiempo que se superan nuevos desafíos ambientales y sociales asociados a esta producción.

El concepto de tierra marginal ha sido ampliamente discutido por muchos investigadores, aunque todavía no se ha llegado a una opinión común. El término "tierra marginal" puede ser ambiguo, habitualmente, la tierra de mala calidad se ha asociado con tierra marginal, pero incluso la tierra productiva de España, por ejemplo, podría clasificarse como relativamente marginal si se compara con la tierra de la cuenca de París [7]. Una de las primeras definiciones de tierra marginal fue propuesta por Ricardo (1817) [8] y por Hollander (1895) [9], quienes definieron las tierras marginales como las tierras más pobres que se utilizan y que no cubren el precio de renta de las mismas con su cultivo. Según diferentes autores [10-12], las tierras marginales son zonas donde la producción de alimentos no es rentable bajo las condiciones, las técnicas de cultivo, las políticas agrícolas y las condiciones macroeconómicas y legales dadas. En tales casos, los ingresos son menores o iguales al coste de producción [13]. El bajo rendimiento económico de la actividad agrícola se suele asociar a la baja producción de cultivos y las limitaciones biofísicas que afectan a estas tierras. Por lo tanto, las tierras agrícolas marginales se caracterizan generalmente por una baja productividad de los cultivos con destino a la alimentación y la producción de piensos, debido a las limitaciones ambientales y del suelo $[6,14,15]$.

Desde una perspectiva física y productiva, la marginalidad se basa en niveles de idoneidad del suelo, de los que depende la planificación del uso de la tierra, se refiere a tierras de mala calidad susceptibles a la erosión u otros factores que degradan el suelo [16].

Se ha tenido conocimiento de estudios sobre tierras marginales en la literatura, aunque estas tierras son difíciles de identificar, ya que la definición e identificación debe garantizar que se busquen las limitaciones biofísicas y la ausencia de otros usos de la tierra [4,17]. En Europa, el proyecto Tierras marginales para el cultivo de cultivos industriales (Magic) [18] y el Proyecto de explotación sostenible de biomasa para bioenergía de tierras marginales (Seemla) [4], han evaluado y cuantificado la superficie de tierras marginales en Europa con especial atención. a las limitaciones biofísicas de las tierras agrícolas y forestales (pastizales, tierras arables, tierras de cultivo permanente), utilizando herramientas de Sistemas de Información Geográfica (SIG), aunque sin considerar las consecuencias socioeconómicas. Además, en España se han 
utilizado herramientas SIG para detectar tierras con una sola restricción biofísica [19], pero no hay constancia de la determinación general de la tierra agrícola marginal cultivable para todo el país. Este artículo identifica las tierras marginales en España desde una perspectiva económica, pero también identifica y correlaciona siete limitaciones biofísicas en aquellas áreas donde las producciones de los cultivos tradicionales no son rentables a escala nacional, proporcionando así un paso adicional en la metodología para identificar las tierras marginales.

En España, la agricultura tradicional y especialmente los cultivos herbáceos en condiciones de secano han proporcionado a menudo bajos rendimientos económicos. Esta situación se ha agravado desde 2010, cuando el precio de las principales materias primas utilizadas se ha incrementado, superando los $50 € \cdot$ ha $^{-1}$ entre 2010 y 2016 . Los incrementos durante este período en el coste de los fertilizantes, las semillas y los herbicidas suponían un $26 \%, 31 \%$ y $22 \%$, respectivamente. Estos datos mostraron una reducción en los márgenes económicos de alrededor de un $35 \%$ en la producción de cultivos de secano [20]. En consecuencia, de 1986 a 2016, el número de explotaciones agrícolas españolas ha disminuido en torno al 60\%, de 2.284.900 en 1989 a 945.024 en 2016 y más de 2 Mha con fines agrícolas han sido abandonadas durante ese período $[21,22]$

La agricultura española tiene alrededor de 17 Mha de tierras de cultivo, de las cuales, 10,5 Mha son cultivos herbáceos de secano y tierras en barbecho [23]. Parte de esta superficie tiene un alto riesgo de abandono y es imperativo comprender las razones de esta marginalidad y encontrar alternativas sostenibles para corregir esta situación.

En este contexto, el objetivo general de este estudio fue definir áreas en España donde los cultivos alimentarios tradicionales no son económicamente sostenibles y podrían ser sustituidos por cultivos energéticos sin cambiar el uso de la tierra.

Los objetivos específicos fueron la identificación y mapeo de las tierras arables marginales de secano en España, a partir de la rentabilidad de los principales cereales de invierno cultivados, y determinar las limitaciones biofísicas existentes en esas zonas. Además, también se identifican otras tierras con limitaciones biofísicas similares. 


\subsection{Material y Métodos}

\subsubsection{Zona de estudio}

El estudio analizó las tierras arables de secano que se dedican a la producción de cultivos herbáceos extensivos en España, excluyendo las ciudades autónomas españolas del norte de África de Ceuta y Melilla. El área tiene una extensión de alrededor de 10,5 Mha divididas en 8122 municipios.

Para determinar qué se puede considerar tierra agrícola marginal en España, se estudió el margen económico de los principales cultivos (trigo y cebada), considerando toda la superficie sembrada en condiciones de secano. El trigo y la cebada representan el $80 \%$ de la superficie total de los cultivos herbáceos sembrados en secano [24]. Los márgenes económicos de estos cultivos pueden ayudar a determinar las zonas con limitaciones económicas, donde los agricultores no pueden recuperar los costes de producción. Estas áreas tienen problemas de sostenibilidad y son las que los agricultores tienden a abandonar primero [10].

Una vez determinado el umbral para cubrir el coste del cultivo, se lleva a cabo la localización de las citadas zonas utilizando una base de datos del Ministerio de Agricultura de España. Esta base de datos está compuesta por la producción media anual de cereales de invierno en España (trigo y cebada entre otros cultivos), para cada municipio durante los últimos 39 años (1979-2018), la cual, se actualiza cada año [25].

Después de identificar los municipios españoles que podrían considerarse como tierras marginales, donde el valor de producción apenas cubría los costes de producción del trigo y la cebada en condiciones de secano, el siguiente paso fue mapear y analizar las limitaciones biofísicas en estas zonas. También se incluyó la identificación de estas limitaciones biofísicas en otras áreas donde la producción de cada municipio era mayor que el umbral establecido. Esto permitió una determinación más precisa de las áreas con limitaciones biofísicas dentro del sistema agrícola español de secano.

\subsubsection{Estudio económico}

La metodología utilizada para determinar el margen económico de los dos cultivos de referencia se basó en la producción mínima por hectárea que necesitan los agricultores para recuperar los costes de producción. Se calcularon los inputs que se utilizan normalmente para la producción de estos cultivos además de los costes de maquinaria (inversión, depreciación, costos de mantenimiento y combustible) (Tabla 7), costes laborales, semillas, productos fitosanitarios y fertilizantes (Tabla 8). Como output 
se consideró el rendimiento de grano de los cultivos y los precios medios durante seis años. Los costes de las materias primas, los costes de maquinaria y los precios de producción de los seis años considerados fueron proporcionados por el Ministerio de Agricultura [26, 27].

Tabla 7. Costes horarios y mano de obra para cada tipo de trabajo agrícola.

\begin{tabular}{|c|c|c|c|c|c|}
\hline & $\begin{array}{c}\text { Combustible } \\
\left(\mathrm{L} \cdot \mathrm{ha}^{-1}\right)\end{array}$ & $\begin{array}{c}\text { Coste } \\
\text { horario } \\
\left(h \cdot h^{-1}\right)\end{array}$ & $\begin{array}{c}\text { Coste de } \\
\text { tractor y } \\
\text { apero }\left(€ \cdot \mathrm{ha}^{-1}\right)\end{array}$ & $\begin{array}{c}\text { Mano de } \\
\text { obra }\left(€ \cdot \text { ha }^{-1}\right)\end{array}$ & $\begin{array}{l}\text { Total } \\
\left(€ \cdot \text { ha }^{-1}\right)\end{array}$ \\
\hline Alzado & 13,9 & 0,98 & 33,59 & 9,80 & 43,39 \\
\hline Abonado de fondo & 1,0 & 0,09 & 6,24 & 0,87 & 7,11 \\
\hline Cultivado & 6,1 & 0,56 & 12,62 & 5,55 & 18,17 \\
\hline Siembra & 4,3 & 0,39 & 15,48 & 3,92 & 19,40 \\
\hline $\begin{array}{l}\text { Abonado de } \\
\text { cobertera }\end{array}$ & 0,7 & 0,07 & 5,24 & 0,87 & 6,11 \\
\hline Pase de rodillo & 2,7 & 0,21 & 3,61 & 2,10 & 5,71 \\
\hline Pulverización & 0,7 & 0,07 & 4,60 & 0,65 & 5,25 \\
\hline Cosecha & 17,1 & 0,44 & 39,60 & 4,40 & 44,00 \\
\hline
\end{tabular}

Los costes de maquinaria se basaron en el laboreo tradicional, el cuál es el más habitual en España, utilizando un tractor de $112 \mathrm{KW}$ y los equipos agrícolas adecuados para la potencia. Con respecto a los trabajos agrícolas, se consideró la tarifa horaria por cada actividad agrícola (es decir, alzado, cultivado, abonado de fondo, siembra, tratamiento con herbicida, abonado de cobertera, rodillado y cosecha), el precio del combustible de $0,89 € \cdot \mathrm{L}^{-1}$ [27], así como un coste laboral de $10 € \cdot \mathrm{h}^{-1}$ [27]. La tabla 7 muestra los costes de cada actividad agrícola. 
Tabla 8. Inputs y outputs estudiados para rendimientos de trigo y cebada.

\begin{tabular}{|c|c|c|c|}
\hline & Unidades & Trigo & Cebada \\
\hline $\begin{array}{l}\text { Costes de maquinaria y mano de } \\
\text { obra }\end{array}$ & $€ \cdot$ ha $^{-1}$ & 149 & 149 \\
\hline \multicolumn{4}{|l|}{$\begin{array}{l}\text { Fertilización de fondo para } \\
\text { cosecha esperada: }\end{array}$} \\
\hline $1,0 \mathrm{Mg} \cdot \mathrm{ha}^{-1}$ & \multirow{5}{*}{$€ \cdot \mathrm{ha}^{-1}$} & 50 & 40 \\
\hline $1,5 \mathrm{Mg} \cdot \mathrm{ha}^{-1}$ & & 63 & 48 \\
\hline $2,0 \mathrm{Mg} \cdot \mathrm{ha}^{-1}$ & & 84 & 60 \\
\hline $2,5 \mathrm{Mg} \cdot \mathrm{ha}^{-1}$ & & 100 & 80 \\
\hline $3,0 \mathrm{Mg} \cdot \mathrm{ha}^{-1}$ & & 125 & 80 \\
\hline Semilla & $€ \cdot$ ha $^{-1}$ & 39 & 33 \\
\hline Herbicida & $€ \cdot \mathrm{ha}^{-1}$ & 23 & 22 \\
\hline $\begin{array}{l}\text { Fertilización de cobertera para } \\
\text { cosecha esperada: }\end{array}$ & \multirow{6}{*}{$€ \cdot \mathrm{ha}^{-1}$} & & \\
\hline 1,0 Mg $\cdot \mathrm{ha}^{-1}$ & & 20 & 20 \\
\hline $1,5 \mathrm{Mg} \cdot \mathrm{ha}^{-1}$ & & 25 & 25 \\
\hline $2,0 \mathrm{Mg} \cdot \mathrm{ha}^{-1}$ & & 30 & 30 \\
\hline $2,5 \mathrm{Mg} \cdot \mathrm{ha}^{-1}$ & & 41 & 41 \\
\hline $3,0 \mathrm{Mg} \cdot \mathrm{ha}^{-1}$ & & 50 & 50 \\
\hline Output & $€ \cdot \mathrm{Mg}^{-1}$ & 190 & 161 \\
\hline
\end{tabular}

El abonado de fondo se calculó utilizando el fertilizante complejo comercial NPK 8-24-8 para el trigo y 8-15-15 para la cebada, así como en la fertilización de cobertera se usó para los cálculos el complejo de nitrato amónico cálcico con alto contenido de $\mathrm{N}$ (27\%). También se calcularon las restituciones dependiendo de la cosecha prevista [28]. La siembra se realizó usando $0,19 \mathrm{Mg} \cdot \mathrm{ha}^{-1}$ para el trigo y $0,18 \mathrm{Mg} \cdot \mathrm{ha}^{-1}$ para la cebada [29]. El tratamiento con herbicida se calculó para eliminar malas hierbas monocotiledóneas y dicotiledóneas.

Las ayudas directas de la PAC, la renta de la tierra y los costes de oportunidad no se consideraron por diferentes razones. Los pagos directos de la PAC y la renta de la tierra como renta y coste son muy importantes, pero presentan una gran variabilidad dentro de las explotaciones agrícolas españolas y no es posible comparar las medias por falta de datos fiables. El coste de oportunidad es un término comparativo y no es un coste real incurrido por el cultivo.

\subsubsection{Restricciones biofísicas}

Se estudiaron siete factores biofísicos limitantes en las zonas donde el valor de producción no cubría los costes de producción: tipo, profundidad, pedregosidad, contenido de materia orgánica (MO), pH y salinidad del suelo y la precipitación anual. 
La clasificación del suelo se basó en los cuatro tipos principales de suelo que se encuentran en España según la taxonomía de suelos del USDA: Inceptisol, Alfisol, Entisol y Aridisol. Inceptisol y Alfisol son tipos de suelos que no requieren riego para lograr rendimientos competitivos. Tienen una retención adecuada de agua y nutrientes, a diferencia de las otras dos categorías Entisol y Aridisol, que no son aptas para la agricultura de secano. Aridisol es representativo de regiones áridas donde la evapotranspiración de los cultivos en condiciones estándar (ETc) es mayor que la transpiración durante la mayor parte del año. Por tanto, el régimen de humedad suele ser árido. Entisol es un suelo con un desarrollo de perfil muy bajo y casi sin diferencias entre horizontes [30].

La profundidad del suelo se consideró desde la capa superficial hasta la roca madre. La distribución vertical de los sistemas rocosos tiene un impacto muy significativo en el rendimiento [31]. Esto implica que una mayor uniformidad en la distribución de raíces podría mejorar la rentabilidad económica de los cultivos. Los cereales de invierno tienen entre el $90 \%-100 \%$ del sistema radicular en los primeros $100 \mathrm{~cm}$ del suelo.

La pedregosidad es un factor importante para los cultivos, debido a que está asociado a problemas mecánicos de los equipos de trabajo, su relación con la expansión de las raíces en el suelo y la retención de agua. El suelo se caracteriza como "pedregoso" cuando el volumen de concentración de piedras es superior al 15\% de la fracción del suelo [32].

El contenido de materia orgánica está relacionado con la fertilidad del suelo. El nivel deseable de materia orgánica en los suelos agrícolas es de al menos alrededor del $2 \%$, aunque es posible cultivar cereales de invierno con un contenido de $\mathrm{MO}$ superior al $1 \%$ [33]. En consecuencia, las tierras con menos del 1\% de contenido de MO fueron seleccionadas como tierras marginales.

$\mathrm{El} \mathrm{pH}$ del suelo es un parámetro relevante en la productividad de las plantas, porque de este valor depende la disponibilidad de nutrientes esenciales para las plantas. Si el pH del suelo no es el adecuado, puede afectar al crecimiento del cultivo. La mayoría de las plantas necesitan un $\mathrm{pH}$ del suelo entre 5,5 y 7,5 para una óptima absorción de nutrientes. Por ejemplo, el pH ideal para los cereales de invierno es 6,5 [34], aunque los cereales se pueden cultivar con un $\mathrm{pH}$ de 8 [35]. Un pH inferior a 6 podría afectar a la absorción de magnesio o nitrógeno, y un pH superior a 7 podría afectar la disponibilidad de manganeso [36]. 
También se observó salinidad. Cuando los cereales de invierno se sembraron en superficies sin pendiente, el límite de resistencia a la salinidad del trigo y la cebada fue de $4 \mathrm{dS} \cdot \mathrm{m}^{-1}$. Los valores de salinidad del suelo superiores a $4 \mathrm{dS} \cdot \mathrm{m}^{-1}$ tienden a afectar la productividad de las plantas, aunque pueden resistir un contenido de salinidad de 6 $\mathrm{dS} \cdot \mathrm{m}^{-1}[37]$.

En cuanto al clima, los cereales de invierno necesitan para completar el ciclo de crecimiento al menos $400 \mathrm{~mm}$ de precipitación en España [38]. Por tanto, el hecho de que la precipitación anual sea inferior a $400 \mathrm{~mm}$ plantea un problema.

\subsubsection{Fuente de mapas y herramienta informática utilizada}

Se utilizó la herramienta informática del Environmental Research Institute (ESRI) Inc. y ArcMAPTM Spatial Analyst. ArcGIS versión 10.5 fue el software GIS utilizado para organizar, agregar y representar los datos cartográficos.

Los mapas de características del suelo fueron recabados de un sistema para el mapeo automatizado del suelo basado en una compilación global de datos de perfiles de suelos y datos de detección remota disponibles públicamente llamados SoilGrids. El conjunto de datos para establecer las limitaciones de precipitación usados fueron el promedio de precipitación anual acumulada durante 30 años, de 1975 a 2005 [39].

\subsubsection{Potencial energético}

El potencial energético se estimó utilizando la aplicación BIORAISE CE [40]. BIORAISE CE es una herramienta que proporciona información a nivel municipal en España sobre diferentes cultivos para la producción de biomasa. El método se basa en la utilización del Sistema de Información de Ocupación del Suelo en España (SIOSE) [41] y modelos de producción de cultivos para las diferentes especies consideradas. Dentro de esta capa base (SIOSE) se pueden diferenciar las áreas de secano y de regadío y sobre ella, se definen según criterios definidos para cada cultivo, las denominadas Áreas Agronómicas Homogéneas (AAH), que son zonas geográficas que diferencian la productividad de diferentes áreas para un cultivo determinado. Una vez que las AAH están preparadas, se obtienen los mapas de distribución superficial de los cultivos energéticos. El rendimiento se calculó para cada cultivo estudiado para cada $\mathrm{AAH}$, la cual tiene como base la información experimental disponible para los cultivos energéticos determinados. 
El cardo y el triticale fueron los elegidos por su adaptabilidad a condiciones de secano. El cardo es un cultivo perenne que se cosecha anualmente con un poder calorífico inferior (PCI) de 16,7 GJ. $\mathrm{Mg}^{-1}$ de materia seca (MS), y el triticale es un cultivo anual con un $\mathrm{PCl}$ de $16,8 \mathrm{GJ}^{\mathrm{Mg}}{ }^{-1} \mathrm{MS}[40]$.

Los rendimientos de triticale se estiman en BIORAISE CE como la producción total de biomasa cosechada en la etapa de grano pastoso (etapa Z75 en la escala de Zadoks) [42] y los rendimientos de cardo se estiman al final del ciclo de cultivo [43].

\subsection{Resultados}

\subsubsection{Umbral económico}

Los principales inputs y outputs de acuerdo con la sección 3.2.2 se muestran en la Tabla 8.

Según los costes de producción y los precios de venta de los cultivos durante el período estudiado (Tabla 8 ), se encontró que la productividad anual $\leq 1,5 \mathrm{Mg} \mathrm{ha}^{-1}$ para trigo y cebada fue insuficiente para cubrir los costes de producción (Tabla 9).

Tabla 9. Resultado de los inputs y outputs de los cultivos y margen económico calculado de acuerdo con la producción de grano esperada.

\begin{tabular}{ccc|cc|cc}
\hline \multirow{2}{*}{$\begin{array}{c}\text { Rendimiento } \\
\left(\mathbf{M g} \cdot \mathbf{h a}^{-1}\right)\end{array}$} & \multicolumn{2}{c|}{$\begin{array}{c}\text { Input } \\
\left(\boldsymbol{(} \cdot \mathbf{h a}^{-1}\right)\end{array}$} & \multicolumn{2}{c|}{$\begin{array}{c}\text { Output } \\
\left(\boldsymbol{\epsilon} \cdot \mathbf{h a}^{-1}\right)\end{array}$} & \multicolumn{2}{c}{$\begin{array}{c}\text { Margen económico } \\
\left(\boldsymbol{\epsilon} \cdot \mathbf{h a}^{-1}\right)\end{array}$} \\
\cline { 2 - 7 } ) & Trigo & Cebada & Trigo & Cebada & Trigo & Cebada \\
\hline 1,0 & 280 & 263 & 190 & 161 & -90 & -102 \\
$\mathbf{1 , 5}$ & $\mathbf{2 9 8}$ & $\mathbf{2 7 6}$ & $\mathbf{2 8 5}$ & $\mathbf{2 4 1}$ & -13 & $-\mathbf{3 5}$ \\
2,0 & 324 & 293 & 380 & 322 & 56 & 29 \\
2,5 & 351 & 324 & 475 & 403 & 124 & 79 \\
3,0 & 385 & 333 & 570 & 483 & 185 & 150 \\
\hline
\end{tabular}

Alrededor del $50 \%$ de los costes de producción de los cultivos considerados estaba relacionados con los costes de maquinaria, combustible y mano de obra, mientras que el otro $50 \%$ estaba relacionado con las materias primas en la siguiente proporción: $30 \%$ fertilizantes, $10 \%$ semillas y $10 \%$ herbicidas.

\subsubsection{Identificación de las áreas marginales y áreas con limitaciones biofísicas}

La superficie de trigo y cebada con un rendimiento medio de $1,5 \mathrm{Mg} \cdot \mathrm{ha}^{-1}$ o menor fue predominante en la superficie agrícola de secano de 1678 municipios españoles y alcanzó 1.960 .316 ha de tierra arable, que es casi el $20 \%$ del área total de secano nacional, $11,5 \%$ de la superficie total de cultivo y $4 \%$ de la superficie total de España. 
La superficie total afectada por al menos una de las limitaciones biofísicas estudiadas fue de 1.920 .940 ha. La Tabla 10 muestra el número de hectáreas afectadas por cada restricción biofísica.

Tabla 10. Superficie de las diferentes restricciones biofísicas en municipios con una productividad media $\leq 1,5 \mathrm{Mg} \cdot \mathrm{ha}^{-1}$ en condiciones de secano.

\begin{tabular}{lc}
\hline \multicolumn{1}{c}{ Restricciones biofísicas } & Superficie afectada (ha) \\
\hline Pedregosidad & 1.383 .612 \\
Materia orgánica (MO) & 1.171 .564 \\
Profundidad & 505.866 \\
Tipo de suelo & 449.346 \\
Precipitación anual & 435.093 \\
Salinidad & 281.879 \\
pH & 162.261 \\
\hline
\end{tabular}

Además, en España, se han identificado 7.971 .373 ha que tienen al menos una restricción biofísica similar a las restricciones estudiadas para municipios con rendimientos $\leq 1,5 \mathrm{Mg} \cdot \mathrm{ha}^{-1}$ en condiciones de secano (Tabla 11). Sin embargo, en estos municipios, la productividad media de trigo y cebada fue superior a $1,5 \mathrm{Mg} \cdot \mathrm{ha}^{-1}$, lo que probablemente previene o retrasa el abandono de esa superficie.

Tabla 11. Superficie con restricciones biofísicas en tierra arable de secano en España municipios con rendimientos $>1,5 \mathrm{Mg} \cdot \mathrm{ha}^{-1}$.

\begin{tabular}{lc}
\hline Restricciones biofísicas & Superficie afectada (ha) \\
\hline Pedregosidad & 3.183 .996 \\
Materia orgánica (MO) & 6.011 .766 \\
Profundidad & 894.298 \\
Tipo de suelo & 1.797 .789 \\
Precipitación anual & 673.591 \\
Salinidad & 1.419 .527 \\
pH & 624.906 \\
\hline
\end{tabular}

Al comparar las diferentes restricciones biofísicas (Tabla 12), se puede observar una alta relación entre ellas. Los suelos con limitaciones de pedregosidad, baja profundidad, tipo de suelo, baja precipitación anual y suelos salinos presentan limitaciones de $\mathrm{MO}$ en más del $57 \%$ de su superficie. 
Tabla 12. Superposición de dos restricciones biofísicas (Valores expresados en \% de superficie).

\begin{tabular}{lccccccc}
\hline $\begin{array}{l}\text { Restricción } \\
\text { biofísica }\end{array}$ & $\begin{array}{c}\text { Pedregosidad } \\
\text { (\%) }\end{array}$ & $\begin{array}{c}\text { MO } \\
\text { (\%) }\end{array}$ & $\begin{array}{c}\text { Profundidad } \\
(\%)\end{array}$ & $\begin{array}{c}\text { Tipo } \\
\text { de } \\
\text { suelo } \\
\text { (\%) }\end{array}$ & $\begin{array}{c}\text { Precipitación } \\
\text { anual (\%) }\end{array}$ & $\begin{array}{c}\text { Salinidad } \\
(\%)\end{array}$ & $\begin{array}{c}\text { pH } \\
(\%)\end{array}$ \\
\hline Pedregosida & - & 58 & 24 & 17 & 6 & 10 & 4 \\
MO & 37 & - & 16 & 18 & 14 & 18 & 4 \\
Profundidad & 78 & 82 & - & 2 & 2 & 5 & 0 \\
Tipo de & 35 & 57 & 1 & - & 29 & 26 & 30 \\
suelo & 24 & 89 & 3 & 58 & - & 40 & 21 \\
Precip. anual & 27 & 78 & 4 & 34 & 26 & - & 8 \\
Salinidad & 26 & 36 & 1 & 84 & 29 & 16 & - \\
pH & & & & & & & \\
\hline
\end{tabular}

\subsubsection{Localización espacial}

En la figura 1 se muestran las tierras arables de secano con un rendimiento medio de trigo y cebada $\leq 1,5 \mathrm{Mg} \cdot \mathrm{ha}^{-1}$. Las zonas sur y oeste, además de Canarias y Baleares, son las principales zonas de España donde las bajas tasas de producción son más habituales.

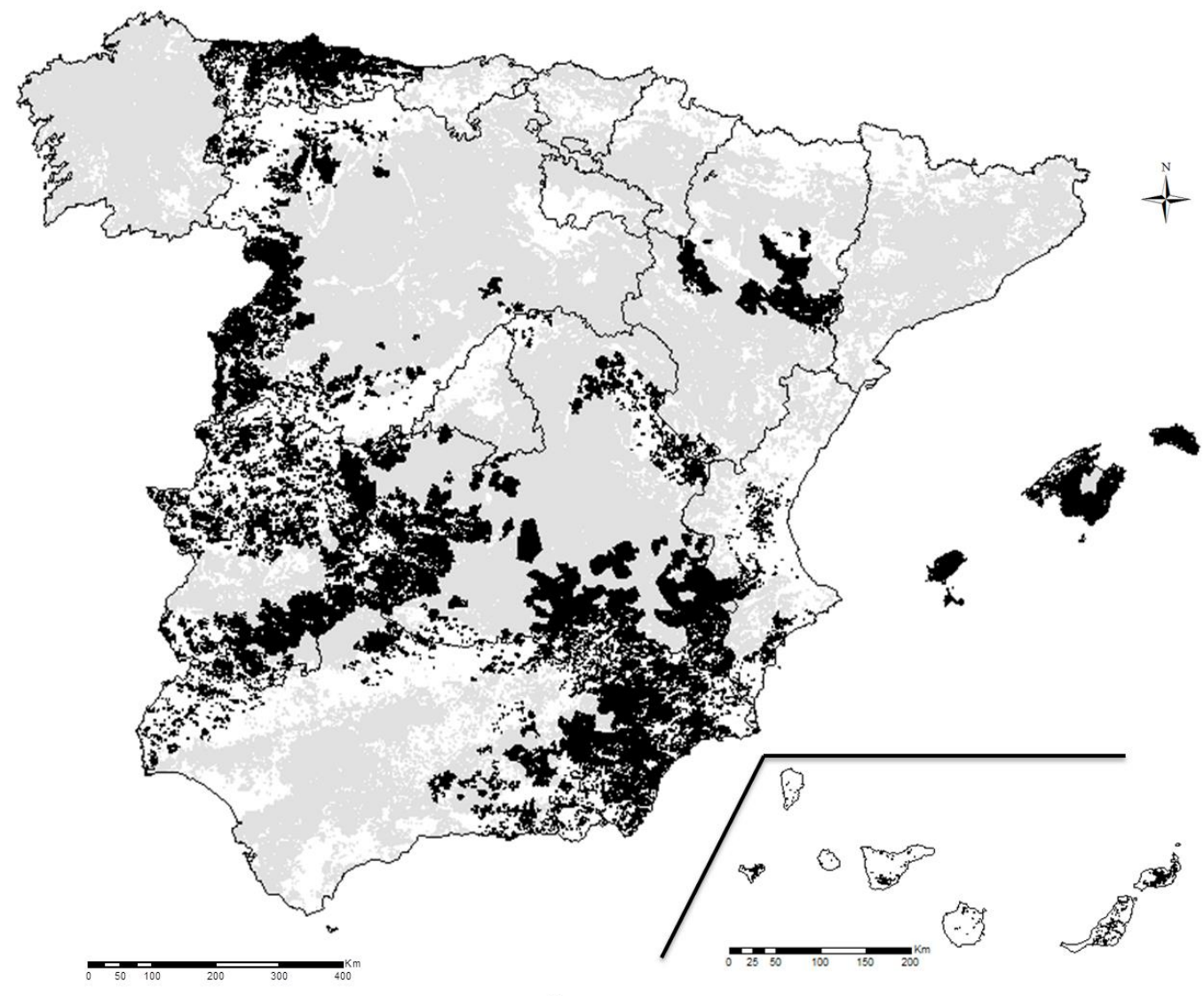

Tierra arable de secano

Tierra arable afectada por restricciones económicas

Figura 1. Distribución espacial de tierras arables de secano con rendimiento principal de cereales de invierno $\leq 1.5 \mathrm{Mg} \cdot \mathrm{ha}^{-1}$. 
Además, las figuras 2, 3, 4, 5, 6, 7 y 8 muestran la distribución espacial de las diferentes limitaciones biofísicas que se estudiaron en todas las tierras arables de secano de España, que también afectan a las zonas de bajo rendimiento. Específicamente, áreas cuya profundidad es inferior a $100 \mathrm{~cm}$ (Figura 2); áreas donde el contenido de $\mathrm{MO}$ es inferior al 1\%; (Figura 3); áreas con pH menor a 6 y mayor a 8 (Figura 4); áreas cuyo volumen de piedras es superior al 15\% (Figura 5); áreas donde el tipo de suelo es Entisol o Aridisol, según clasificación TAXOUSDA (Figura 6); áreas con contenido de sal superior a $4 \mathrm{dS} \cdot \mathrm{m}^{-1}$ (Figura 7) y finalmente, áreas cuya precipitación anual histórica es menor a $400 \mathrm{~mm}$ (Figura 8). Superponiendo todas las figuras, la figura 9 muestra el área total con alguna restricción.

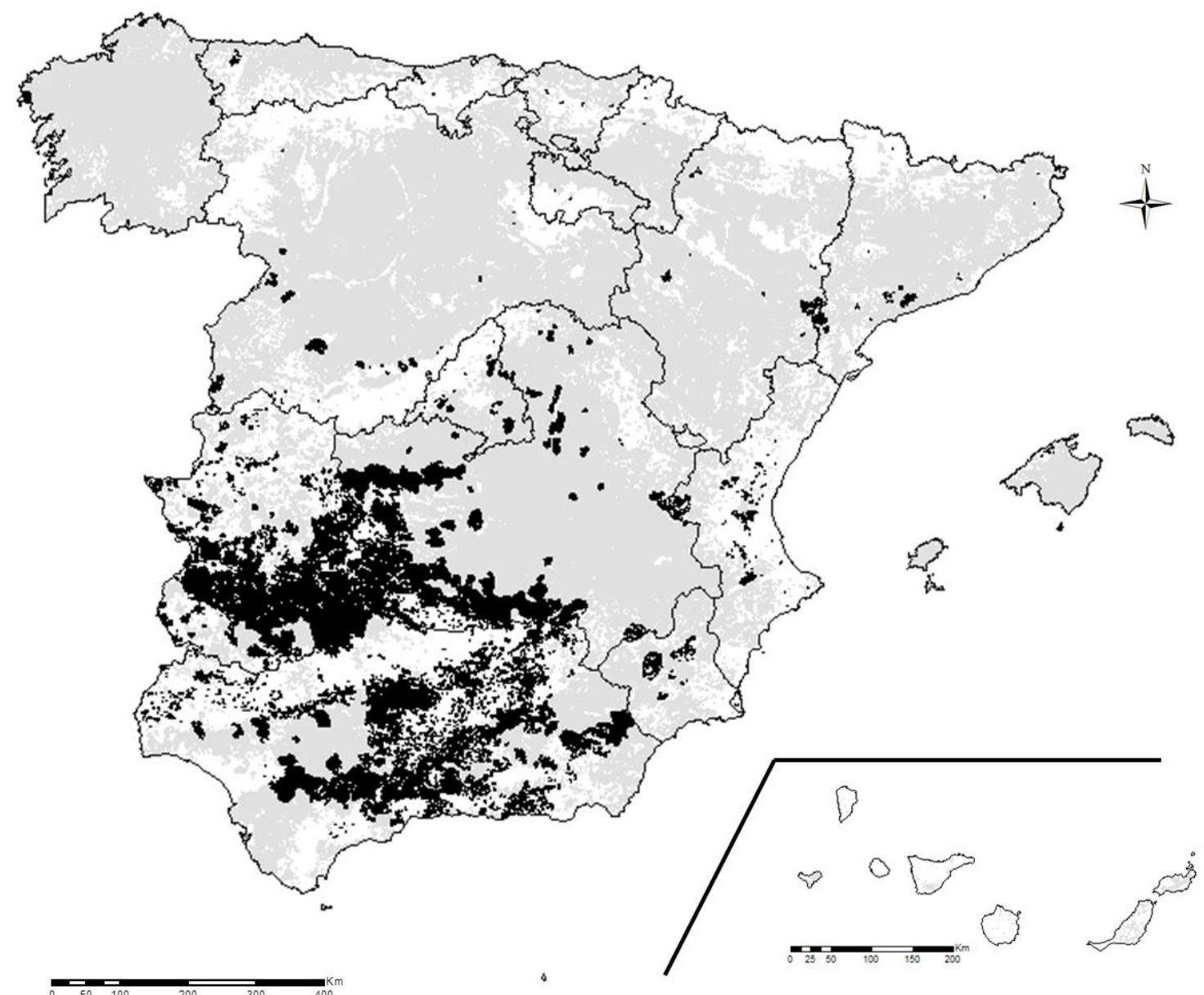

Tierra arable de secano

Tierra arable afectada por restricciones biofísicas

Figura 2. Tierra arable de secano con profundidad de suelo $<100 \mathrm{~cm}$. 


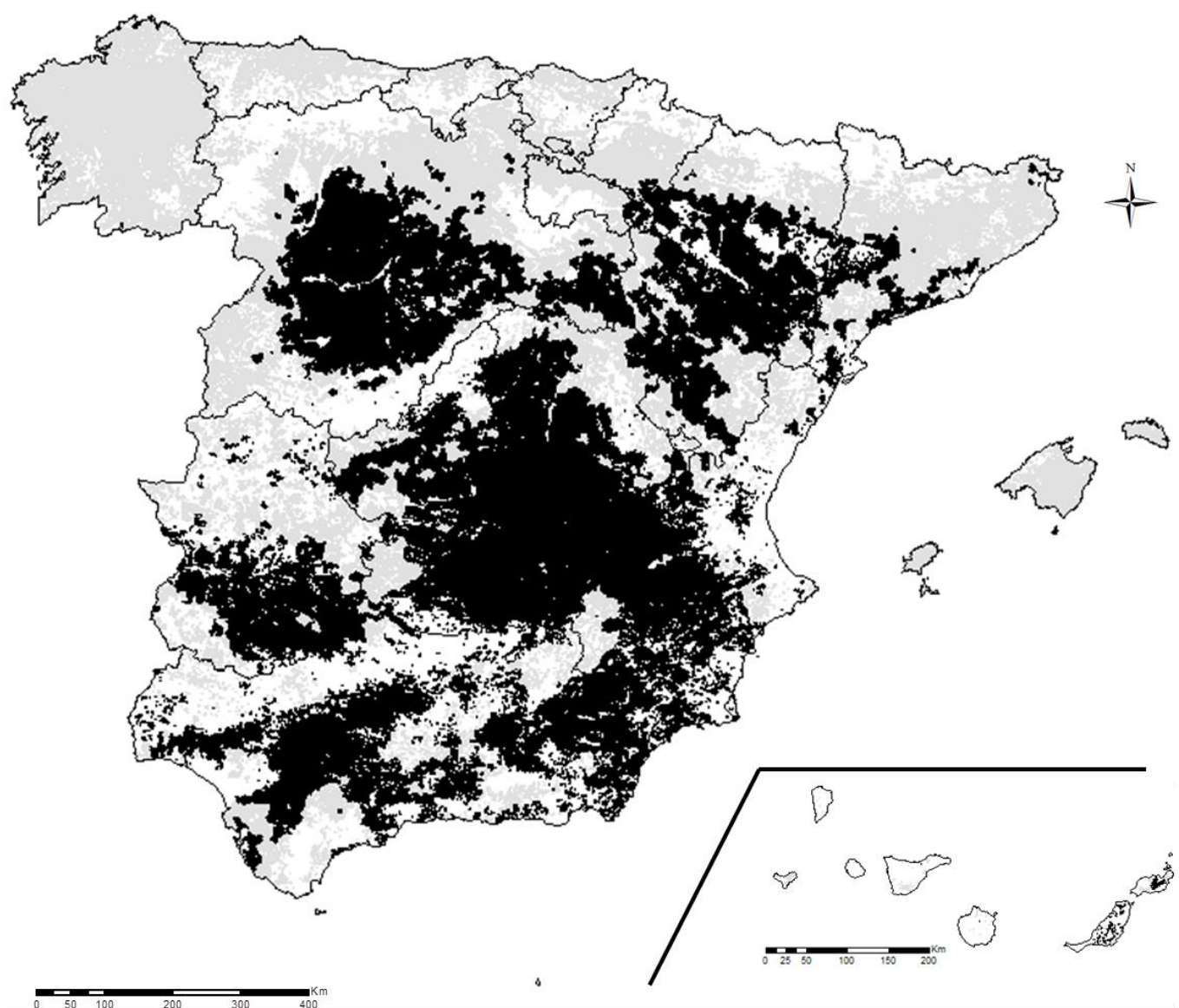

Tierra arable de secano

Tierra arable afectada por restricciones biofísicas

Figura 3. Tierra arable de secano con contenido en $\mathrm{MO}<1 \%$. 


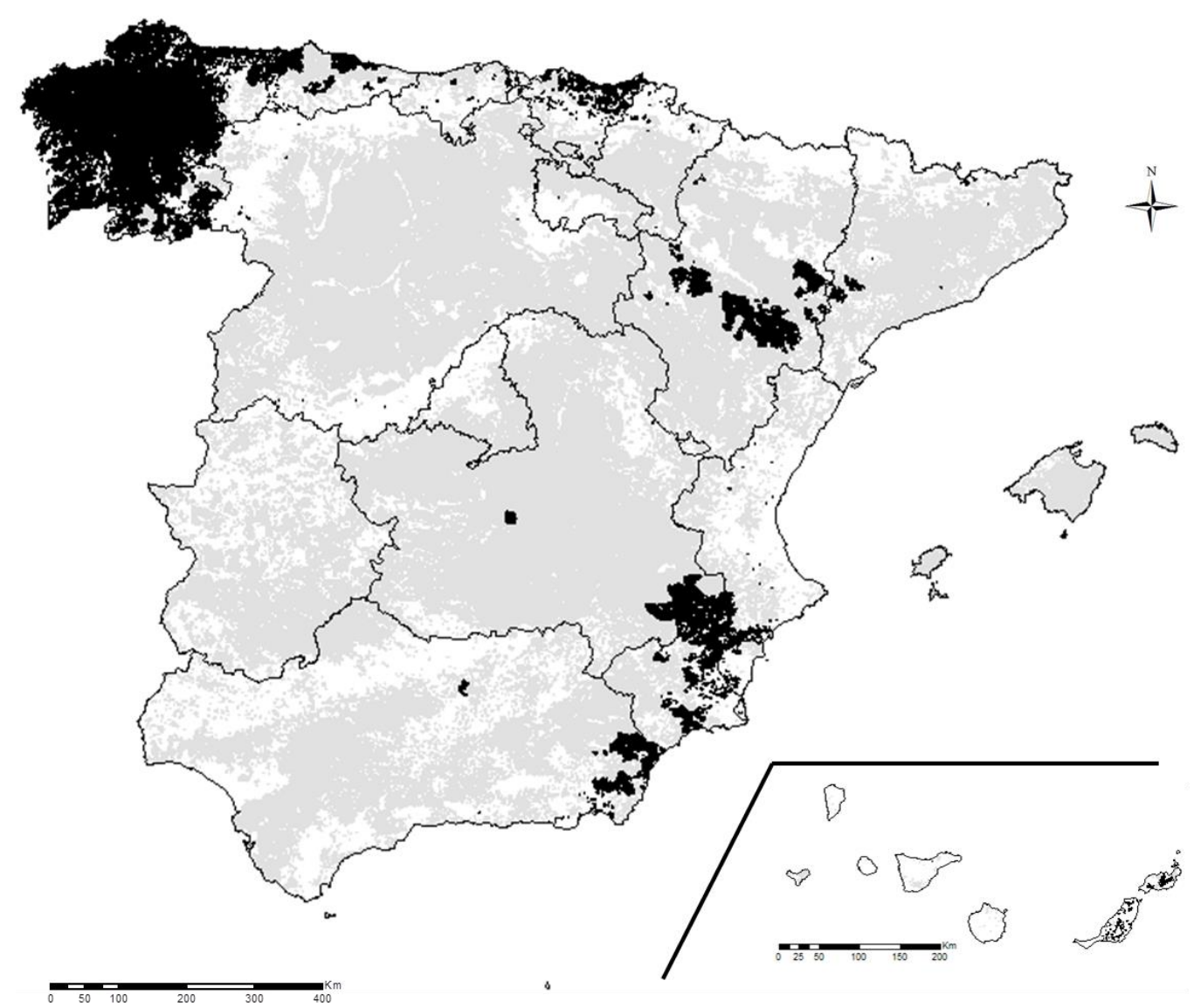

Tierra arable de secano

Tierra arable afectada por restricciones biofísicas

Figura 4. Tierra arable de secano con $\mathrm{pH}<6$ y $>8$. 


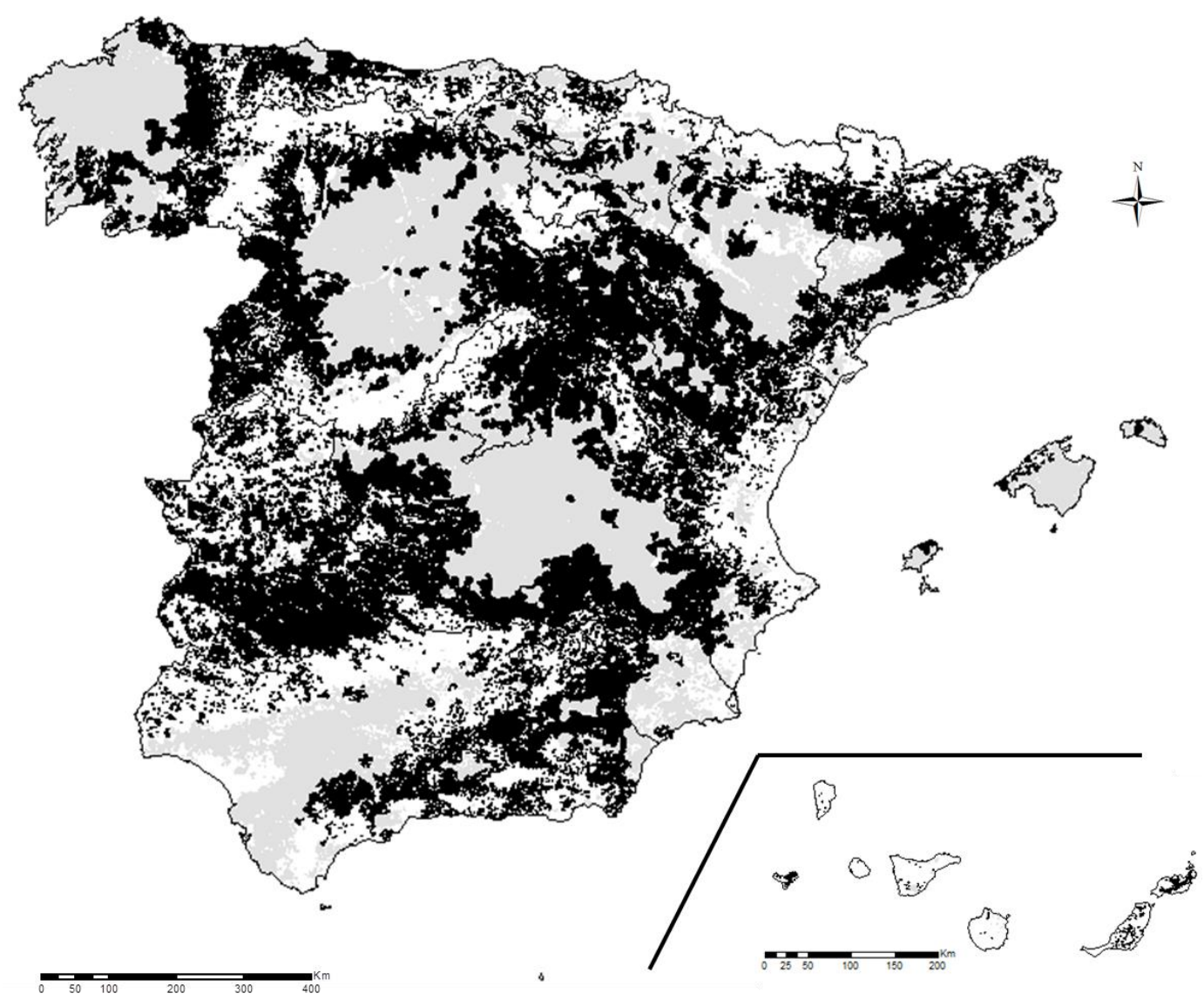

Tierra arable de secano

Tierra arable afectada por restricciones biofísicas

Figura 5. Tierra arable de secano con volumen de piedras $\geq 15 \%$. 


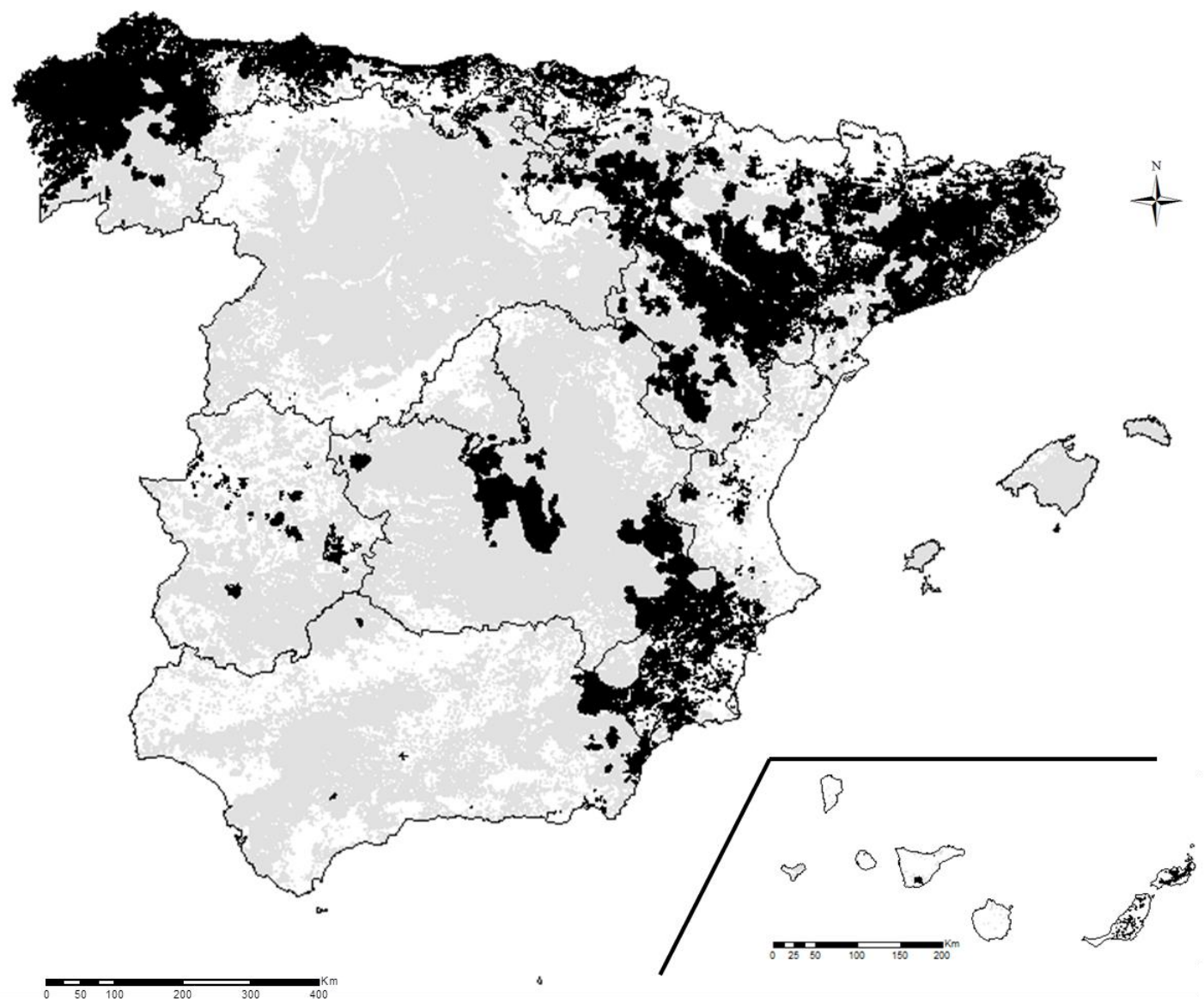

Tierra arable de secano

Tierra arable afectada por restricciones biofísicas

Figura 6. Tierra arable de secano con suelos tipo Entisol and Aridisol, de acuerdo con la clasificación TAXOUSDA. 


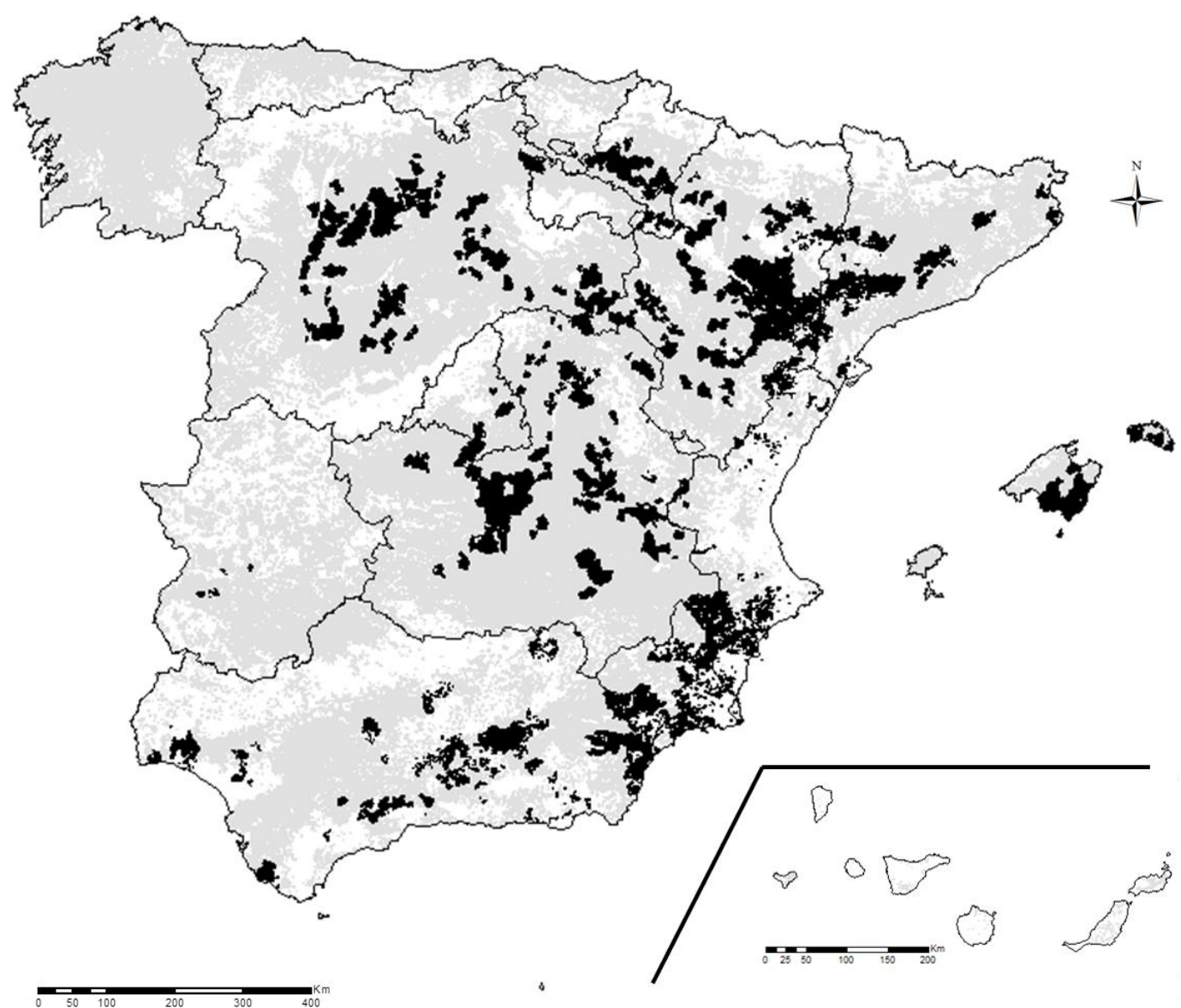

Tierra arable de secano

Tierra arable afectada por restricciones biofíscas

Figura 7. Tierra arable de secano con concentración de sales $>4 \mathrm{dS} \cdot \mathrm{m}^{-1}$. 


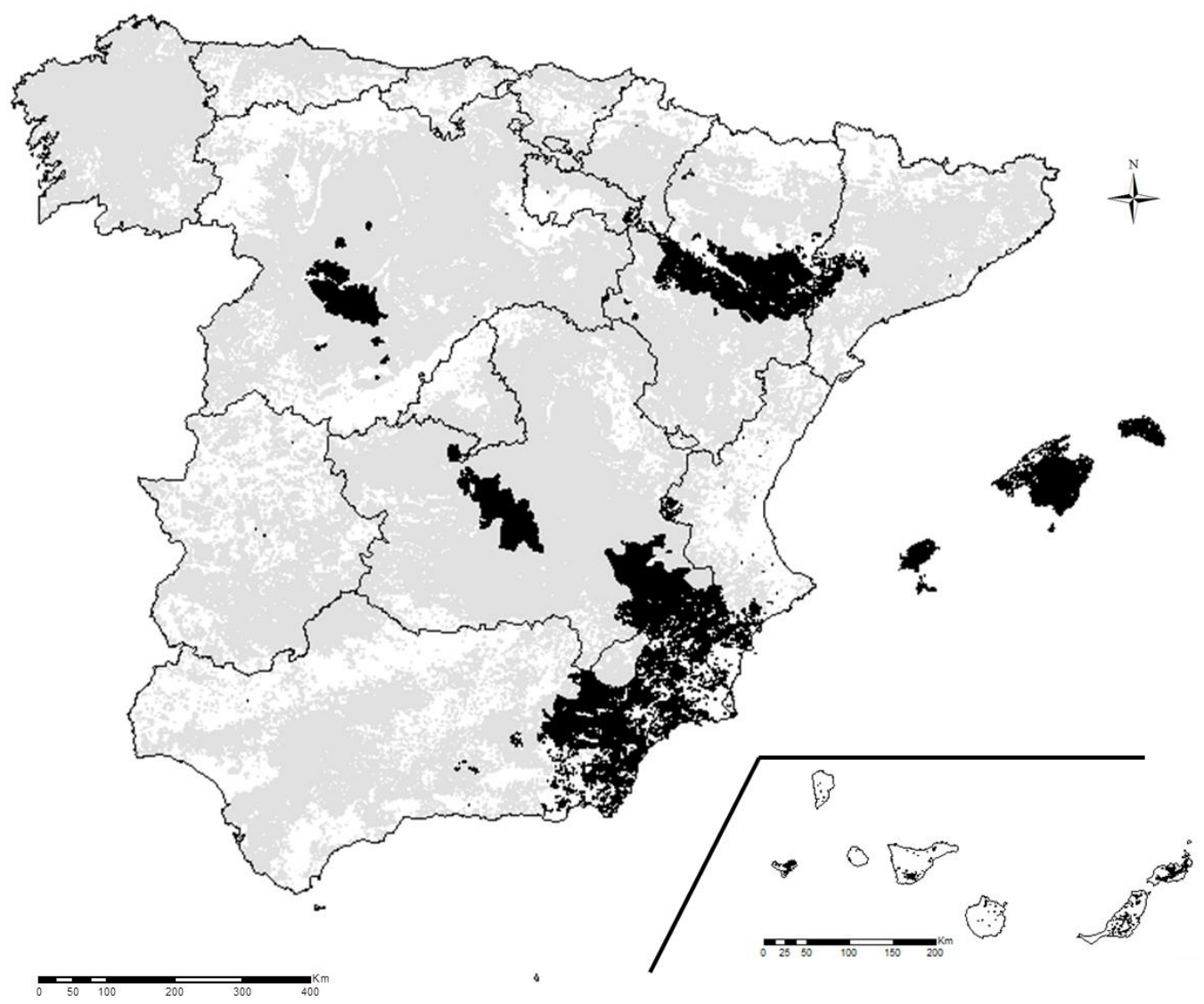

Tierra arable de secano

Tierra arable afectada por restricciones biofíscas

Figura 8. Tierra arable de secano con precipitaciones anuales menores de $400 \mathrm{~mm}$. 
Superponiendo todas las figuras (Figura 9) se muestra la superficie total con las restricciones estudiadas.

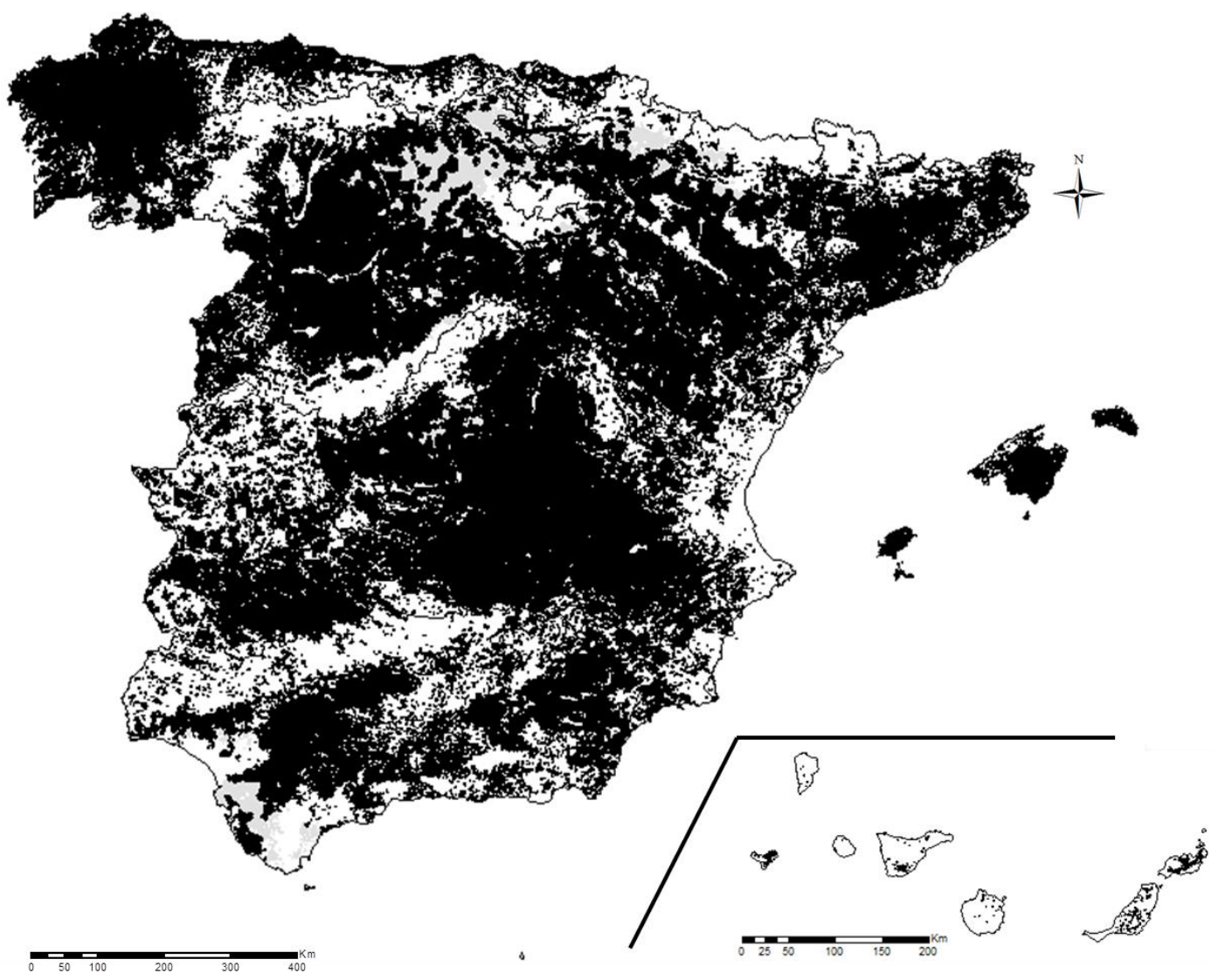

Tierra arable de secano sin restricciones económicas y biofíscas.

Tierra arable de secano con restricciones económicas y/o biofísicas.

Figura 9. Distribución espacial de la tierra arable de secano con alguna restricción considerada.

\subsubsection{Potencial energético}

Como se ha comentado anteriormente, el triticale y el cardo fueron los cultivos herbáceos seleccionados entre los propuestos por BIORAISE CE para determinar el potencial de biomasa en el área marginal identificada. Según cálculos de BIORAISE CE,

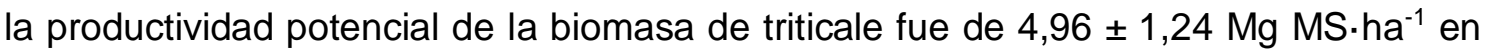
1.838.978 ha (96\% del área marginal de estudio), mientras que 1.571 .827 ha (82\% del

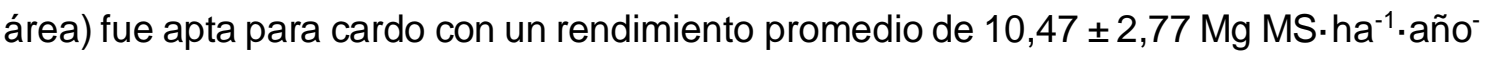
${ }^{1}$. Por tanto, se determinaron potenciales de, $83,33 \mathrm{GJ}^{-h^{-1}}$ para triticale y $174,85 \mathrm{GJ} \cdot \mathrm{ha}^{-}$ ${ }^{1}$ para cardo para producción de biomasa. 


\subsection{Discusión}

Estudios previos de tierras marginales definieron tierras agrícolas marginales como tierras que no vale la pena cultivar con cultivos alimentarios debido a las limitaciones económicas y biofísicas como las condiciones climáticas extremas, suelos con baja calidad, terrenos difíciles de trabajar o largas distancias a los mercados entre otras [44]. Según los resultados de este estudio, en España hay 9.931 .689 ha de tierra cultivable en condiciones de secano que tienen algunas limitaciones biofísicas y/o económicas. El área anterior se reparte entre 1.960.316 ha de tierra marginal arable actualmente y 7.971.373 ha con al menos una restricción biofísica, que podrían ser potenciales tierras marginales en el futuro, si su manejo continúa en la misma dirección que en la actualidad. El bajo contenido de MO es la restricción biofísica con mayor superposición con el resto de las restricciones biofísicas, que oscilan entre el $36 \%$ y el $89 \%$ de superposición. La pedregosidad es otra limitación biofísica con un alto nivel de superposición, principalmente con la profundidad del suelo con la que tiene una superposición del $78 \%$.

El margen económico de los cultivos aumentó cuando aumentaron los rendimientos. Los resultados económicos obtenidos en este estudio fueron similares a otros estudios llevados a cabo en el valle del Ebro para trigo y cebada en secano, que obtuvieron importes de $320 € \cdot$ ha $^{-1}$ para rendimientos entre 2 y $2,5 \mathrm{Mg} \cdot \mathrm{ha}^{-1}$ para cebada y $389 € \cdot$ ha $^{-}$ ${ }^{1}$ para trigo blando con un rendimiento superior a $3,0 \mathrm{Mg} \cdot \mathrm{ha}^{-1}[45]$.

De las 1.960.316 ha descritas como tierras arables marginales, sólo 39.376 ha (2\%) estaban fuera de los umbrales marcados por criterios biofísicos estudiados. La superficie con restricciones económicas representaba alrededor del $20 \%$ de la superficie arable de secano, el $11,5 \%$ de la superficie total de cultivos y el $4 \%$ de la superficie total de España. En Europa, aproximadamente 257 Mha se han identificado como marginales incluyendo pastizales, y la superficie disponible para la producción de biomasa ha sido de aproximadamente 58,2 Mha [4], en este sentido España representa el 3,4\% de la superficie total disponible en Europa en condiciones marginales para la producción de cultivos energéticos.

En relación a la producción de biomasa en tierras arables marginales, los resultados obtenidos con BIORAISE CE para el cardo se situaron en el rango de 3,4-25,2 Mg $M S \cdot h^{-1}$, los cuales fueron similares a los resultados obtenidos en otro estudio de diez años en España [46]. Esta alta variabilidad en el rendimiento se debe al hecho de que el cardo depende en gran medida de las precipitaciones y del suelo profundo. Con 529 
$\mathrm{mm}$ de precipitación anual el rendimiento fue de 23,1 Mg MS $\cdot \mathrm{ha}^{-1}$ y 6,5 Mg MS $\cdot \mathrm{ha}^{-1}$ con $280 \mathrm{~mm}$ de precipitación anual [43]. El cultivo a gran escala del cardo en el sur de Europa, en Portugal, con 77,4 ha produjeron un rendimiento medio de biomasa de 7,5 Mg MS ha ${ }^{-1}$ con una precipitación anual de 556 mm [47]. Además, el cardo se incluyó en el proyecto europeo Optimización de Pastos Perennes para la Producción de Biomasa en el Área mediterránea (OPTIMA) por su alto rendimiento y adaptabilidad a las áreas marginales Mediterránea [48], con el objetivo de establecer nuevas estrategias para el uso sostenible de las tierras marginales en las zonas mediterráneas. Estos hechos demuestran su idoneidad para su inclusión en sistemas de cultivo energético en tierras marginales [49]. Los rendimientos de triticale fueron similares a otro estudio que aportó resultados obtenidos en siete localidades de España con cuatro cultivares

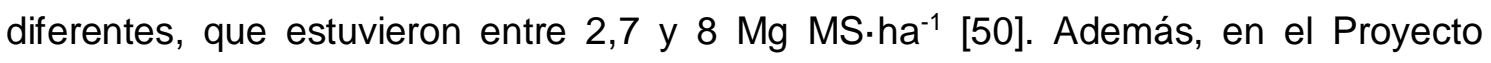
Singular y Estratégico "On Cultivos", se llevó a cabo una serie de ensayos con triticale durante un período de 3 años en diferentes provincias de ocho comunidades autónomas de España, aportando rendimientos de biomasa entre 1,6 y 12,4 Mg MS ha ${ }^{-1}$ [51]. Los ensayos de campo realizados en dos localidades durante dos años en el norte de España con tres cultivares diferentes, ofrecieron rendimientos entre 4,60 y 7,84 Mg MS $\cdot$ ha $^{-1}$ para la provincia de Soria, y entre 6,20 y 10,25 Mg MS $\cdot$ ha $^{-1}$ en la provincia de León [52]. En muchos casos estos cultivos están adaptados a suelos pobres, teniendo una producción adecuada en tierras arables marginales [6].

Los cultivos lignocelulósicos perennes son menos flexibles que los cultivos anuales en términos de propagación, procesamiento y utilización, pero pueden proporcionar alternativas rentables a los cultivos alimentarios [53]. Además, la erosión del suelo y problemas como la contaminación de tierras pueden reducirse sustituyendo los cultivos convencionales por especies perennes con baja demanda de inputs con fines bioenergéticos [54].

El consumo total de energía primaria en España fue de 123.868 ktep en 2015 [55]; por tanto, según los resultados de este estudio, la producción de biomasa en esta zona cubriría entre el 3\% y el 5\% de las necesidades de energía primaria de España. La producción de energía aumentaría si la biomasa se mezcla con digestato u otros abonos animales o con pastizales, prados y pastos residuales con finalidad de producir biogás [2,56-59].

Las tierras marginales y las tierras con limitaciones biofísicas tienen potencial para producir cultivos energéticos, pero sería necesario realizar un estudio en profundidad para analizar los rendimientos y la viabilidad económica. En los últimos años, los pastos 
perennes como el agropiro alargado (Thinopyrum ponticum (Podp.) Barkworth \& D.R. Dewey) [60] han mostrado un mayor potencial de secuestro de carbono del suelo en comparación con los cultivos anuales, como resultado de la cobertura continua del suelo, la reducción del laboreo en el suelo y la mejora con la producción de biomasa de raíces [61]. Además, las gramíneas perennes han obtenido mayores rendimientos en áreas con limitaciones biofísicas que el trigo [62]. Debido a las condiciones climáticas y edáficas, la gama de especies que pueden ser adecuadas para tales condiciones no es amplia; por lo tanto, es necesaria más investigación sobre estos temas. Además, las gramíneas perennes son hábitats de muchas especies de flora y fauna [56]. La implementación exitosa de cultivos energéticos como parte integral de los sistemas de producción tradicionales es una tarea difícil que requiere una evaluación agronómica precisa en términos de adaptabilidad ambiental, productividad, logística, factores restrictivos y sinergias con esquemas de rotación de cultivos; donde la producción de cultivos y las necesidades de inputs son las cuestiones más importantes para determinar la idoneidad de diferentes cultivos [53].

En este sentido, la siembra de cultivos energéticos en tierras marginales podría utilizarse como un instrumento para evitar el abandono de las zonas rurales y alcanzar múltiples objetivos políticos de la UE, como mejorar el desarrollo rural, impulsar la bioeconomía y alcanzar los objetivos de mitigación de los gases de efecto invernadero (GEI).

\subsection{Conclusiones}

El balance económico del trigo y la cebada en condiciones de secano indica que los rendimientos $\leq 1,5 \mathrm{Mg} \cdot \mathrm{ha}^{-1}$ hacen que el cultivo de la tierra no sea rentable para los agricultores que realizan laboreo convencional, lo que significa que estas zonas se consideran tierras marginales. El estudio de estas áreas muestra claramente que estas limitaciones económicas están vinculadas a limitaciones biofísicas. La superposición de limitaciones biofísicas podría hacer que ciertas áreas sean demasiado sensibles para una producción sostenible. El bajo contenido de MO es la restricción biofísica más frecuente de las consideradas en el estudio.

La evolución del suelo dependerá de la gestión del mismo. Los cambios en la preparación de la cama de siembra y cambios en los cultivos sembrados en esas zonas podrían mejorar estos suelos. En este contexto, es importante que la selección de la especie adecuada para cada zona por parte de los agricultores no asocie los rendimientos de los cultivos con la idoneidad del mismo para otros fines. 
El rendimiento de los cultivos energéticos también es menor en tierras marginales, por lo que debería ser necesario evaluar los impactos positivos que tiene esta actividad en el medio ambiente y en las zonas rurales. Evitar el abandono de estas áreas marginales mediante la siembra de cultivos energéticos ayudaría a lograr algunos de los objetivos de la PAC para el período 2021-2027, utilizando una agricultura de bajos inputs, a través de cultivos energéticos que pueden mejorar el medio ambiente (mejorar la restauración de carbono del suelo y evitar la erosión del suelo) y también aumentar las oportunidades en las zonas rurales. Además, la generación de energía utilizando cultivos producidos en estas tierras no entraría en conflicto con la producción de alimentos.

Además, el uso de tierras marginales puede contribuir al objetivo de la política de la UE de reducir las emisiones de $\mathrm{CO}_{2}$ en un $40 \%$ en 2030 y, en particular, lograr la contribución del $32 \%$ en el consumo total de energía con fuentes renovables al año, contenido en el nuevo Directiva de Energías Renovables 2021-2030 que promueve el uso de fuentes de energía renovables.

La metodología desarrollada en este trabajo puede ser un paso adelante en la identificación de tierras marginales y la identificación de los factores limitantes que hacen que estas áreas sean marginales. Podría replicarse en otros países de la UE con los mismos problemas, principalmente en la cuenca mediterránea.

\subsection{Referencias}

1. FAO. Global Agriculture Towards 2050. How to Feed the World 2050? Available online: www.fao.org/.../wsfs/.../How to Feed the World in 2050.pdf (accessed on 1 April 2017).

2. Mantineo, M.; D'Agosta, G.M.; Copani, V.; Patane, C.; Cosentino, S.L. Biomass yield and energy balance of three perennial crops for energy use in the semi-arid Mediterranean environment. Field Crop Res. 2009, 114, 204-213, doi: https://doi.org/10.1016/.ffcr.2009.07.020.

3. Sevigne, E.; Gasol, C.M.; Brun, F.; Rovira, L.; Pages, J.M.; Camps, F.; Rieradevall, J.; Gabarrell, X. Water and energy consumption of Populus spp. bioenergy systems: A case study in Southern Europe. Renew. Sustain. Energy Rev. 2011, 15, 1133-1140, doi: https://doi.org/10.1016/j.rser.2010.11.034.

4. Gerwin, W.; Repmann, F.; Spyridon, G.; Despoina, V.; Gounairs, N.; Baumgarten, W.; Christiane, V.; Keramitzis, D.; Kiourtsis, F.; Freese, D. Assessment and quantification of marginal lands for biomass production in Europe using soil quality indicators. Soil 2018, 4, 267-290, doi: https://doi.org/10.5194/soil-4-267-2018.

5. Dauber, J.; Miyake, S. To integrate or to segregate food crop and energy crop cultivation at the landscape scale? Perspectives on biodiversity conservation in agriculture in Europe. Energy Sustain. Soc. 2016, 11, 19, doi: https://doi.org/10.1186/s13705-016-0089-5.

6. Mehmood, M.A.; Ibrahim, M.; Rashid, U.; Nawaz, M.; Ali, S.; Hussain, A.; Gull, M. Biomass production for bioenergy using marginal lands. Sustain. Prod. Consum. 2017, 9, 3-21, doi: https://doi.org/10.1016/i.spc.2016.08.003.

7. James, L. Theory and Identification of Marginal Land and Factors Determining Land Use Change. Master's Thesis, University of Michigan, Lansing, MI, USA, 2010. 
8. Ricardo, D. On the Principles of Political Economy and Taxation, 3rd ed.; J.M. Dent and Sons Ltd.: London, UK, 1817.

9. Hollander, J.H. The concept of marginal rent. Q. J. Econ. 1895, 9, 175-187.

10. Shujiang, K.; Post, W.M.; Nichols, J.A.; Wang, D.; West, T.O.; Bandaru, V.; Izaurralde, R.C. Marginal lands: Concept, assessment and management. J. Agric. Sci. 2013, 5, 129-139, doi: https://doi.org/10.5539/jas.v5n5p129.

11. Schroers, J.O. Towards the Development of Marginal Land Use Depending on the Framework of Agricultural Market, Policy and Production Techniques; University of Giessen: Giessen, Germany, 2006.

12. European Environmental Agency (EEA). Marginal Land Concept. Available online: http://www.eionet.europa.eu/gemet/concept/5023 (accessed on 30 April 2018).

13. Peterson, G.M.; Galbraith, J.K. The concept of marginal land. J. Farm Econ. 1932, 14, 295310, doi:https:doi.org/10.2307/1230112.

14. Yakubu, A.S.; Ehlers, M.H.; Harnmeijer, J. Anaerobic Digestion of Feedstock Grown on Marginal Land: Break-Even Electricity Prices. Energies 2017, 10, 21, doi: https://doi.org/10.3390/en10091416.

15. Shortall, O.K. "Marginal land" for energy crops: Exploring definitions and embedded assumption. Energy Policy 2013, 62, 19-27, doi: https://doi.org/10.1016/i.enpol.2013.07.048.

16. Lal, R. World crop residues production and implications of its ude as a biofuel. Environ. Int. 2005, 31, 575-584, doi: https://doi.org/10.1016/j.envint.2004.09.005.

17. Pointereau, P.; Coulon, F.; Girard, P.; Lambotte, M.; Stuczynski, T.; Sanchez Ortega, V.; Del Rio, A. Analysis of Farmland Abandonment and the Extent and Location of Agricultural Areas that Are Actually Abandoned or Are in Risk to be Abandoned, 1st ed.; Anguiano, E., Bamps, C., Terres, J.M., Eds.; OPOCE: Luxembourg, 2008; pp. 13-93.

18. Van Eupen, M.; Elbersen, B.; Mantel, S. Marginal Land. Available online: https://iiasaspatial.maps.arcgis.com/apps/webappviewer/index.html?id=c0105c0d94c34048a1c32fba1 d65a6b1 (accessed on 9 September 2018).

19. Sanchez, J.; Curt, M.D.; Fernandez, J. Approach to the potential production of giant reed in surplus saline lands of Spain. Glob. Chang. Biol. Bioenergy 2017, 9, 105-118, doi: https://doi.org/10.1111/gcbb.12329.

20. Atance, I.; Orodea, L.F.; Puente, J.F.; Garcia, L.; Gonzalez, B.; Olmedilla, S. MAGRAMA (2013): Resultados Técnico-Económicos de Cultivos Herbáceos 2011, 1st ed.; Subdirección General de Análisis, Prospectiva y Coordinación, Subsecretaria; Ministerio de Agricultura, Alimentacion y Medio Ambiente: Madrid, Spain, 2013; pp. 1-36.

21. Instituto Nacional de Estadística (INE Base). Censo Agrario. Available online: https://www.ine.es/dyngs/INEbase/es/operacion.htm?c=Estadistica C\&cid=125473617685 $1 \&$ menu=resultados\&secc $=1254736194955 \&$ idp $=1254735727106$ (accessed on 29 March 2018).

22. Instituto Nacional de Estadística (INE Base). Encuesta Sobre la Estructura de las Explotaciones Agrarias. Available online: https://www.ine.es/dyngs/INEbase/es/operacion.htm?c=Estadistica C\&cid=125473617685 4\&menu=ultiDatos\&idp $=1254735727106$ (accessed on 3 April 2018).

23. Ministerio de Agricultura, Pesca y Alimentación (MAPA). Anuario de Estadística 2016. Available online: https://www.mapa.gob.es/es/estadistica/temas/publicaciones/anuario-deestadistica/2016/default.aspx (accessed on 7 November 2018).

24. Secretaria General de Agricultura y Alimentación. Evolución de la Superficie y Producción de Cereales en España; Ministerio de Agricultura, Pesca y Alimentación: Madrid, Spain, 2016.

25. Ministerio de Agricultura, Pesca y Alimentación. Bienes y los Rendimientos Asegurables, las Condiciones Técnicas Mínimas de Cultivo, el Ámbito de Aplicación, los Periodos de Garantía, las Fechas de Suscripción y los Precios Unitarios del Seguro de Explotaciones de Cultivos Herbáceos Extensivos, Comprendido en el Trigésimo Noveno Plan de Seguros Agrarios Combinados; MAPA: Madrid, Spain, 2018; pp. 84078-84263.

26. Eiriz, G.; Orodea, L.F.; García, L.; Ramírez, G.; Simarro, J.C. MAGRAMA (2017): Resultados Técnico Económicos de Cultivos Herbáceos 2016, 1st ed.; Subdirección General de Análisis, Prospectiva y Coordinación, Subsecretaria; Ministerio de Agricultura, Alimentacion y Medio Ambiente: Madrid, Spain, 2017; pp. 1-78.

27. Ministerio de Agricultura, Pesca y Alimentación (MAPA). Hojas de Cálculo de Costes de Maquinaria.

Available

online: 
https:/www.mapa.gob.es/es/ministerio/servicios/informacion/plataforma-de-conocimientopara-el-medio-rural-y-pesquero/observatorio-de-tecnologias-probadas/maquinariaagricola/hojas-calculo-maqui.aspx (accessed on 18 October 2018).

28. Lopez, L.; Betran, J.; Ramos, A.; Lopez, H.; Lopez, P.; Bermejo, J.L.; Urbano, P.; Piñeiro, J.; Castro, J.; Blazquez, R.; et al. Guía Práctica de la Fertilización Racional de los Cultivos en España. Parte II, 1st ed.; Ministerio de Medio Ambiente, Medio Rural y Marino: Madrid, Spain, 2009; pp. 1-144.

29. Fombellida, A.; Garijo, J. Manual Para el Cumplimiento de la Condicionalidad. Cereales de Invierno, 1st ed.; Ministerio de Agricultura, Alimentacion y Medio Ambiente: Madrid, Spain, 2011; pp. 1-34.

30. Hispagua. Soils. Available online: http://hispagua.cedex.es/en/datos/suelos (accessed on 27 September 2018).

31. King, J.; Gay, A.; Sylvester-Bradley, R.; Bingham, I.; Foulkes, J.; Gregory, P.; Robinson, D. Modelling cereal root systems for water and nitrogen capture: Towards an economic optimum. Ann. Bot. 2003, 91, 383-390, doi: https://doi.org/10.1093/aob/mcg033.

32. Jahn, R.; Blume, H.P.; Asio, V.B.; Spaargaren, O.; Schad, P. Guidelines for Soil Description, 4th ed.; FAO: Rome, Italy, 2006; pp. 1-109.

33. Reeves, D.W. The role of soil organic matter in maintaining soil quality in continous cropping systems. Soil Till. Res. 1997, 43, 131-167, doi: https://doi.org/10.1016/s01671987(97)00038-x.

34. Lynch, J.; Spink, J.; Doyle, D.; Hackett, R.; Phelan, S.; Forristal, D.; Kildea, S.; Glynn, L.; Plunkett, M., Wall, D.; et al. The Winter Wheat Guide,1st ed.; Agriculture and Food Authority: Carlow, Ireland, 2016; pp. 1-40.

35. Arregui, L.M.; Maetzu, I.; Quemada, M. Estimación del drenaje y lavado de nitratos en un sistema de cultivo de cereal de invierno en condiciones de secano y clima Mediterráneo húmedo. In Estudios de la Zona no Saturada del Suelo, 1st ed.; Samper, F.J., Paz, A., Eds.; Dialnet: Madrid, Spain, 2005; Volume 7, pp. 137-143.

36. Vitosh, H.L. Wheat Fertily and Fertilization. Wheat Facts, 1st ed.; Michigan State University: Lansing, MI, USA, 1998; pp. 1-4.

37. FAO. Annex 1. Crop Salt Tolerance Data. Available online: http://www.fao.org/docrep/005/y4263e/y4263e0e.htm (accessed on 21 April 2018).

38. Fleming, P.; Perrier, A.; Cavazza, L.; Tombesi, L.; Feddes, R.; Doorenbos, J.; Pereira, L.S.; Monteith, J.L.; Gunston, H.; Allen, R.; et al. Evapotranspiración del cultivo. In Guías Para la Determinación de los Requerimientos de Agua de los Cultivos, 1st ed.; FAO: Rome, Italy, 1990; pp. 87-156.

39. Ninyerola, M.; Pons, X.; Roure, J.M. Atlas Climático Digital de la Peninsula Ibérica. Metodología y Aplicaciones en Bioclimatologia y Geobotanica, Universidad Autonoma de Barcelona. Available online: http://www.opengis.uab.es/wms/iberia/mms/index.htm (accessed on 30 September 2018).

40. Ciria, P.; Perez, P.; Maletta, E.; Carrasco, J.; Esteban, L.S. BIORAISE-CE. Available online: http://bioraise.ciemat.es/BioraiseCE (accessed on 25 October 2018).

41. Villodre, J.; Castaño, S.; Sánchez, D.; Alfaro, M.; Ruiz, J.R.; Lopez, E.; Colina, A. Cartografía de Ocupación del Suelo en España. Proyecto SIOSE, 1st ed.; CNIG: Madrid, Spain, 2012; pp. 41-51, ISBN 978-84-695-6882-8.

42. Zadoks, J.C.; Chang, T.T.; Konzak, C.F. Decimal code for growth stages of cereals. Weed Res. 1974, 14, 415-421, doi: https://doi.org/10.1111/j.1365-3180.1974.tb01084.x.

43. Fernandez, J.; Curt, M.D. State of the art of Cynara cardunculus L. as an energy crop. In Proceedings of the 14th European Biomass Conference, Paris, France,17-21 October 2005; Sjunnesson, L., Carrasco, J.E., Helm, P., Grassi, A., Ed.; ETA-Renewable Energies \& WIPRenewable Energies: Paris, France, 2005; pp. 22-27.

44. Soldatos, P. Economic aspects of bioenergy production from perennial grasses in marginal lands of South Europe. Bioenergy Res. 2015, 8, 1562-1573, doi: https://doi.org/10.1007/s12155-015-9678-y.

45. Lloveras, J.; Cabases, M.A. Costes de producción de cultivos extensivos en secano y regadío. Vida Rural 2005, 401, 38-47.

46. Fernandez, J.; Hidalgo, M.; Monte, J.P.; Curt, M.D. Cynara cardunculus L. as a perennial crop for non-irrigated lands: Yields and applications. In Proceedings of the 4th International Congress on Artichoke 17-21 October 2000, Valenzano, Italy; Bianco, V.V., Calabrese, N., Rubaztky, V., Ed; ISHS (International Society for Horticultural Science). Acta Horticulturae 681: Valenzano, Italypp. 109-115. DOI: https://doi.org/10.17660/ActaHortic.2005.681.10 
47. Gominho, J.; Lourenco, A.; Palma, P.; Lourenco, M.E.; Curt, M.D.; Fernandez, J.; Pereira, $\mathrm{H}$. Large scale cultivation of Cynara cardunculus L. for biomass production-A case study. Ind. Crop. Prod. 2011, 33, 1-6, doi: https://doi.org/10.1016/i.indcrop.2010.09.011.

48. Fernando, A.L.; Boleó, S.; Barbosa, B.; Costa, J.; Duarte, M.P.; Monti, A. Perennial grass production opportunities on Marginal Mediterranean land. Bioenergy Res. 2015, 8, 15231537, doi: https://doi.org/10.1007/s12155-015-9692-0.

49. Monti, A.; Cosentino, S.L. Conclusive results of the European project OPTIMA: Optimization of perennial grasses for biomass production in the Mediterranean area. Bioenergy Res. 2015, 8, 1459-1460, doi: https://doi.org/10.1007/s12155-015-9679-x.

50. Sanz, M.; Mosquera, F.; Sanchez, G.; Barreiro, M.; Aguado, P.L.; Sanchez, J.; Curt, M.D.; Fernandez, J. Biomass potential of triticale and rye in two different phenological stages and energy characterization. In Proceedings of the 19th European Biomass Conference, Berlin, Germany, 6-11 July 2011; Faulstich, M., Ossenbrink, H., Dallemand, J.F., Baxter, D., Grassi, A., Helm, P., Eds.; ETA Renewable Energies: Berlin, Germany, 2011; pp. 591-595.

51. Ciria, P.; Maletta, E.; Del Val, M.A.; Pérez, J.; Pérez, P.; Carrasco, J. Cultivos Herbáceos Anuales para Producción de Biomasa en España en el Marco del Proyecto Singular Estratégico On- Cultivos, 1st ed.; Ciemat: Madrid, Spain, 2015; pp. 1-116, ISBN 978-847834-732-2.

52. Sastre, C.M.; Maletta, E.; Gonzalez-Arechavala, Y.; Ciria, P.; Santos, A.M.; Del Val, A.; Perez, P.; Carrasco, J. Centralised electricity production from winter cereals biomass grown under central-northern Spain conditions: Global warming and energy yield assessments. Appl. Energy 2014, 114, 737-748, doi:https://doi.org/10.1016/j.apenergy.2013.08.035.

53. Pulighe, G.; Bonati, G.; Fabiani, S.; Barsali, T.; Lupia, F.; Vanino, S.; Nino, P.; Arca, P.; Roggero, P.P. Assessment of the Agronomic Feasibility of Bioenergy Crop Cultivation on Marginal and Polluted Land: A GIS-Based Suitability Study from the Sulcis Area, Italy. Energies 2016, 9, 18, doi: https://doi.org/10.3390/en9110895.

54. Campbell, J.E.; Lobell, D.B.; Genova, R.C.; Field, C.B. The global potential of bioenergy on abandoned agriculture lands. Environ. Sci. Technol. 2008, 42, 5791-5794, doi: https://doi.org/10.1021/es800052w.

55. INE. España en Cifras 2017 (INE Base). 2017. Available online: https://www.ine.es/prodyser/espa cifras/2017/index.html\#38 (accessed on 7 November 2018).

56. Meyer, A.K.P.; Ehimen, E.A.; Holm-Nielsen, J.B. Future European biogas: Animal manure, straw and grass potentials for a sustainable European biogas production. Biomass Bioenergy 2018, 111, 154-164, doi: https://doi.org/10.1016/j.biombioe.2017.05.013.

57. Mattioli, A.; Boscaro, D.; Dalla Venezia, F.; Santacroce, F.C.; Pezzuolo, A.; Sartori, L. Biogas from residual grass: A territorial approach fos sustainable bioenergy production. Waste Biomass Valor. 2017, 8, 2747-2756, doi: https://doi.org/10.1007/s12649-017-0006-y.

58. Nizami, A.S.; Orozco, A.; Groom, E.; Dieterich, B.; Murphy, J.D. How much gas can we get from grass? Appl. Energy 2012, 92, 783-790, doi: https://doi.org/10.1016/j.apenergy.2011.08.033.

59. Chiumenti, A.; Boscaro, D.; da Borso, F.; Sartori, L.; Pezzuolo, A. Biogas from fresh spring and summer grass: Effect of the harvesting period. Energies 2018, 11, 1466-1478, doi: https://doi.org/10.3390/en11061466.

60. Ciria, C.S.; Carrasco, J.; Perez, J.; Barro, R.; Ciria, P. Pure and mixed perennial biomass crops for a constraint marginal land in north-central Spain (a 6-year study). In Proceedings of the 25th European Biomass Conference \& Exhibition, Stockholm, Sweden, 12-15 June 2016; pp. 120-124, doi: https://doi.org/10.5071/25thEUBCE2017-1CO.5.3.

61. Glover, J.D.; Culman, S.W.; DuPont, S.T.; Broussard, W.; Young, L.; Mangan, M.E.; Mai, J.G.; Crews, T.E.; DeHaan, L.R.; Buckley, D.H.; Ferris, H.; et al. Harvested perennial grasslands provide ecological benchmarks for agricultural sustainability. Agric. Ecosyst. Environ. 2010, 137, 3-12, doi: https://doi.org/10.1016/.agee.2009.11.001.

62. Ciria, P.; Ciria, C.S.; Maletta, E.; Perez, J.; Barro, R.; Carrasco, J.E. Varietal response of Elytrigia elongata under semiarid conditions in Spain: Establishment. In Proceedings of the 23rd European Biomass Conference and Exhibition, Vienna, Austria, 1-4 June 2015; Baxter, D., Grassi, A., Helm, P., Eds.; ETA-Florence: Vienna, Austria, 2015; pp. 139-146, doi: https://doi.org/10.5071/23rdEUBCE2015-1CV.1.8. 


\section{CAPÍTULO IV: Artículo 2: Rendimiento y calidad a largo plazo de}

especies perennes para energía (Agropyron spp.)

Ciria, C.S.; Barro, R.; Sanz, M.; Ciria, P. Long-Term Yield and Quality Performance of Perennial Energy Grasses (Agropyron spp.) on Marginal Land. Agronomy 2020, 10, 1051. https://doi.org/10.3390/agronomy10071051 ISSN: 2073-4395

Agronomy-Basel: Q1 in Agronomy. Factor de Impacto (2019) 2.603 
Resumen: El cultivo de gramíneas perennes es una de las alternativas más deseables como materia prima para energía, pero es difícil lograr rendimientos competitivos en las condiciones marginales del clima Mediterráneo. El objetivo de este estudio fue evaluar el rendimiento de tres gramíneas C3 (Agropyron spp.) desde el punto de vista agronómico y energético, comparando los rendimientos de materia seca (MS), la eficiencia en el uso de la lluvia, la composición química y la calidad de la biomasa durante un período de ocho años en España en condiciones marginales de secano. Los cultivares de agropiro alargado (Agropyron elongatum (Host) Beauv.), Alkar (4,8 Mg MS $\left.\cdot \mathrm{ha}^{-1}\right)$ y José $\left(4,7 \mathrm{Mg} \mathrm{MS} \cdot \mathrm{ha}^{-1}\right)$, lograron los rendimientos más altos. Se obtuvieron producciones inferiores a $0,5 \mathrm{Mg} \mathrm{MS} \cdot \mathrm{ha}^{-1}$ cuando las precipitaciones fueron inferiores a $150 \mathrm{~mm}$ entre marzo y junio. La biomasa obtenida de los cultivos ensayados mostró contenidos relativamente altos de ceniza, silicio y elementos alcalinos. Los poderes caloríficos netos oscilaron entre 16,7 y $18,5 \mathrm{MJ} \cdot \mathrm{kg}^{-1}$ en base seca (bs). Las diferencias en la composición entre especies y cultivares no es probable que afecte a su comportamiento en la combustión desde un punto de vista práctico. El contenido de cenizas, así como las concentraciones de $\mathrm{K}, \mathrm{S}, \mathrm{Na}$ y $\mathrm{Cl}$, tendieron a disminuir con los años. Los resultados ofrecidos serían muy útiles para la implantación de este tipo de cultivo en tierras marginales.

Palabras clave: Gramíneas C3; cultivos alternativos; agropiro alargado; agropiro crestado; agropiro siberiano; cultivos energéticos.

\subsection{Introducción}

El optimismo sobre el potencial de los biocombustibles como alternativa a los combustibles fósiles era alto a principios del siglo XXI [1]. Se esperaba que el uso de biocombustibles produjera beneficios tales como la reducción de las emisiones de gases de efecto invernadero (GEI), la descarbonización de la electricidad y del calor y el desarrollo de las zonas rurales [2]. Sin embargo, crea controversia la contribución de los biocombustibles en el aumento de los precios de los alimentos y en el uso del agua dulce para su producción [3,4]. Esto planteó importantes cuestiones relativas a la utilización de las tierras arables para la producción de cultivos destinados al ámbito de la bioenergía [5-7] lo que desembocó en un conflicto entre ambas alternativas [8].

En este contexto, las tierras marginales se han revelado como una importante fuente de tierras para los cultivos energéticos [7]. Las tierras marginales son zonas en las que es difícil cultivar alimentos de manera rentable dadas las condiciones existentes en el lugar, las políticas agrícolas y los métodos de cultivo disponibles, así como la 
situación económica mundial o nacional $[9,10]$. Según la Agencia Europea del Medio Ambiente (EEA), las tierras marginales son "tierras de baja calidad cuya producción apenas cubre los costes de cultivo". El Departamento de Agricultura de los Estados Unidos (USDA) define las tierras marginales como "en el ámbito de la agricultura, tierras de baja calidad que es probable que produzcan un rendimiento pobre". Por lo tanto, esas tierras se caracterizan por una baja productividad de alimentos asociada a limitaciones socioeconómicas y biofísicas [11,12].

Se ha informado ampliamente de que los usos de las gramíneas perennes son la mejor alternativa para producir biomasa en tierras marginales en términos agronómicos, económicos y ambientales. Las gramíneas perennes, en comparación con los cultivos anuales tradicionales, reducen la esquilmación de nutrientes del suelo y la erosión de éste, requieren bajos inputs para su producción y proporcionan un mejor margen de beneficio, aumentan la calidad del suelo y la retención de carbono, mejoran la biodiversidad de los ecosistemas agrícolas evitando los monocultivos y proporcionando protección y alimentación a la fauna silvestre (mamíferos, aves e insectos), y aumentan la retención de agua en el suelo [13-29]. Las gramíneas perennes más utilizadas para producir biomasa en Europa y los Estados Unidos son el miscanthus (Miscanthus giganteus Greef et Deuter), la caña común (Arundo donax L.), el panizo de pradera (Panicum virgatum L.) y el alpiste (Phalaris arundinacea L.), aunque no se recomienda su implantación en condiciones marginales debido a sus necesidades de suelo y agua [30]. A su vez, otras gramíneas perennes C3 pueden ser cultivos energéticos alternativos para la producción sostenible de biomasa en tierras marginales, que generalmente no son aptas para la producción de cultivos tradicionales [31,32]. En particular, el agropiro alargado, el agropiro crestado (Agropyron cristatum (L.) Gaertn.) y el agropiro siberiano (Agropyron sibiricum (Willd.) P. Beauv.) poseen características favorables para su producción en tierras marginales. Estas especies comparten rasgos similares en cuanto a su tolerancia a la sequía, resistencia a las heladas invernales y a plagas y enfermedades [33-35], además del resto de las ventajas descritas anteriormente por ser especies perennes. Todos ellos son especies C3 que se han utilizado tradicionalmente como pastos para su aprovechamiento a diente o para la obtención de forraje [36].

Muchos estudios realizados en todo el mundo aportan información sobre los rendimientos y la calidad de estas gramíneas en cuanto a la producción de forraje para el ganado [36,37], mientras que otros muestran la producción y la calidad de la biomasa de diferentes cultivares en tierras fértiles de cultivo o en pastizales [38-41]. Sin embargo, se dispone de muy poca información sobre la utilización de estas especies de Agropyron 
como materia prima para su utilización como combustible en tierras de cultivo marginales. La composición y el comportamiento en la combustión de la biomasa de las especies C3 está fuertemente influenciada por la gestión de los cultivos y la etapa de desarrollo, pero también depende de las especies consideradas y de factores tales como, las características del suelo y las condiciones meteorológicas [30,42,43]. La bibliografía muestra cómo la composición de las gramíneas C3 difiere enormemente entre localizaciones $[30,44,45]$, por lo que pueden tener cantidades considerablemente diferentes de ciertos minerales "anti calidad" como $\mathrm{Cl}, \mathrm{K}, \mathrm{Si}, \mathrm{N}$, o $\mathrm{S}$ que causan emisiones, escorias y/o corrosión a las temperaturas a las que trabajan las plantas de combustión $[30,42,43,45,46]$. Por todas estas razones, es importante aclarar desde una perspectiva productiva y de calidad si las gramíneas C3 pueden ser o no un recurso sostenible a largo plazo para la materia prima energética en condiciones marginales.

En el contexto anterior, el objetivo principal de este estudio fue evaluar tres especies de Agropyron spp. desde una perspectiva agronómica y energética, comparando su rendimiento, composición y calidad de biomasa en una zona agrícola de baja productividad en condiciones de secano. Se ensayaron durante ocho años en una ubicación marginal un cultivar (cv.) de agropiro crestado (Hycrest), un cultivar de agropiro siberiano (Vavilov II) y tres cultivares de agropiro alargado (Alkar, Jose y Riparianslopes), mientras que otros tres cultivares de agropiro alargado (Alkar, Bamar y Szarvasi-1) se ensayaron durante cinco años en una segunda ubicación. Estos resultados son de importancia clave para determinar el futuro comercial de estos cultivos como materia prima para la producción de energía cuando crecen en condiciones marginales.

\subsection{Material y métodos}

\subsubsection{Localización y características edafoclimáticas de las parcelas experimentales}

El estudio se realizó en dos localizaciones diferentes de la Meseta Norte de España, en una de las zonas de agricultura de secano más extensas del sur de Europa. Las parcelas experimentales se ubicaron en Cubo de la Solana (CS) $\left[41^{\circ} 36^{\prime} \mathrm{N}\right.$ y $2^{\circ}$ 28'W], a $1010 \mathrm{~m}$ sobre el nivel del mar, y en Alconaba (AL) [ $41^{\circ} 42^{\prime} \mathrm{N}$ y $2^{\circ} 22^{\prime} \mathrm{W}$ ], a 1000 $\mathrm{m}$ sobre el nivel del mar en zonas con limitaciones biofísicas [47]. En ambos lugares, los suelos eran pobres y arenosos (81\% de arena en las parcelas CS y $86 \%$ de arena en las parcelas de $A L$ ), con un contenido de elementos gruesos (>2 mm) superior al $15 \%$ en volumen de suelo. Los suelos se caracterizaban por bajos niveles de materia orgánica $(\leq 1 \%)$ y baja retención de agua y nutrientes, lo que indica posibles pérdidas 
por lixiviación. Los suelos tenían un pH neutro y no presentaban problemas de salinidad. El contenido de nitrógeno fue de $0,06 \%$ en las parcelas de CS y de $0,05 \%$ en las de AL; el contenido de fósforo $\left(\mathrm{P}_{2} \mathrm{O}_{5}\right)$ fue de 10,2 y $10,0 \mathrm{mg} \cdot \mathrm{kg}^{-1}$ en las parcelas de $\mathrm{CS}$ y $\mathrm{AL}$, respectivamente; y el contenido de potasio del suelo $\left(\mathrm{K}_{2} \mathrm{O}\right)$ fue de $152,5 \mathrm{mg} \cdot \mathrm{kg}^{-1}$ en las parcelas de CS y de $150 \mathrm{mg} \cdot \mathrm{kg}^{-1}$ en las de $\mathrm{AL}$. Se tomaron muestras de suelo de la capa más superficial $(0-30 \mathrm{~cm})$ como indica la norma ISO 10381-1, estas muestras se analizaron de acuerdo con las normas ISO para textura (ISO 11277), pH (ISO 10390), conductividad eléctrica (ISO 11265), materia orgánica (ISO 10694), fósforo (ISO 11263), potasio (ISO 11260), y amonio y nitratos (ISO/TS 14256-1 EX).

El clima de la zona donde se ubicaban las parcelas experimentales era mediterráneo-continentalizado, con inviernos fríos, veranos cálidos y bajo nivel de precipitación. Los datos climáticos se tomaron de la red que controla la Agencia Estatal de Meteorología (AEMET). El promedio de precipitación anual durante el período de estudio fue de 502,7 mm en los ensayos de CS, siendo 2018 el año más húmedo (669 mm) y 2017 el más seco (315 mm). La cosecha obtenida en 2017 fue casi imposible de recolectar por medios mecánicos debido a la extrema baja producción de biomasa obtenida como consecuencia de las bajas precipitaciones anuales registradas, particularmente entre marzo y junio $(123 \mathrm{~mm})$. La temperatura media anual fue de $10,6^{\circ} \mathrm{C}$, con temperaturas absolutas mínimas y máximas de $-11,9^{\circ} \mathrm{C}$ en enero de 2011 y $37^{\circ} \mathrm{C}$ en agosto de 2012 , respectivamente. El período libre de heladas fue de finales de mayo a principios de octubre, y la sequía aparecía generalmente durante los meses de verano. La figura 10 muestra las precipitaciones mensuales y las temperaturas medias durante el período de estudio en los ensayos experimentales de CS.

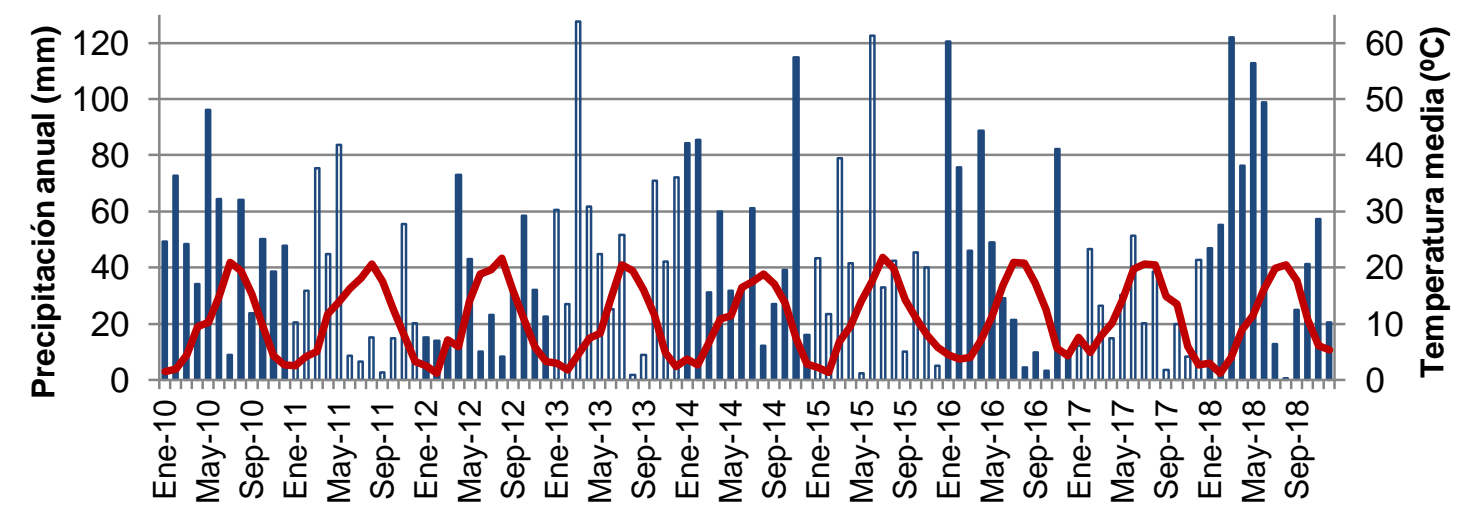

Precipitación (mm)

Temperatura media $\left({ }^{\circ} \mathrm{C}\right)$

Figura 10. Diagrama ombrotérmico de las parcelas experimentales de Cubo de la Solana. Barras azules y blancas indican un año diferente. 
El ensayo de $A L$ registró $437 \mathrm{~mm}$ de precipitación media anual, siendo 2018 el año más húmedo $(524 \mathrm{~mm})$ y 2017 el más seco con $351 \mathrm{~mm}$. La temperatura media anual fue de $10,5^{\circ} \mathrm{C}$, y las temperaturas mínimas y máximas absolutas fueron de $-10,5^{\circ} \mathrm{C}$ en enero de 2017 y $36,01^{\circ} \mathrm{C}$ en julio de 2015, respectivamente. AL exhibió los mismos períodos de heladas y sequías que CS. La figura 11 muestra las precipitaciones mensuales y las temperaturas medias.

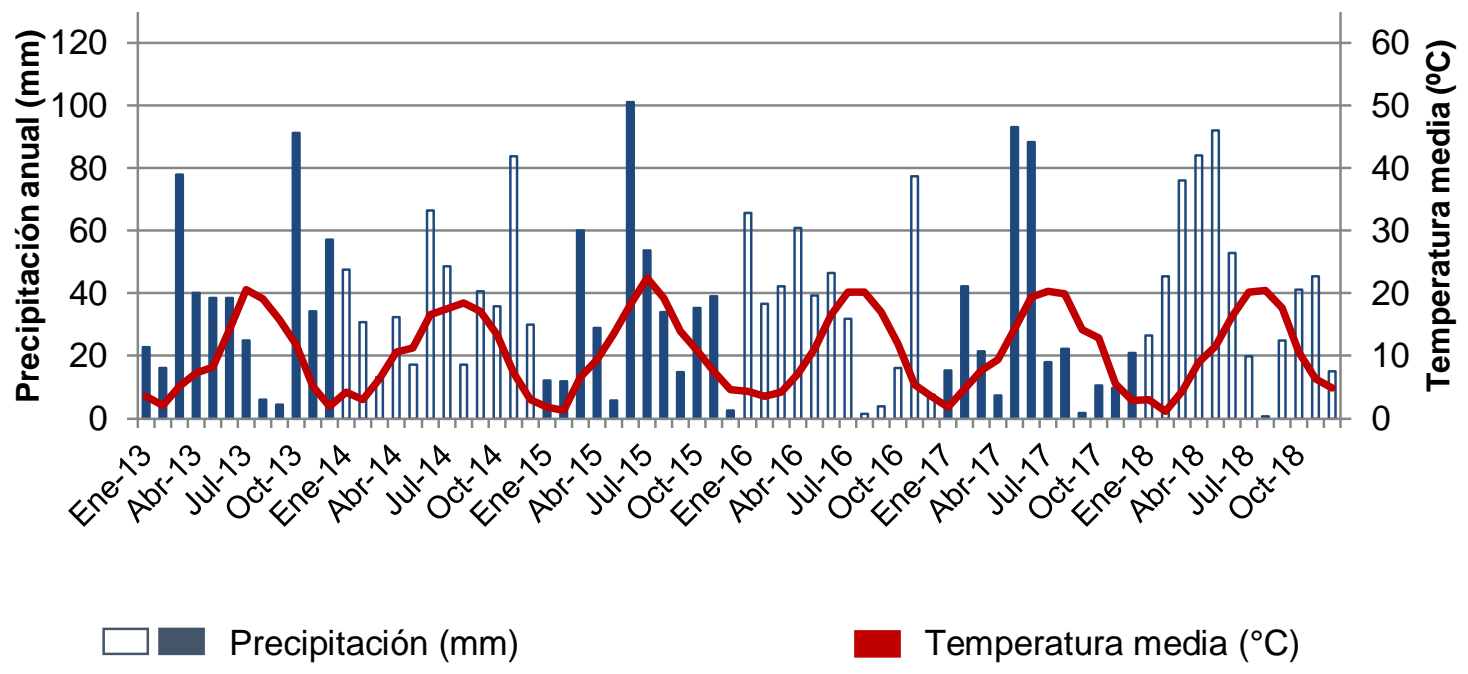

Figura 11. Diagrama ombrotérmico de las parcelas experimentales de Alconaba. Barras azules y blancas indican un año diferente.

\subsubsection{Diseño experimental y gestión de los cultivos}

Se tomaron datos de las parcelas experimentales durante 8 años en CS (de octubre de 2010 a agosto de 2018). El experimento de CS se diseñó sembrando tres repeticiones con un diseño aleatorio completo de bloques con parcelas de $300 \mathrm{~m}^{2}$ (3 m de ancho $\times 100 \mathrm{~m}$ de largo) para cada unidad experimental. Como se ha comentado anteriormente, los cultivares sembrados fueron agropiro alargado (cv. Alkar (TWA), cv. José (TWJ), cv. Riparianslopes (TWR)), agropiro crestado (cv. Hycrest) (CWH), y agropiro siberiano (cv. Vavilov) (SWV)

En los ensayos de AL se sembraron 3 cultivares de agropiro alargado en 4 repeticiones que fueron estudiadas durante 5 años (octubre 2013-agosto 2018) en parcelas con una superficie, forma y diseño similares a las parcelas de CS. Los cultivares sembrados de agropiro alargado en el experimento de AL fueron (cv. Alkar (TWA), cv. Bamar (TWB), y cv. Szarvasi-1 (TWS)).

El cultivo anterior en ambos ensayos fue barbecho. Las parcelas se labraron siete meses antes, se cultivaron en verano y se sembraron en octubre (en 2010 las 
localizadas en CS y en 2013 en AL). Las parcelas se sembraron con una sembradora de chorrillo con $13 \mathrm{~cm}$ de distancia entre líneas, la dosis de siembra fue de $20 \mathrm{~kg} \cdot \mathrm{ha}^{-1}$ para los cultivares de agropiro alargado y $15 \mathrm{~kg} \cdot \mathrm{ha}^{-1}$ para el agropiro crestado y el agropiro siberiano. El abonado de fondo se realizó con un fertilizante complejo NPK con fórmula 8-24-8 a una dosis de $300 \mathrm{~kg} \cdot \mathrm{ha}^{-1}$. Se aplicó dos días antes de la siembra y se envolvió con el cultivador. Se realizó un pase de rodillo a mediados de marzo el año de implantación antes de la aplicación del abonado de cobertera y se pulverizaron a finales de abril para controlar las malas hierbas de hoja ancha con $1 \mathrm{~L} \cdot \mathrm{ha}^{-1}$ de 2,4-D ácido 34,5\%+2-metil-4-clorofenoxiacético 34,5\%. La fertilización nitrogenada se aplicó entre mediados y finales de marzo de cada año utilizando nitrato amónico cálcico con el $27 \%$ de pureza a $300 \mathrm{~kg} \cdot \mathrm{ha}^{-1} \cdot a_{n} \mathrm{o}^{-1}$. La recolección se realizó con una segadora acondicionadora entre mediados de julio y principios de agosto dependiendo el año, siempre se cosechó cuando los cultivos estaban en la fase de grano pastoso y dejando $10 \mathrm{~cm}$ de rastrojo para fomentar un mayor rebrote al año siguiente. Después de 5 o 6 días de henificado en el campo la biomasa fue empacada en pacas prismáticas con \% de humedad menor del $10 \%$.

El principal factor limitante del crecimiento de los cultivos en condiciones de secano es la disponibilidad de agua. La producción de biomasa de los cultivos depende de su eficiencia en el uso del agua, así pues, los cultivos con mayor eficiencia en el uso del agua también logran un mejor margen económico. La eficiencia del uso del agua (EUA) se expresa a menudo también como la eficiencia en el uso de la lluvia y se mide en términos de producción por unidad de agua. Específicamente, EUA= rendimiento ( $\mathrm{g}$ $M S \cdot h^{-1}$ ) / precipitaciones (L) [48]. Aunque la EUA se ha evaluado principalmente en los cultivos tradicionales, también se pueden testar con cultivos energéticos [49]. La EUA se calculó para evaluar las diferencias entre cultivares y especies. El periodo de cálculo se realizó durante los meses de mayor actividad vegetativa (marzo a junio), que es cuando se considera que las precipitaciones tienen una importancia clave para la producción de biomasa en las especies C3 en condiciones de secano, como indican otros autores $[48,50]$.

\subsubsection{Características experimentales y métodos analíticos}

La preparación de las muestras se realizó de acuerdo con la norma ISO 14780:2017 [51], y los análisis de las muestras se llevaron a cabo siguiendo las normas internacionales correspondientes a los biocombustibles sólidos (Tabla 13). 
Tabla 13. Técnicas analíticas y normas seguidas durante las pruebas.

\begin{tabular}{lcc}
\hline \multicolumn{1}{c}{ Propiedad } & Técnica analítica (Equipo) & Norma \\
\hline $\begin{array}{l}\text { Preparación de muestras } \\
\text { Cenizas }\end{array}$ & $\begin{array}{c}\text { Submuestreos y molienda } \\
\text { Calcinación a 550 }{ }^{\circ} \mathrm{C}\end{array}$ & ISO 14780:2017 \\
$\mathrm{C}, \mathrm{H}, \mathrm{N}$ & ISO 18122:2015 \\
$\mathrm{S}$ y Cl & Análisis elemental con IRD y TCD & ISO 16948:2015 \\
Poder calorífico & $\begin{array}{c}\text { Bombec, Leco) } \\
\text { Basic IC Plus, Metrohm) }\end{array}$ & ISO 16994:2016 \\
Elementos mayoritarios: Al, Ca, & Calorímetro (C5003, Ika Verke) & ISO 18125:2017 \\
Fe, K, Mg, Mn, Na, P, Si, Ti, Zn & $\begin{array}{c}\text { Milestone) + ICP-OES (Jarrell Ash, } \\
\text { Thermo Fisher) }\end{array}$ & ISO 16967:2015 \\
\hline
\end{tabular}

IRD: Detección infrarroja; TCD: Detección conductividad térmica, IC: Cromatógrafo iónico; MW: Digestión por microondas; ICP-OES: Plasma de inducción-Espectroscopio de emisión óptica.

Las pacas se pesaron con una balanza de laboratorio en el campo. El contenido de humedad se realizó secando submuestras en una estufa a 105ํㅡ hasta un peso constante. El rendimiento de la materia seca se calculó teniendo en cuenta el área recolectada de la parcela, el peso de la paca y el contenido de humedad de las pacas.

Antes de segar, se muestreó la biomasa en cada parcela, especie, cultivar y año para determinar las principales propiedades y la composición química de la biomasa. Cada muestra se formó recolectando manualmente 3 submuestras de diferentes lugares escogidos al azar en la parcela y dejando el mismo rastrojo que el que dejaba la segadora-acondicionadora (10 $\mathrm{cm}$ aproximadamente). La biomasa de las parcelas de CS fue analizada durante 7 años desde 2012 hasta 2018. La biomasa del año de implantación no fue analizada. La biomasa de las parcelas de AL fue analizada entre 2014 y 2018.

Los elementos principales fueron analizados mediante la digestión de las cenizas de la biomasa obtenida a 550ㄷ (ISO 18122:2015), seguida de la determinación del ICPOES según la ISO 16967:2015. Los resultados se expresaron en base seca (bs) de biomasa. El contenido de titanio era muy bajo y con frecuencia inferior al límite de cuantificación del método $(<0,0002 \%)$, por lo que los resultados obtenidos para este elemento no se muestran ni se tratan estadísticamente. Los poderes caloríficos se analizaron por calorimetría (ISO 16994:2016) y se expresaron como el poder calorífico superior a volumen constante (PCS v,o) y el poder calorífico inferior a presión constante (PCl p,o), ambos en bs.

Se calcularon varios índices de predicción de combustible y las relaciones entre elementos químicos para predecir el comportamiento de la combustión de la biomasa recolectada. Estos índices se seleccionaron de la literatura, los cuales se utilizaron 
previamente como medida de la calidad de otros biocombustibles herbáceos con destino a la combustión.

En este sentido, la relación entre los óxidos alcalinos terrestres y los óxidos alcalinos $(\mathrm{AE} / \mathrm{A})$, la relación entre el contenido de $\mathrm{K}$ y la suma de $\mathrm{Ca}$ y $\mathrm{Mg}[\mathrm{K} /(\mathrm{Ca}+\mathrm{Mg})]$, así como la relación molar entre la suma de $\mathrm{Si}, \mathrm{P}$ y $\mathrm{K}$ y la suma de $\mathrm{Ca}$ y $\mathrm{Mg}[(\mathrm{Si}+\mathrm{P}+\mathrm{K})$ $/(\mathrm{Ca}+\mathrm{Mg})]$ se utilizó como indicadores de los problemas relacionados con la sinterización y fusión de las cenizas.

El $\mathrm{AE} / \mathrm{A}$ se calcula dividiendo las concentraciones de $\mathrm{CaO}$ y $\mathrm{MgO}$ y las concentraciones de $\mathrm{K}_{2} \mathrm{O}$ y $\mathrm{Na}_{2} \mathrm{O}$ en las cenizas del combustible [52]. Los biocombustibles sólidos con proporciones de $A E / A$ superiores a 2 se han asociado con un menor riesgo de sinterización de la ceniza en una planta piloto de combustión de lecho fluidizado de $1 \mathrm{MWth}$ [52].

La relación $\mathrm{K} /(\mathrm{Ca}+\mathrm{Mg})$ se utilizó como indicador de las escorias para el procesamiento termoquímico de los cultivos [53]. Se estimó que las especies con proporciones inferiores a 0,5 no planteaban problemas en cuanto a la sinterización o fusión de las cenizas, por ejemplo, en los gasificadores operacionales [53].

También se demostró empíricamente una correlación lineal entre la temperatura de sinterización de las cenizas (TSC) y la relación molar $(\mathrm{Si}+\mathrm{P}+\mathrm{K}) /(\mathrm{Ca}+\mathrm{Mg})$ para las cenizas ricas en $\mathrm{P}$ y $\mathrm{K}[54,55]$. Zeng y otros encontraron una buena correlación entre la TSC y los pellets producidos a partir de mezclas de miscanthus, una especie C4, con madera y paja de trigo [55]. Los combustibles con proporciones molares $(\mathrm{Si}+\mathrm{P}+\mathrm{K})$ /(Ca+Mg) más bajas tienden a mostrar temperaturas de sinterización de cenizas más altas [54]. Se prevé que los combustibles con índices inferiores a 1 y 3 exhiban TSC iguales o superiores a 1200 y $1000^{\circ} \mathrm{C}$, respectivamente [54].

La suma de $\mathrm{K}+\mathrm{Na}+\mathrm{Zn}+\mathrm{Pb}$ puede utilizarse como indicador de las emisiones de PM1 [54]. Se esperan bajas emisiones medias de aerosoles PM1 para índices inferiores a $1000 \mathrm{mg} \cdot \mathrm{kg}^{-1}$. A su vez, los combustibles con índices superiores a $10.000 \mathrm{mg} \cdot \mathrm{kg}^{-1}$ tienden a causar altas emisiones de PM1 [54]. Como no se determinaron los oligoelementos en este estudio, se utilizó un contenido de $\mathrm{Pb}$ de $1 \mathrm{mg} \mathrm{kg}^{-1}$ para calcular este índice, basado en ensayos experimentales anteriores en los que se analizó la biomasa de agropiro alargado en estos sistemas agrarios.

La relación molar Si/K se utilizó para predecir la formación de aerosoles durante la combustión de especies herbáceas, entre otros combustibles [54,56]. Una alta relación molar Si/K puede dar lugar a una formación preferente de silicatos de potasio 
en las cenizas de fondo, lo que da lugar a una menor liberación de $\mathrm{K}$ y a la formación de aerosoles, aunque las emisiones gaseosas de SOx y $\mathrm{HCl}$ pueden aumentar [54].

La relación molar $(\mathrm{K}+\mathrm{Na}) /[\times(2 \mathrm{~S}+\mathrm{Cl})]$ se utilizó para predecir los niveles de emisión de SOx y $\mathrm{HCl}[54,55]$. En este estudio se utilizó un factor $x$ de 4,9 para calcular este índice, ya que es el valor que determinaron experimentalmente Sommersacher y otros para Arundo donax L. En el caso de los combustibles con altas proporciones molares, el $\mathrm{S}$ y el $\mathrm{Cl}$ se incrustan preferentemente en las cenizas, formando sulfatos y cloruros alcalinos, lo que podría dar lugar a bajos niveles de emisión de SOx y $\mathrm{HCl}[54,55]$.

La relación molar $2 \mathrm{~S} / \mathrm{Cl}$ se ha utilizado como indicador de los riesgos de corrosión a alta temperatura [54]. Se espera que los combustibles con proporciones inferiores a 2 planteen un riesgo grave. Se esperan riesgos menores cuando las proporciones son $>4$. A su vez, para las proporciones $2 \mathrm{~S} / \mathrm{Cl}<2$, se deben tener en cuenta los riesgos severos de corrosión, como resultado de un alto excedente de Cl en los aerosoles [54].

\subsubsection{Análisis estadístico}

Los análisis estadísticos se realizaron utilizando el software Statgraphics Centurion XVII (Statpoint Technologies INC, 2017, The Plains, Virginia, EE.UU.). Se evaluaron los efectos de las diferentes especies $(\mathrm{S})$, cultivares $(\mathrm{C})$ y años $(\mathrm{Y})$ en la producción y composición de la biomasa, así como en los índices empíricos de combustible, mediante el análisis de varianza (ANOVA). Se utilizaron ANOVA multifactoriales de dos vías (sumas de cuadrados de Tipo III) con una interacción de orden máximo 2. Todas las relaciones-F se basaron en el error cuadrático medio residual. La normalidad de los datos y la homocedasticidad de las varianzas se verificaron utilizando la asimetría/curtosis estandarizada y la prueba de Levene, respectivamente. No se consideraron necesarias transformaciones de los datos. En los ensayos de $A L, C, Y, y$ la interacción entre ambos factores ( $C x Y$ ) se consideraron efectos fijos. En los ensayos de CS, se realizaron dos tipos de análisis ya que se probaron diferentes especies y cultivares. Por un lado, un análisis de la varianza con $\mathrm{S}$, Y, y SxY como efectos fijos, con la especie del factor en tres niveles (agropiro alargadoTW, agropiro crestado-CW, y agropiro siberiano-SW). Por otra parte, se realizó un análisis de la varianza con las especies/cultivares (S/C), Y, y su interacción (X/CxY) como efectos fijos, y se consideraron cinco niveles para el factor S/C (TWR, TWA, TWJ, $\mathrm{CWH}$, y SWV). El bloque (parcelas replicadas) se consideró un efecto aleatorio en ambos sitios. Las diferencias medias entre especies, cultivares y años se evaluaron utilizando la prueba de rangos múltiples de acuerdo con la prueba de la diferencia menos 
significativa (LSD) de Fisher. Se revelaron efectos significativos en los valores $\leq 0.05$ (95\% del nivel de confianza). Las interacciones entre los factores (especies y años o cultivares y años) se representaron utilizando los medios y las parcelas de interacción de LSD de Fisher. Las medias, las desviaciones estándar (SD), los percentiles del $75 \%$ (P75), así como los valores individuales mínimos y máximos obtenidos para cada propiedad también se incluyeron en sus tablas correspondientes.

\subsection{Resultados}

\subsubsection{Rendimientos y eficiencia en el uso del agua}

De acuerdo con los resultados obtenidos (Tabla 14), se encontraron diferencias significativas en la producción de biomasa entre especies, cultivares y años en ambas zonas experimentales. La EUA también tuvo efectos significativos entre las especies, cultivares y años en ambos lugares.

Tabla 14. Análisis de varianza de los efectos fijos de especies (S), cultivares (C) y año $(Y)$ de los rendimientos en MS de la biomasa y EUA de la biomasa producida.

\begin{tabular}{cccc|ccc}
\hline \multicolumn{4}{c|}{ Producción anual } & \multicolumn{3}{c}{ EUA } \\
\hline Fuente & gl & Valor- $F$ & Valor- $p$ & gl & Valor- $F$ & Valor- $p$ \\
\hline \multicolumn{6}{c}{ Ensayos de CS } \\
\hline $\mathrm{S}$ & 2 & 4,51 & 0,0130 & 2 & 7,91 & 0,0006 \\
$\mathrm{Y}$ & 7 & 45,61 & 0,0000 & 7 & 28,56 & 0,0000 \\
$\mathrm{~S} \times \mathrm{Y}$ & 14 & 3,65 & 0,0001 & 14 & 3,63 & 0,0001 \\
\hline \multicolumn{6}{c}{ Ensayos de AL } \\
\hline $\mathrm{C}$ & 2 & 2,70 & 0,0357 & 2 & 5,17 & 0,0087 \\
$\mathrm{Y}$ & 4 & 9,38 & 0,0000 & 4 & 3,53 & 0,0124 \\
$\mathrm{C} \times \mathrm{Y}$ & 8 & 3,98 & 0,0012 & 8 & 6,45 & 0,0000 \\
\hline \multicolumn{6}{c}{}
\end{tabular}

gl: grados de libertad.

Los rendimientos de las parcelas experimentales de CS y AL se muestran en la Tabla 15. En los ensayos de CS, el año de mayor producción fue 2018 (9,8 Mg MS·ha${ }^{1}$ de media), siendo el agropiro alargado cv. Jose la especie más productiva con 12,6 Mg MS $h^{-1}$. Cabe destacar también, que las menores producciones de biomasa se alcanzaron durante el año anterior (2017), debido a los bajísimos niveles de precipitación registrados, especialmente en primavera, que incluso dificultaron el empacado con los medios mecánicos utilizados en este estudio. Además, también se obtuvieron bajos rendimientos durante el año de implantación (1,7 Mg MS $\left.\cdot \mathrm{ha}^{-1}\right)$. Si se tiene en cuenta todo el período de estudio (2011-2018), los cultivares TWA y TWJ obtuvieron los mayores rendimientos, con producciones medias anuales de 4,8 y 4,7 Mg MS ha $^{-1}$, respectivamente. A su vez, CWH proporcionó los rendimientos anuales más bajos (2,8 Mg MS ha-1). 
En las parcelas $\mathrm{AL}$, los mejores rendimientos se obtuvieron en 2018 (4,9 Mg

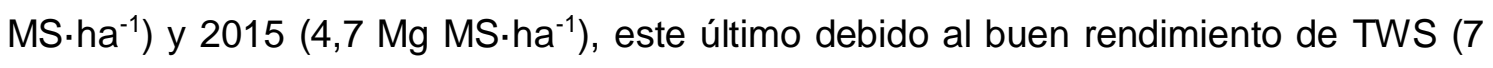
Mg MS ha ${ }^{-1}$ en 2015). En general, los rendimientos más bajos se lograron durante el año de establecimiento (1,9 Mg MS·ha-1 ${ }^{-1}$, que se acercaron a los registrados en 2017 (2,8 Mg MS·ha-1 ${ }^{-1}$, el de menor precipitación anual. TWS proporcionó los rendimientos anuales medios más altos (4,3 Mg MS·ha-1), seguido de TWB (3,5 Mg MS ha $\left.{ }^{-1}\right)$ y TWA $\left(3,0 \mathrm{Mg} \mathrm{MS} \cdot \mathrm{ha}^{-1}\right)$. Cabe destacar, que el cultivar TWS obtuvo mejores resultados durante los primeros años del experimento, mientras que el TWA tuvo mejores resultados con el experimento más avanzado.

Todos los cultivares de agropiro alargado probados en CS mostraron más eficiencia en el uso del agua (alrededor de 2,0 g MS. $\mathrm{L}^{-1}$ ) (Tabla 16) que el agropiro crestado y el agropiro siberiano, que proporcionaron rendimientos de biomasa más bajos para la misma precipitación. En comparación con los años anteriores, la mejor eficiencia de la lluvia se registró en 2013 y 2018 (2,6 g de MS.L $\mathrm{L}^{-1}$ y 2,4 g de MS. $\mathrm{L}^{-1}$, respectivamente). Se lograron eficiencias de agua similares en 2014 y 2015 . En relación con la producción de biomasa, 2017 fue el año con la menor eficiencia de lluvia debido a la baja precipitación registrada durante el período de mayor actividad vegetativa (123 $\mathrm{mm})$. En los ensayos de AL, TWS fue el cultivar con la mayor EUA $\left(2,2 \mathrm{~g} \mathrm{MS} \cdot \mathrm{L}^{-1}\right)$, a diferencia de TWA (1,4 g MS· $\left.\mathrm{L}^{-1}\right)$, siendo este último el de menor EUA. 
Tabla 15. Rendimientos de biomasa de las parcelas experimentales de CS y AL. Datos proporcionados en Mg de MS.ha-1.

\begin{tabular}{|c|c|c|c|c|c|c|c|c|c|c|}
\hline \multirow{2}{*}{ Ensayo } & \multirow{2}{*}{$\mathrm{S} / \mathrm{C}$} & \multicolumn{9}{|c|}{ Años } \\
\hline & & 2011 & 2012 & 2013 & 2014 & 2015 & 2016 & 2017 & 2018 & Media \\
\hline \multirow{6}{*}{ CS } & TWA & 2,0 & 2,6 & 7,5 & 3,3 & 5,3 & 5,9 & 0,1 & 11,5 & $4,8 \pm 3,6^{a}$ \\
\hline & TWJ & 2,0 & 2,6 & 7,6 & 2,8 & 4,0 & 5,9 & 0,2 & 12,6 & $4,7 \pm 3,9^{a}$ \\
\hline & TWR & 2,0 & 2,1 & 7,1 & 3,3 & 4,6 & 5,8 & 0,2 & 11,5 & $4,6 \pm 3,6^{a, b}$ \\
\hline & CWR & 1,2 & 2,6 & 5,7 & 1,7 & 2,8 & 1,9 & 0,3 & 6,5 & $2,8 \pm 2,2^{b}$ \\
\hline & SWV & 1,3 & 2,2 & 6,3 & 1,9 & 2,9 & 2,1 & 0,3 & 6,7 & $2,9 \pm 2,3^{a, b}$ \\
\hline & Media \pm SD & $1,7 \pm 0,4^{d}$ & $2,4 \pm 0,2^{d}$ & $6,9 \pm 0,8^{b}$ & $2,6 \pm 0,8^{d}$ & $3,9 \pm 1,1^{c}$ & $4,3 \pm 2,1^{\mathrm{c}}$ & $0,2 \pm 0,1^{\mathrm{e}}$ & $9,8 \pm 2,9^{a}$ & \\
\hline \multirow{4}{*}{$A L$} & TWB & - & - & - & 1,3 & 4,7 & 3,9 & 3,2 & 4,4 & $3,5 \pm 1,5^{a, b}$ \\
\hline & TWS & - & - & - & 3,5 & 7,0 & 3,7 & 2,3 & 5,1 & $4,3 \pm 1,8^{a}$ \\
\hline & TWA & - & & - & 0,9 & 2,5 & 3,7 & 2,8 & 5,2 & $3,0 \pm 1,3^{b}$ \\
\hline & Media \pm SD & - & - & - & $1,9 \pm 1,4^{\mathrm{c}}$ & $4,7 \pm 2,2^{a}$ & $3,8 \pm 0,1^{\mathrm{ab}}$ & $2,8 \pm 0,4^{b, c}$ & $4,9 \pm 0,4^{a}$ & \\
\hline
\end{tabular}

S: especies; C: cultivar; SD: desviación estándar. Diferentes letras indican diferencias significativas en las medias entre cultivares y años con el $95 \%$ de nivel de confianza de acuerdo con el test de múltiples rangos.

Tabla 16. EUA de las parcelas de CS y AL. Datos reportados en $\mathrm{g} M S \cdot \mathrm{L}^{-1}$.

\begin{tabular}{|c|c|c|c|c|c|c|c|c|c|c|}
\hline \multirow{2}{*}{ Ensayo } & \multirow{2}{*}{$S / C$} & \multicolumn{9}{|c|}{ Años } \\
\hline & & 2011 & 2012 & 2013 & 2014 & 2015 & 2016 & 2017 & 2018 & Media \\
\hline \multirow{6}{*}{ CS } & TWA & 0,9 & 1,9 & 2,9 & 2,1 & 2,2 & 2,8 & 0,1 & 2,8 & $2,0 \pm 1,0^{a}$ \\
\hline & TWJ & 1,0 & 1,9 & 2,9 & 1,8 & 1,6 & 2,8 & 0,2 & 3,1 & $1,9 \pm 1,0^{a}$ \\
\hline & TWR & 1,0 & 1,5 & 2,8 & 2,1 & 1,9 & 2,7 & 0,2 & 2,8 & $1,9 \pm 0,9^{a}$ \\
\hline & CWR & 0,6 & 1,9 & 2,2 & 1,1 & 1,2 & 0,9 & 0,2 & 1,6 & $1,2 \pm 0,7^{b}$ \\
\hline & SWV & 0,6 & 1,6 & 2,4 & 1,2 & 1,2 & 1,0 & 0,2 & 1,6 & $1,2 \pm 0,7^{b}$ \\
\hline & $\begin{array}{c}\text { media } \pm \\
\text { SD }\end{array}$ & $0,8 \pm 0,2^{d}$ & $1,8 \pm 0,2^{c}$ & $2,6 \pm 0,3^{a}$ & $1,6 \pm 0,5^{c}$ & $1,6 \pm 0,4^{c}$ & $2,0 \pm 1,0^{b c}$ & $0,2 \pm 0,1^{\mathrm{e}}$ & $2,4 \pm 0,7^{a, b}$ & \\
\hline \multirow{4}{*}{$\mathrm{AL}$} & TWB & - & - & - & 1,0 & 2,4 & 2,0 & 1,8 & 1,4 & $1,8 \pm 0,5^{a, b}$ \\
\hline & TWS & - & - & - & 2,7 & 3,6 & 2,0 & 1,1 & 1,7 & $2,2 \pm 0,9^{a}$ \\
\hline & TWA & - & & - & 0,7 & 1,3 & 2,0 & 1,3 & 1,7 & $1,4 \pm 0,5^{b}$ \\
\hline & $\begin{array}{l}\text { media } \pm \\
\text { SD }\end{array}$ & - & - & - & $1,5 \pm 1,1^{b}$ & $2,4 \pm 1,1^{a}$ & $2,0 \pm 0,1^{a, b}$ & $1,4 \pm 0,4^{b}$ & $1,6 \pm 0,1^{b}$ & \\
\hline
\end{tabular}

S: especies; C: cultivar; SD: desviación estándar. Diferentes letras indican diferencias significativas en las medias entre cultivares y años con el $95 \%$ de nivel de confianza de acuerdo con el test de múltiples rangos. 


\subsubsection{Composición de la biomasa}

En la tabla 17 se indica la significancia estadística de los factores considerados (especies, cultivares y años) y sus correspondientes interacciones en las propiedades de la biomasa y la composición química de las gramíneas cultivadas en ambos sitios (CS y AL). En las tablas 18 y 19 se indican las principales propiedades y la composición química de las diferentes gramíneas perennes cultivadas en CS durante el período 2011-2018. Como se explica en la sección 4.2.1, se ensayaron las especies CWH, SWV y tres cultivares de agropiro alargado (TWA, TWJ y TWR). Los resultados de los tres cultivares de agropiro alargado estudiados en los ensayos experimentales de AL (TWA, TWB y TWS, véase la Sección 4.2.1) desde 2013 hasta 2018 figuran en las tablas 20 y 21. Estas tablas incluyen los valores medios de cuatro parcelas replicadas por especie, cultivar y año (Tablas 18-21).

Tabla 17. Influencia de la especie, cultivar, y año en las propiedades y composición química de la biomasa en los dos campos de ensayo estudiados (CS y $A L$ ).

\begin{tabular}{ccccccc}
\hline & \multicolumn{3}{c}{ Biomasa de CS } & \multicolumn{3}{c}{ Biomasa de AL } \\
\cline { 2 - 7 } Factor & S/C & Y & S/CxY & C & Y & CxY \\
\hline gl & 4 & 6 & 24 & 2 & 4 & 8 \\
Cenizas & $* *$ & $* *$ & $\mathrm{~ns}$ & $* *$ & $* *$ & $\mathrm{~ns}$ \\
$\mathrm{C}$ & $*$ & $* *$ & $\mathrm{~ns}$ & $* *$ & $* *$ & $\mathrm{~ns}$ \\
$\mathrm{H}$ & $* *$ & $* *$ & $\mathrm{~ns}$ & $*$ & $\mathrm{~ns}$ & $*$ \\
$\mathrm{~N}$ & $\mathrm{~ns}$ & $* *$ & $\mathrm{~ns}$ & $* *$ & $* *$ & $\mathrm{~ns}$ \\
$\mathrm{~S}$ & $\mathrm{~ns}$ & $* *$ & $\mathrm{~ns}$ & $* *$ & $* *$ & $\mathrm{~ns}$ \\
$\mathrm{Cl}$ & $\mathrm{ns}$ & $* *$ & $\mathrm{~ns}$ & $* *$ & $* *$ & $* *$ \\
$\mathrm{PCSv}, 0$ & $* *$ & $* *$ & $\mathrm{~ns}$ & $* *$ & $* *$ & $\mathrm{~ns}$ \\
$\mathrm{PClp}, 0$ & $*$ & $* *$ & $\mathrm{~ns}$ & $* *$ & $* *$ & $\mathrm{~ns}$ \\
$\mathrm{Al}$ & $\mathrm{ns}$ & $* *$ & $\mathrm{~ns}$ & $\mathrm{~ns}$ & $* *$ & $\mathrm{~ns}$ \\
$\mathrm{Ca}$ & $\mathrm{ns}$ & $* *$ & $*$ & $\mathrm{~ns}$ & $* *$ & $\mathrm{~ns}$ \\
$\mathrm{Fe}$ & $\mathrm{ns}$ & $* *$ & $\mathrm{~ns}$ & $\mathrm{~ns}$ & $\mathrm{~ns}$ & $\mathrm{~ns}$ \\
$\mathrm{~K}$ & $* *$ & $* *$ & $\mathrm{~ns}$ & $*$ & $* *$ & $\mathrm{~ns}$ \\
$\mathrm{Mg}$ & $*$ & $* *$ & $\mathrm{~ns}$ & $\mathrm{~ns}$ & $\mathrm{~ns}$ & $\mathrm{~ns}$ \\
$\mathrm{Mn}$ & $\mathrm{ns}$ & $* *$ & $\mathrm{~ns}$ & $\mathrm{~ns}$ & $*$ & $\mathrm{~ns}$ \\
$\mathrm{Na}$ & $* *$ & $*$ & $\mathrm{~ns}$ & $\mathrm{~ns}$ & $\mathrm{~ns}$ & $\mathrm{~ns}$ \\
$\mathrm{P}$ & $\mathrm{ns}$ & $*$ & $\mathrm{~ns}$ & $\mathrm{~ns}$ & $* *$ & $* *$ \\
$\mathrm{Si}$ & $*$ & $* *$ & $\mathrm{~ns}$ & $* *$ & $\mathrm{~ns}$ & $\mathrm{~ns}$ \\
$\mathrm{Zn}$ & $* *$ & $* *$ & $* *$ & $* *$ & $* *$ & $\mathrm{~ns}$ \\
\hline
\end{tabular}

S: especie; C: cultivar; Y: año; gl: grados de libertad; ** valor- $p<0,01 ;{ }^{*}$ valor- $p=0,01-0,05$; ns: valor $-p>0,05$, de acuerdo con los test de Fisher (ANOVA de orden 2).

Como puede verse en la tabla 17, las especies y los cultivares ensayados en las parcelas de CS difieren significativamente en su poder calorífico, contenido en cenizas, $\mathrm{C}, \mathrm{H}, \mathrm{K}, \mathrm{Mg}, \mathrm{Na}$, Si y Zn. No se encontraron diferencias significativas en sus contenidos en $\mathrm{N}, \mathrm{S}, \mathrm{Cl}, \mathrm{Al}, \mathrm{Ca}, \mathrm{Fe}, \mathrm{Mn}$ y $\mathrm{P}$.

Para todas las propiedades con $p$-valores inferiores a 0,05 para el factor $S / C$, las principales diferencias se encontraron entre las especies más que entre los cultivares. En este sentido, el agropiro alargado mostró diferencias significativas con respecto a las 
demás especies de agropiro examinadas (crestado y siberiano), mientras que todos los cultivares de agropiro alargado mostraron composiciones químicas similares (Tablas 18 y 19). 
Tabla 18. Contenido en cenizas, poderes caloríficos y análisis inmediato de la biomasa de las diferentes gramíneas perennes recolectadas entre 2012 y 2018 en las parcelas de CS. Valores medios de tres repeticiones por especie, cultivar y año.

\begin{tabular}{|c|c|c|c|c|c|c|c|c|c|}
\hline S/C & $\mathbf{Y}$ & $\begin{array}{c}\text { Cenizas } \\
\left(\mathrm{g} \cdot \mathrm{kg}^{-1} \mathbf{b s}\right)\end{array}$ & $\begin{array}{c}\mathrm{C} \\
\left(\mathrm{g} \cdot \mathrm{kg}^{-1} \mathrm{bs}\right)\end{array}$ & $\begin{array}{c}\mathrm{H} \\
\left(\mathrm{g} \cdot \mathrm{kg}^{-1} \mathrm{bs}\right)\end{array}$ & $\begin{array}{c}\mathrm{N} \\
\left(\mathrm{g} \cdot \mathrm{kg}^{-1} \mathrm{bs}\right)\end{array}$ & $\begin{array}{c}\mathrm{S} \\
\left(\mathrm{g} \cdot \mathrm{kg}^{-1} \mathrm{bs}\right)\end{array}$ & $\begin{array}{c}\mathrm{Cl} \\
\left(\mathrm{g} \cdot \mathrm{kg}^{-1} \mathrm{bs}\right)\end{array}$ & 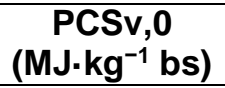 & $\begin{array}{c}\text { PClp,0 } \\
\text { (MJ.kg } \text {.1 }^{-1} \text { bs) }\end{array}$ \\
\hline \multirow[t]{7}{*}{ TWA } & 2012 & 48 & 482 & 60 & 14 & 1,6 & 1,7 & 19,1 & 17,8 \\
\hline & 2013 & 44 & 473 & 60 & 10 & 1,0 & 1,1 & 19,0 & 17,7 \\
\hline & 2014 & 45 & 459 & 60 & 9,5 & 1,0 & 1,7 & 18,6 & 17,3 \\
\hline & 2015 & 39 & 473 & 61 & 11 & 1,3 & 1,9 & 19,2 & 17,9 \\
\hline & 2016 & 43 & 470 & 61 & 12 & 0,7 & 1,1 & 18,5 & 17,2 \\
\hline & 2017 & 47 & 484 & 61 & 15 & 0,9 & 2,0 & 19,1 & 17,8 \\
\hline & 2018 & 38 & 472 & 61 & 8,4 & 0,6 & 1,4 & 18,6 & 17,3 \\
\hline \multicolumn{2}{|c|}{ media \pm SD } & $44 \pm 4^{a}$ & $473 \pm 8^{b}$ & $6,1 \pm 0,5^{b}$ & $11 \pm 2,4$ & $1,0 \pm 0,4$ & $1,5 \pm 0,4$ & $18,9 \pm 0,3^{b}$ & $17,6 \pm 0,3^{b}$ \\
\hline \multirow[t]{7}{*}{ TWJ } & 2012 & 50 & 480 & 60 & 13,9 & 1,6 & 2,1 & 19,0 & 17,7 \\
\hline & 2013 & 45 & 469 & 60 & 9,6 & 1,1 & 1,4 & 18,8 & 17,5 \\
\hline & 2014 & 36 & 458 & 60 & 8,6 & 1,0 & 1,4 & 18,5 & 17,2 \\
\hline & 2015 & 37 & 469 & 61 & 8,5 & 1,2 & 1,9 & 19,0 & 17,6 \\
\hline & 2016 & 44 & 477 & 61 & 10,9 & 0,8 & 1,2 & 18,8 & 17,5 \\
\hline & 2017 & 48 & 482 & 63 & 14,9 & 1,3 & 3,2 & 19,6 & 18,3 \\
\hline & 2018 & 41 & 475 & 61 & 7,7 & 0,7 & 1,4 & 18,7 & 17,3 \\
\hline \multicolumn{2}{|c|}{ media \pm SD } & $43 \pm 5^{a}$ & $473 \pm 8^{b}$ & $61 \pm 1,0^{b}$ & $11 \pm 3$ & $1,1 \pm 0,3$ & $1,8 \pm 0,7$ & $18,9 \pm 0,3^{b}$ & $17,6 \pm 0,3^{b}$ \\
\hline \multirow[t]{7}{*}{ TWR } & 2012 & 48 & 482 & 60 & 14,5 & 1,6 & 1,5 & 19,2 & 17,9 \\
\hline & 2013 & 41 & 472 & 60 & 10,0 & 1,0 & 1,0 & 19,4 & 18,1 \\
\hline & 2014 & 40 & 458 & 60 & 10,1 & 1,0 & 1,8 & 18,6 & 17,3 \\
\hline & 2015 & 38 & 456 & 62 & 9,5 & 1,2 & 2,1 & 19,0 & 17,7 \\
\hline & 2016 & 46 & 476 & 61 & 9,9 & 0,5 & 1,4 & 19,1 & 17,8 \\
\hline & 2017 & 46 & 484 & 63 & 16,1 & 1,1 & 2,5 & 19,6 & 18,2 \\
\hline & 2018 & 37 & 472 & 61 & 7,8 & 0,5 & 1,2 & 18,7 & 17,4 \\
\hline \multicolumn{2}{|c|}{ media \pm SD } & $42 \pm 4^{b}$ & $471 \pm 11^{b}$ & $61 \pm 1,0^{b}$ & $11,1 \pm 3,0$ & $1,0 \pm 0,4$ & $1,6 \pm 0,5$ & $19,1 \pm 0,4^{a}$ & $17,8 \pm 0,4^{a}$ \\
\hline \multirow[t]{7}{*}{ CWH } & 2012 & 38 & 487 & 61 & 12,4 & 1,1 & 1,9 & 19,2 & 17,9 \\
\hline & 2013 & 39 & 462 & 61 & 13,5 & 0,8 & 1,4 & 18,9 & 17,6 \\
\hline & 2014 & 39 & 460 & 61 & 10,9 & 1,0 & 1,5 & 18,9 & 17,6 \\
\hline & 2015 & 32 & 475 & 62 & 11,5 & 1,2 & 2,6 & 19,5 & 18,1 \\
\hline & 2016 & 29 & 465 & 63 & 08,1 & 0,6 & 0,9 & 18,9 & 17,5 \\
\hline & 2017 & 42 & 486 & 63 & 15,6 & 0,9 & 2,0 & 19,7 & 18,3 \\
\hline & 2018 & 30 & 474 & 62 & 08,1 & 0,5 & 0,9 & 18,6 & 17,2 \\
\hline
\end{tabular}




\begin{tabular}{|c|c|c|c|c|c|c|c|c|c|}
\hline \multicolumn{2}{|c|}{ media \pm SD } & $36 \pm 5^{b}$ & $473 \pm 11^{b}$ & $62 \pm 1,0^{a}$ & $11,4 \pm 2,8$ & $0,9 \pm 0,2$ & $1,6 \pm 0,6$ & $19,1 \pm 0,4^{a}$ & $17,7 \pm 0,4^{2}$ \\
\hline \multirow[t]{7}{*}{ SWV } & 2012 & 40 & 488 & 61,3 & 13,1 & 1,2 & 1,6 & 19,4 & 18,1 \\
\hline & 2013 & 3,5 & 475 & 61,0 & 10,4 & 1,0 & 1,3 & 19,0 & 17,7 \\
\hline & 2014 & 45 & 460 & 61,0 & 14,7 & 1,1 & 1,8 & 18,8 & 17,5 \\
\hline & 2015 & 33 & 481 & 61,0 & 12,0 & 1,3 & 2,1 & 19,4 & 18,0 \\
\hline & 2016 & 36 & 475 & 62,3 & 13,4 & 1,1 & 1,6 & 18,9 & 17,5 \\
\hline & 2017 & 40 & 487 & 63,0 & 14,4 & 0,8 & 1,6 & 19,5 & 18,2 \\
\hline & 2018 & 30 & 479 & 62,0 & 09,4 & 0,5 & 1,0 & 18,8 & 17,4 \\
\hline \multicolumn{2}{|c|}{ media \pm SD } & $3,7 \pm 0,5^{b}$ & $478 \pm 9,0^{a}$ & $61,7 \pm 0,8^{a}$ & $12,5 \pm 2,0$ & $1,0 \pm 0,3$ & $1,6 \pm 0,4$ & $19,1 \pm 0,3^{a}$ & $17,8 \pm 0,3^{\circ}$ \\
\hline \multicolumn{2}{|c|}{$\begin{array}{c}\text { Media global } \pm \\
\text { SD }\end{array}$} & $41 \pm 7$ & $476 \pm 9$ & $61 \pm 1,0$ & $11,7 \pm 3,1$ & $1,0 \pm 0,4$ & $1,6 \pm 0,7$ & $19,0 \pm 0,4$ & $17,7 \pm 0,4$ \\
\hline \multicolumn{2}{|c|}{ Min. valor } & 27 & 456 & 60 & 6,2 & 0,4 & 0,8 & 18,3 & 16,9 \\
\hline \multicolumn{2}{|c|}{ Max. valor } & 58 & 491 & 64 & 18,9 & 1,9 & 4,6 & 19,8 & 18,5 \\
\hline \multicolumn{2}{|c|}{ P75 } & 46 & 484 & 62 & 14,0 & 1,2 & 1,9 & 19,3 & 17,9 \\
\hline
\end{tabular}

Letras diferentes indican medias con diferencias significativas entre especie/cultivar para esa propiedad 95\% de nivel de confianza de acuerdo con el test de múltiples rangos. Las letras han sido incluidas cuando el valor-p para el factor cultivar era menor de 0,05.

Tabla 19. Elementos mayoritarios presentes en la biomasa de las diferentes especies perennes recolectadas en CS entre 2012 y 2018. Valores medios de tres repeticiones por especie y año.

\begin{tabular}{|c|c|c|c|c|c|c|c|c|c|c|c|}
\hline $\mathbf{S} / \mathbf{C}$ & $\mathbf{Y}$ & $\begin{array}{c}\text { Al } \\
\left(g \cdot \mathrm{kg}^{-1} \mathrm{bs}\right)\end{array}$ & $\begin{array}{c}\mathrm{Ca} \\
\left(\mathrm{g} \cdot \mathrm{kg}^{-1} \mathrm{bs}\right)\end{array}$ & $\begin{array}{c}\mathrm{Fe} \\
\left(\mathrm{g} \cdot \mathrm{kg}^{-1} \mathrm{bs}\right)\end{array}$ & $\begin{array}{c}\mathrm{K} \\
\left(\mathrm{g} \cdot \mathrm{kg}^{-1} \mathrm{bs}\right)\end{array}$ & $\begin{array}{c}M g \\
\left(g \cdot \mathrm{kg}^{-1} \mathrm{bs}\right)\end{array}$ & $\begin{array}{c}\text { Mn } \\
\left(\mathrm{g} \cdot \mathrm{kg}^{-1} \mathrm{bs}\right)\end{array}$ & $\begin{array}{c}\mathrm{Na} \\
\left(\mathrm{g} \cdot \mathrm{kg}^{-1} \mathrm{bs}\right)\end{array}$ & $\begin{array}{c}P \\
\left(g \cdot \mathrm{kg}^{-1}\right. \\
\mathrm{bs})\end{array}$ & $\begin{array}{c}\mathrm{Si} \\
\left(\mathrm{g} \cdot \mathrm{kg}^{-1} \mathrm{bs}\right)\end{array}$ & $\begin{array}{c}\mathrm{Zn} \\
\left(\mathrm{g} \cdot \mathrm{kg}^{-1} \mathrm{bs}\right)\end{array}$ \\
\hline \multirow[t]{7}{*}{ TWA } & 2012 & 0,09 & 2,3 & 0,033 & 14,3 & 0,78 & 0,069 & 0,35 & 1,1 & 4,3 & 0,012 \\
\hline & 2013 & 0,03 & 2,2 & 0,025 & 13,8 & 0,70 & 0,073 & 0,12 & 1,2 & 4,6 & 0,013 \\
\hline & 2014 & 0,05 & 2,1 & 0,004 & 11,2 & 0,55 & 0,079 & 0,06 & 1,0 & 6,8 & 0,013 \\
\hline & 2015 & 0,22 & 1,9 & 0,098 & 8,6 & 0,61 & 0,071 & 0,08 & 0,9 & 5,8 & 0,008 \\
\hline & 2016 & 0,06 & 2,3 & 0,029 & 10,8 & 0,68 & 0,067 & 0,07 & 1,0 & 6,9 & 0,008 \\
\hline & 2017 & 0,20 & 3,1 & 0,062 & 11,0 & 0,85 & 0,106 & 0,12 & 0,9 & 7,3 & 0,011 \\
\hline & 2018 & 0,04 & 1,6 & 0,011 & 11,4 & 0,56 & 0,052 & 0,22 & 1,2 & 4,9 & 0,011 \\
\hline \multicolumn{2}{|c|}{ media \pm SD } & $0,10 \pm 0,08$ & $2,2 \pm 0,4$ & $0,037 \pm 0,032$ & $1,1,6 \pm 1,9^{a}$ & $0,68 \pm 0,11^{a}$ & $0,074 \pm 0,016$ & $0,15 \pm 0,10^{a}$ & $1,0 \pm 0,1$ & $5,8 \pm 1,2^{a}$ & $0,011 \pm 0,002^{a}$ \\
\hline \multirow[t]{5}{*}{ TWJ } & 2012 & 0,14 & 2,5 & 0,049 & 15,5 & 0,73 & 0,095 & 0,21 & 1,3 & 4,3 & 0,013 \\
\hline & 2013 & 0,01 & 1,6 & 0,008 & 14,5 & 0,58 & 0,033 & 0,14 & 1,4 & 4,3 & 0,011 \\
\hline & 2014 & 0,04 & 1,6 & 0,019 & 10,5 & 0,45 & 0,085 & 0,05 & 1,0 & 4,0 & 0,012 \\
\hline & 2015 & 0,14 & 2,1 & 0,083 & 8,4 & 0,61 & 0,093 & 0,10 & 0,8 & 5,7 & 0,010 \\
\hline & 2016 & 0,08 & 2,6 & 0,044 & 12,1 & 0,70 & 0,093 & 0,07 & 1,0 & 5,6 & 0,011 \\
\hline
\end{tabular}




\begin{tabular}{|c|c|c|c|c|c|c|c|c|c|c|c|}
\hline & 2017 & 0,30 & 3,6 & 0,066 & 11,8 & 0,92 & 0,105 & 0,09 & 1,0 & 6,8 & 0,012 \\
\hline & 2018 & 0,05 & 1,4 & 0,022 & 13,2 & 0,55 & 0,089 & 0,02 & 1,3 & 4,6 & 0,017 \\
\hline medi & \pm SD & $0,11 \pm 0,10$ & $2,2 \pm 0,8$ & $0,042 \pm 0,027$ & $12,3 \pm 2,4^{a}$ & $0,65 \pm 0,15^{a, b}$ & $0,085 \pm 0,024$ & $0,10 \pm 0,06^{a}$ & $1,1 \pm 0,2$ & $5,1 \pm 1,0^{a, b}$ & $0,012 \pm 0,002^{a}$ \\
\hline TWR & 2012 & 0,09 & 2,5 & 0,033 & 14,4 & 0,77 & 0,076 & 0,34 & 1,1 & 4,3 & 0,012 \\
\hline & 2013 & 0,05 & 1,9 & 0,019 & 14,0 & 0,62 & 0,060 & 0,14 & 1,2 & 4,4 & 0,014 \\
\hline & 2014 & 0,03 & 1,9 & 0,007 & 11,1 & 0,52 & 0,070 & 0,05 & 1,0 & 4,7 & 0,013 \\
\hline & 2015 & 0,14 & 2,2 & 0,071 & 8,7 & 0,67 & 0,066 & 0,16 & 0,9 & 5,3 & 0,008 \\
\hline & 2016 & 0,04 & 2,2 & 0,020 & 12,9 & 0,66 & 0,079 & 0,07 & 1,0 & 6,0 & 0,011 \\
\hline & 2017 & 0,27 & 3,2 & 0,055 & 11,7 & 0,90 & 0,090 & 0,13 & 1,0 & 6,5 & 0,011 \\
\hline & 2018 & 0,06 & 1,6 & 0,034 & 11,1 & 0,56 & 0,111 & 0,12 & 1,1 & 4,3 & 0,0013 \\
\hline medi & \pm SD & $0,10 \pm 0,08$ & $2,2 \pm 0,05$ & $0,034 \pm 0,022$ & $12,0 \pm 2,0^{a}$ & $0,67 \pm 0,13^{a}$ & $0,079 \pm 0,017$ & $0,15 \pm 0,10^{a}$ & $1,0 \pm 0,1$ & $5,1 \pm 0,9^{a, b}$ & $0,012 \pm 0,002^{a}$ \\
\hline CWH & 2012 & 0,08 & 1,8 & 0,033 & 13,1 & 0,47 & 0,049 & 0,01 & 1,0 & 2,6 & 0,013 \\
\hline & 2013 & 0,02 & 1,9 & 0,018 & 13,2 & 0,50 & 0,063 & 0,04 & 1,0 & 3,4 & 0,018 \\
\hline & 2014 & 0,02 & 2,8 & 0,010 & 08,7 & 0,52 & 0,111 & 0,01 & 0,8 & 4,6 & 0,017 \\
\hline & 2015 & 0,13 & 2,3 & 0,061 & 07,3 & 0,52 & 0,064 & 0,03 & 0,8 & 4,8 & 0,010 \\
\hline & 2016 & 0,05 & 2,2 & 0,032 & 07,5 & 0,52 & 0,080 & $<0,01$ & 0,7 & 3,0 & 0,010 \\
\hline & 2017 & 0,24 & 4,1 & 0,054 & 08,9 & 0,92 & 0,213 & 0,01 & 0,8 & 5,8 & 0,022 \\
\hline & 2018 & 0,05 & 2,1 & 0,015 & 08,4 & 0,53 & 0,080 & $<0,01$ & 1,0 & 3,8 & 0,014 \\
\hline medi & \pm SD & $0,09 \pm 0,08$ & $2,5 \pm 0,8$ & $0,032 \pm 0,019$ & $9,6 \pm 2,5^{b}$ & $0,57 \pm 0,16^{b, c}$ & $0,094 \pm 0,056$ & $0,02 \pm 0,01^{b}$ & $0,9 \pm 0,1$ & $4,0 \pm 1,1^{b}$ & $0,015 \pm 0,004^{b}$ \\
\hline SWV & 2012 & 0,15 & 1,7 & 0,051 & 13,3 & 0,48 & 0,048 & 0,02 & 1,2 & 2,9 & 0,013 \\
\hline & 2013 & 0,02 & 1,8 & 0,018 & 11,1 & 0,43 & 0,043 & 0,02 & 1,1 & 3,3 & 0,011 \\
\hline & 2014 & 0,05 & 4,3 & 0,026 & 9,8 & 0,70 & 0,147 & 0,03 & 1,1 & 5,9 & 0,039 \\
\hline & 2015 & 0,16 & 2,5 & 0,010 & 7,4 & 0,56 & 0,107 & 0,04 & 1,0 & 4,2 & 0,012 \\
\hline & 2016 & 0,08 & 3,1 & 0,043 & 9,8 & 0,57 & 0,128 & 0,01 & 0,7 & 3,5 & 0,012 \\
\hline & 2017 & 0,22 & 3,7 & 0,064 & 8,4 & 0,70 & 0,191 & 0,01 & 0,8 & 6,3 & 0,016 \\
\hline & 2018 & 0,05 & 1,9 & 0,011 & 8,6 & 0,42 & 0,080 & $<0,01$ & 0,9 & 3,1 & 0,014 \\
\hline medi & \pm SD & $0,10 \pm 0,07$ & $2,7 \pm 1,0$ & $0,045 \pm 0,026$ & $9,8 \pm 2,0^{b}$ & $0,55 \pm 0,12^{c}$ & $0,106 \pm 0,054$ & $0,02 \pm 0,01^{b}$ & $1,0 \pm 0,2$ & $4,2 \pm 1,4^{\mathrm{b}}$ & $0,017 \pm 0,010^{b}$ \\
\hline Media & $\begin{array}{l}\text { lobalı } \\
\text { D }\end{array}$ & $0,11 \pm 0,08$ & $2,4 \pm 0,8$ & $0,038 \pm 0,024$ & $11,2 \pm 2,6$ & $0,64 \pm 0,17$ & $0,090 \pm 0,05$ & $0,09 \pm 0,13$ & $1,0 \pm 0,2$ & $4,8 \pm 1,7$ & $0,013 \pm 0,005$ \\
\hline Min. & valor & 0,01 & 1,1 & $<0,001$ & 6,9 & 0,39 & 0,030 & $<0,01$ & 0,5 & 1,8 & 0,007 \\
\hline Max. & valor & 0,42 & 4,4 & 0,100 & 18,4 & 1,02 & 0,280 & 0,62 & 1,6 & 9,3 & 0,039 \\
\hline $\mathbf{P}$ & & 0,14 & 2,8 & 0,053 & 13,2 & 0,78 & 0,100 & 0,12 & 1,2 & 5,9 & 0,014 \\
\hline
\end{tabular}

Letras diferentes indican medias con diferencias significativas entre especie/cultivar con el $95 \%$ de nivel de confianza de acuerdo con el test de

múltiples rangos. Las letras han sido incluidas cuando el valor-p para el factor cultivar era menor de 0,05. 
Los cultivares de agropiro alargado mostraron contenidos de ceniza significativamente más altos, con valores medios entre 42 y $44 \mathrm{~g} \cdot \mathrm{kg}^{-1} \mathrm{bs}$, dependiendo del cultivar, que el agropiro crestado $\left(36 \mathrm{~g} \cdot \mathrm{kg}^{-1} \mathrm{bs}\right)$ y el siberiano $\left(37 \mathrm{~g} \cdot \mathrm{kg}^{-1} \mathrm{bs}\right)$ (Tabla 18). En consecuencia, los poderes caloríficos del TWA y el TWJ fueron ligeramente inferiores a los mostrados por el resto de los cultivares de agropiro considerados, con $\mathrm{PCl}$ medios de 17,6 MJ.kg-1 bs (TWA y TWJ), frente a 17,7-17,8 MJ. $\mathrm{kg}^{-1}$ bs (TWR, CWH y SWV). Con respecto a los elementos principales (Tabla 19), los cultivares de agropiro alargado mostraron contenidos más altos en $\mathrm{K}$ y $\mathrm{Na}$ (y en general en $\mathrm{Mg}$ y $\mathrm{Si}$ ) y concentraciones más bajas en Zn que las otras especies (CWH y SWV). Los cultivares de TW promediaron $12 \mathrm{~g} \cdot \mathrm{kg}^{-1}$ bs de $\mathrm{K}, 0,67 \mathrm{~g} \cdot \mathrm{kg}^{-1}$ bs de $\mathrm{Mg}, 5,3 \mathrm{~g} \cdot \mathrm{kg}^{-1}$ bs en Si, 0,13 $\mathrm{g} \cdot \mathrm{kg}^{-1}$ bs en $\mathrm{Na}$, y $0.012 \mathrm{~g} \cdot \mathrm{kg}^{-1}$ bs en $\mathrm{Zn}$, frente a CWH y SWV con valores medios de $9,7 \mathrm{~g} \cdot \mathrm{kg}^{-1}$ bs para $\mathrm{K}, 0,56 \mathrm{~g} \cdot \mathrm{kg}^{-1}$ bs en $\mathrm{Mg}, 4,1 \mathrm{~g} \cdot \mathrm{kg}^{-1}$ bs en Si, 0,02 $\mathrm{g} \cdot \mathrm{kg}^{-1}$ bs en Na, y $0,016 \mathrm{~g} \cdot \mathrm{kg}^{-1}$ bs en $\mathrm{Zn}$.

Los tres cultivares de agropiro alargado que se sembraron en los campos de ensayo de CS sólo difieren en sus poderes caloríficos (Tabla 18), teniendo un $\mathrm{PCl}$ de 17,7 MJ $\cdot \mathrm{kg}^{-1}$ bs el TWR y 17,6 MJ $\mathrm{kg}^{-1}$ para los cultivares TWA y TWJ, en conexión con el contenido medio de cenizas que es ligeramente inferior en la biomasa del primero (no significativo).

Las propiedades y la composición de la biomasa mostraron diferencias significativas a lo largo de los años para ambos campos experimentales (Tabla 17). En las parcelas de CS, se encontraron variaciones anuales significativas (2012-2018) para todas las propiedades (Tabla 17). La figura 12 muestra cómo el contenido de cenizas, el $\mathrm{PCl}$ y las concentraciones de $\mathrm{N}, \mathrm{S}, \mathrm{Cl}, \mathrm{K}$ y $\mathrm{P}$ variaron a través de las especies y los años (gráficos de interacción). En general, los contenidos medios de cenizas, $\mathrm{S}, \mathrm{K}, \mathrm{Na}$, y $\mathrm{Cl}$ tendieron a disminuir con el tiempo. Se encontraron reducciones medias del $22 \%$ de ceniza, $60 \%$ de S, $27 \%$ de $\mathrm{K}, 48 \%$ de $\mathrm{Na}$, y $35 \%$ de $\mathrm{Cl}$ en la biomasa recolectada en 2018 con respecto a la recolectada en 2012, el siguiente período vegetativo después de la siembra. El contenido de cenizas de los cultivares de TW disminuyó de un contenido medio de $49 \mathrm{~g} \cdot \mathrm{kg}^{-1}$ bs en 2012 a $39 \mathrm{~g} \cdot \mathrm{kg}^{-1}$ bs en 2018 (una reducción del 21\%, Tabla 20). El contenido de cenizas de CW y de SW también disminuyó con el tiempo, de 39 $\mathrm{g} \cdot \mathrm{kg}^{-1}$ bs en 2012 a $30 \mathrm{~g} \cdot \mathrm{kg}^{-1}$ bs en 2018, una reducción del 24\%. Los contenidos de $\mathrm{N}$, $\mathrm{S}$ y $\mathrm{Cl}$ en los cultivares de TW disminuyeron de $14 \mathrm{~g} \cdot \mathrm{kg}^{-1} \mathrm{bs}, 1,6 \mathrm{~g} \cdot \mathrm{kg}^{-1} \mathrm{bs}$ y $1,8 \mathrm{~g} \cdot \mathrm{kg}^{-1} \mathrm{bs}$ en 2012, respectivamente, a $8,0 \mathrm{~g} \cdot \mathrm{kg}^{-1} \mathrm{bs}, 0,6 \mathrm{~g} \cdot \mathrm{kg}^{-1} \mathrm{bs}$, y $1,3 \mathrm{~g} \cdot \mathrm{kg}^{-1}$ bs en 2018 . Las especies CW y SW mostraron la misma tendencia, $13 \mathrm{~g} \cdot \mathrm{kg}^{-1} \mathrm{bs} \mathrm{N}, 1,1 \mathrm{~g} \cdot \mathrm{kg}^{-1} \mathrm{bs} \mathrm{S}$, y 1,8 $\mathrm{g} \cdot \mathrm{kg}^{-1}$ bs Cl en 2012 y $8,7 \mathrm{~g} \cdot \mathrm{kg}^{-1}$ bs $\mathrm{N}, 0,5 \mathrm{~g} \cdot \mathrm{kg}^{-1}$ bs S, y $0,9 \mathrm{~g} \cdot \mathrm{kg}^{-1}$ bs Cl en 2018 , el último año del estudio. 
Los valores del PCl oscilaron entre 16,9 y $18,5 \mathrm{MJ} \cdot \mathrm{kg}^{-1}$, y el promedio fue de 17,7 $\mathrm{MJ} \cdot \mathrm{kg}^{-1}$ bs entre especies y años (Tabla 18). Cuando se tiene en cuenta un cultivar o una especie en particular, las desviaciones estándar a través de los años para los poderes caloríficos medios se mantuvieron en el rango de 0,3-0,4 $\mathrm{MJ} \cdot \mathrm{kg}^{-1}$. Los contenidos de $\mathrm{N}$ y Cl promediaron $12 \mathrm{~g} \cdot \mathrm{kg}^{-1}$ bs y $1,6 \mathrm{~g} \cdot \mathrm{kg}^{-1}$ bs entre especies y años, pero variaron en gran medida a lo largo de los años. El $\mathrm{N}$ varió de 6,2 a $19 \mathrm{~g} \cdot \mathrm{kg}^{-1} \mathrm{bs}$ y el $\mathrm{Cl}$ varió entre 0,8 y $4,6 \mathrm{~g} \cdot \mathrm{kg}^{-1} \mathrm{bs}$, dependiendo de las especies y los años considerados.

Con respecto a los principales elementos formadores de cenizas (Tabla 19), la biomasa recogida en 2012 mostró contenidos de K, Na, Al y Fe superiores a los de la biomasa analizada en 2018. En este período de tiempo, el $\mathrm{K}$ disminuyó de $15 \mathrm{~g} \cdot \mathrm{kg}^{-1} \mathrm{bs}$ a $12 \mathrm{~g} \cdot \mathrm{kg}^{-1}$ bs en los cultivares TW (19\%), y de $13 \mathrm{~g} \cdot \mathrm{kg}^{-1}$ bs a $8,5 \mathrm{~g} \cdot \mathrm{kg}^{-1}$ bs en las especies CW y SW (36\%). Las concentraciones de Na también disminuyeron de 0,30 $\mathrm{g} \cdot \mathrm{kg}^{-1}$ bs en 2012 a $0,12 \mathrm{~g} \mathrm{~g} \cdot \mathrm{kg}^{-1}$ bs en 2018 en los cultivares de TW (59\%). Como se mencionó anteriormente, CW y SW mostraron contenidos en $\mathrm{Na}$ inferiores a los de TW, con un promedio de $0,016 \mathrm{~g} \cdot \mathrm{kg}^{-1}$ bs en 2012 , y fueron inferiores a $0,010 \mathrm{~g} \cdot \mathrm{kg}^{-1} \mathrm{bs}$ en 2018. 
Cenizas $\left(\mathrm{g} \cdot \mathrm{kg}^{-1} \mathrm{bs}\right)$

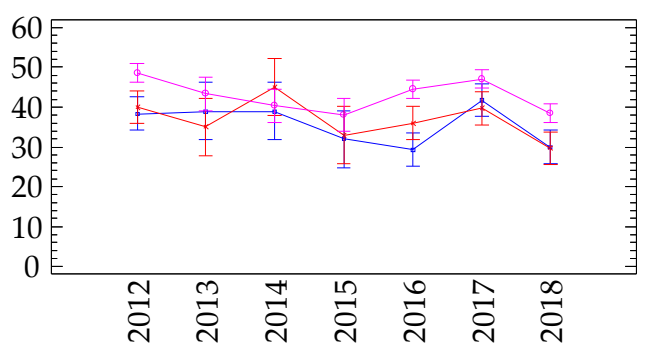

$\mathrm{N}\left(\mathrm{g} \cdot \mathrm{kg}^{-1} \mathrm{bs}\right)$

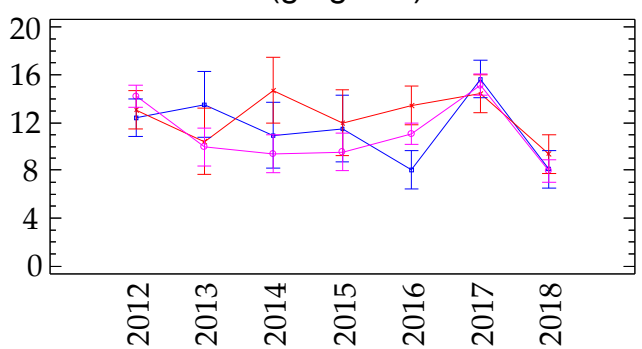

$\mathrm{Cl}\left(\mathrm{g} \cdot \mathrm{kg}^{-1} \mathrm{bs}\right)$

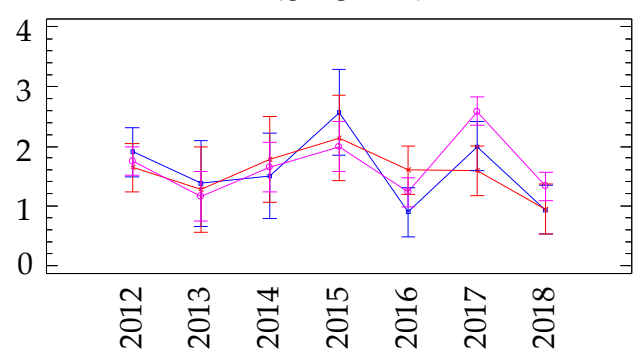

$\mathrm{P}\left(\mathrm{g} \cdot \mathrm{kg}^{-1} \mathrm{bs}\right)$

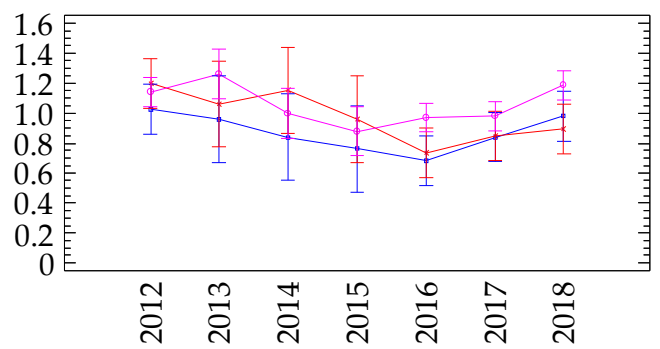

$\mathrm{PCl}\left(\mathrm{MJ} \cdot \mathrm{kg}^{-1} \mathrm{bs}\right)$

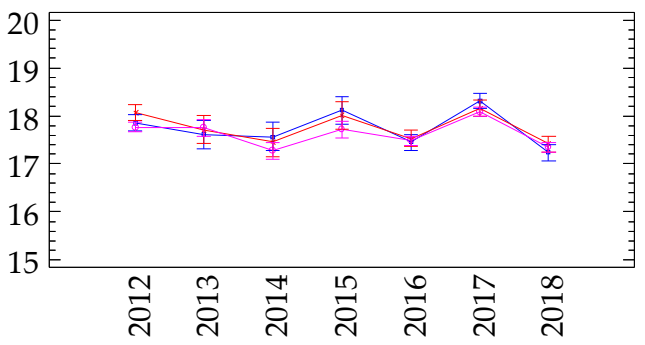

$\mathrm{S}\left(\mathrm{g} \cdot \mathrm{kg}^{-1} \mathrm{bs}\right)$

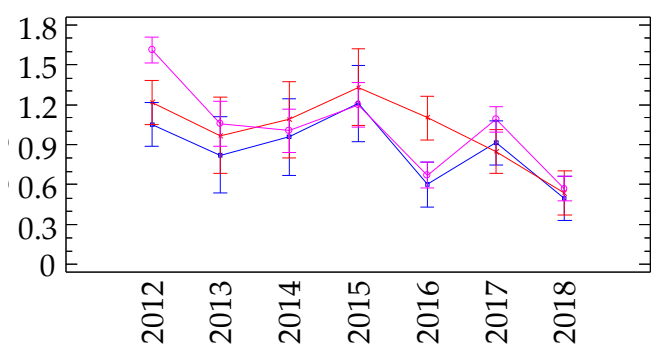

$\mathrm{K}\left(\mathrm{g} \cdot \mathrm{kg}^{-1} \mathrm{bs}\right)$

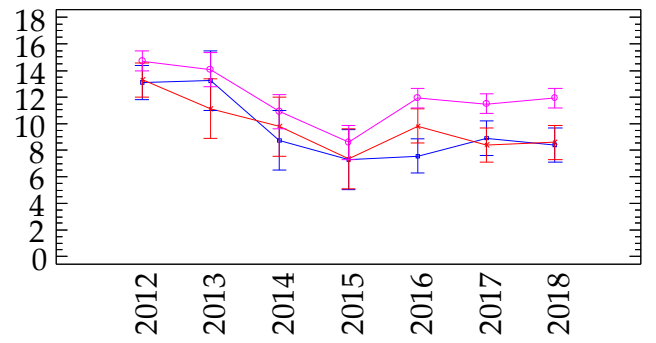

Agropiro alargado

Agropiro crestado

Agropiro Siberiano

Figura 12. $\mathrm{PCl}$, contenido en cenizas, $\mathrm{N}, \mathrm{P}, \mathrm{K}, \mathrm{S}, \mathrm{y} \mathrm{Cl}$ de las especies y años de la biomasa cultivada en CS. Medias y gráficas de interacción LSD de Fisher.

Las concentraciones de $\mathrm{K}_{2} \mathrm{O}, \mathrm{SiO}_{2}, \mathrm{CaO}$ y $\mathrm{MgO}$ en las cenizas de la biomasa de las parcelas experimentales de CS se muestran en la Figura 13. A partir de 2013, el contenido de $\mathrm{K}_{2} \mathrm{O}$ disminuyó con el tiempo, mientras que las concentraciones de $\mathrm{SiO}_{2}$, $\mathrm{CaO}$ y $\mathrm{MgO}$ tendieron a aumentar a medida que el cultivo envejece. Esta tendencia se observó en todas las especies, salvo en el caso del contenido de $\mathrm{CaO}$ de los cultivares de agropiro alargado, que se mantuvo prácticamente constante durante el período 20122016, aumentó en 2017 (el año más seco) y disminuyó en 2018. En las especies CW y SW las concentraciones de $\mathrm{CaO}$ llegaron a un promedio de $65 \mathrm{~g} \cdot \mathrm{kg}^{-1} \mathrm{bs}$ en 2012 y 2013 
y casi se duplicaron hasta $110 \mathrm{~g} \cdot \mathrm{kg}^{-1}$ bs de 2014 a 2018. Se encontró una disminución media de $\mathrm{K}_{2} \mathrm{O}$ del $21 \%$ (de $390 \mathrm{~g} \cdot \mathrm{kg}^{-1}$ bs a $310 \mathrm{~g} \cdot \mathrm{kg}^{-1} \mathrm{bs}$ ) y un aumento medio del $14 \%$ de $\mathrm{MgO}$ (de $23 \mathrm{~g} \cdot \mathrm{kg}^{-1}$ bs a $27 \mathrm{~g} \cdot \mathrm{kg}^{-1} \mathrm{bs}$ ) y del $39 \%$ de $\mathrm{SiO}_{2}$ (de $200 \mathrm{~g} \cdot \mathrm{kg}^{-1}$ bs a $280 \mathrm{~g} \cdot \mathrm{kg}^{-}$ ${ }^{1}$ bs) en las cenizas de la biomasa a partir de 2012-2013 con respecto al resto del período estudiado (2014-2018). El $\mathrm{Na}_{2} \mathrm{O}$ y el $\mathrm{P}_{2} \mathrm{O}_{5}$ disminuyeron en $50 \%$ y un $9 \%$, respectivamente, mientras que el $\mathrm{ZnO}$ aumentó un $12 \%$.
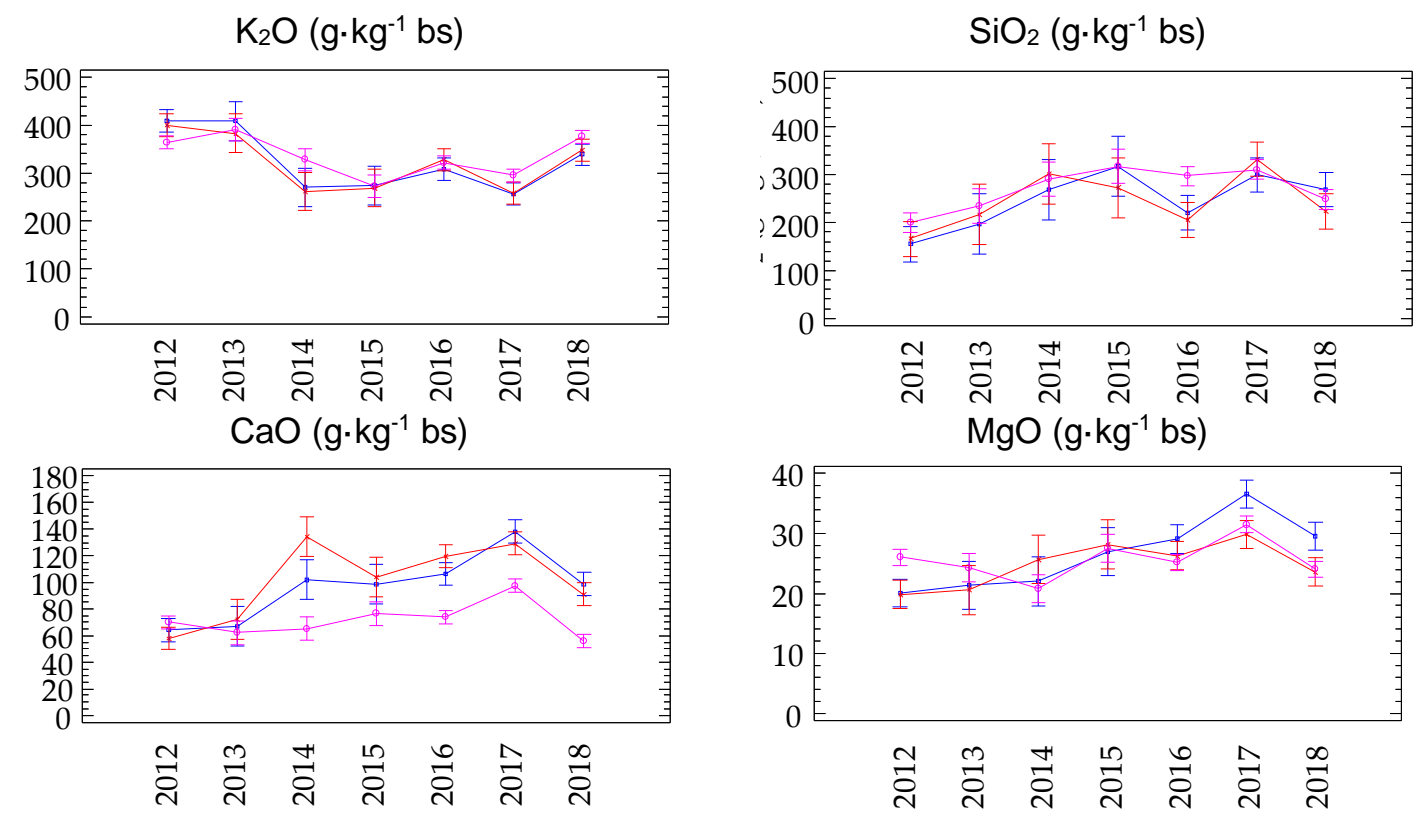

- Agropiro alargado
$-\quad$ Agropiro crestado
$-\quad$ Agropiro Siberiano

Figura 13. Variación de $\mathrm{Si}, \mathrm{K}, \mathrm{Ca}$, y $\mathrm{Mg}$ de especies y años de las parcelas experimentales de CS (concentración y sus correspondientes óxidos en las cenizas). Medias y gráficas de interacción LSD de Fisher.

A pesar de que las variaciones para la mayoría de las propiedades fueron pequeñas, los tres cultivares de agropiro alargado ensayados en las parcelas de $\mathrm{AL}$ (TWA, TWB y TWS) difirieron significativamente en su poder calorífico contenido de ceniza, C, H, N, S, Cl, K, Si y Zn (Tabla 17). No se encontraron diferencias significativas entre los cultivares en cuanto a sus contenidos de Al, Ca, Fe, Mg, Mn, Na y P.

El PCl promedió $17,4 \mathrm{MJ} \cdot \mathrm{kg}^{-1}$ bs en todas los cultivares y años, osciló entre 16,7 y $18,1 \mathrm{MJ} \cdot \mathrm{kg}^{-1}$ bs (Tabla 18). El cultivar TWA mostró valores de poder calorífico ligeramente más altos $\left(17,6 \mathrm{MJ} \cdot \mathrm{kg}^{-1} \mathrm{bs}\right)$ que el TWB y el TWS $\left(17,3 \mathrm{MJ} \cdot \mathrm{kg}^{-1} \mathrm{bs}\right)$, en concordancia con su menor contenido de cenizas $(3,6 \%)$ y su mayor contenido de $\mathrm{C}$ (47,3\%). El cultivar TWB presentó contenidos de cenizas ligeramente más altos $\left(46 \mathrm{~g} \cdot \mathrm{kg}^{-}\right.$ $\left.{ }^{1} \mathrm{bs}\right), \mathrm{K}\left(10 \mathrm{~g} \cdot \mathrm{kg}^{-1} \mathrm{bs}\right)$, Si $\left(7,8 \mathrm{~g} \cdot \mathrm{kg}^{-1} \mathrm{bs}\right)$ y Zn $\left(0,010 \mathrm{~g} \cdot \mathrm{kg}^{-1} \mathrm{bs}\right)$ que el resto de los cultivares, que promediaron $37 \mathrm{~g} \cdot \mathrm{kg}^{-1}$ bs en cenizas, $8,9 \mathrm{~g} \cdot \mathrm{kg}^{-1} \mathrm{bs} \mathrm{K}, 4,9 \mathrm{~g} \mathrm{~g} \cdot \mathrm{kg}^{-1}$ bs Si y 
0,008 $\mathrm{g} \cdot \mathrm{kg}^{-1}$ bs Zn (Tabla 19). El TWA mostró el contenido más bajo de $\mathrm{Cl}$ (con un promedio de 2,0 $\mathrm{g} \cdot \mathrm{kg}^{-1}$ bs a lo largo de los años), mientras que el TWS mostró el contenido más bajo de $\mathrm{N}\left(6,6 \mathrm{~g} \cdot \mathrm{kg}^{-1} \mathrm{bs}\right)$ y $\mathrm{S}\left(0,9 \mathrm{~g} \cdot \mathrm{kg}^{-1} \mathrm{bs}\right)$ (Tabla 20$)$.

Se encontraron variaciones anuales significativas para todas las propiedades durante el período de estudio (2014-2018), excepto para los contenidos de $\mathrm{H}, \mathrm{Fe}, \mathrm{Mg}$, $\mathrm{Na}$ y Si (Tabla 17). De manera similar, los contenidos de ceniza, S y K de la biomasa cultivada en las parcelas de CS tendieron a disminuir con el tiempo (Figura 14). Los contenidos medios de otros elementos, como N, Ca, P y Mn, también disminuyeron a lo largo de los años (Tablas 20 y 21), encontrándose diferencias significativas particularmente entre la biomasa recogida el primer año después del establecimiento (2014) con respecto a la recolectada en los años siguientes (2015-2018). El contenido de cenizas se mantuvo siempre por debajo de $63 \mathrm{~g} \cdot \mathrm{kg}^{-1} \mathrm{bs}$, y alcanzó un promedio de $48 \mathrm{~g} \cdot \mathrm{kg}^{-1}$ bs en 2014 , variando el contenido medio entre $43 \mathrm{~g} \cdot \mathrm{kg}^{-1}$ bs y $58 \mathrm{~g} \cdot \mathrm{kg}^{-1}$ bs según el cultivar, y $38 \mathrm{~g} \cdot \mathrm{kg}^{-1}$ bs entre 2015 y $2018\left(29-47 \mathrm{~g} \cdot \mathrm{kg}^{-1} \mathrm{bs}\right) . \mathrm{K}$, N y S promediaron 12 $\mathrm{g} \cdot \mathrm{kg}^{-1} \mathrm{bs}, 9,6 \mathrm{~g} \cdot \mathrm{kg}^{-1}$ bs y $1,2 \mathrm{~g} \cdot \mathrm{kg}^{-1}$ bs en 2014 , disminuyendo en los años siguientes a contenidos medios de $8,4 \mathrm{~g} \cdot \mathrm{kg}^{-1} \mathrm{bs}, 7,3 \mathrm{~g} \cdot \mathrm{kg}^{-1}$ bs y $0,9 \mathrm{~g} \cdot \mathrm{kg}^{-1} \mathrm{bs}$, respectivamente. Sin embargo, aunque se encontraron diferencias significativas a lo largo de los años, no se encontró una tendencia clara para otros elementos como el $\mathrm{Cl}$ y el $\mathrm{Al}$. 

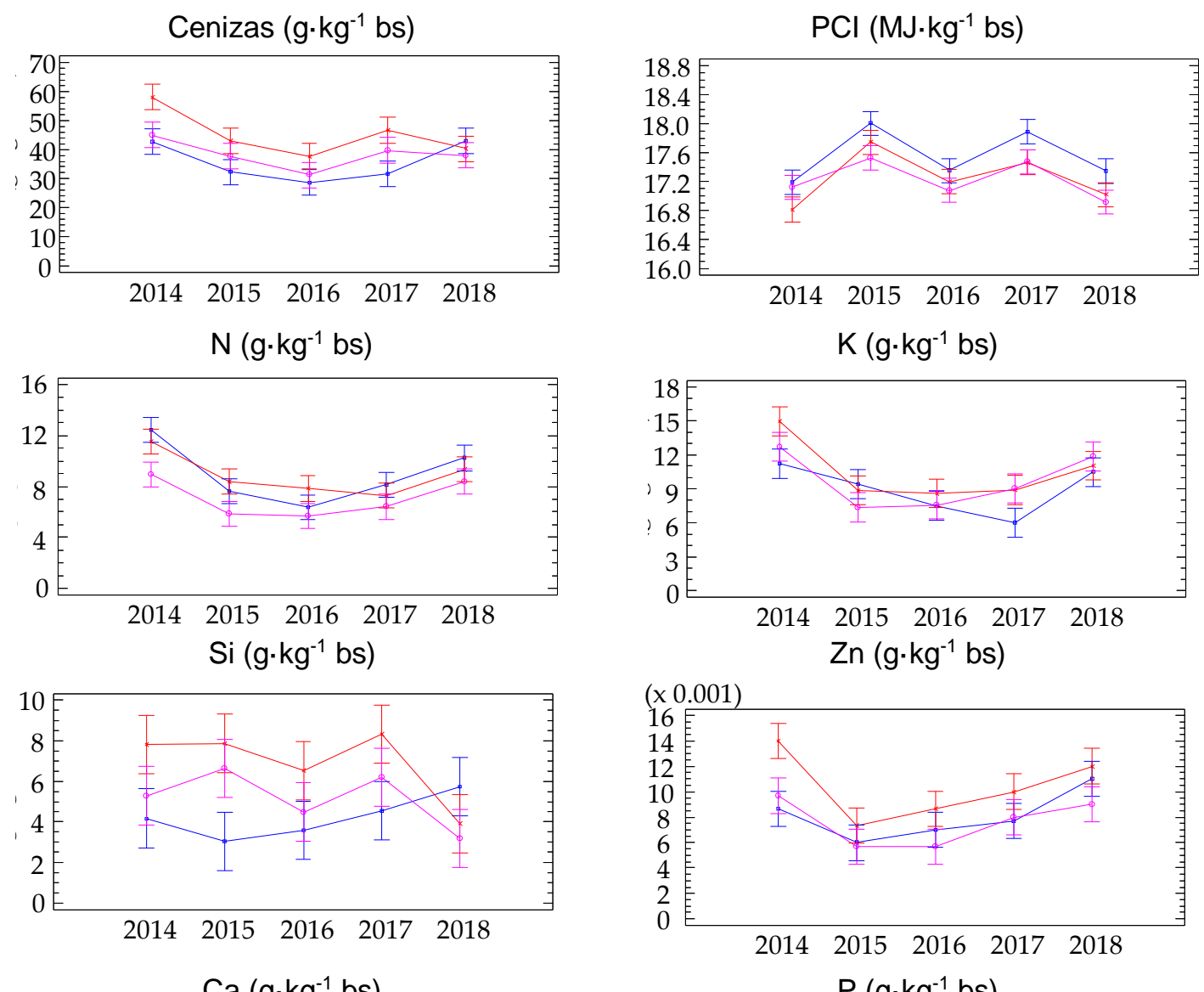

$\mathrm{Ca}\left(\mathrm{g} \cdot \mathrm{kg}^{-1} \mathrm{bs}\right)$
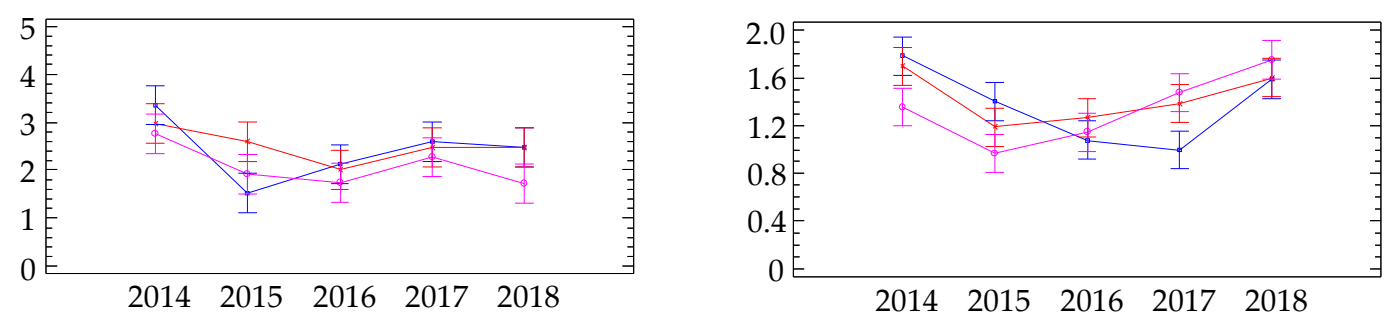

- Agropiro alargado
$-\quad$ Agropiro crestado
$-\quad$ Agropiro Siberiano

Figura 14. $\mathrm{PCl}$, contenido en cenizas, $\mathrm{N}, \mathrm{P}, \mathrm{K}, \mathrm{Ca}, \mathrm{Si}$, y $\mathrm{Zn}$ de cultivares y años para la biomasa producida en los campos experimentales de AL. Medias y gráficas de interacción LSD de Fisher.

Los niveles de concentración de $\mathrm{Na}$ y $\mathrm{Cl}$ de los cultivares de agropiro alargado sembradas en los ensayos de AL (Tablas 20 y 21) fueron superiores a los de la biomasa cultivada en CS (Tablas 18 y 19). EI TWA, el único cultivar sembrado en ambos sitios, promedió $1,5 \mathrm{~g} \cdot \mathrm{kg}^{-1}$ bs de $\mathrm{Cl}$ y $0,15 \mathrm{~g} \cdot \mathrm{kg}^{-1}$ bs de $\mathrm{Na}$ a lo largo de los años (2012-2018) en las parcelas de CS. Cuando el mismo cultivar se sembró en las parcelas experimentales de AL (2014-2018) mostró $2,0 \mathrm{~g} \cdot \mathrm{kg}^{-1}$ bs y $0,31 \mathrm{~g} \cdot \mathrm{kg}^{-1}$ bs $\mathrm{Cl}$ y $\mathrm{Na}$, respectivamente. A su vez, los poderes caloríficos, N, K, Mn y Zn fueron más altos en CS que en $A L$. El resto de las propiedades fueron muy similares entre ambas 
ubicaciones. Sin embargo, como los periodos de estudio son diferentes para CS y AL, es difícil separar el efecto de las condiciones meteorológicas y la edad de los cultivos cuando se compara la composición química entre ambos lugares. 
Tabla 20. Contenido de cenizas, poderes caloríficos y análisis inmediato de los cultivares de agropiro alargado recolectados en las parcelas de AL de 2014 a 2018. Valores medios para cuatro repeticiones por cultivar y año.

\begin{tabular}{|c|c|c|c|c|c|c|c|c|c|}
\hline C & $\mathbf{Y}$ & $\begin{array}{c}\text { Cenizas } \\
\left(\mathrm{g} \cdot \mathrm{kg}^{-1} \mathrm{bs}\right)\end{array}$ & $\begin{array}{c}\mathrm{C} \\
\left(\mathrm{g} \cdot \mathrm{kg}^{-1} \mathrm{bs}\right)\end{array}$ & $\begin{array}{c}\mathbf{H} \\
\left(\mathbf{g} \cdot \mathbf{k g}^{-1} \mathbf{b s}\right)\end{array}$ & $\begin{array}{c}\mathrm{N} \\
\left(\mathrm{g} \cdot \mathrm{kg}^{-1} \mathrm{bs}\right)\end{array}$ & $\begin{array}{c}\mathrm{S} \\
\left(\mathbf{g} \cdot \mathbf{k g}^{-1} \mathbf{b s}\right)\end{array}$ & $\begin{array}{c}\mathrm{Cl} \\
\left(\mathrm{g} \cdot \mathrm{kg}^{-1} \mathrm{bs}\right)\end{array}$ & 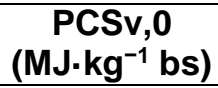 & 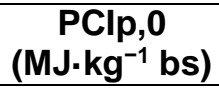 \\
\hline \multirow[t]{5}{*}{ TWA } & 2014 & 43 & 460 & 62 & 12,4 & 1,4 & 2,4 & 18,5 & 17,2 \\
\hline & 2015 & 32 & 478 & 61 & 7,6 & 1,3 & 1,8 & 19,3 & 18,0 \\
\hline & 2016 & 29 & 468 & 61 & 6,4 & 0,7 & 1,4 & 18,7 & 17,4 \\
\hline & 2017 & 32 & 481 & 61 & 8,1 & 1,2 & 1,8 & 19,2 & 17,9 \\
\hline & 2018 & 43 & 480 & 60 & 10,2 & 1,1 & 2,5 & 18,7 & 17,3 \\
\hline \multicolumn{2}{|c|}{ media \pm SD } & $36 \pm 7^{b}$ & $473 \pm 9^{a}$ & $61,1 \pm 0,7^{a}$ & $9,0 \pm 2,4^{a}$ & $1,1 \pm 0,3^{a}$ & $2,0 \pm 0,5^{b}$ & $18,9 \pm 0,4^{a}$ & $17,6 \pm 0,4^{a}$ \\
\hline \multirow[t]{5}{*}{ TWB } & 2014 & 58 & 452 & 60 & 11,5 & 1,4 & 3,4 & 18,1 & 16,8 \\
\hline & 2015 & 43 & 471 & 61 & 8,4 & 1,2 & 3,9 & 19,1 & 17,7 \\
\hline & 2016 & 38 & 460 & 61 & 7,8 & 0,6 & 2,7 & 18,5 & 17,2 \\
\hline & 2017 & 47 & 467 & 60 & 7,3 & 1,0 & 5,2 & 18,8 & 17,5 \\
\hline & 2018 & 46 & 464 & 60 & 8,3 & 1,0 & 3,9 & 18,7 & 17,4 \\
\hline \multicolumn{2}{|c|}{ media \pm SD } & $46 \pm 7^{a}$ & $463 \pm 7^{b}$ & $61 \pm 0,4^{b}$ & $8,7 \pm 1,6^{a}$ & $1,0 \pm 0,3^{a}$ & $3,8 \pm 0,9^{a}$ & $18,6 \pm 0,4^{b}$ & $17,3 \pm 0,4^{b}$ \\
\hline \multirow[t]{5}{*}{ TWS } & 2014 & 45 & 460 & 61 & 9,0 & 1,1 & 5,3 & 18,5 & 17,1 \\
\hline & 2015 & 38 & 468 & 61 & 5,8 & 0,9 & 3,7 & 18,9 & 17,5 \\
\hline & 2016 & 31 & 460 & 62 & 5,7 & 0,5 & 1,3 & 18,4 & 17,1 \\
\hline & 2017 & 40 & 470 & 61 & 6,4 & 1,0 & 3,6 & 18,8 & 17,5 \\
\hline & 2018 & 36 & 466 & 61 & 6,0 & 0,8 & 2,9 & 18,7 & 17,4 \\
\hline \multirow{2}{*}{\multicolumn{2}{|c|}{$\begin{array}{c}\text { media } \pm \text { SD } \\
\text { Media global } \pm \\
\text { SD }\end{array}$}} & $38 \pm 5^{b}$ & $464 \pm 5^{b}$ & $61 \pm 0,4^{a}$ & $6,6 \pm 1,4^{b}$ & $0,9 \pm 0,2^{b}$ & $3,3 \pm 1,4^{a}$ & $18,6 \pm 0,2^{b}$ & $17,3 \pm 0,2^{b}$ \\
\hline & & $40 \pm 8$ & $468 \pm 10$ & $61,0 \pm 0,7$ & $8,3 \pm 2,2$ & $0,10 \pm 0,03$ & $0,28 \pm 0,15$ & $18,7 \pm 0,4$ & $17,3 \pm 0,4$ \\
\hline \multirow{3}{*}{\multicolumn{2}{|c|}{$\begin{array}{l}\text { Min. valor } \\
\text { Max. valor } \\
\text { P75 }\end{array}$}} & 27 & 448 & 59,0 & 5,1 & 0,05 & 0,08 & 18,0 & 16,7 \\
\hline & & 63 & 487 & 62,0 & 14,4 & 0,16 & 0,71 & 19,4 & 18,1 \\
\hline & & 46 & 476 & 61,0 & 9,8 & 0,13 & 0,40 & 19,0 & 17,6 \\
\hline
\end{tabular}

Letras diferentes indican medias con diferencias significativas entre cultivar con el 95\% de nivel de confianza de acuerdo con el test de múltiples rangos. Las letras han sido incluidas cuando el valor-p para el factor cultivar era menor de 0,05. 
Tabla 21. Elementos mayoritarios presentes en la biomasa de los cultivares de agropiro alargado recolectados en las parcelas de $\mathrm{AL}$ de 2014 a 2018. Valores medios para cuatro repeticiones por cultivar y año.

\begin{tabular}{|c|c|c|c|c|c|c|c|c|c|c|c|}
\hline C & $\mathbf{Y}$ & $\begin{array}{c}\text { Al } \\
\left(g \cdot \mathrm{kg}^{-1} \mathrm{bs}\right)\end{array}$ & $\begin{array}{c}\mathrm{Ca} \\
\left(\mathrm{g} \cdot \mathrm{kg}^{-1} \mathrm{bs}\right)\end{array}$ & $\begin{array}{c}\mathrm{Fe} \\
\left(\mathrm{g} \cdot \mathrm{kg}^{-1} \mathrm{bs}\right)\end{array}$ & $\begin{array}{c}\mathrm{K} \\
\left(\mathrm{g} \cdot \mathrm{kg}^{-1} \mathrm{bs}\right)\end{array}$ & $\begin{array}{c}\mathrm{Mg} \\
\left(\mathrm{g} \cdot \mathrm{kg}^{-1} \mathrm{bs}\right)\end{array}$ & $\begin{array}{c}\text { Mn } \\
\left(g \cdot \mathrm{kg}^{-1} \mathrm{bs}\right)\end{array}$ & $\begin{array}{c}\mathrm{Na} \\
\left(\mathrm{g} \cdot \mathrm{kg}^{-1} \mathrm{bs}\right)\end{array}$ & $\begin{array}{c}P \\
\left(g \cdot \mathrm{kg}^{-1}\right. \\
\text { bs) }\end{array}$ & $\begin{array}{c}\text { Si } \\
\left(g \cdot \mathrm{kg}^{-1} \mathrm{bs}\right)\end{array}$ & $\begin{array}{c}\mathrm{Zn} \\
\left(\mathrm{g} \cdot \mathrm{kg}^{-1} \mathrm{bs}\right)\end{array}$ \\
\hline TWA & $\begin{array}{l}2014 \\
2015 \\
2016 \\
2017 \\
2018 \\
\end{array}$ & $\begin{array}{l}0,16 \\
0,05 \\
0,13 \\
0,11 \\
0,09\end{array}$ & $\begin{array}{l}3,4 \\
1,5 \\
2,1 \\
2,6 \\
2,5 \\
\end{array}$ & $\begin{array}{l}0,075 \\
0,021 \\
0,101 \\
0,041 \\
0,136\end{array}$ & $\begin{array}{c}11,2 \\
9,4 \\
7,5 \\
6,0 \\
10,5\end{array}$ & $\begin{array}{l}0,76 \\
0,50 \\
0,56 \\
0,66 \\
0,71\end{array}$ & $\begin{array}{l}0,031 \\
0,021 \\
0,028 \\
0,018 \\
0,024\end{array}$ & $\begin{array}{l}0,31 \\
0,15 \\
0,17 \\
0,49 \\
0,42\end{array}$ & $\begin{array}{l}1,8 \\
1,4 \\
1,1 \\
1,0 \\
1,6 \\
\end{array}$ & $\begin{array}{l}4,2 \\
3,0 \\
3,6 \\
4,6 \\
5,7 \\
\end{array}$ & $\begin{array}{l}0,009 \\
0,006 \\
0,007 \\
0,008 \\
0,011\end{array}$ \\
\hline \multicolumn{2}{|c|}{ media \pm SD } & $0,11 \pm 0,04$ & $2,4 \pm 0,7$ & $0,075 \pm 0,046$ & $8,9 \pm 2,2^{b}$ & $0,64 \pm 0,11$ & $0,024 \pm 0,005$ & $0,31 \pm 0,15$ & $1,4 \pm 0,3$ & $4,2 \pm 1,0^{b}$ & $0,008 \pm 0,002^{b}$ \\
\hline TWB & $\begin{array}{l}2014 \\
2015 \\
2016 \\
2017 \\
2018\end{array}$ & $\begin{array}{l}0,12 \\
0,06 \\
0,08 \\
0,17 \\
0,12\end{array}$ & $\begin{array}{l}3,0 \\
2,6 \\
2,0 \\
2,5 \\
2,7\end{array}$ & $\begin{array}{l}0,046 \\
0,020 \\
0,041 \\
0,030 \\
0,030\end{array}$ & $\begin{array}{c}15,0 \\
8,9 \\
8,6 \\
8,9 \\
8,9\end{array}$ & $\begin{array}{l}0,65 \\
0,59 \\
0,49 \\
0,56 \\
0,55\end{array}$ & $\begin{array}{l}0,032 \\
0,020 \\
0,020 \\
0,018 \\
0,019\end{array}$ & $\begin{array}{l}0,41 \\
0,69 \\
0,33 \\
0,70 \\
0,57\end{array}$ & $\begin{array}{l}1,7 \\
1,2 \\
1,3 \\
1,4 \\
1,3\end{array}$ & $\begin{array}{l}7,8 \\
7,9 \\
6,5 \\
8,3 \\
8,6\end{array}$ & $\begin{array}{l}0,014 \\
0,007 \\
0,008 \\
0,010 \\
0,009\end{array}$ \\
\hline \multicolumn{2}{|c|}{ media \pm SD } & $0,11 \pm 0,04$ & $2,5 \pm 0,35$ & $0,034 \pm 0,010$ & $10,1 \pm 2,7^{a}$ & $0,57 \pm 0,06$ & $0,022 \pm 0,01$ & $0,54 \pm 0,16$ & $1,4 \pm 0,20$ & $7,8 \pm 0,79^{a}$ & $0,010 \pm 0,003^{a}$ \\
\hline TWS & $\begin{array}{l}2014 \\
2015 \\
2016 \\
2017 \\
2018 \\
\end{array}$ & $\begin{array}{l}0,06 \\
0,06 \\
0,07 \\
0,14 \\
0,09\end{array}$ & $\begin{array}{l}2,8 \\
1,9 \\
1,7 \\
2,3 \\
2,0 \\
\end{array}$ & $\begin{array}{l}0,027 \\
0,016 \\
0,051 \\
0,035 \\
0,034\end{array}$ & $\begin{array}{c}12,7 \\
7,3 \\
7,6 \\
9,0 \\
8,0 \\
\end{array}$ & $\begin{array}{l}0,56 \\
0,50 \\
0,50 \\
0,52 \\
0,51\end{array}$ & $\begin{array}{l}0,025 \\
0,016 \\
0,022 \\
0,014 \\
0,017\end{array}$ & $\begin{array}{l}0,38 \\
0,54 \\
0,25 \\
0,40 \\
0,40\end{array}$ & $\begin{array}{l}1,4 \\
1,0 \\
1,1 \\
1,5 \\
1,2 \\
\end{array}$ & $\begin{array}{l}5,3 \\
6,6 \\
4,5 \\
6,2 \\
5,8 \\
\end{array}$ & $\begin{array}{l}0,010 \\
0,006 \\
0,006 \\
0,008 \\
0,006\end{array}$ \\
\hline \multicolumn{2}{|c|}{ media \pm SD } & $0,09 \pm 0,03$ & $2,1 \pm 0,4$ & $0,033 \pm 0,013$ & $8,9 \pm 2,2^{b}$ & $0,52 \pm 0,02$ & $0,019 \pm 0,005$ & $0,40 \pm 0,10$ & $1,2 \pm 0,2$ & $5,7 \pm 0,8^{b}$ & $0,007 \pm 0,002^{b}$ \\
\hline \multicolumn{2}{|c|}{$\begin{array}{c}\text { Media global } \pm \\
\text { SD }\end{array}$} & $0,10 \pm 0,06$ & $2,3 \pm 0,6$ & $0,050 \pm 0,051$ & $9,7 \pm 2,6$ & $0,59 \pm 0,014$ & $0,025 \pm 0,015$ & $0,36 \pm 0,029$ & $1,4 \pm 0,3$ & $5,4 \pm 2,2$ & $0,009 \pm 0,03$ \\
\hline \multicolumn{2}{|c|}{$\begin{array}{l}\text { Min. valor } \\
\text { Max. valor } \\
\text { P75 }\end{array}$} & $\begin{array}{l}0,02 \\
0,28 \\
0,13 \\
\end{array}$ & $\begin{array}{l}1,3 \\
3,8 \\
2,8 \\
\end{array}$ & $\begin{array}{l}0,014 \\
0,327 \\
0,055\end{array}$ & $\begin{array}{c}5,5 \\
16,8 \\
11,4 \\
\end{array}$ & $\begin{array}{l}0,38 \\
1,14 \\
0,66\end{array}$ & $\begin{array}{l}0,011 \\
0,108 \\
0,028\end{array}$ & $\begin{array}{l}0,00 \\
1,27 \\
0,54\end{array}$ & $\begin{array}{l}0,9 \\
2,0 \\
1,6 \\
\end{array}$ & $\begin{array}{c}2,3 \\
10,4 \\
7,1 \\
\end{array}$ & $\begin{array}{l}0,005 \\
0,017 \\
0,010\end{array}$ \\
\hline
\end{tabular}

Letras diferentes indican medias con diferencias significativas entre cultivar con el $95 \%$ de nivel de confianza de acuerdo con el test de múltiples rangos. Las letras han sido incluidas cuando el valor-p para el factor cultivar era menor de 0,05. 


\subsection{3 Índices de predicción de combustible}

Se calcularon varios índices para predecir qué tipo de combustible y qué comportamiento va a tener la biomasa cultivada en los campos de ensayo de CS y AL (véase sección 4.2.4). En la tabla 22 se muestran los resultados de las diferentes especies testadas en CS y los tres cultivares de agropiro alargado cultivados en los campos $A L$, promediados a lo largo de los años. Las gráficas de interacción entre especies y años se representan en la figura 15 para los índices de combustible $A E / A$, $\mathrm{Si} / \mathrm{K},(\mathrm{Si}+\mathrm{P}+\mathrm{K}) /(\mathrm{Ca}+\mathrm{Mg})$, y $\mathrm{K}+\mathrm{Na}+\mathrm{Pb}+\mathrm{Zn}$.

Tabla 22. Índices empíricos de predicción de combustible para la biomasa cultivada en ambos lugares (CS y AL) y niveles de significación para los factores considerados. Valores promediados a lo largo de los años.

\begin{tabular}{|c|c|c|c|c|c|c|c|}
\hline \multirow{2}{*}{$\begin{array}{c}\text { Biomasa de CS } \\
\text { Índices de combustible }\end{array}$} & \multirow[b]{2}{*}{ Unidades } & \multicolumn{3}{|c|}{ Especies } & \multicolumn{3}{|c|}{ Valores-p } \\
\hline & & TW & CW & SW & $\mathbf{S}$ & $\mathbf{Y}$ & SxY \\
\hline $\mathrm{AE} / \mathrm{A}$ & & $0,30^{b}$ & $0,41^{a}$ & $0,42^{a}$ & $\star *$ & ** & $\star \star$ \\
\hline $\mathrm{K} /(\mathrm{Ca}+\mathrm{Mg})$ & & $4,4^{a}$ & $3,5^{b}$ & $3,4^{b}$ & $* *$ & $\star \star$ & ** \\
\hline$(\mathrm{Si}+\mathrm{P}+\mathrm{K}) /(\mathrm{Ca}+\mathrm{Mg})$ & molar ratio & $7,5^{a}$ & $5,8^{b}$ & $5,7^{b}$ & ** & $\star *$ & ** \\
\hline $\mathrm{K}+\mathrm{Na}+\mathrm{Pb}+\mathrm{Zn}$ & $\mathrm{mg} \mathrm{kg}^{-1} \mathrm{bs}$ & $12100^{a}$ & $9600^{b}$ & $9800^{b}$ & ** & $\star \star$ & ns \\
\hline $\mathrm{Si} / \mathrm{K}$ & molar ratio & $0,65^{a}$ & $0,63^{a}$ & $0,63^{a}$ & ns & $\star \star$ & ns \\
\hline $2 \mathrm{~S} / \mathrm{Cl}$ & molar ratio & $1,5^{a}$ & $1,3^{a}$ & $1,4^{\mathrm{a}}$ & ns & $\star \star$ & ns \\
\hline$(\mathrm{K}+\mathrm{Na}) / 4.9^{*}(2 \mathrm{~S}+\mathrm{Cl})$ & molar ratio & $1,9^{a}$ & $1,5^{a}$ & $1,5^{a}$ & ns & $\star \star$ & ns \\
\hline Biomasa de AL & & \multicolumn{3}{|c|}{ Cultivares } & \multicolumn{3}{|c|}{ Valores-p } \\
\hline Índices de combustible & Unidades & TWA & TWB & TWS & C & $\mathbf{Y}$ & CxY \\
\hline $\mathrm{AE} / \mathrm{A}$ & & $0,47^{\mathrm{a}}$ & $0,37^{a, b}$ & $0,34^{b}$ & * & * & * \\
\hline $\mathrm{K} /(\mathrm{Ca}+\mathrm{Mg})$ & & $2,8^{a}$ & $3,1^{\mathrm{a}}$ & $3,3^{a}$ & ns & * & * \\
\hline$(\mathrm{Si}+\mathrm{P}+\mathrm{K}) /(\mathrm{Ca}+\mathrm{Mg})$ & molar ratio & $5,1^{b}$ & $7,3^{a}$ & $6,9^{a}$ & $\star \star$ & ns & ns \\
\hline $\mathrm{K}+\mathrm{Na}+\mathrm{Pb}+\mathrm{Zn}$ & $\mathrm{mg} \mathrm{kg}^{-1} \mathrm{bs}$ & $8400^{b}$ & $10700^{a}$ & $9500^{a, b}$ & * & $\star *$ & ns \\
\hline $\mathrm{Si} / \mathrm{K}$ & molar ratio & $0,75^{a}$ & $1,20^{a}$ & $0,91^{\mathrm{a}}$ & ns & $\star \star$ & ns \\
\hline $2 \mathrm{~S} / \mathrm{Cl}$ & molar ratio & $1,38^{a}$ & $0,60^{b}$ & $0,63^{b}$ & $\star *$ & ns & ** \\
\hline$(\mathrm{K}+\mathrm{Na}) / 4.9^{*}(2 \mathrm{~S}+\mathrm{Cl})$ & molar ratio & $1,0^{a}$ & $0,6^{a}$ & $0,7^{a}$ & ns & $\star \star$ & * \\
\hline
\end{tabular}

S: especies; C: cultivar; Y: año; ** valor- $p<0.01 ;{ }^{*}$ valor- $p=0.01-0.05$; ns: valor $-p>0.05$, de acuerdo con el test de Fisher (ANOVA de orden 2). Diferentes letras indican medias diferentes significativamente entre especies para estos índices con un nivel de confianza del 95\% de acuerdo con el test de múltiples rangos.

La biomasa de los cultivares de agropiro alargado mostraron índices $A E / A$ significativamente más bajos y mayores índices $\mathrm{K} /(\mathrm{Ca}+\mathrm{Mg}),(\mathrm{Si}+\mathrm{P}+\mathrm{K}) /(\mathrm{Ca}+\mathrm{Mg})$, y $\mathrm{K}+\mathrm{Na}+\mathrm{Pb}+\mathrm{Zn}$ que la biomasa de agropiro crestado y siberiano (Tabla 22), en relación con su mayor contenido de K, Na y Si (Tabla 21). Aunque se detectaron diferencias significativas entre las especies (Tabla 19), cabe señalar que la biomasa producida se caracterizó por índices de combustible similares (Tabla 22). Los cultivares de TW mostraron un índice $\mathrm{AE} / \mathrm{A}$ de 0,30 , un índice $\mathrm{K} /(\mathrm{Ca}+\mathrm{Mg})$ de 4,4 , y una relación molar $(\mathrm{Si}+\mathrm{P}+\mathrm{K}) /(\mathrm{Ca}+\mathrm{Mg})$ de 7,5, frente a CW y SW con índices de 0,41-0,42, 3,4-3,5 y 5,75,8 , respectivamente. El índice de combustible de $\mathrm{K}+\mathrm{Na}+\mathrm{Pb}+\mathrm{Zn}$ promedió 12.100 $\mathrm{mg} \cdot \mathrm{kg}^{-1}$ bs para las especies TW y $9600-9800 \mathrm{mg} \cdot \mathrm{kg}^{-1}$ bs para CWH y SWV. No se encontraron diferencias estadísticamente significativas entre las distintas especies 
cultivadas en lo que respecta a las relaciones molares de $\mathrm{Si} / \mathrm{K}, 2 \mathrm{~S} / \mathrm{Cl}$ y $(\mathrm{K}+\mathrm{Na})$ $14,9^{*}(2 \mathrm{~S}+\mathrm{Cl})($ Tabla 22$)$.

Los índices $\mathrm{AE} / \mathrm{A}$ y $\mathrm{Si} / \mathrm{K}$ aumentaron después de los dos primeros años del estudio para todas las especies consideradas, mientras que los índices $\mathrm{K} /(\mathrm{Ca}+\mathrm{Mg})$, $(\mathrm{Si}+\mathrm{P}+\mathrm{K}) /(\mathrm{Ca}+\mathrm{Mg})$, y $\mathrm{K}+\mathrm{Na}+\mathrm{Pb}+\mathrm{Zn}$ tendieron a disminuir con el tiempo, con la excepción de la relación molar $(\mathrm{Si}+\mathrm{P}+\mathrm{K}) /(\mathrm{Ca}+\mathrm{Mg})$ de los cultivares de TW (Figura 15). Las diferencias más importantes entre los índices parecen estar relacionadas principalmente con la disminución del K observada a lo largo de los años (Figuras 12 y 13). La biomasa recogida en años posteriores (2014-2018) obtuvo reducciones medias del $30 \%$ para $\mathrm{K} /(\mathrm{Ca}+\mathrm{Mg})$, del $24 \%$ para $\mathrm{K}+\mathrm{Na}+\mathrm{Pb}+\mathrm{Zn}$, y del $6 \%$ para $(\mathrm{Si}+\mathrm{P}+\mathrm{K})$ $/(\mathrm{Ca}+\mathrm{Mg})$, y aumentos del $33 \%$ para $\mathrm{AE} / \mathrm{A}$ y del $73 \%$ para $\mathrm{Si} / \mathrm{K}$ con respecto a la cultivada en los primeros años (2012-2013). No se encontró una tendencia clara a lo largo de los años para el resto de los índices calculados.

La biomasa de los tres cultivares de TW de Alconaba (TWA, TWB y TWS) difirió estadísticamente en sus índices $\mathrm{AE} / \mathrm{A},(\mathrm{Si}+\mathrm{P}+\mathrm{K}) /(\mathrm{Ca}+\mathrm{Mg}), \mathrm{K}+\mathrm{Na}+\mathrm{Pb}+\mathrm{Zn}$ y $2 \mathrm{~S} / \mathrm{Cl}$, pero nuevamente mostrando valores muy cercanos entre ellos para estos índices (Tabla 21). El AE/A varió entre los cultivares en el rango de 0,34-0,47, y $(\mathrm{Si}+\mathrm{P}+\mathrm{K}) /(\mathrm{Ca}+\mathrm{Mg})$ estuvo entre 5,1 y 7,3 . TWA obtuvo una relación molar de $2 \mathrm{~S} / \mathrm{Cl}$ más alto $(1,38)$ que el TWB y el TWS $(0,6)$, pero aun así estos valores se mantuvieron bajos y siempre $<2$.

Los resultados también mostraron índices de combustible comparables entre las especies cultivadas en CS y los cultivares de agropiro alargado cultivados en AL (Tabla 22). 
$\mathrm{AE} / \mathrm{A}$

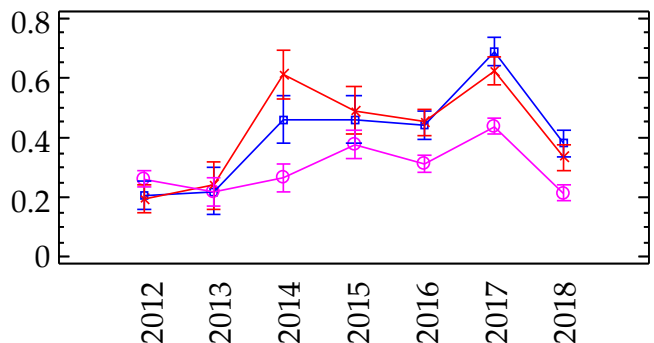

$(\mathrm{Si}+\mathrm{P}+\mathrm{K}) /(\mathrm{Ca}+\mathrm{Mg})$

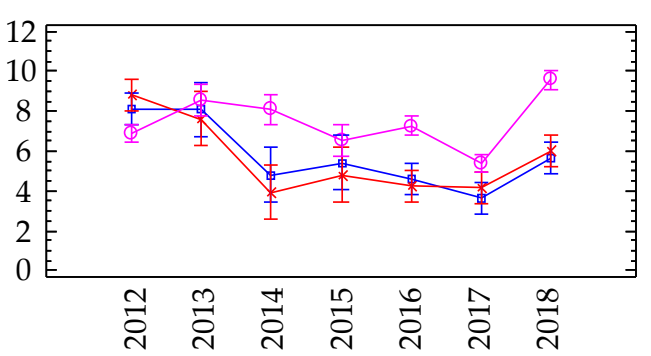

$\mathrm{Si} / \mathrm{K}$

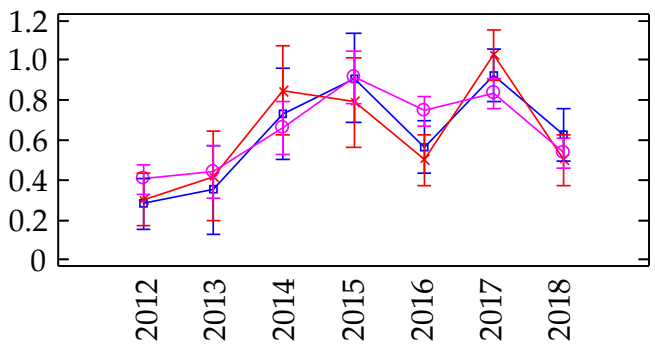

$\mathrm{K}+\mathrm{Na}+\mathrm{Pb}+\mathrm{Zn}\left(\mathrm{mg} \mathrm{kg}^{-1} \mathrm{bs}\right)$

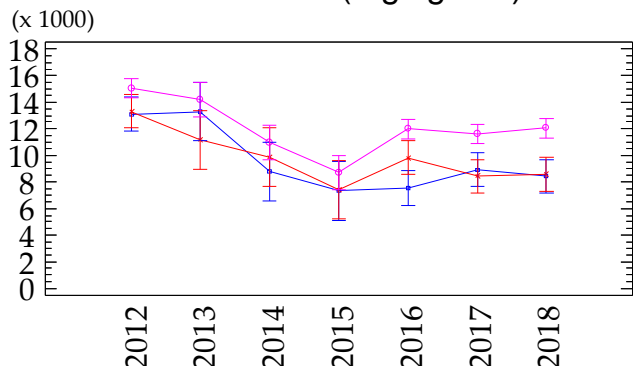

- Agropiro alargado

$\rightarrow$ Agropiro crestado

Agropiro Siberiano

Figura 15. Índices de combustible por especies y años para la biomasa cultivada en las parcelas de CS. Medias y gráficas de interacción LSD de Fisher.

\subsection{Discusión}

Como suele ocurrir en todas las especies de gramíneas perennes [57], los rendimientos más bajos se obtuvieron durante la primera cosecha, independientemente de la especie, el cultivar o la ubicación considerados, con la excepción de 2017. El mayor rendimiento entre todas las especies y cultivares examinados en CS (TWA, TWJ, TWR, CWH y SWV) fue alcanzado por TWA (4,8 Mg MS.ha $\left.{ }^{-1}\right)$ y TWJ (4,7 Mg MS'ha-1). A su vez, TWA fue el cultivar que proporcionó el

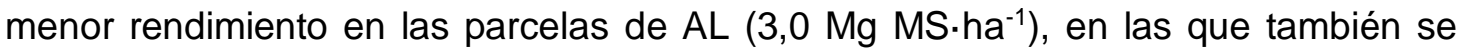
ensayaron otros dos cultivares de agropiro alargado (TWB y TWS).

Sólo unos pocos estudios se ocupan de testar gramíneas perennes en tierras marginales, en particular cuando se trata de especies del género Agropyron spp. dedicadas a la producción de energía. Estos estudios se realizan normalmente en pastizales y tierras fértiles. En este estudio, los cultivares de agropiro alargado obtuvieron mejores resultados en cuanto a la producción de biomasa que en otros estudios llevados a cabo en condiciones marginales en los Estados Unidos, donde se reportaron rendimientos de 3,1 $\mathrm{Mg} \mathrm{MS} \cdot \mathrm{ha}^{-1}$ [58]. Sin embargo, bajo condiciones de riego o en zonas sin limitaciones alcanzaron producciones de biomasa superiores a 10 
Mg MS $\cdot h^{-1}$ en América del Norte $[37,59]$ y de 17,2 Mg MS ha-1 en Alemania para la producción de biogás [23].

Como se comentó anteriormente, el cultivar TWA promedió 4,8 y 3,0 Mg MS'ha1 en las parcelas experimentales de CS y AL respectivamente, más bajos que los rendimientos de 8,2 $\mathrm{Mg} \mathrm{MS} \cdot \mathrm{ha}^{-1}$ reportados en un estudio de 3 años en tierra fértil en los EE.UU. [39].

TWJ llegó a producir 12,6 Mg MS·ha-1 un año en el presente estudio. El mismo cultivar obtuvo rendimientos más bajos $\left(8 \mathrm{Mg} \mathrm{MS} \cdot \mathrm{ha}^{-1} \cdot \mathrm{año}^{-1}\right)$ en zonas de regadío de la cuenca Mediterránea con problemas de salinidad [60]. Este cultivar alcanzó rendimientos de 5,9-8,3 Mg MS·ha-1 (producción media durante un período de 2 años) bajo condiciones de riego en tierras marginales para la producción de forraje [61].

TWS rindió hasta $25 \mathrm{Mg} \mathrm{MS} \cdot$ ha $^{-1}$ en tierra fértil, obteniendo producciones anuales de biomasa de $5 \mathrm{Mg} \mathrm{MS} \cdot \mathrm{ha}^{-1}$ en zonas con limitaciones biofísicas [62], cercanas a las obtenidas en los ensayos de $\mathrm{AL}\left(4,3 \mathrm{Mg} M \mathrm{MS} \cdot \mathrm{ha}^{-1}\right)$.

En un estudio de tres años realizado en Polonia [63], TWB proporcionó rendimientos del orden de 6,6-10,4 $\mathrm{Mg} \mathrm{MS} \cdot \mathrm{ha}^{-1}$. Estos resultados se obtuvieron también en tierras de baja calidad, aunque en una zona caracterizada por precipitaciones más altas que las de este estudio.

La producción de biomasa obtenida en CS para CWH (2,8 Mg MS ha $\left.{ }^{-1}\right)$ fue similar a la notificada en América del Norte (2,9 a 3,6 Mg MS $\left.\cdot \mathrm{ha}^{-1}\right)$, donde este cultivar se estudió durante dos años en condiciones de secano para la producción de forraje [64]. Se notificaron mayores producciones de biomasa (5,55 a 8,05 Mg MS'ha ${ }^{-1}$ ) en las tierras de regadío de Estados Unidos [65].

Sin importar la especie o el cultivar, la producción de biomasa aumentó con el aumento de las precipitaciones anuales. Sin embargo, las precipitaciones no afectaron igual a todas las especies [28]. En general, la EUA de las gramíneas C4, como el Panicum virgatum L., es mayor que la de las gramíneas C3 debido a su diferente metabolismo [49]. También cabe mencionar que se observó que la producción de biomasa aumentaba en relación con las precipitaciones de primavera, ya que ésta es la estación en que las especies estudiadas atraviesan su período vegetativo activo más alto. Otros autores también observaron una correlación similar [49,66,67]. Según los resultados, las especies consideradas en este estudio lograron mayores rendimientos de biomasa cuando las precipitaciones registradas entre marzo y junio fueron superiores a $240 \mathrm{~mm}$. Los rendimientos de biomasa más pobres se obtuvieron 
cuando la precipitación durante el período mencionado fue de alrededor de $150 \mathrm{~mm}$. Los niveles de precipitación inferiores a $120 \mathrm{~mm}$ dieron lugar a unos rendimientos difíciles de recolectar mecánicamente, como también señalaron otros autores [13].

Las especies de Agropyron spp., cultivadas en las localizaciones marginales de este estudio, exhibieron la composición química típica de las especies perennes C3, que se caracterizan por su alto contenido de ceniza, silicio y elementos alcalinos $[30,42,43,46,68]$.

Las gramíneas perennes cultivadas en ambos lugares (CS y $A L$ ) tenían un promedio de $40 \mathrm{~g} \cdot \mathrm{kg}^{-1}$ bs de ceniza y oscilaron entre $27-63 \mathrm{~g} \cdot \mathrm{kg}^{-1} \mathrm{bs}$. El $75 \%$ de todas las muestras analizadas era $\leq 46 \mathrm{~g} \cdot \mathrm{kg}^{-1}$ bs sin importar el lugar. Esto se encuentra dentro de los valores medios típicos de ceniza y de los rangos especificados en la norma ISO 17225-1:2014 [68] para hierbas en general (heno, $10-100 \mathrm{~g} \cdot \mathrm{kg}^{-1} \mathrm{bs}$ ) y otras especies C3, como el alpiste (cosechado en verano $25-100 \mathrm{~g} \cdot \mathrm{kg}^{-1} \mathrm{bs}$ ). Sin embargo, el contenido de ceniza de las gramíneas sembradas en este estudio es más comparable al del miscanthus, una gramínea C4 que suele caracterizarse por un contenido de ceniza más bajo que las gramíneas C3, mostrando en la bibliografía un contenido medio de ceniza de $40 \mathrm{~g} \cdot \mathrm{kg}^{-1}$ bs $[30,46,68]$ y una variación típica de $10-60 \mathrm{~g} \cdot \mathrm{kg}^{-1} \mathrm{bs}$ [68]. Martyniak y otros [41] estudiaron el TWS y cuatro poblaciones silvestres de agropiro alargado en Polonia, reportando un elevado contenido de ceniza para estas hierbas (78 g. $\mathrm{kg}^{-1}$ bs para el TWS y $100-170 \mathrm{~g} \cdot \mathrm{kg}^{-1}$ bs para las poblaciones silvestres). Nazli y otros informaron de un contenido de ceniza de entre 51 y $96 \mathrm{~g} \cdot \mathrm{kg}^{-1} \mathrm{bs}$ para otros pastos C3 (Arundo donax L. y Phalaris aquatica L) y en el rango de 31 a $60 \mathrm{~g} \cdot \mathrm{kg}^{-}$ ${ }^{1}$ bs para las especies C4 (Miscanthus spp y Panicum virgatum L.) en tierras marginales de Turquía [31]. Se ha informado de que la temperatura del aire, la disponibilidad de agua y la distribución de la lluvia desempeñan un papel importante en el contenido de cenizas de la biomasa [42]. Se ha observado una disminución del contenido de cenizas en Arundo donax L. cultivado en secano [30] en el centro de Italia, en los años de baja precipitación y después de largos períodos de sequía estival [42]. Además de las condiciones meteorológicas, los suelos arenosos como los del estudio tienen una baja capacidad de retención de agua, lo que aumenta la probabilidad de estrés hídrico [69]. Por lo tanto, el contenido relativamente bajo de cenizas encontrado en nuestro estudio podría deberse a los suelos arenosos y al clima seco donde se llevó a cabo el estudio. No obstante, cabe señalar que se puede esperar un contenido de cenizas mayor que el que se muestra en nuestro estudio, donde las muestras se recogieron manualmente, cuando la biomasa se recolecta mecánicamente porque podría dar lugar a la inclusión de impurezas minerales del suelo. 
Los $\mathrm{PCl}$ en bs oscilaron entre 16,7 y $18,5 \mathrm{MJ} \cdot \mathrm{kg}^{-1}$, y promediaron $17,7 \mathrm{MJ} \cdot \mathrm{kg}^{-1}$ para la biomasa cultivada en CS y $17,3 \mathrm{MJ} \cdot \mathrm{kg}^{-1}$ para la cultivada en $\mathrm{AL}$. Se encuentran dentro de los rangos típicos que figuran en la norma ISO 17225-1 [58] para las gramíneas perennes (16-19 MJ. $\left.\mathrm{kg}^{-1}\right)$. Esta norma internacional [68] también enumera los PCI medios típicos para especies silvestres $\left(17,1 \mathrm{MJ} \cdot \mathrm{kg}^{-1}\right)$, Phalaris arundinacea $\mathrm{L}$. $\left(16,6 \mathrm{MJ} \cdot \mathrm{kg}^{-1}\right)$ y Miscanthus spp. (17,7 MJ $\left.\mathrm{kg}^{-1}\right)$. Una vez más, los cultivares de agropiro alargado considerados en este estudio mostraron poderes caloríficos medios más cercanos al miscanthus, una especie C4, que a otras especies C3. Como se sabe que los poderes caloríficos están negativamente correlacionados con el contenido de ceniza $[43,70]$, los poderes caloríficos más altos encontrados en nuestro estudio están en consonancia con el contenido relativamente más bajo de ceniza. Los PCls de este estudio están muy próximos a los encontrados para Arundo donax L. cosechado en otoño $\left(17,4 \mathrm{MJ} \cdot \mathrm{kg}^{-1}\right)$ y Phalaris aquatica L. $\left(17,2 \mathrm{MJ} \cdot \mathrm{kg}^{-1}\right)$, este último en tierras marginales de un entorno mediterráneo semiárido en Turquía [31]. Se encontraron PCls más bajos para las poblaciones silvestres de agropiro alargado en Polonia (15,8$\left.17,0 \mathrm{MJ} \cdot \mathrm{kg}^{-1}\right)$, en relación con el elevado contenido de cenizas obtenido para la biomasa $\left(78-170 \mathrm{~g} \cdot \mathrm{kg}^{-1}\right)[41]$.

La composición química de las especies cultivadas en este estudio está dentro de los rangos documentados en la literatura para las gramíneas perennes [30,4146,56,60,68]. Las especies del género Agropyron promediaron $12 \mathrm{~g} \cdot \mathrm{kg}^{-1} \mathrm{bs}$ y $8,3 \mathrm{~g} \cdot \mathrm{kg}^{-}$ ${ }^{1}$ bs de $\mathrm{N}$ en CS y AL, respectivamente, $1,6 \mathrm{~g} \cdot \mathrm{kg}^{-1} \mathrm{bs} \mathrm{Cl}$ en CS, $2,8 \mathrm{~g} \cdot \mathrm{kg}^{-1} \mathrm{bs}$ de $\mathrm{Cl}$ en $\mathrm{AL}$, y $0,10 \% \mathrm{~S}$ en ambos sitios. La norma ISO 17225-1 especifica valores típicos de $1,3 \%$ de $N, 0,1-0,2 \%$ de $S$ y $0,5-0,7 \%$ para las especies silvestres y el alpiste, y $0,7 \%$ de $\mathrm{N}$ y $0,2 \%$ de $\mathrm{S}$ y $\mathrm{Cl}$ para el miscanthus [68]. Se notificaron contenidos de azufre entre 0,9 y $1,0 \mathrm{~g} \cdot \mathrm{kg}^{-1}$ bs y contenidos de cloro de $0,13-0,25 \%$ para el TWS y las poblaciones silvestres de agropiro alargado en Polonia [41]. El agropiro alargado osciló entre $6-11 \mathrm{~g} \cdot \mathrm{kg}^{-1}$ bs su contenido de $\mathrm{N}$, dependiendo de la tasa de fertilización con $\mathrm{N}$ en el clima mediterráneo de California [60]. En tierras marginales, Arundo donax L y Phalaris aquatica $L$ recolectados en otoño, dos especies $C 3$, oscilaron entre 5,4-16 $\mathrm{g} \cdot \mathrm{kg}^{-1}$ bs de $\mathrm{N}$ y 1,1-3,0 $\mathrm{g} \cdot \mathrm{kg}^{-1}$ bs de $\mathrm{S}$ en función de diferentes tasas de fertilización con $\mathrm{N}$ y años estudiados [56]. Los pastos perennes dominados por especies C3 en Estados Unidos oscilaron entre $6-18 \mathrm{~g} \cdot \mathrm{kg}^{-1}$ bs en $\mathrm{N}, 1,0-2,5 \% \mathrm{~S}$, y $1,0-5,0 \mathrm{~g} \cdot \mathrm{kg}^{-1}$ bs en $\mathrm{Cl}$ [44]. También se han notificado concentraciones similares para especies C4 en la etapa de madurez en el oeste de los Estados Unidos [45], obteniéndose 0,3-1,8 g. $\mathrm{kg}$ ${ }^{1}$ bs de $S$ y $0,5-4,0 \mathrm{~g} \cdot \mathrm{kg}^{-1}$ bs de $\mathrm{Cl}$. 
Cuando la concentración de $\mathrm{N}$ del combustible supera los $6 \mathrm{~g} \cdot \mathrm{kg}^{-1} \mathrm{bs}$, los límites de emisión de NOx durante la combustión podrían ser superados [46]. También cabe esperar problemas de corrosión y de emisión de $\mathrm{HCl}$ en concentraciones de $\mathrm{Cl}$ superiores a $1 \mathrm{~g} \cdot \mathrm{kg}^{-1}$ bs y concentraciones de $S$ superiores a $1 \mathrm{~g} \cdot \mathrm{kg}^{-1} \mathrm{bs}$, mientras que las emisiones de dioxinas y furanos podrían ser relevantes cuando la concentración de $\mathrm{Cl}$ supera el 0,3\% [46]. También deben considerarse emisiones significativas de SOx cuando la concentración de $S$ en el combustible es $>20 \mathrm{~g} \cdot \mathrm{kg}^{-1}$ bs [46]. Además, cuando se utilice este tipo de biomasa con fines de combustión, deberán tenerse en cuenta los graves y altos riesgos de corrosión. La biomasa cultivada en este estudio siempre exhibió relaciones molares de $2 \mathrm{~S} / \mathrm{Cl}$ por debajo de 2 , la pauta especificada en [54] para evitar este problema.

Otros elementos importantes desde el punto de vista de la calidad, como el K, el $\mathrm{Si}$, el $\mathrm{Ca}$, el $\mathrm{Mg}$, el $\mathrm{P}$ y el $\mathrm{Na}$ también estaban dentro de los valores típicos recogidos en la literatura para otras especies C3 cultivadas en condiciones diferentes $[30,43,46,68]$. Además de la etapa de desarrollo, el contenido de los principales elementos de las gramíneas está fuertemente influenciado por los factores de lugar y las condiciones ambientales, como el tipo de suelo y las condiciones meteorológicas, y por lo tanto se esperaban diferencias en las concentraciones minerales de estas gramíneas entre diferentes lugares $[30,42,45]$. Según la ubicación, nuestras gramíneas promediaron 2,3-2,4 $\mathrm{g} \cdot \mathrm{kg}^{-1}$ bs de $\mathrm{Ca}, 9,7-11 \mathrm{~g} \mathrm{~g} \cdot \mathrm{kg}^{-1}$ bs de $\mathrm{K}, 0,09-0,36$ $\mathrm{g} \cdot \mathrm{kg}^{-1}$ bs de Na, 4,8-5,4 $\mathrm{g} \cdot \mathrm{kg}^{-1}$ bs de Si, $1,0-1,4 \mathrm{~g} \cdot \mathrm{kg}^{-1}$ bs de $\mathrm{P}$, y $0,59-0,64 \mathrm{~g} \cdot \mathrm{kg}^{-1}$ bs de Mg. Para especies recolectadas en verano o en otoño, otros autores indicaron valores que oscilaban entre $0,6-8,1 \mathrm{~g} \cdot \mathrm{kg}^{-1}$ bs en $\mathrm{K}, 5,6-37 \mathrm{~g} \mathrm{~g} \cdot \mathrm{kg}^{-1}$ bs en Si, y 0,8-3,2 $\mathrm{g} \cdot \mathrm{kg}^{-1} \mathrm{bs}$ en Ca para el alpiste [30], o 2,2-23 $\mathrm{g} \cdot \mathrm{kg}^{-1}$ bs en Si, 0,9-3,0 $\mathrm{g} \cdot \mathrm{kg}^{-1}$ bs en $\mathrm{P}$, y 9,6-22 $\mathrm{g}$ $\mathrm{g} \cdot \mathrm{kg}^{-1}$ bs en $\mathrm{K}$ para los pastos silvestres de zonas templadas del oeste de Estados Unidos [45]. Se obtuvieron concentraciones minerales similares en tierras marginales para el Arundo donax L. y Phalaris aquatica L., con 7,0-21 g. $\mathrm{kg}^{-1} \mathrm{bs}$ en K, 4,4-16 g. $\mathrm{kg}^{-}$ ${ }^{1}$ bs en P, 1,6-3,7 $\mathrm{g} \cdot \mathrm{kg}^{-1}$ bs en Ca, $12-21 \mathrm{~g} \cdot \mathrm{kg}^{-1}$ bs en Si, y 0,9-1,4 $\mathrm{g} \cdot \mathrm{kg}^{-1}$ bs en $\mathrm{Mg}[56]$.

Cuando se cultivan en el mismo lugar (CS), las principales diferencias se encuentran entre las especies y no entre los cultivares. En este sentido, la composición química de los cultivares de agropiro alargado difería de la del agropiro crestado y del agropiro siberiano, encontrándose en el primero un mayor contenido de ceniza, $\mathrm{K}, \mathrm{Na}$ y $\mathrm{Si}$, lo que dio lugar a menores proporciones $\mathrm{AE} / \mathrm{A}$ y mayores índices $\mathrm{K} /(\mathrm{Ca}+\mathrm{Mg})$, $(\mathrm{Si}+\mathrm{P}+\mathrm{K}) /(\mathrm{Ca}+\mathrm{Mg})$, y $\mathrm{K}+\mathrm{Na}+\mathrm{Pb}+\mathrm{Zn}$. Por lo tanto, los índices de combustible predicen un comportamiento de combustión ligeramente mejor para el agropiro crestado y 
agropiro siberiano con respecto a la sinterización de cenizas y las emisiones de aerosoles.

Cuando se sembraron diferentes cultivares de agropiro alargado en el mismo ambiente (TWA, TWJ y TWR en CS y TWA, TWB y TWS en AL), la mayoría de sus propiedades variaron en un rango relativamente estrecho. Se han notificado anteriormente diferencias genotípicas en la acumulación de minerales y la calidad del combustible de otras especies de gramíneas [30,45,71], y sólo pueden cuantificarse cuando las gramíneas se cultivan en el mismo lugar.

Sin embargo, cabe destacar que no se espera que las leves diferencias encontradas entre todas las especies y cultivares examinados tengan ninguna relevancia práctica si estas especies se utilizan en procesos de combustión. Independientemente de la especie o el año considerados, las proporciones AE/A se mantuvieron siempre bajas $(<0,8)$, y las proporciones $K /(\mathrm{Ca}+\mathrm{Mg})$ fueron $>2$, lejos de las directrices para evitar problemas de sinterización ( $\mathrm{AE} / \mathrm{A}>2$ [52], y $\mathrm{K} /(\mathrm{Ca}+\mathrm{Mg})<0,5$ [53]). Además, las relaciones molares $(\mathrm{Si}+\mathrm{P}+\mathrm{K}) /(\mathrm{Ca}+\mathrm{Mg})$ fueron siempre de 3-10. Por lo tanto, se esperan bajas temperaturas de sinterización para las especies estudiadas [52-55]. $\mathrm{K}+\mathrm{Na}+\mathrm{Pb}+\mathrm{Zn}$ estuvieron siempre entre 8000 y $16.000 \mathrm{mg} \cdot \mathrm{kg}^{-1}$ (Figura 14), lo que sugiere emisiones medias de aerosoles (PM1) para el agropiro crestado y siberiano y emisiones altas de aerosoles en el caso de los cultivares de TW [54]. Las relaciones molares Si/K fueron bajas (<1,2, Figura 14), lo que también sugiere una alta liberación de $\mathrm{K}$ y formación de aerosoles.

Estos resultados indican una mejora en la calidad de la biomasa de las especies con la edad de los cultivos. En este sentido, el contenido de cenizas, así como las concentraciones de $\mathrm{K}, \mathrm{S}, \mathrm{Na}$ y $\mathrm{Cl}$, tendieron a disminuir con los años, mientras que el contenido de $\mathrm{CaO}, \mathrm{MgO}$ y $\mathrm{SiO}_{2}$ en las cenizas tendió a aumentar. Como resultado de los cambios observados en la composición química, la biomasa recolectada durante los primeros años exhibió índices menores de $A E / A$ y $\mathrm{Si} / \mathrm{K}$, y mayores $(\mathrm{Si}+\mathrm{P}+\mathrm{K})$ $/(\mathrm{Ca}+\mathrm{Mg})$ y $\mathrm{K}+\mathrm{Na}+\mathrm{Pb}+\mathrm{Zn}$. Por lo tanto, los resultados obtenidos sugieren un mejor comportamiento de fusibilidad de la ceniza para la biomasa recolectada durante los últimos años del estudio, así como menores emisiones gaseosas y de aerosoles. El efecto positivo de la edad del cultivo en las características químicas de otras especies fue documentado previamente $[31,42,45,56,71]$. De manera similar a nuestros resultados, se encontraron reducciones del contenido de ceniza y mayores proporciones de $\mathrm{SiO}_{2} / \mathrm{K}_{2} \mathrm{O}$ y CaO$/ \mathrm{K}_{2} \mathrm{O}$ en cultivos de Arundo donax L. de 10 años de edad en el centro de Italia [42]. La disminución de la concentración de minerales con 
la maduración de las plantas se ha relacionado anteriormente con las diferentes características morfológicas de los cultivos cuando envejecen, que produce una mayor cantidad de tallos más finos por unidad de superficie con menos hojas [42,72]. Sin embargo, como sugiere Di Nasso [42], es muy difícil separar el efecto de la edad de los cultivos del efecto de las diferentes condiciones meteorológicas anuales, en particular de la distribución de las lluvias durante los períodos de crecimiento.

Basándose en la composición química y la evaluación de los índices de combustión calculados, se esperaba que las especies cultivadas muestren el comportamiento de combustión típico de las especies C3. Al evaluar los índices de combustible, los resultados sugieren que las diferencias encontradas entre las especies y los cultivares de los agropiros para algunas de sus propiedades de combustión y características químicas, no es probable que afecten a su comportamiento de combustión desde un punto de vista práctico. Si estas especies se van a utilizar para producir bioenergía en un proceso de conversión termoquímica, se deberían aplicar medidas tecnológicas en las centrales eléctricas para evitar la sinterización, la corrosión y los problemas relacionados con las emisiones [30,45,46]. Otra posibilidad que vale la pena considerar sería tratar de reducir el contenido de elementos problemáticos directamente en el combustible. Prácticas como la lixiviación durante el secado en el campo o el retraso de la cosecha han demostrado su eficacia en el caso de las gramíneas $[30,31,43,56,68,71]$, debido a la reducción del contenido de cenizas y de elementos solubles en agua en el combustible, así como al aumento de las temperaturas de deformación de las cenizas. El impacto de la lixiviación y/o el retraso de la cosecha en la composición química y los parámetros de calidad del combustible de estas gramíneas debe explorarse en tierras marginales y entornos semiáridos con escasa precipitación y distribución variable de la lluvia. Además, también sería útil una evaluación económica para determinar si estas alternativas son viables en suelos de baja productividad, ya que la mejora de las propiedades de calidad del combustible suele ir acompañada de importantes pérdidas de materia seca y del riesgo de desplazar la recolección a períodos con condiciones meteorológicas desfavorables [43,71]. La biomasa cultivada en este estudio también podría utilizarse para producir pellets herbáceos, clase B [73]. Las limitaciones establecidas en la norma ISO 17225-6 para los pellets herbáceos, clase A, no se cumplirían, ya que el contenido de $\mathrm{Cl}$ de las especies perennes cultivadas superaba la limitación de $1,0 \mathrm{~g} \cdot \mathrm{kg}^{-}$ ${ }^{1}$ bs en ambos lugares, pero especialmente en $\mathrm{AL}$, donde se encontraron niveles más altos de $\mathrm{Na}$ y $\mathrm{Cl}$. 


\subsection{Conclusiones}

El agropiro alargado puede ser una alternativa eficaz para el cultivo de materias primas energéticas en condiciones desfavorables, ya que proporciona mejores rendimientos de biomasa y eficiencia en el uso de la lluvia que el agropiro crestado y el agropiro siberiano. De todos los cultivares de agropiro alargado testadas, tanto Alkar como el Szarvasi-1 obtuvieron la mejor producción de biomasa. Agropyron spp. puede producir biomasa en zonas con limitaciones biofísicas en condiciones de secano siempre que la precipitación entre marzo y junio sea superior a $150 \mathrm{~mm}$.

Las principales diferencias en la composición de la biomasa fueron entre especies más que entre cultivares. El agropiro alargado exhibió el mayor contenido de cenizas, de concentraciones de K, Na y Si. EI PCl fue mayor en el agropiro crestado, siberiano, y agropiro alargado cv. Riparianslopes que en el resto de los cultivares de agropiro alargado. Todas las especies y cultivares mostraron índices de combustible similares, siendo ligeramente mejores para el agropiro crestado y el siberiano. En este sentido, es probable que las diferencias encontradas entre las especies y cultivares en cuanto a sus principales propiedades y composición química no tengan ninguna relevancia práctica si estas gramíneas se utilizan en procesos de combustión. El contenido de cenizas, así como las concentraciones de $\mathrm{K}, \mathrm{S}, \mathrm{Na}$ y $\mathrm{Cl}$, tendieron a disminuir con los años del cultivo, mientras que el contenido de otros elementos formadores de cenizas, como $\mathrm{Ca}, \mathrm{Mg}$ y $\mathrm{Si}$, tendieron a aumentar, haciendo que la biomasa recogida durante los años posteriores sea de mejor calidad.

La mejora genética de estas especies podría ser útil para mejorar las producciones de biomasa con destino la producción de bioenergía en la agricultura de bajos inputs en zonas con limitaciones biofísicas. También deberían explorarse las cosechas tardías para mejorar la calidad de la combustión de este tipo de biocombustibles.

Este experimento podría replicarse en más de 10 millones de hectáreas situadas en Europa que han sido clasificadas como tierras marginales [13], y en las que Agropyron spp., particularmente agropiro alargado, podría funcionar en términos de producción de biomasa y eficiencia en el uso del agua. Según FAOSTAT [74], hay más de cinco millones de hectáreas en todo el mundo sembradas con centeno anualmente, las cuales ofrecen un dudoso margen económico y más dudoso equilibrio ambiental [16], que podrían utilizarse para cultivar especies del género Agropyron con fines energéticos. Deberían realizarse más investigaciones para evaluar si es factible, en condiciones marginales, fijar fechas de cosecha más tardías, con el fin de mejorar la 
calidad de la biomasa producida. Además, sería útil una evaluación de la aplicabilidad de estas especies como materia prima para biocombustibles de segunda generación.

\subsection{Referencias}

1. Rajagopal, D.; Sexton, S.E.; Roland-Holst, D.; Zilberman, D. Challenge of biofuel: Filling the tank without emptying the stomach? Environ. Res. Lett. 2007, 2, 1-9.

2. Mantineo, D.; D'Angosta, G.M.; Copani, V.; Patance, C.; Cosentino, S.L. Biomass yield and energy balance of three perennial crops for energy use in the semi-arid Mediterranean environment. Field Crop Res. 2009, 114, 204-213.

3. Nalepa, R.A.; Bauer, D.M. Marginal lands: The role of remote sensing in constructing landscapes for agrofuel development. J. Peasant Stud. 2012, 39, 403-422.

4. Dominguez Faus, R.; Powers, S.E.; Burken, J.G.; Alvarez, P.J. The water footprint of biofuels: A drink or drive issue? Environ. Sci. Technol. 2009, 43, 3005-3010.

5. Dauber, J.; Miyake, S. To integrate or to segregate food crop and energy crop cultivation at the landscape scale? Perspectives on biodiversity conservation in agriculture in Europe. Energy Sustain. Soc. 2016, 6, 25.

6. Mehmood, M.A.; Ibrahim, M.; Rashid, U.; Nawaz, M.; Ali, S.; Hussain, A.; Gull, M. Biomass production for bioenergy using marginal lands. Sustain. Prod. Consum. 2017, 9, 3-21.

7. Gerwin, W.; Repmann, F.; Spyridon, G.; Despoina, V.; Gounairs, N.; Baumgarten, W.; Christianes, V.; Keramitzis, D.; Kiourtsis, F.; Freese, D. Assessment and quantification of marginal lands for biomass production in Europe using soil quality indicators. Soil 2018, 4, 267-290.

8. Bordonal, R.d.O.; Nunes, J.L.; Lal, R.; de Figueiredo, E.B.; de Oliveira, B.G.; La Scala, N.J. Sustainability of sugarcane production in Brazil. A review. Agron. Sustain Dev. 2018, 38, 13.

9. Peterson, G.M.; Galbraith, J.K. The concept of marginal land. J. Farm Econ. 1932, 14, 295310.

10. Liu, T.T.; McConkey, B.G.; Ma, Z.Y.; Liu, Z.G.; Li, X.; Cheng, L.L. Strengths, weaknesses, opportunities and threats analysis of bioenergy production on marginal land. Energy Procedia. 2011, 5, 2378-2386.

11. Yakubu, A.S.; Ehlers, M.H.; Harnmeijer, J. Anaerobic digestion of feedstock grown on marginal land: Break-even electricity prices. Energies 2017, 10, 21.

12. Shortall, O.K. "Marginal land" for energy crops. Exploring definitions and embedded assumtions. Energy Policy 2013, 62, 19-27.

13. Von Cossel, M.; Lewandowski, I.; Elbersen, B.; Staritsky, I.; Van Eupen, M.; Iqbal, Y.; Mantel, S.; Scordia, D.; Testa, G.; Cosentino, S.L.; et al. Marginal agricultural land lowinput systems for biomass production. Energies 2019, 12, 25.

14. Ruf, T.; Audu, V.; Holzhauser, K.; Emmerling, C. Bioenergy from periodically waterlogged cropland in Europe: A first assessment of the potential of five perennial energy crops to provide biomass and their interactions with soil. Agronomy 2019, 9, 25.

15. Acharya, B.S.; Blanco-Canqui, H. Lignocellulosic-based bioenergy and water quality parameters: A review. Glob. Change Biol. Bioenergy 2018, 10, 504-533.

16. Ciria, C.S.; Sastre, C.M.; Carrasco, J.; Ciria, P.; Tall wheatgrass (Thinopyrum ponticum (Podp.)) in a real farm context, a sustainable perennial alternative to rye (Secale cereale L.) cultivation in marginal lands. Ind. Crop. Prod. 2020, 146, 8.

17. Blanco-Canqui, H. Energy crops and their implications on soil and environment. Agron. J. 2010, 102, 403-419.

18. Chimento, C.; Almagro, M.; Amaducci, S. Carbon sequestration potential in perennial bioenergy crops: The importance of organic matter inputs and its physical protection. Glob. Change Biol. Bioenergy 2016, 8, 111-121.

19. Haughton, A.J.; Bohan, D.A.; Clark, S.J.; Mallot, M.D.; Mallot, V.; Sage, R.; Karp, A. Dedicated biomass crops can enhance biodiversity in the arable landscape. Glob. Change Biol. Bioenergy 2016, 8, 1071-1081.

20. Fernando, A.L.; Boleó, S.; Barbosa, B.; Costa, J.; Duarte, M.P.; Monti, A. Perennial grass production opportunities on marginal Mediterranean land. Bioenergy Res. 2015, 8, 15231537. 
21. Landis, D.A.; Gratton, C.; Jackson, R.D.; Gross, K.L.; Duncan, D.S.; Liang, C.; Meehan, T.D.; Robertson, B.A.; Schmidt, T.M.; Stahlheber, K.A.; et al. Biomass and biofuel crop effects on biodiversity and ecosystem services in the North Central US. Biomass Bioenergy 2018, 114, 18-29.

22. Ruf, T.; Makselon, J.; Udelhoven, T.; Emmerling, C. Soil quality indicator response to landuse change from annual to perennial bioenergy cropping systems in Germany. Glob. Change Biol. Bioenergy 2018, 10, 444-459.

23. Dickeduisberg, M.; Laser, H.; Tonn, B.; Isselstein, J. Tall wheatgrass (Agropyron elongatum) for biogas production: Crop management more important for biomass and methane yield than grass provenance. Ind. Crop. Prod. 2017, 97, 653-663.

24. Tufekcioglu, A.; Raich, J.W.; Isenhart, T.M.; Schultz, R.C. Biomass, carbon and nitrogen dynamics of multi-species riparian buffers within an agricultural watershed in lowa, USA. Agrofor. Syst. 2003, 57, 187-198.

25. Glover, J.D.; Culman, S.W.; DuPont, S.T.; Broussard, W.; Young, L.; Mangan, M.E.; Mai, J.G.; Crews, T.E.; DeHaan, L.R.; Buckley, D.H.; et al. Harvested perennial grasslands provide ecological benchmarks for agricultural sustainability. Agr. Ecosyst. Environ. 2010, 137, 3-12.

26. Pulighe, G.; Bonati, G.; Fabiani, S.; Barsali, T.; Lupia, F.; Vanino, S.; Nino, P.; Arca, P.; Roggero, P.P. Assessment of the agronomic feasibility of bioenergy crop cultivation on marginal and polluted land: A GIS-based. Suitability study from Sulcis area, Italy. Energies 2016, 9, 19.

27. Jiang, W.; Jacobson, M.G.; Langholtz, M.H. A sustainability framework for assessing studies about marginal lands for planting perennial energy crops. Biofuel Bioprod. Bior. 2019, 13, 228-240.

28. Podlaski, S.; Pietkiewicz, S.; Choluj, D.; Horaczek, T.; Wisniewski, G.; Gozdowski, D.; Kalaji, H.M. The relationship between the soil water storage and water-use efficiency of seven energy crops. Photosynthetica 2017, 55, 210-218.

29. Agostini, F.; Gregory, A.S.; Richter, G.M. Carbon sequestration by perennial energy crops: Is the jury still out? Bioenergy Res. 2015, 8, 1057-1080.

30. Lewandowski, I.; Scurlock, J.M.O.; Lindwall, E.; Christou, M. The development and current status of perennial rhizomatous grasses as energy crops in the US and Europe. Biomass Bioenergy 2003, 25, 335-361.

31. Nazli, R.I.; Tansi, V.; Ozturk, H.H.; Kusvuran, A. Miscanthus, switchgrass, giant reed, and bulbous canary grass as potential bioenergy crops in a semi-arid Mediterranean environment. Ind. Crop. Prod. 2018, 125, 9-23.

32. Cherney, J.H.; Johnson, K.D.; Lechtenberg, V.L.; Hertel, J.M. Biomass yield, fiber composition and persistence of cool season grasses. Agric. Biomass 1986, 10, 175-186.

33. Shan, C.J.; Liang, Z.S. Jasmonic acid regulates ascorbate and glutathione metabolism in Agropyron cristatum leaves under water stress. Plant Sci. 2010, 178, 130-139.

34. Wu, J.; Yang, X.M.; Wang, H.; Li, H.J.; Li, L.H.; Li, X.Q.; Liu, W.H. The introgression of chromosome 6P specifying for increased numbers of florets and kernels from Agropyron cristatum into wheat. Theor. Appl. Genet. 2006, 114, 13-20.

35. Himmel, M.E.; Ding, S.Y.; Johnson, D.K.; Adney, W.S.; Nimlos, M.R.; Brady, J.W.; Foust, T.D. Biomass recalcitrance: Engineering plants and enzymes for biofuels production. Science 2007, 315, 804-807.

36. Jafari, A.A.; Elmi, A.; Bakhtiari, M. Evaluation of yield and quality traits in 17 population of tall wheatgrass (Agropyron elongatum) grown in a rainfed area of Iran, under two cutting management. Rom. Agric. Res. 2014, 31, 792-797.

37. Lauriault, L.M.; Kirksey, R.E.; Donart, G.B. Irrigation and nitrogen effects on tall wheatgrass yield in the Southern High Plains. Agron. J. 2002, 94, 792-797.

38. Jasinskas, A.; Zaltauskas, A.; Kryzeuiciene, A. The investigation of growing and using of tall perennial grasses as energy crops. Biomass Bioenergy 2008, 32, 981-987.

39. Monono, E.M.; Nyren, R.E.; Berti, M.T.; Pryor, S.W. Variability in biomass yield, chemical composition, and ethanol potential of individual and mixed herbaceous biomass species grown in North Dakota. Ind. Crop. Prod. 2013, 41, 331-339.

40. Jefferson, P.G.; McCaughey, W.P.; May, K.; Woosaree, J.; McFarlane, L. Potential utilization of native prairie grasses from western Canada as ethanol feedstock. Can. J. Plant Sci. 2004, 84, 1067-1075.

41. Martyniak, D.; Zurek, G.; Prokopiuk, K. Biomass yield and quality of wild populations of tall wheatgrass Elymus elongatus (Host.) Runemark. Biomass Bioenergy 2017, 101, 21-29. 
42. Di Nasso, N.N.O.; Angelini, L.G.; Bonari, E. Influence of fertilisation and harvest time on fuel quality of giant reed (Arundo donax L.) in central Italy. Eur. J. Agron. 2010, 32, 219227.

43. Prochnow, A.; Heiermann, M.; Ploechl, M.; Linke, B.; Idler, C.; Amon, T.; Hobbs, P.J. Bioenergy from permanent grassland-A review: 1. Biogas. Bioresour. Techol. 2009, 100, 4931-4944.

44. Florine, S.E.; Moore, K.J.; Fales, S.L.; White, T.A.; Burras, C.L. Yield and composition of herbaceous biomass harvested from naturalized grassland in southern lowa. Biomass Bioenergy 2006, 30, 522-528.

45. El Nashaar, H.M.; Griffith, S.M.; Steiner, J.J.; Banowetz, G.M. Mineral concentration in selected native temperate grasses with potential use as biofuel feedstock. Bioresour. Technol. 2009, 100, 3526-3531.

46. Obernberger, I.; Brunner, T.; Baernthaler, G.; Chemical properties of solid biofuelssignificance and impact. Biomass Bioerg. 2006, 30, 973-982.

47. Ciria, C.S.; Sanz, M.; Carrasco, J.; Ciria, P. Identification of arable marginal lands under rainfed conditions for bioenergy purposes in Spain. Sustainability 2019, 11, 17.

48. Dardel, C.; Kergoat, L.; Hiernaux, P.; Grippa, M.; Mougin, E.; Ciais, P.; Nguyen, C. RainUse-Efficiency: What it tells us about the conflicting Sahel greening and Sahelian paradox. Remote Sens. 2014, 6, 3446-3474.

49. Hendrickson, J.R.; Schmer, M.R.; Sanderson, M.A. Water use efficency by switchgrass compared to a native grass or a native grass alfalfa mixture. Bioenergy Res. 2013, 6, 746754.

50. Frank, A.B.; Bauer, A.; Rooting activity and water-use during vegetative development of crested and western wheatgrass. Agron. J. 1991, 83, 906-910.

51. ISO 14780:2017 Solid Biofuels-Sample Preparation. Available online: https://www.iso.org/standard/66480.html (accessed on 4 April 2020).

52. Llorente, M.J.; Carrasco, J.E.; Comparing methods for predicting the sintering of biomass ash in combustion. Fuel 2005, 84, 1893-1900.

53. Johnson, J.M.F.; Gresham, G.L. Do yield and quality of big bluestem and switchgrass feedstock decline over winter? Bioenergy Res. 2014, 7, 68-77.

54. Sommersacher, P.; Brunner, T.; Obernberger, I. Fuel indexes: A novel method for the evaluation of relevant combustion properties of new biomass fuels. Energy Fuel 2012, 26, 380-390.

55. Zeng, T.; Weller, N.; Pollex, A.; Lenz, V. Blended biomass pellets as fuel for small scale combustion appliances: Influence on gaseous and total particulate matter emissions and applicability of fuel indices. Fuel 2016, 184, 689-700.

56. Nazli, R.I.; Tansi, V. Influences of nitrogen fertilization and harvest time on combustion quality of four perennial grasses in a semi-arid Mediterranean climate. Ind. Crop. Prod. 2019, 128, 239-247.

57. Boehmel, C.; Lewandowski, I.; Claupein, W. Comparing annual and perennial energy cropping systems with different management intensities. Agric. Syst. 2008, 96, 224-236.

58. Pearson, C.H.; Larson, S.R.; Keske, C.M.H.; Jensen, K.B. Native grasses for biomass production at high elevation, in Industrial crops. In Handbook of Plant Breeding, 1st ed.; Cruz, V.M.V., Dierig, D.A., Eds.; Springer: New York, NY, USA, 2014; Volume 9, pp. 101132.

59. Wang, G.J.; Nyren, P.; Xue, Q.W.; Aberle, E.; Eriksmoen, E.; Tjelde, T.; Liebig, M.; Nichols, K.; Nyren, A. Establishment and Yield of Perennial Grass Monocultures and Binary Mixtures for Bioenergy in North Dakota. Agron. J. 2014, 106, 1605-1613.

60. Pedroso, G.M.; Hutmacher, R.B.; Putnam, D.; Six, J.; Van Kessel, C.; Linquist, B.A. Biomass yield and nitrogen use of potential C-4 and C-3 dedicated energy crops in a Mediterranean climate. Field Crops Res. 2014, 161, 149-157.

61. Suyama, H.; Benes, S.E.; Robinson, P.H.; Getachew, G.; Grattan, S.R.; Grieve, C.M. Biomass yield and nutritional quality of forage species under long-term irrigation with saline-sodic drainage water: Field evaluation. Anim. Feed Sci. Tech. 2007, 135, 329-345.

62. Sandor, C. Tall wheatgrass cultivar Szarvasi-1 (Elymus elongatus subsp. ponticus cv. Szarvasi-1) as a potential energy crop for semi-arid lands of eastern Europe. In Sustainable Growth and Applications in Renewable Energy Sources, 1st ed.; Nayeripour, M., Ed.; Intech Open: Pécs, Hungary, 2011; pp. 269-294. 
63. Danielewicz, D.; Surma-Slusarska, B.; Zurek, G.; Martyniak, D. Selected grass plants as biomass fuels and raw materials for papermaking. Part I. Calorific value and chemical composition. Bioresources 2015, 10, 8539-8551.

64. Jensen, K.B.; Johnson, D.A.; Asay, K.H.; Olson, K.C. Seasonal-accumulated growth and forage quality of range grasses for fall and winter grazing. Can. J. Plant Sci. 2002, 82, 329336.

65. Johnson, D.A.; Asay, K.H.; Jensen, K.B. Carbon isotope discrimination and yield in 14 coolseason grasses. J. Range Manag. 2003, 56, 654-659.

66. Cable, D.R. Influence of precipitation on perennial grass production in semidesert southwest. Ecology 1975, 56, 981-986.

67. Tello-Garcia, E.; Huber, L.; Leitinger, G.; Peters, A.; Newesely, C.; Ringler, M.E.; Tasser, E. Drought- and heat-induced shifts in vegetation composition impact biomass production and water use of alpine grasslands. Environ. Exp. Bot. 2020, 169, 10.

68. ISO 17225-1:2014 Solid Biofuels-Fuel Specifications and Classes-Part 1: General requirements. Available online: https://www.iso.org/standard/59456.html (accessed on 4 April 2020).

69. Shield, I.F.; Barraclough, T.J.P.; Riche, A.B.; Yates, N.E. The yield response of the energy crops switchgrass and reed canary grass to fertiliser applications when grown on a low productivity sandy soil. Biomass Bioenergy 2012, 42, 86-96.

70. Jenkins, B.M.; Bakker, R.R.; Wei, J.B. On the properties of washed straw. Biomass Bioenergy 1996, 10, 177-200.

71. Iqbal, Y.; Lewandowski, I. Inter-annual variation in biomass combustion quality traits over five years in fifteen Miscanthus genotypes in south Germany. Fuel Process. Technol. 2014, $121,47-55$.

72. Angelini, L.G.; Ceccarini, L.; Bonari, E. Biomass yield and energy balance of giant reed (Arundo donax L.) cropped in central Italy as related to different management practices. Eur. J. Agron. 2005, 22, 375-389.

73. ISO 17225-6:2014 Solid Biofuels-Fuel Specifications and Classes_Part 6: Graded non woody pellets. Available online: https://www.iso.org/standard/59461.html (accessed on 7 April 2020).

74. FAOSTAT, Food and Agriculture Data. Available at: http://www.fao.org/faostat/en/\#data/QC (accessed on 15 February 2020). 
CAPÍTULO V: Artículo 3: Agropiro alargado (Thinopyrum ponticum (Podp) Barkworth \& D.R.Dewey) en el contexto de una explotación agrícola real, una alternativa sostenible comparado con el centeno (Secale cereale L.) en tierra marginal.

Ciria, C. S., Sastre, C. M., Carrasco, J., \& Ciria, P. (2020). Tall wheatgrass (Thinopyrum ponticum (Podp)) in a real farm context, a sustainable perennial alternative to rye (Secale cereale L.) cultivation in marginal lands (№. 2003.13395). https://doi.org/10.1016/j.indcrop.2020.112184 ISSN: 0926-6690.

Industrial Crops and Products: Q1 in Agronomy. Impact Factor (2019) 4.244 
Resumen: Para hacer frente al aumento previsto de la demanda de cultivos energéticos sin crear conflictos de sostenibilidad con la ocupación de la tierra, los agricultores deben encontrar alternativas en tierras agrícolas marginales, donde la producción de alimentos casi nunca es económica y ambientalmente sostenible. El propósito de este trabajo fue el estudio de la viabilidad de la introducción de nuevos cultivos no alimentarios en las zonas marginales de una explotación agrícola real. Este estudio compara el margen económico y el rendimiento energético y ambiental del cultivo del agropiro alargado en la zona marginal de una explotación agrícola de secano, con el centeno, que era el cultivo anual que se sembraba tradicionalmente en las superficies menos productivas de la explotación. La citada explotación poseía 300 hectáreas de las cuales alrededor del 13\% tenían grandes limitaciones biofísicas. La metodología de este estudio se basó en el uso del margen económico de los cultivos como indicador para la evaluación económica y el análisis de evaluación del ciclo de vida (ACV) como técnica para las evaluaciones energéticas y ambientales. Los resultados del análisis económico mostraron una ligera mejora del margen económico del agropiro alargado (156 €·ha ${ }^{-1} \cdot$ año $^{-1}$ ) en comparación con el centeno (145 €·ha${ }^{1}$.año-1 ${ }^{-1}$. En el análisis ambiental fue estudiada la fijación de $\mathrm{CO}_{2}$ debido al aumento de la materia orgánica del suelo y la reducción del consumo de inputs para la producción de agropiro alargado que produjo un potencial de calentamiento global (PCG) de -1,9 $\mathrm{Mg}$ de $\mathrm{CO}_{2}$ eq $\cdot$ ha ${ }^{-1} \cdot$ año-1 frente a $1,6 \mathrm{Mg}$ de $\mathrm{CO}_{2}$ eq $\cdot \mathrm{ha}^{-1} \cdot$ año-1 obtenido para el centeno. El consumo de energía primaria del agropiro alargado fue menos del $40 \%$ del consumo de centeno. De acuerdo con los resultados obtenidos se concluyó que el agropiro alargado es mejor opción que el centeno desde el punto de vista energético y ambiental y una opción ligeramente mejor desde el punto de vista económico. Teniendo en cuenta estos resultados, la monetización de las reducciones de $\mathrm{CO}_{2}$ del agropiro alargado en comparación con el centeno es esencial para mejorar su margen económico y promover la implantación de este nuevo cultivo en las zonas marginales de las explotaciones agrícolas.

Palabras clave: Agricultura de secano, cultivos herbáceos, análisis económico, análisis de ciclo de vida, potencial de calentamiento global.

\subsection{Introducción}

Hoy en día, la agricultura tiene múltiples retos que afrontar, debido al continuo aumento de la demanda de alimentos y fibras con métodos de producción más eficientes y sostenibles [1]. Otro desafío de la agricultura moderna es la despoblación de las zonas rurales derivada de las constantes pérdidas de empleo en el sector 
primario debido a la modernización de la economía [2] y al progreso de la automatización [3]. En este contexto, los cultivos energéticos en tierras productivas arables crean cada vez más un conflicto con la producción de alimentos y plantea importantes cuestiones sobre la sostenibilidad de esta opción [4]. Ejemplo de ello es el apoyo que se da al cultivo de maíz (Zea mays L.) para la producción de biogás en los países de Europa central, que está causando graves consecuencias para el medio ambiente [5], cuando había otros métodos de producción más sostenibles desde el punto de vista ambiental [6]. Sin embargo, las nuevas técnicas para mejorar el rendimiento de los cultivos energéticos [7] y el uso de especies perennes en tierras marginales como fuente potencial para la producción de biomasa [9] se consideran formas sostenibles de superar los problemas anteriores, aunque el escaso margen económico se ha identificado como una de las principales barreras que hay que derribar [9].

La última reforma de la PAC europea aprobada en 2015 introdujo pagos vinculados a las buenas prácticas ambientales y climáticas (prácticas ecológicas) comprometiendo alrededor del $50 \%$ de los pagos directos totales de los agricultores, algunos de los cuales, tenían que introducir cambios en sus rotaciones de cultivos. A este respecto, las gramíneas perennes pueden representar una nueva alternativa que puede integrarse en los planes de intensificación de la agricultura como sistemas de producción de forraje, combinando altos rendimientos con beneficios económicos y ambientales [10] y permitir a los agricultores cumplir los requisitos de la PAC en zonas degradadas. Al considerar posibles nuevas alternativas de cultivos, en lugar de los cultivos tradicionales, se ha informado ampliamente de que el uso de estas especies es una opción ambientalmente sostenible en la UE [11]. Históricamente, el centeno ha sido el cereal tradicional establecido en las zonas de menor rendimiento cerealista, debido a su conocida alta rusticidad y mejor adaptación en comparación con el trigo [12].

Muchos estudios en la literatura proporcionan datos agronómicos [13], económicos [14] y ambientales [15] sobre cultivos energéticos en tierras agrícolas marginales. Los estudios se basan en los resultados obtenidos en parcelas aisladas experimentales y de demostración. Además, hay estudios a gran escala que, sólo se centran en la parte agronómica de los cultivos energéticos [16] pero se dispone de muy poca información, si es que se dispone de ella, sobre el impacto que puede tener sobre el equilibrio económico y medioambiental de las explotaciones la introducción de nuevos cultivos en zonas marginales de los sistemas agrícolas de secano. 
En este contexto, el objetivo principal de este trabajo es evaluar si el agropiro alargado es mejor opción que el centeno, teniendo en cuenta el rendimiento económico, ambiental y energético de ambas especies cultivadas en las tierras marginales de una verdadera explotación agrícola de secano. Con esta información, los productores pueden disponer de nuevas pruebas científicas para tomar una decisión sobre qué alternativa es mejor para sembrar en zonas marginales. También se ha evaluado el rendimiento económico de los cultivos tradicionales sembrados en la zona no marginal de la explotación agrícola para elaborar las cifras económicas de la misma y poner en evidencia las diferencias de rentabilidad de los cultivos de las tierras marginales en el contexto de una explotación agrícola.

\subsection{Material y métodos}

\subsubsection{Descripción de la explotación estudiada}

El estudio está basado es una explotación agrícola representativa de la meseta Norte de España, una de las zonas de cultivo de cereales de invierno más extensas del sur de Europa, pero fuertemente afectada por factores edafoclimáticos y socioeconómicos marginales. El Joint Research Center (JRC) la define como una tierra de cultivo de intensidad media-baja, con graves limitaciones y con bajas tasas de productividad [17]. El objeto principal de la explotación es el cultivo de cereales de invierno en condiciones de secano con prácticas de laboreo tradicional principalmente.

La explotación tenía una extensión de 302 ha distribuidas en 38 parcelas con una superficie media de 7,9 ha (la superficie máxima era de 37 ha y la mínima de 1 ha por parcela). La distancia máxima entre las parcelas de la explotación era de $15 \mathrm{~km}$. Un total de 40 hectáreas de la superficie de la explotación se consideraban tierras marginales debido a las limitaciones económicas (bajo rendimiento de los cereales) y biofísicas (bajo contenido de materia orgánica $(\mathrm{OM})(\leq 1 \%)$ y pedregosidad $(\geq 15 \%$ del volumen del suelo).

La explotación tenía su propia maquinaria necesaria para la mecanización de los cultivos y contaba con $2000 \mathrm{~m}^{2}$ de instalaciones para el almacenamiento de la cosecha y guardar los equipos agrícolas.

\subsubsection{Manejo de los cultivos en la explotación}

El propósito principal de la explotación agraria era la producción de cereales de invierno que obtenía como subproducto de esta actividad la paja que también se 
vendía. El laboreo convencional se utilizaba para producir estos cultivos. Las especies sembradas en la tierra marginal durante los cuatro años estudiados fueron principalmente cereales de invierno y también girasol (Helianthus annus L.). Los cereales de invierno fueron el trigo (Triticum aestivum L.) que fue el cultivo principal (promedió 111 ha de ocupación), la cebada con una superficie media anual de 62 ha y el triticale (Triticosecale $x$ Wittmack) con una distribución media anual de 32 ha. La distribución media del girasol fue de 30 ha y del barbecho de 27 ha, en el periodo de estudio. El agricultor utilizó semillas comerciales multiplicadas los años anteriores en la propia explotación agrícola, excepto las semillas híbridas de girasol que las compraba cada año. El cultivo tradicional sembrado en las zonas marginales de la explotación era el centeno.

La metodología para sembrar cereales en la explotación consistía en una labor de alzado y otra complementaria de cultivador, y entre medio un abonado de fondo en otoño (de principios de octubre a diciembre) del complejo NPK antes de la siembra. Después de la siembra, se realizaba la fertilización nitrogenada con nitrato de amónico cálcico con un $27 \%$ de riqueza en nitrógeno (NAC 27\%), un pase de rodillo a principios de la primavera (mediados de marzo) y la pulverización de productos fitosanitarios para el control de malas hierbas en abril y principios de mayo en la cebada, el triticale y el centeno. Para el trigo, el tratamiento con herbicidas se hacía a finales de otoño. El período de siembra de los cereales fue de octubre a principios de diciembre.

El girasol se sembraba a finales de mayo y se cosechaba a mediados de octubre. Las parcelas eran labradas a principios de invierno y luego, se pasaba un cultivador dos veces antes de sembrar en primavera. Se aplicaba glifosato antes de la siembra.

La tierra que se dejaba en barbecho se labraba a finales de la primavera y se cultivaba en verano para preparar las parcelas para el siguiente período de siembra.

A principios del otoño de 2013 se estableció la parcela de agropiro alargado en la tierra marginal de la explotación. La preparación de la tierra fue similar a la de los cereales de invierno con la misma fertilización. Se aplicó un tratamiento fitosanitario en el año de establecimiento contra las malas hierbas dicotiledóneas. La fertilización con NAC $27 \%$, la siega y el empacado del cultivo en los primeros días de agosto fueron los únicos trabajos de campo que se realizaban cada año.

En la tabla 23 se muestran los inputs utilizados en los cultivos agrícolas durante los cuatro años del estudio. 
Tabla 23. Inputs y dosis utilizadas para cada cultivo durante los años de estudio.

\begin{tabular}{|c|c|c|c|c|c|c|}
\hline & \multicolumn{4}{|c|}{ Tierra no marginal } & \multicolumn{2}{|c|}{ Tierra marginal } \\
\hline & Trigo & Triticale & Cebada & Girasol & Centeno & Agropiro \\
\hline $\begin{array}{l}\text { Cultivar } \\
\text { Dosis de }\end{array}$ & Berdún & Verato & Cometa & Krisol & Petkus & Szarvasi1 \\
\hline $\begin{array}{c}\text { siembra } \\
\left({\left.\mathrm{Mg} \cdot h a^{-1}\right)}^{2}\right.\end{array}$ & 0,20 & 0,20 & 0,18 & 0,004 & 0,15 & 0,02 \\
\hline $\begin{array}{l}\text { Producto } \\
\text { (NPK) }\end{array}$ & $8-24-8$ & $8-24-8$ & 8-15-15 & - & 8-24-8 & 8-24-8 \\
\hline $\begin{array}{c}\text { Abonado de } \\
\text { fondo } \\
\left(\mathrm{Mg} \cdot \mathrm{ha}^{-1}\right)\end{array}$ & 0,30 & 0,25 & 0,30 & - & 0,20 & $\begin{array}{c}\text { 0,30 (Año } \\
\text { de } \\
\text { siembra) }\end{array}$ \\
\hline Producto & NAC $27 \%$ & NAC $27 \%$ & NAC $27 \%$ & - & $\begin{array}{l}\text { NAC } \\
27 \%\end{array}$ & NAC $27 \%$ \\
\hline $\begin{array}{l}\text { Abonado de } \\
\text { cobertera } \\
\left({\left.\mathrm{Mg} \cdot \mathrm{ha}^{-1}\right)}^{-1}\right.\end{array}$ & 0,30 & 0,20 & 0,20 & - & 0,15 & 0,15 \\
\hline Herbicida & $\begin{array}{c}\text { Clorsulfuron } \\
75 \%+ \\
\text { Clortoluron } \\
50 \%\end{array}$ & $\begin{array}{c}2,4-\mathrm{D} \\
\text { acido } \\
60 \%\end{array}$ & $\begin{array}{c}\text { Metsulfuron } \\
\text { methyl } \\
11,1 \% \\
\text { Tribenuron- } \\
\text { methyl } \\
22,2 \%+2,4- \\
\text { D acid } 34,5 \% \\
+ \text { MCPA } \\
34,5 \%(2- \\
\text { methyl-4- } \\
\text { chlorophenox } \\
\text { yacetic acid) }\end{array}$ & $\begin{array}{c}\text { Glifosato } \\
45 \%\end{array}$ & $\begin{array}{l}2,4-D \\
\text { acido } \\
60 \%\end{array}$ & $\begin{array}{c}2,4-\mathrm{D} \\
\text { acido } \\
60 \%\end{array}$ \\
\hline $\begin{array}{l}\text { Dosis de } \\
\text { herbicida } \\
\text { (ud. } \text { ha }^{-1} \text { ) }\end{array}$ & $20 \mathrm{~g}+2 \mathrm{~L}$ & $0,8 \mathrm{~L}$ & $45 \mathrm{~g}+1 \mathrm{~L}$ & $\begin{array}{c}2,5 \mathrm{~L} \\
\text { Presiembra }\end{array}$ & $0,8 \mathrm{~L}$ & $1 \mathrm{~L}$ \\
\hline
\end{tabular}

Los cereales se cosechaban a mediados de julio; el girasol a mediados de octubre y la paja de cereal se empacaba después de terminar el período de cosecha. El agropiro alargado se segaba a principios de agosto dejando el forraje 4-5 días en la parcela para la henificación y finalmente se empacaba.

\subsubsection{Condiciones edafoclimáticas}

El clima en la zona de estudio era mediterráneo-continentalizado, caracterizado por inviernos fríos, veranos cálidos y bajo nivel de precipitaciones. Las condiciones meteorológicas en la zona de cultivo correspondientes al período de estudio se tomaron de la estación más cercana del AEMET. La temperatura media anual durante el estudio fue de $11,0^{\circ} \mathrm{C}$, con una temperatura máxima absoluta en julio de 2015 de $36^{\circ} \mathrm{C}$ y una temperatura mínima absoluta en enero de 2017 de $-11,7^{\circ} \mathrm{C}$. La precipitación anual media total fue de $513 \mathrm{~mm}$, siendo el año más húmedo el 2014 (595 mm) y el más seco el 2017 (315 mm). El período libre de heladas extremo fue 
desde principios de mayo hasta mediados de septiembre. El período de sequía fue generalmente de julio a agosto.

La tierra marginal de la explotación se caracterizaba por un suelo arenoso (88\% de arena, $8 \%$ de limo y $4 \%$ de arcilla), un contenido de materia orgánica del $0,54 \%$, un contenido de nitrógeno del $0,03 \%, 6,73 \mathrm{mg} \cdot \mathrm{kg}^{-1}$ de fósforo asimilable y $58,19 \mathrm{mg} \cdot \mathrm{kg}^{-1}$ de potasio, con una densidad aparente de $1,37 \mathrm{Mg} \cdot \mathrm{m}^{-3} \mathrm{y}$ un contenido en elementos gruesos (>2mm) del 29,58\% en volumen. Estos suelos presentaban un alto drenaje, en consecuencia, una baja retención de agua, un bajo contenido de nutrientes, altas pérdidas por lixiviación y ningún problema de salinidad. En general, es un suelo de baja productividad para la mayoría de los cultivos alimentarios comunes.

Se tomaron muestras de suelo de la capa más superficial $(0-30 \mathrm{~cm})$ de acuerdo con la norma ISO 10381-1; para textura (ISO 11277), pH (ISO 10390), conductividad eléctrica (ISO 11265), contenido en MO (ISO 10694), contenido en fósforo Olsen (ISO 11263), contenido en potasio (ISO 11260) y contenido en amonio y nitratos (ISO/TS 14256-1 EX.).

\subsubsection{Gestión de la tierra marginal}

Con el fin de estudiar la alternativa más adecuada para las tierras marginales de la explotación, en octubre de 2013 se establecieron en la zona marginal de la explotación dos parcelas experimentales, una de centeno (el cultivo alimentario tradicional sembrado en este tipo de tierras) y otra de agropiro alargado, como cultivo alternativo, de dos hectáreas cada una, gestionadas como se comentó en la sección 5.2.2. El análisis económico, energético y ambiental de ambas parcelas se realizó durante los cuatro años de estudio (octubre de 2013 a septiembre de 2017).

\subsubsection{Análisis económico}

El análisis económico de la explotación agrícola, incluidas las dos alternativas sobre la zona marginal descritas en la sección 5.2.4, se realizó teniendo en cuenta los precios de las materias primas (semillas, fertilizantes, herbicidas, combustibles) y la maquinaria utilizada por el agricultor durante el período de estudio (4 años). Los costes de mano de obra y maquinaria, incluyendo los aperos agrícolas para cada actividad, se calcularon de acuerdo con las características técnicas, la capacidad real de realizar el trabajo, los costes de utilización y las condiciones de la explotación, como el tipo de suelo. El cálculo de los mismos se realizó utilizando la base de datos proporcionada por el Ministerio de Agricultura de España [18]. Las diferencias entre los costes y las 
ventas más las ayudas de la PAC fueron el resultado final mostrado en el balance económico.

El estudio económico de la parte no marginal de la explotación se realizó calculando la media ponderada de los inputs y outputs de los diferentes cultivos sembrados en la explotación durante los años de estudio con el precio real antes de impuestos de las facturas proporcionadas por el agricultor. En la zona marginal los cálculos de costes se realizaron extrapolando los resultados de las parcelas experimentales ( 2 ha cada una) a toda la superficie de tierra marginal (40 ha) de la explotación, ya que la tierra marginal de la explotación presentaba limitaciones biofísicas similares y una producción de cereales (centeno) equivalente a lo largo de los años.

Los costes de implantación del agropiro alargado se distribuyeron a lo largo de los cuatro años del estudio, aunque hay experiencias en la en la región de estudio que informan de rendimientos competitivos de ese cultivo durante seis años por lo menos [19] y otros estudios para el mismo cultivo informaron de períodos de vida de 10 a 15 años [20].

Para la biomasa recolectada de agropiro alargado se consideró el mismo precio que tiene la paja de cereal para alimentación animal según los precios del mercado español durante el período considerado, debido a la falta de mercado actual para este producto.

\subsubsection{Evaluación energética y ambiental}

\section{A) Objetivo y alcance}

El objetivo de la evaluación era determinar y comparar los consumos de energía y los impactos ambientales de las dos alternativas de cultivos que se realizan en la zona marginal de la explotación agrícola descrita en la sección 5.2.2, desde la perspectiva del ciclo de vida. El ACV es la herramienta de gestión ambiental, regulada por las normas ISO 14040 e ISO 14044, seleccionada para realizar las evaluaciones.

El tipo de ACV realizado fue atributivo, desde la cuna hasta la puerta de la explotación (Figura 16). Los límites del estudio incluyeron: a) la producción y el transporte de los inputs agrícolas consumidos; b) la fabricación y el uso de maquinaria, incluido el consumo de gasóleo, así como las emisiones de gases de escape que afectan al potencial de calentamiento global (PCG), y c) la aplicación de fertilizantes y 
las emisiones de campo asociadas que afectan al PCG. Para llevar a cabo los análisis del ciclo de vida se utilizaron la herramienta informática Simapro 9.0 y la base de datos europea Ecoinvent 3.5. Se seleccionó la versión "corte/asignación, contenido reciclado" de esta base de datos para la modelización porque sigue el mismo enfoque que el Ecoinvent 1 y 2 y, por lo tanto, permite mejores comparaciones con otros estudios de ACV que utilizaron esta base de datos.

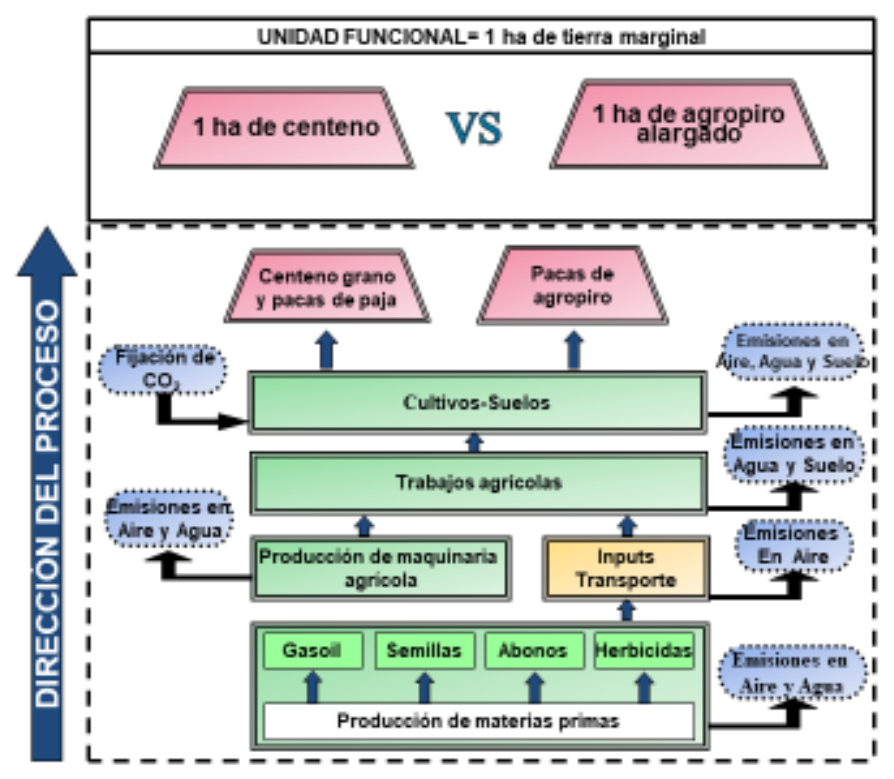

Figura 16. Descripción del sistema de evaluación ambiental y energética gráficamente. Incluye el diagrama de flujo con todos los procesos considerados, los límites del sistema, así como la unidad funcional especificada para las dos alternativas de cultivo en la zona de tierras marginales de la explotación en estudio

Como se muestra en la figura 16, la unidad funcional seleccionada para la evaluación es 1 ha de cada una de las dos alternativas ensayadas en la zona marginal de la explotación.

B) Análisis del inventario del ciclo de vida

Los métodos utilizados para la modelización de los inventarios siguieron los descritos en Sastre et al (2016) [13], que afectaban a los cálculos del potencial de calentamiento global y a cálculos energéticos, que fueron pertinentes para la fase de cultivo. La modelización del inventario se hizo coherente con los análisis económicos. En esta sección se describen detalladamente todos los datos necesarios como inputs para los métodos anteriores y los procesos para su obtención. Los trabajos de campo y las materias primas anuales consideradas fueron las mismas todos los años en el 
caso del centeno y en el caso del agropiro alargado, los inputs y los trabajos de campo adicionales del año de implantación se distribuyeron durante los años que duró el estudio (sección 5.2.5), para obtener un promedio representativo. La productividad media de los cultivos, el consumo de fertilizantes, herbicidas y semillas se tomaron de la tabla 23. El consumo de gasóleo de la maquinaria agrícola, así como su amortización (proporción de la producción y el mantenimiento atribuible a su uso para el cultivo) se calcularon según los trabajos de campo realizados (sección 5.2.5) utilizando la base de datos del Ministerio de Agricultura de España [18]. Los procesos de fondo para la modelización de todos los inventarios se tomaron de Ecoinvent 3.5.

La producción de semillas se modeló considerando un rendimiento de igual al rendimiento producido por el centeno (tabla 24) y de $0,165 \mathrm{Mg} \cdot \mathrm{ha}^{-1} \cdot \mathrm{año}^{-1}$ para agropiro alargado. El rendimiento de la semilla agropiro alargado se estimó en un $3 \%$ del rendimiento de la biomasa del cultivo (Tabla 24) [21]. Los inputs considerados para la modelización del inventario de semillas fueron los mismos que los consumidos para las alternativas evaluadas, sumando el consumo de energía adicional para el transporte y el procesamiento de las semillas, como se describe en Nemecek et al., (2007) [22]. Las dosis de siembra de las semillas fueron de 0,02 $\mathrm{Mg} \cdot \mathrm{ha}^{-1}$ para el agropiro alargado y $0,15 \mathrm{Mg} \cdot \mathrm{ha}^{-1}$ para el centeno.

Los trabajos realizados para el cultivo del agropiro alargado dieron como resultado un consumo de gasóleo de $31,95 \mathrm{~L} \cdot \mathrm{ha}^{-1} \mathrm{y}$ una amortización de la maquinaria de 0,00099 Mg.ha-1 del tractor, 0,00020 de $\mathrm{Mg}^{-h^{-1}}$ de los aperos de laboreo y de $0,00251 \mathrm{Mg} \cdot \mathrm{ha}^{-1}$ de otros aperos. En el caso del centeno, el consumo medio de gasóleo fue de 55,39 L·ha-1 y la amortización media de la maquinaria fue de 0,00135 $\mathrm{Mg} \cdot \mathrm{ha}^{-1}$ del tractor, 0,00098 $\mathrm{Mg} \cdot \mathrm{ha}^{-1}$ de la cosechadora, 0,00082 de $\mathrm{Mg} \cdot \mathrm{ha}^{-1}$ de los aperos de laboreo y de $0,00201 \mathrm{Mg} \cdot \mathrm{ha}^{-1}$ de otros aperos.

Las emisiones de gases de escape de la maquinaria agrícola se consideraron según el consumo de gasóleo [22]. También se contabilizaron las emisiones de $\mathrm{N}_{2} \mathrm{O}$ [23] debido a la aplicación de fertilizantes, la descomposición de los residuos de los cultivos y la conversión de $\mathrm{NH}_{3}$ en $\mathrm{N}_{2} \mathrm{O}$. Las emisiones medias anuales de $\mathrm{N}_{2} \mathrm{O}$ fueron de $0,000817 \mathrm{Mg} \cdot \mathrm{ha}^{-1} \cdot \mathrm{año}^{-1}$ para el agropiro alargado y de $0,001757 \mathrm{Mg} \cdot \mathrm{ha} \mathrm{a}^{-1} \cdot \mathrm{año}^{-1}$ para el centeno.

Como las técnicas de laboreo convencional no ayudan a aumentar la materia orgánica del suelo [24] y la práctica común para las tierras marginales de la explotación es el cultivo de centeno con recolección de paja, se ha considerado que el contenido de materia orgánica $(0,540 \%)$ y el contenido de carbono orgánico $(0,313 \%)$ obtenidos 
de los análisis iniciales del suelo $(0-30 \mathrm{~cm})$ eran estables y correspondían a un punto de equilibrio. En la bibliografía hay estudios que sostienen que el centeno mejora la materia orgánica del suelo sólo cuando se utiliza como cultivo cobertor bajo condiciones de laboreo convencional [25], pero no se han encontrado pruebas que sugieran que el centeno mejora la materia orgánica del suelo cuando se siembra utilizando la técnica de laboreo convencional y se recolecta tanto el grano como la paja. Por lo tanto, se consideró que la alternativa del centeno era una continuación de las prácticas comunes descritas anteriormente en las tierras marginales de la explotación agrícola y, por lo tanto, esto no cambiaba el equilibrio de la composición del suelo. Dado este hecho, no se consideró ningún crédito o deuda de $\mathrm{CO}_{2}$, debido a los cambios en la materia orgánica del suelo y el carbono orgánico con el sistema de cultivo de centeno. Sin embargo, en el caso del agropiro alargado, debido a su carácter perenne, la acumulación de biomasa subterránea y la ausencia de operaciones de laboreo [26], se esperaba un incremento de la materia orgánica del suelo y del carbono. Esta ausencia de laboreo también contribuye a mantener la calidad de la materia orgánica debido a la menor actividad de los microorganismos del suelo, lo que ayudará a mantenerla más estable [27]. Estos incrementos fueron confirmados por los análisis de suelo de las parcelas experimentales realizados después de tres años de implantación del cultivo que revelaron un aumento hasta el 0,677\% y el 0,393\% de los contenidos de materia orgánica y carbono orgánico del suelo, respectivamente. El aumento del carbono orgánico del suelo correspondió a una fijación anual de 0,765 Mg $\mathrm{C} \cdot \mathrm{ha}^{-1}$ equivalente a 2,805 $\mathrm{Mg} \mathrm{CO} \cdot \mathrm{Ca}^{-1}$ Estas cifras se obtuvieron utilizando la densidad aparente del suelo $\left(1,370 \mathrm{Mg}\right.$ suelo. $\left.\mathrm{m}^{-3}\right)$ de la capa de 0-30 $\mathrm{cm}$ y considerando la influencia de los elementos gruesos (>2 $\mathrm{mm})(29,58 \%$ en volumen) que se eliminaron previamente de las muestras utilizadas para determinar el contenido de materia orgánica.

\subsubsection{Métodos de evaluación del impacto}

Se seleccionaron dos métodos de evaluación de impactos para transformar los elementos del ACV en impactos.

El método de evaluación del impacto para la evaluación del PCG fue el del Grupo Intergubernamental de Expertos sobre el Cambio Climático (IPCC) 2013 para un horizonte temporal de "100 años" [28]. 
El análisis de los requisitos de energía acumulada (CERA) fue el método seleccionado para evaluar la energía primaria consumida por las dos alternativas evaluadas [28].

\subsection{Resultados y discusión}

\subsubsection{Balance económico de la explotación}

Como era de esperar, los cultivos de mayor rentabilidad fueron los sembrados en la zona no marginal de la explotación (Tabla 24) (media anual ponderada durante cuatro años): trigo: $416,62 € \cdot$ ha $^{-1}$, cebada: $339,31 € \cdot$ ha $^{-1}$ y girasol: $316,04 € \cdot h^{-1}$. Las cifras incluyen las ayudas de la PAC, un total de $165 € \cdot$ ha $^{-1}$ en todos los casos.

Los cultivos en la zona marginal también lograron resultados positivos, aunque tuvieron un margen mucho menor que los de las zonas no marginales de la explotación agrícola, siendo ligeramente más rentable la opción de sembrar agropiro alargado $\left(156,19 € \cdot h^{-1} \cdot a_{n ̃ o}^{-1}\right)$ en comparación con el centeno $\left(145,14 € \cdot h^{-1} \cdot a_{n ̃ o}{ }^{-1}\right)$. Sin embargo, el balance económico fue negativo para ambos cultivos cuando no se consideraron las ayudas de la PAC (Tabla 24), lo que demuestra que estos pagos fueron esenciales para obtener un margen de beneficio positivo en el caso de los cultivos de la zona marginal. De hecho, sin las ayudas de la PAC el saldo económico era de $-19,86 € \cdot h a^{-1} \cdot a_{n} o^{-1}$ para el centeno y de $-8,81 € \cdot h^{-1} \cdot a n ̃ o^{-1}$ para agropiro alargado. Los principales costes (Tabla 24) de los cultivos en las tierras marginales fueron los asociados a la maquinaria y la mano de obra (54\% de centeno y $53 \%$ agropiro alargado), seguidos por los costes de los fertilizantes (34\% de centeno y $33 \%$

agropiro alargado). Las semillas (10\% de centeno y $14 \%$ para agropiro alargado) y las herbicidas ( $1,8 \%$ de centeno y $0,7 \%$ para el agropiro alargado) fueron costes menos relevantes. 
Tabla 24. Balance económico de los cultivos sembrados en la explotación de estudio (valores anuales medios ponderados en los 4 años).

\begin{tabular}{|c|c|c|c|c|c|c|c|}
\hline & \multicolumn{5}{|c|}{ Tierra no marginal } & \multicolumn{2}{|c|}{ Tierra marginal } \\
\hline & Trigo & Cebada & Triticale & Girasol & Barbecho & Centeno & Agropiro \\
\hline Semillas $\left(€ \cdot\right.$ ha $\left.^{-1}\right)$ & 44,48 & 37,11 & 36,54 & 40,86 & & 31,00 & 35,00 \\
\hline Herbicidas $\left(€ \cdot\right.$ ha $\left.^{-1}\right)$ & 21,89 & 20,50 & 5,50 & 14,51 & & 5,50 & 1,73 \\
\hline Fertilizantes $\left(€ \cdot\right.$ ha $\left.^{-1}\right)$ & 174,94 & 168,78 & 133,26 & 0,00 & & 103,80 & 81,30 \\
\hline $\begin{array}{l}\text { Maquinaria y mano de obra } \\
\left(€ \cdot \mathrm{h}^{-1}\right)\end{array}$ & 186,20 & 182,99 & 177,10 & 160,92 & 59,47 & 164,50 & 131,85 \\
\hline Costes totales & 427,51 & 409,38 & 352,40 & 216,28 & 59,47 & 304,80 & 249,87 \\
\hline Rendimiento (Mg.ha-1) & 3,38 & 3,11 & 2,56 & 1,14 & & 1,50 & \\
\hline Precio de venta $\left(€ \cdot \mathrm{Mg}^{-1}\right)$ & 174,78 & 161,52 & 155,43 & 322,76 & & 158,69 & \\
\hline Rendimiento de paja $\left(\mathrm{Mg} \cdot \mathrm{ha}^{-1}\right)$ & 2,03 & 1,86 & 1,54 & 0,00 & & 1,07 & 5,50 \\
\hline Precio venta de paja $\left(€ \cdot \mathrm{Mg}^{-1}\right)$ & 43,83 & 43,83 & 43,83 & & & 43,83 & 43,83 \\
\hline Ventas totales $\left(€ \cdot \mathrm{ha}^{-1}\right)$ & 679,13 & 583,68 & 466,09 & 367,33 & & 284,93 & 241,07 \\
\hline Pagos PAC $\left(€ \cdot\right.$ ha $\left.^{-1}\right)$ & 165,00 & 165,00 & 165,00 & 165,00 & 165,00 & 165,00 & 165,00 \\
\hline Balance sin PAC $\left(€ \cdot\right.$ ha $\left.^{-1}\right)$ & 251,62 & 174,31 & 113,69 & 151,04 & $-59,47$ & $-19,86$ & $-8,81$ \\
\hline Balance con PAC ( $\left(€ \cdot\right.$ ha $\left.^{-1}\right)$ & 416,62 & 339,31 & 278,69 & 316,04 & 105,53 & 145,14 & 156,19 \\
\hline
\end{tabular}


Si las tierras marginales de la explotación (40 ha) se sembraran completamente de agropiro alargado, los ingresos totales de la explotación, teniendo en cuenta la superficie media de cada cultivo citado en la sección 5.2.2 y el balance económico (Tabla 24), serían de 94.778,44 €·año-1; en comparación con 94.336,16 €·año-1 cuando se siembra de centeno. Esto aparece un incentivo económico muy pobre para que el agricultor se decida por sembrar agropiro alargado, debido a que el incremento final del balance económico es sólo del $0,5 \%$ en comparación con el centeno, considerando también los inconvenientes relativos a la ocupación permanente de la tierra y los riesgos de mercado asociados al nuevo cultivo. Para estudiar la influencia del aumento de la superficie marginal de la explotación, se estimó una superficie marginal de hasta el $50 \%$ de la superficie total de la explotación, revelando un ligero incremento $(2,3 \%)$ de la diferencia económica a favor del agropiro alargado en comparación con la opción del centeno. Sin embargo, en la siguiente sección 5.3.2 se analizan importantes ventajas del agropiro alargado en comparación con el centeno, relacionadas con el menor impacto ambiental y el menor consumo de energía.

La sensibilización de los consumidores debería ayudar a demostrar los beneficios ambientales del agropiro alargado, además de otro tipo de beneficios como la creación de trabajos realizados en su mayoría por trabajadores autónomos [29] que trabajen en un contexto de creciente digitalización y conexión permanente con toda la cadena de valor [30]

\subsubsection{Evaluación del potencial de calentamiento global de la explotación y de la energía primaria consumida para las alternativas de cultivo en tierra marginal}

Los resultados del PCG y de la energía primaria se señalan para cada alternativa propuesta en las figuras 17, 18 y 19. Los resultados del ACV y balance energético del agropiro alargado se hicieron considerando la siega de la planta entera, henificada la biomasa y empacada y los resultados del centeno se hicieron cosechando el grano y empacando la paja. En la figura 17 se evaluó por fases el potencial de calentamiento global para un horizonte temporal de 100 años utilizando la metodología del IPCC 2013, para ambas alternativas. 


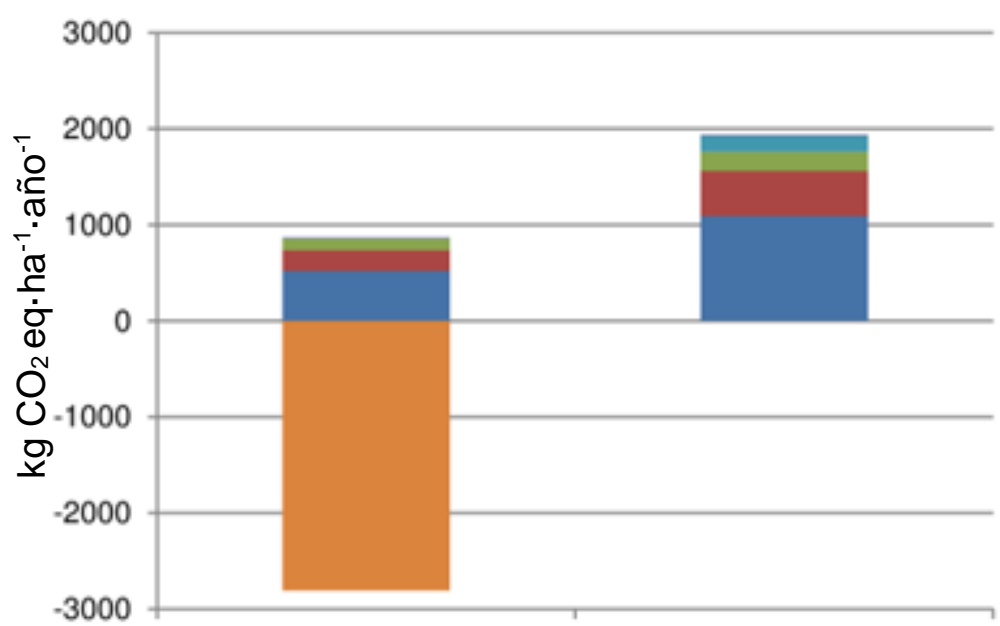

Agropiro alargado

Centeno

- Herbicidas (producción y transporte)

- Trabajos de campo

- Fertilización (producción y transporte)

- Semillas (producción y transporte

- Emisiones de fertilizantes y del suelo - Fijación de $\mathrm{CO} 2$

Figura 17. Potencial de calentamiento global para cada alternativa.

La producción y el transporte de fertilizantes fue la fase que generó mayores impactos en el PCG, contabilizada como la suma de todas las fases que generaron impactos positivos (Figura 17), con un $60,2 \%$ para agropiro alargado y un 56,6\% para el centeno. Las emisiones del suelo y de los fertilizantes derivadas de la liberación de $\mathrm{N}_{2} \mathrm{O}$ principalmente, produjeron el segundo impacto positivo más alto en el PCG con un $25,1 \%$ para el agropiro alargado y un $24,1 \%$ para el centeno. Los trabajos de campo, la producción y el transporte de semillas tuvieron menor influencia en la contabilización del PCG, con un 14,6\% en el caso del agropiro alargado y un 19,2\% en el caso del centeno. La producción de semillas produjo un impacto menor en las emisiones de PCG del agropiro en comparación con el centeno (0,7\% frente a 8,7\%) debido a la menor dosis de siembra requerida y al carácter perenne del cultivo. La producción y el transporte de plaguicidas tuvieron los menores efectos en los impactos del PCG de todas las fases estudiadas, con cifras inferiores al $0,2 \%$ del PCG total en las dos alternativas.

Todas las fases del cultivo del agropiro alargado que contribuyeron a aumentar el PCG generaron en conjunto $0,863 \mathrm{Mg}$ de $\mathrm{CO} 2 \mathrm{eq} \cdot \mathrm{ha}^{-1} \cdot \mathrm{año}^{-1}$, notablemente inferior al impacto de estas fases para el cultivo del centeno $\left(1,934 \mathrm{Mg}\right.$ de CO2 eq $\left.\cdot \mathrm{ha}^{-1} \cdot \mathrm{año}^{-1}\right)$ (Figura 17). La fijación de $\mathrm{CO}_{2}$ debida al aumento de la materia orgánica del suelo tuvo una influencia significativa para el agropiro, permitiendo una reducción de $2.805 \mathrm{Mg}$ $\mathrm{CO} 2 \mathrm{eq} \cdot \mathrm{ha}^{-1} \cdot$ año $^{-1}$ de PCG en el período evaluado. Esto equivalía al 3,5\% del PCG producido por la suma de las fases que producen un aumento del PCG de los cultivos. 
No se consideró la fijación neta de $\mathrm{CO}_{2}$ para el centeno, ya que este cultivo con el manejo con el que se producía en la explotación se consideró que no alteraba el equilibrio de la materia orgánica del suelo (véase 5.2.6.B). El balance negativo del PCG obtenido para el agropiro $\left(-1,942 \mathrm{Mg} \mathrm{CO} 2 \mathrm{eq} \cdot \mathrm{ha}^{-1} \cdot \mathrm{año}^{-1}\right)$ podría tener una importancia notable si esta externalidad positiva se monetizara en forma de pagos PAC.

La energía primaria consumida para la producción de agropiro $\left(6,0 \mathrm{GJ} \cdot \mathrm{ha}^{-1} \cdot\right.$ año $^{-}$ 1) fue aproximadamente el $38 \%$ de la energía consumida para la producción de centeno con 15,8 GJ.ha-1 año $^{-1}$ (Figura 18). Esta diferencia entre ambos cultivos se debe al carácter perenne del agropiro, ya que la siembra, el abonado de fondo y los trabajos de campo para la preparación del terreno sólo se realizan el primer año de su vida útil. El consumo de fertilizantes fue la fase que más energía consumió en las dos alternativas estudiadas, con un $67,1 \%$ en el caso del agropiro alargado y un $55,5 \%$ en el caso del centeno, mientras que el consumo de semillas fue la segunda fase que más energía consumió en el caso del centeno, con un $24,5 \%$, y la tercera en el caso agropiro, con sólo un 2,1\% de los costes energéticos totales del cultivo. Los trabajos de campo fueron la segunda fase de consumo de energía para el agropiro alargado con $30,4 \%$ y la tercera para el centeno con $19,6 \%$. Los plaguicidas tuvieron muy poca influencia en el consumo de energía primaria con menos del $0,5 \%$ para los dos cultivos evaluados.

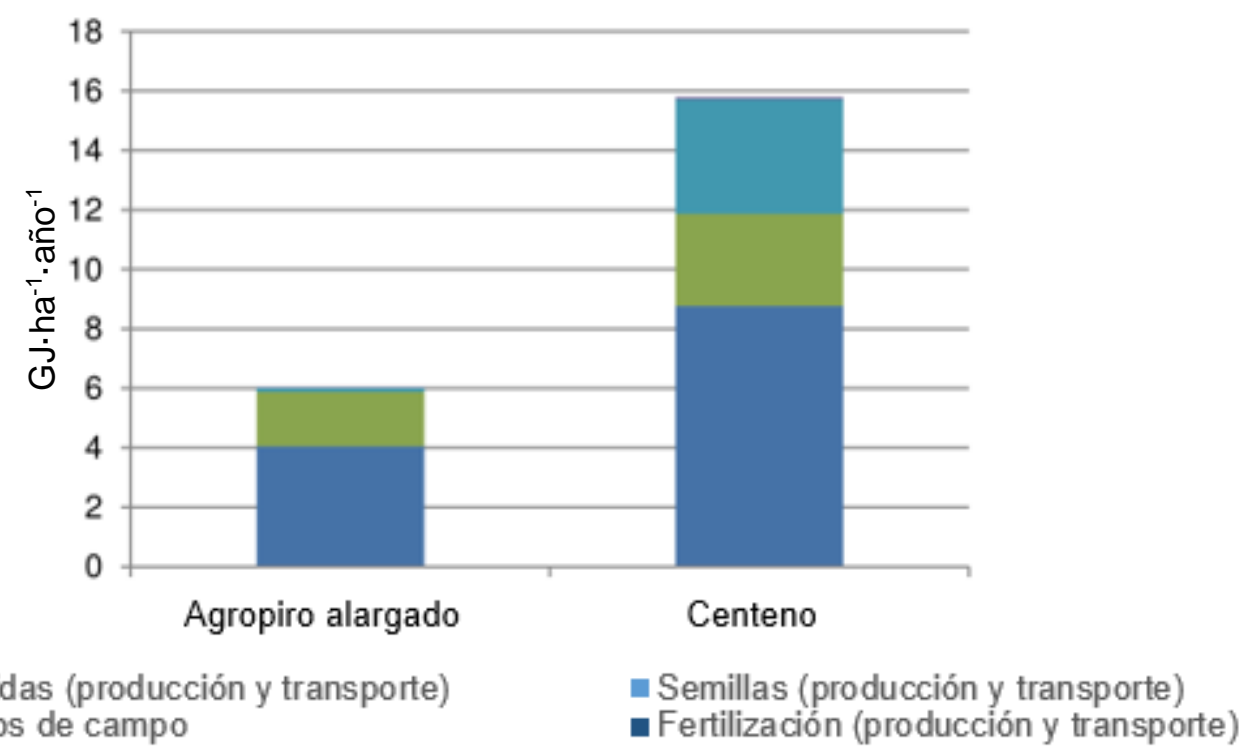

Figura 18. Energía primaria total consumida para el cultivo del agropiro alargado y el centeno en la explotación estudiada.

El consumo de energía primaria renovable fue mucho más importante en el caso del centeno $(18,3 \%)$ que en el del agropiro (3,5\%). Esta diferencia se atribuye 
principalmente al contenido de energía de las semillas, dada la dosis mucho menor de semillas utilizada para agropiro, 0,02 Mg $\cdot \mathrm{ha}^{-1}$ frente a $0,15 \mathrm{Mg} \cdot \mathrm{ha}^{-1}$ para el centeno y el hecho de que las semillas sólo se utilizan el primer año en el caso del agropiro alargado. El consumo de energía no renovable, en el que los efectos de la siembra tuvieron menos influencia, fue mayor para el centeno con 12,9 $\mathrm{GJ}^{-} \mathrm{ha}^{-1} \cdot \mathrm{año}^{-1}$ en comparación con el agropiro con 5,8 GJ.ha ${ }^{-1} \cdot$ año $^{-1}$ de media en el período estudiado.

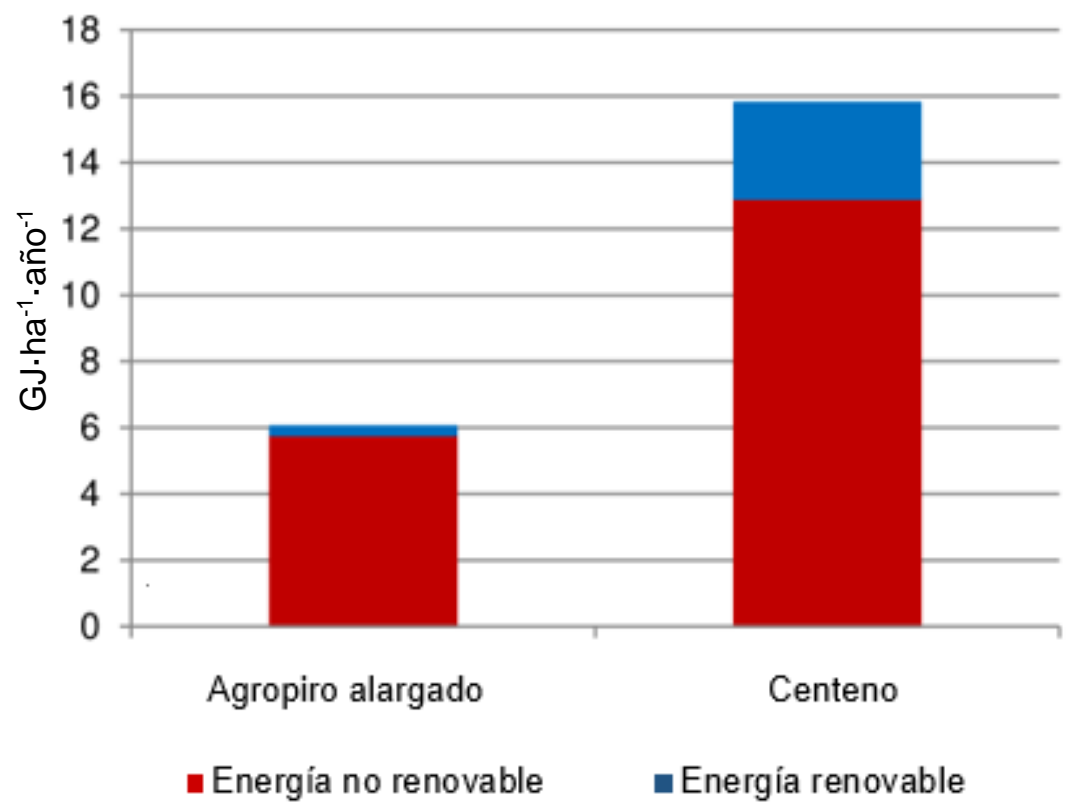

Figura 19. Diferencias entre la energía primaria renovable y no renovable consumida para cada alternativa.

Este estudio puede complementarse en el futuro con ensayos de otras gramíneas perennes como la festuca (Festuca arundinacea Schreb.) o los pastizales silvestres autóctonos, diferentes técnicas de laboreo [31], y nuevos productos que mejoren los suelos deben ser probados [32] para comprobar los impactos ambientales y económicos en zonas marginales de estas alternativas.

Este estudio puede replicarse en más de 10,5 millones de hectáreas de tierras marginales en las que se puede cultivar agropiro alargado en Europa [33]. Además, según FAOSTAT [34], entre 2007 y 2017 se sembraron más de 5 millones de hectáreas anuales de centeno en el mundo, situadas principalmente en Europa con un rendimiento medio de 2,04 $\mathrm{Mg} \cdot \mathrm{ha}^{-1} \cdot \mathrm{año}^{-1}$ que puede ser un potencial sumidero de carbono introduciendo agropiro alargado en parte de ellas. 


\subsection{Conclusiones}

Los márgenes económicos obtenidos para el agropiro alargado y el centeno fueron negativos para ambos cultivos cuando no se contabilizó la ayuda de la PAC, pero se obtuvieron menos pérdidas en el caso del agropiro alargado en comparación con el centeno. El agropiro produjo un aumento anual importante de la materia orgánica del suelo que, junto con la reducción de los trabajos de campo y de los inputs consumidos, dio lugar a una notable mejora de la huella de carbono (aproximadamente $200 \%$ menos). Además, el consumo de energía primaria en el cultivo del agropiro alargado fue inferior al $40 \%$ de la de centeno. Según estos resultados, el agropiro alargado es más sostenible que el centeno, ya que los inputs para su producción son menores, la diferencia casi insignificante entre los márgenes económicos de ambos cultivos no hace atractiva la opción del agropiro alargado frente a la tradicional, debido a factores como la ocupación permanente de las tierras y los riesgos asociados a la implantación de un nuevo cultivo desconocido para el agricultor. La monetización de los impactos ambientales y energéticos positivos derivados del incremento del carbono del suelo sería esencial para que los agricultores introdujeran este cultivo en zonas marginales. Así pues, la implantación del agropiro alargado en zonas marginales donde tradicionalmente se siembran cereales de invierno aumentará la retención de carbono en el suelo haciendo que los sistemas agrícolas sean más sostenibles en comparación con el manejo tradicional de estas tierras y logrando un beneficio económico similar.

\subsection{Referencias}

[1] FAO, 2009. Global agriculture towards 2050. How to feed the world 2050? Rome, Italy.

[2] Deggans, J., Krulicky, T., Kovacova, M., Valaskova, K., Poliak, M., 2019. Cognitively enhaced products, output growth, and labor market changes: will artificial intelligence replace workers by automating their jobs?. Econ. Manag. Finan. Mkt. 14. 38-43. https://doi 10.22381/EMFM14120194

[3] Udell, M., Stehel, V., Kliestik, T., Kliestikova, J., Durana, P., 2019. Towards a smart automated society: cognitive technologies, knowledge production and economic growth. Econ. Manag. Finan. Mkt. 14, 44-49. https://doi: 10.22381/EMFM14120195

[4] Bordonal, R.O., Nunes, J.L., Lal, R., Figueiredo, E.B., Oliveira, B.G., La Scala, N., 2018. Sustainability of sugarcane production in Brazil. A review. Agron Sustain Dev 38:13. https://doi.org/10.1007/s13593-018-0490-x

[5] Mardoyan, A., Braun, P., 2015. Analysis of Czech subsidies for solid biofuels. Int. J. Green Energy. 12. 405-408. https://doi:10.1080/15435075.2013.841163

[6] Marousek, J., 2013. Two-fraction anaerobic fermentation of grass waste. J. Sci. Food Agric. 93. 2410-2414. https://doi:10.1002/jsfa.6046

[7] Marousek, J., 2014. Novel technique to enhance the disintegration of grass waste. Ind. Crop. Prod. 53, 1-5. https://doi:10.1016/j.indcrop.2013.11.048

[8] Shujiang, K., Post, W.M., Nichols, J.A., Wang, D., West, T.O., Bandaru, V., Izaurralde, R.C., 2013. Marginal lands: concept, assessment and management. J Agr Sci 5, 10. https://doi.org/10.5539/jas.v5n5p129 
[9] Liu, T.T., McConkey, B.G., Ma, Z.Y., Liu, Z.G., Li, X., Cheng, L.L., 2011. Strengths, weaknessness, opportunities and threats analysis of bioenergy production on marginal land. Energy Procedia 5, 2378-2386. https://doi.org/10.1016/j.egypro.2011.03.409

[10] Sulas, L., Franca, A., Sanna, F., A. Re, G., Melis, R., Porqueddu, C., 2015. Biomass characteristics in Mediterranean populations of Piptatherum miliaceum-A native perennial grass species for bioenergy. Ind. Crop. Prod. 75, 76-84. https://doi.org/10.1016/i.indcrop.2015.07.014

[11] James, L., 2010. Theory and identification of marginal land and factors determining land use -change, Michigan State University

[12] Wrigley, C.W., Batey, I.L., 2010. Cereal grains: assessing and managing quality. Florida, USA

[13] Sastre, C.M., Carrasco, J., Barro, R., Gonzalez-Arechavala, Y., Maletta, E., Santos, A.M., Ciria, P., 2016. Improving bioenergy sustainability evaluations by using soil nitrogen balance coupled with life cycle assessment: A case study for electricity generated from rye biomass. Appl Energ 179, 847-863. https://doi.org/10.1016/j.apenergy.2016.07.022

[14] Ciria, C.S., Sanz, M., Carrasco, J., Ciria, P., 2019. Identification of arable marginal lands under rainfed conditions for bioenergy purpose in Spain. Sustainability-Basel 11, 17. https://doi.org/10.3390/su11071833

[15] Sastre, C.M., Maletta, E., Gonzalez-Arechavala, Y., Ciria, P., Santos, A.M., del Val, A., Perez, P., Carrasco, J., 2014. Centralised electricity production from winter cereals biomass grown under Central-Northern Spain conditions: global warming and energy $\begin{array}{lllll}\text { yields assessments. Appl } & \text { 737-748. }\end{array}$ https://doi.org/10.1016/j.apenergy.2013.08.035

[16] Gominho, J., Lourenco, A., Palma, P., Lourenco, M.E., Curt, M.D., Fernandez, J., Pereira, $H$., 2011. Large scale cultivation of Cynara cardunculus L. for biomass production-A case study. Ind. Crop. Prod. 33, 1-6. https//doi.org/10.1016/j.indcrop.2010.09.011.

[17] Meyer, R., 2014. Diversity of European farming systems and pathways to sustainable intensification. Technikfolgenabschätzung - Theorie und Praxis 23, 11

[18] MAPA (2018) Fact sheet of machinery cost. Publishing MAPA Web. https://www.mapa.gob.es/es/ministerio/servicios/informacion/plataforma-deconocimiento-para-el-medio-rural-y-pesquero/observatorio-de-tecnologiasprobadas/maquinaria-agricola/hojas-calculo-maqui.aspx. (accessed 31 January 2019)

[19] Ciria, C.S., Carrasco, J., Perez, J., Barro, R., Ciria, P., 2017. Pure and mixed perennial biomass crops for a constraint marginal land in north-central Spain(a 6-year study) In: Baxter D (ed) 25th EUBCE. Setting the course for a biobased economy, Stockholm, Sweden, pp 120-124. https://doi.org/10.5071/25thEUBCE2017-1CO.5.3

[20] Sandor. C., 2011. Tall wheatgrass cultivar Szarvasi-1 as a potential energy crop for semiarid lands of Eastern Europe. In: Nayeripour M (ed) Sustainable growth and applications in renewable energy sources. Hungary, pp 269-294 https://doi.org/10.5772/2433

[21] Liu, Z.W., Wang, R.C., 2011. Tall wheatgrass ( Thinopyrum ponticum (Podp.)) plant guide, USDA-NRCS

[22] Nemecek, T., Kägi, T., Blaser, S., 2007. Life cycle inventories of agricultural production systems. Ecoinvent final report $v 2.0,15$

[23] Nemecek, T., Schnetzer, J., 2011. Methods of assessment of direct field emissions for LCls of agricultural production systems. Agroscope Reckenholz-Tänikon Research Station ART

[24] Balesdent, J., Chenu, C., Balabane, M., 2000. Relationship of soil organic matter dynamics to physical protection and tillage. Soil Till Res 53, 215-230. https://doi.org/10.1016/s0167-1987(99)00107-5

[25] Jarecki, M.K., Lal, R., 2003. Crop management for soil carbon sequestration. Crit. Rev. Plant. Sci. 22, 471-502. https://doi:10.1080/07352680390253179

[26] Signor, D., Deon, M.D.I., de Camargo, P.B., Pellegrino-Cerri, C.E., 2018. Quantity and quality of soil organic matter as a sustainability index under different land uses in Eastern Amazon. Sci. Agric. 75. 225-232. https://doi: 10.1590/1678-992x-2016-0089

[27] Sanchez-Gonzalez, A., Chapela-Lara, M., German-Venegas, E., Fuentes-Garcia, R., del Rio-Portilla, F., Siebe, C., 2017. Changes in quality and quantity of soil organic matter stocks resulting from wastewater irrigation in formerly forested land. Geoderma 306. 99107. https://doi: 10.1016/i.geoderma.2017.07.009 
[28] Frischknecht, R., Jungbluth, N., Althaus, H.J., Hischier, R., Doka, G., Bauer, C., Dones, R., Nemecek, T., Hellweg, S., Humbert, S., Margni, M., Koellner, T., Loerincik, Y.,2010. Implementation of life cycle impact assessment methods. Data v2.2. Ecoinvent report 3. Dübendorf, Switzerland

[29] Graessly, S., Horak, J., Kovacova, M., Valaskova, K., Poliak, M., 2019. Consumer attitudes and behaviors in the technology-driven sharing economy. Motivations for participating in collaborative consumption. J. Self-Gov Manag. Econ. 7, 25-30. https:// doi:10.22381/JSME7120194

[30] Ludbrook, F., Frajtova, K., Musova, Z., Suler, P. 2019. Bussiness models for sustainable innovation in industry 4.0: smart manufacturing processes, digitalization of production systems, and data-driven decision making. J. Self-Gov Manag. Econ. 7, 21-26. https://doi:10.22381/JSME7320193

[32] Marousek, J., Strunecky, O., Stehel, V., 2019. Biochar farming: defining economically perspective applications. Clean Technol. Envir. 21. 1389-1395. https://doi:10.1007/s10098-019-01728-7

[31] Pearson, C.H., Larso, S.R., Keske, C.M.H., Jensen, K.B., 2014. Native grasses for biomass production at high elevation, in: Cruz, M.V.M, Dierig, D.A. (Eds.) Industrial crops Handbook of Plant Breeding. Springer, New York, pp. 101-132. https://doi.org/10.1007/978-1-4939-1447-0 6

[33] Von Cossel, M., Lewandowski, I., Elbersen, B., Staritsky, I., Van Eupen, M., Iqbal, Y., Mantel, S., Scordia, D., Testa, G., Cosentino, S.L., Maliarenko, O., Eleftheriadis, I., Zanetti, F., Monti, A., Lazdina, D., Neimane, S., Lamy, I., Ciadamidaro, L., Sanz, M., Carrasco, J., Ciria, P., McCallum, I., Trindade, L.M., Van Loo, E.N., Elbersen, W., Fernando, A.L., Papazoglou, E.G., Alexopoulou, E., 2019. Marginal agricultural land lowinput systems for biomass production. Energies, 12. https://doi:10.3390/en12163123

[34] FAO, 2020. Food and agriculture data. Publishing FAOSTAT web. http://www.fao.org/faostat/en/\#data/QC. (accessed 20/01/2020) 


\section{DISCUSIÓN GENERAL}




\section{CAPÍTULO VI: DISCUSIÓN GENERAL}

En España, existe una superficie de tierra cultivable en condiciones de secano de 9.931.689 ha que tiene al menos alguna limitación biofísica y/o económica para el cultivo de cereales de invierno, de los cuales 1.960 .316 ha son tierra marginal en la que difícilmente se pueden obtener rendimientos económicos viables en la producción de cultivos alimentarios debido a sus restricciones biofísicas [10]. El resto de superficie (7.971.373 ha) tienen potencial para convertirse en tierra marginal en el caso de que se continuara con su manejo actual. Las principales restricciones biofísicas del secano español son la baja cantidad de materia orgánica que tienen los suelos, así como la pedregosidad.

De 1.960.316 ha caracterizadas en el estudio por sus limitaciones económicas y biofísicas, solo 39.376 ha (2\%) no tienen ninguna de las 7 limitaciones biofísicas estudiadas, otras limitaciones climáticas como altas y bajas temperaturas o de suelo relacionadas con la pendiente pueden estar detrás de la marginalidad de esas áreas. El área evaluada en este estudio por sus restricciones económicas representa alrededor del $20 \%$ del secano español, el $11,5 \%$ de la superficie total de cultivo y el $4 \%$ de la superficie total de España.

A través de diversos estudios, en Europa, se han identificado aproximadamente 257 Mha como marginales entre las que se incluían los pastizales, de las cuales 58,2 Mha pueden estar disponibles para el cultivo de biomasa [6, 48], en este aspecto, España representa el 3,4\% de la superficie total europea de tierra marginal que puede estar disponible para la producción de biomasa a gran escala.

Cultivos tradicionales como el triticale o cultivos alternativos como el cardo o las gramíneas forrajeras perennes con destino a la producción de biomasa, pueden ser alternativas a tener en cuenta en el secano marginal español. Según la plataforma BIORAISE CE [144], en España, los rendimientos con destino al aprovechamiento para biomasa de cultivos tradicionales como el triticale pueden oscilar entre 2,7 y $8 \mathrm{Mg}$ $M S \cdot h a^{-1}$ en las superficies agrícolas de secano, los cuales están en línea con los resultados obtenidos por otros autores [145] en siete ubicaciones y con cuatro cultivares diferentes. Además, en el Proyecto Singular y Estratégico "On Cultivos", se realizaron una serie de ensayos con triticale durante un período de 3 años en ocho regiones españolas, con rendimientos de biomasa entre 1,6 a 12,4 Mg MS.ha-1 [146]. Aunque estos cultivos pueden presentar resultados aceptables en tierra marginal, es difícil que con su producción puedan revertir la situación de marginalidad de las áreas consideradas, procesos como la ganancia de carbono del suelo o la disminución de la 
erosión de los suelos serían imposibles de revertir con el cultivo de las especies citadas $[140,141]$.

Los cultivos leñosos con destino a biomasa pueden proporcionar alternativas rentables a los cultivos anteriormente citados aunque son menos flexibles que los cultivos anuales en términos de propagación y utilización [50].

Las gramíneas perennes se han mostrado en los últimos años como la mejor alternativa para tierras marginales en sustitución a los cultivos tradicionales ya que requieren menor cantidad de inputs para su producción [39] y tienen mayor potencial en cuanto a reducción de la erosión del suelo (Foto 10) y secuestro de carbono, entre otros, como resultado de la cobertura continua del suelo, la reducción de la perturbación del suelo debido al laboreo y la mejora de la producción de la biomasa subterránea [49], así como la mejora de los hábitats donde se implantan, ya que estos cultivos son refugio de gran número de especies de flora y fauna [147].

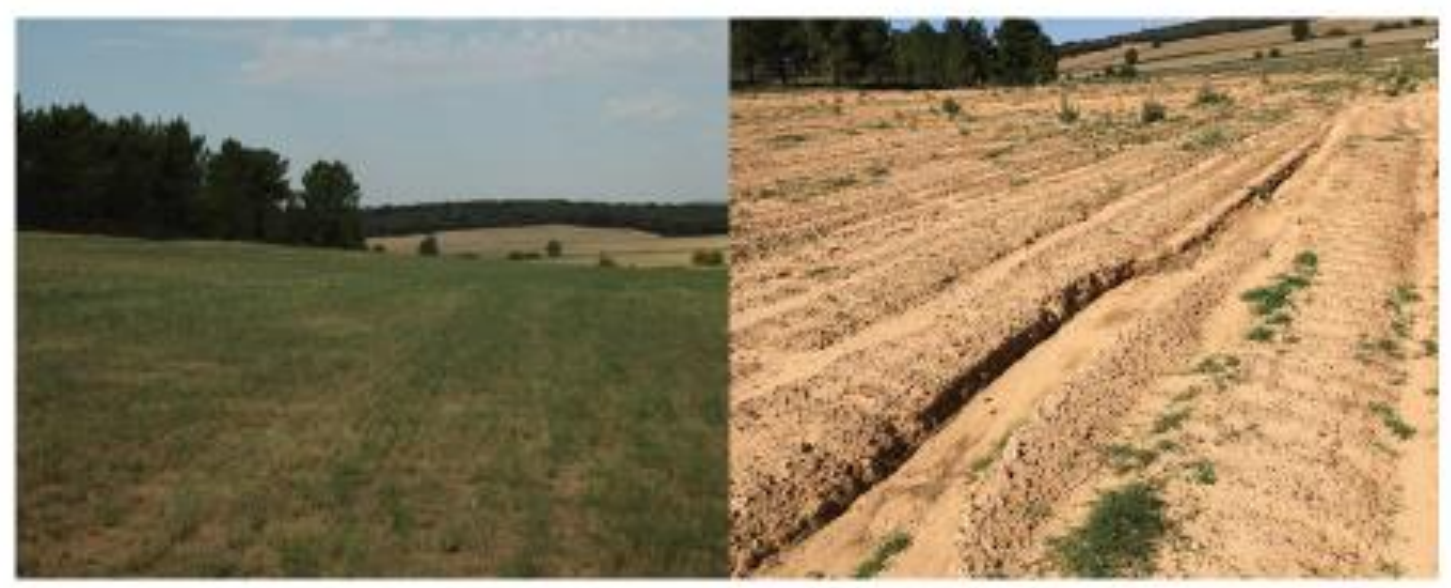

Foto 10. Parcela de agropiro alargado (izquierda) y parcela adyacente de barbecho tradicional (derecha) después de una tormenta (agosto de 2018).

Los resultados de ensayos con gramíneas perennes en tierra marginal en España, obtuvieron los rendimientos más bajos el año de implantación, sin importar la especie, cultivar o ubicación, como ocurre normalmente en todas las gramíneas perennes [148]. El rendimiento más alto entre todas las especies y cultivares probados se logró con el agropiro alargado en un ensayo de ocho años con medias de 4,8 Mg MS.ha ${ }^{-1}$. Los ensayos realizados en España en tierra marginal muestran mejores rendimientos que otros estudios realizados en tierras marginales de EE.UU. donde se obtuvieron 3,1 Mg MS.ha-1.año-1 [149]. Otros estudios reportaron similares rendimientos en Europa en terrenos con restricciones biofísicas [107]. Sin embargo, rendimientos para agropiro alargado cultivar Jose de $8 \mathrm{Mg} \mathrm{MS} \cdot \mathrm{ha}^{-1}$ se obtuvieron en el área mediterránea, en zonas marginales con alto nivel de salinidad, pero bajo 
condiciones de riego [150]. Este mismo cultivar, durante un periodo de dos años y sin tener en cuenta el año de implantación, también bajo condiciones de riego obtuvo rendimientos de 5,9 y 8,3 $\mathrm{Mg} \mathrm{MS} \cdot$ ha $^{-1}$ para su utilización como forraje en California [151]. Bajo condiciones más favorable en áreas sin restricciones biofísicas, distintos cultivares de agropiro proporcionaron mejores rendimientos, con producciones de biomasa superiores a $10 \mathrm{Mg} \mathrm{MS} \cdot \mathrm{ha}^{-1}$ en América del Norte $[152,153]$ y de 17,2 Mg MS $\cdot \mathrm{ha}^{-1}$ en Alemania para la producción de biogás [154].

La producción de biomasa aumentó cuando aumentó la precipitación sin importar la especie o el cultivar. Sin embargo, la medida en que las precipitaciones afectaron los rendimientos depende de las especies consideradas [155]. También cabe mencionar que la producción de biomasa aumentó en relación con la cantidad de lluvia caída en primavera, ya que esta es la temporada en que las gramíneas perennes C3 tienen su actividad vegetativa más activa. Otros autores también observaron una correlación similar [136, 156, 157]. Según los resultados de los ensayos realizados en este trabajo, las especies del género Agropyron alcanzaron mayores rendimientos de biomasa cuando la precipitación registrada entre marzo y junio fue superior a $240 \mathrm{~mm}$. Se obtuvieron bajos rendimientos cuando la precipitación durante el período mencionado fue de alrededor de $150 \mathrm{~mm}$. Las precipitaciones por debajo de $120 \mathrm{~mm}$ resultaron insuficientes para el desarrollo del cultivo y la obtención de rendimientos favorables, como así lo corroboran otros autores [6].

Los análisis de composición química realizados en las especies y cultivares del género Agropyron cultivadas en este estudio exhibieron una composición química típica de las gramíneas perennes $\mathrm{C} 3$, que se caracterizan por un alto contenido de cenizas, silicio y elementos alcalinos [65, 158-161]. Las gramíneas perennes estudiadas promediaron $40 \mathrm{~g} \cdot \mathrm{kg}^{-1}$ en base seca de cenizas, valor que está dentro de los rangos especificados por la norma ISO 17225-1:2014 que, para especies pratenses, sitúa los valores entre 10 y $100 \mathrm{~g} \cdot \mathrm{kg}^{-1}$ en base seca.

El poder calorífico inferior en base seca varió entre $16,7-18,5 \mathrm{MJ} \cdot \mathrm{kg}^{-1}$ valor que se sitúa dentro de los rangos típicos enumerados en la norma ISO 17225-1 [149] para gramíneas perennes (16-19 $\left.\mathrm{MJ} \cdot \mathrm{kg}^{-1}\right)$. Esta norma internacional también enumera los poderes caloríficos típicos medios para especies pratenses $\left(17,1 \mathrm{MJ}^{\mathrm{kg}} \mathrm{kg}^{-1}\right)$, Phalaris arundinacea L. (16,6 MJ. $\left.\mathrm{kg}^{-1}\right)$ y Miscanthus spp. (17,7 MJ. $\left.\mathrm{kg}^{-1}\right)$. Nuevamente, los cultivares de agropiro alargado considerados mostraron poderes caloríficos inferiores medios más cercanos al Miscanthus spp., una especie C4 que a otras especies C3. Como se sabe que los poderes caloríficos están correlacionados negativamente con 
el contenido de cenizas [159, 162], los más altos encontrados en el presente estudio están en consonancia con los contenidos de cenizas relativamente más bajos que caracterizaron esta biomasa. Los valores del poder calorífico inferior medidos en el experimento están muy cercanos a los encontrados para Arundo donax L. cosechado en otoño $\left(17,4 \mathrm{MJ} \cdot \mathrm{kg}^{-1}\right)$ y Phalaris aquatica L. (17,2 MJ $\left.\mathrm{kg}^{-1}\right)$, este último estudiado en condiciones de tierra marginal en un entorno mediterráneo semiárido en Turquía [163]. En la bibliografía también se encontraron poderes caloríficos más bajos para poblaciones silvestres de agropiro alargado en Polonia $\left(15,8-17,0 \mathrm{MJ} \cdot \mathrm{kg}^{-1}\right)$ [164]. La composición química de las especies estudiadas tampoco mostró ningún elemento o valor fuera de los rangos establecidos por las normas y otros autores en la bibliografía $[65,150,158-161,164-167]$.

Los resultados de evaluar los índices de combustión de las especies y cultivares estudiados sugieren que las diferencias probablemente no afecten su comportamiento de combustión desde un punto de vista práctico. Si estas especies se van a utilizar para producir bioenergía en un proceso de conversión termoquímica o eléctrica, se deben implementar medidas tecnológicas en las centrales transformadoras para evitar problemas relacionados con la sinterización, la corrosión y las emisiones [65, 160, 166]. La biomasa recolectada en este estudio también podría utilizarse para producir pellets herbáceos de clase $B$ [168]. No se cumplirían las limitaciones establecidas en la norma ISO 17225-6 para pellets herbáceos clase $\mathrm{A}$, ya que el contenido de $\mathrm{Cl}$ obtenido en los resultados de laboratorio supera la limitación de $1,0 \mathrm{~g} \cdot \mathrm{kg}^{-1}$ en base seca.

Es importante resaltar también que, aunque la recolección es anual, los resultados de las especies estudiadas sugieren una mejora en la calidad de la biomasa con la edad del cultivo. En este sentido, el contenido de cenizas, así como las concentraciones de $\mathrm{K}, \mathrm{S}$, Na y $\mathrm{Cl}$, tendieron a disminuir con el paso de los años.

Los resultados económicos obtenidos en una explotación real muestran que el agropiro alargado tiene un margen económico positivo $\left(154,6 € \cdot \mathrm{ha}^{-1} \cdot \mathrm{año}^{-1}\right)$, similar al del centeno $\left(145,14 € \cdot \mathrm{ha}^{-1} \cdot \mathrm{año}^{-1}\right)$, cultivo tradicional utilizado por los agricultores para sembrar las tierras con más restricciones biofísicas, aunque muy lejos de cultivos como el trigo $\left(416,62 € \cdot h^{-1} \cdot\right.$ año $\left.^{-1}\right)$ y la cebada $\left(339,31 € \cdot \mathrm{ha}^{-1} \cdot\right.$ año $\left.^{-1}\right)$ sembrados en la explotación en áreas más fértiles. Esto es un incentivo económico insuficiente para que los agricultores cultiven agropiro alargado. Hay que considerar también, los inconvenientes relacionados con los riesgos de mercado asociados con el nuevo cultivo. Cabe resaltar, que estos resultados se han obtenido con medias de producción 
de 5,5 t MS $\cdot$ ha $^{-1}$, elevadas para esta especie cultivada en tierra marginal en un estudio de cuatro años que, como se ha visto, serán difíciles de sostener en el tiempo cuando la plantación vaya envejeciendo. Además, este balance económico no hubiera sido positivo en el caso de que el agricultor no percibiera fondos de la PAC, lo que demuestra que esos pagos son fundamentales para obtener balances económicos positivos en las explotaciones agrarias, especialmente en áreas poco productivas y así evitar el abandono de esas áreas por motivos económicos.

La mejora del balance económico es muy pobre en comparación con el centeno, sin embargo, las diferencias medioambientales son más claras a favor del agropiro alargado. Todas las fases del cultivo de agropiro alargado tienen un potencial de calentamiento global de un $66 \%$ menor si se compara con el cultivo de centeno para grano. Además, según el estudio realizado, la fijación de $\mathrm{CO}_{2}$ debido al aumento de materia orgánica del suelo tuvo una influencia significativa para el agropiro alargado permitiendo una reducción de 2,805 $\mathrm{Mg} \mathrm{CO}_{2}$ eq. ha ${ }^{-1} \cdot \mathrm{año}^{-1}$ a diferencia del centeno que, como se ha comprobado en la bibliografía, debido al laboreo tradicional [140] y a la especie [141], no es capaz de fijar carbono en el suelo. Teniendo en cuenta estos dos parámetros, el agropiro alargado obtuvo un balance del potencial de calentamiento global negativo a diferencia del centeno. Este balance negativo podría tener una notable importancia en el caso de que, mediante medidas adoptadas enmarcadas en la mejora del medio ambiente, se pudieran evaluar económicamente ayudando así a mejorar el balance económico de estas especies y haciendo el cultivo de las mismas más atractivo para los agricultores en el futuro.

A este respecto, el establecimiento de especies como el agropiro alargado con destino a la producción de energía en tierras marginales podría utilizarse como un instrumento para evitar el abandono de las zonas rurales y alcanzar múltiples objetivos políticos de la UE, como mejorar el desarrollo rural, impulsar la bioeconomía y alcanzar objetivos de mitigación de los gases de efecto invernadero.

Una mejora genética de las gramíneas perennes con destino a biomasa, la implementación de nuevos mercados donde se demande este tipo de biomasa y la búsqueda de alternativas de estas especies como biocombustibles de segunda generación son fundamentales para la implantación de estas especies en las explotaciones agrarias.

Solo en Europa existen al menos 10,5 Mha de tierra marginal donde el agropiro alargado puede cultivarse con producciones competitivas [6]. Además, según FAOSTAT [169] entre 2007 y 2017 había anualmente más de 5 Mha sembradas de 
centeno en el mundo, ubicadas principalmente en Europa con un rendimiento promedio de 2,04 Mg $\cdot \mathrm{ha}^{-1} \cdot \mathrm{año}^{-1}$ de dudosa rentabilidad que podrían ser un sumidero potencial de carbono cambiando de cultivo parte de ellas y apostando por cultivos como los estudiados en este trabajo. 


\section{CONCLUSIONES}

El balance económico del trigo y la cebada en condiciones de secano bajo laboreo tradicional indica que los rendimientos $\leq 1,5 \mathrm{Mg} \mathrm{ha}^{-1}$ hacen que el cultivo de la tierra no sea rentable para los agricultores en España. Estas producciones sostenidas en el tiempo provocan que se pueda catalogar una determinada área como tierra marginal. El estudio de estas áreas muestra claramente que estas limitaciones económicas están vinculadas a limitaciones biofísicas. La superposición de limitaciones biofísicas podría hacer poco sostenible su uso bajo condiciones de laboreo tradicional. El bajo contenido de materia orgánica de los suelos es la restricción biofísica más frecuente en los secanos españoles.

La evolución de estas tierras agrícolas dependerá del manejo futuro por parte de los productores. Cambios en la preparación del terreno para la siembra y los cambios de cultivo podrían mejorar estas zonas. En este contexto, es importante una selección de la especie adecuada por parte de los agricultores y que no se asocie la idoneidad del cultivo solo con el rendimiento de este.

La metodología desarrollada en este trabajo puede ser un avance en la identificación de tierras marginales y de los factores limitantes que hacen que estas áreas sean marginales. Podría replicarse en otros países de la UE con los mismos problemas, principalmente en la cuenca mediterránea.

El agropiro alargado puede ser una alternativa eficaz para el cultivo de zonas marginales, ya que proporcionó mejores rendimientos de biomasa y eficiencias en el uso de la lluvia que otras especies. Entre todos los cultivares de agropiro alargado estudiados, tanto Alkar como Szarvasi-1 obtuvieron el mejor rendimiento de biomasa. El cultivo de especies del género Agropyron en tierra marginal de secano presenta condiciones para soportar precipitaciones de tan solo $150 \mathrm{~mm}$ entre marzo y junio, aunque con mínimos rendimientos.

El rendimiento de alguna de las especies perennes estudiadas es similar en términos económicos que los cultivos tradicionales sembrados en tierra marginal, por lo que debería ser necesario evaluar los impactos positivos que tiene esta actividad en el medio ambiente y cómo afecta a las zonas rurales en las que se implanta evaluando parámetros económicos y sociales. Evitar el abandono de estas áreas marginales mediante la siembra de especies herbáceas perennes con destino a la producción energética ayudaría a lograr algunos de los objetivos fijados por la PAC para el período 2021-2027, una agricultura de bajos inputs que puede mejorar el medio ambiente. 
Además, la producción de especies perennes en tierras marginales puede contribuir al objetivo de la política de la UE de reducir las emisiones de $\mathrm{CO}_{2}$ en un $40 \%$ en 2030 y, en particular, lograr la contribución del 32\% con fuentes renovables al consumo total de energía indicado en la nueva Directiva de Energías Renovables 2021-2030 que promueve el uso de fuentes de energía renovables. 
REFERENCIAS 


\section{CAPÍTULO VII: REFERENCIAS}

En la siguiente lista se muestran las referencias de los capítulos I, II y VI:

1. EUROPEAN COMMISSION. CAP context indicators, 2018 [consulta: 26/01/2019]. Disponible en: https://ec.europa.eu/info/sites/info/files/foodfarming-fisheries/farming/documents/cap-context-indicators-

table 2018 en.pdf.

2. EUROPEAN COMMISSION. Overview of CAP reform 2014-2020, 2019 [consulta: 12/12/2019]. Disponible en: https://bit.ly/2BJztPs

3. EUROPEAN COMMISSION. EU Budget: The Common Agricultural Policy beyond 2020, 2018 [consulta: 24/01/2020]. Disponible en: https://ec.europa.eu/commission/presscorner/detail/en/MEMO $18 \quad 3974$

4. EUROPEAN COMMISSION. Direct payments, 2018 [consulta: 07/01/2019]. Disponible en: https://bit.ly/2PuRZ3U

5. SHUJIANG, K., Post, W.M., Nichols, J.A., Wang, D., West, T.O., Bandaru, V., Izaurralde, R.C. Marginal lands: concept, assessment and management. Journal of Agricultural Science, 2013, 5, pp. 129-138. Disponible en: https://doi.org/10.5539/jas.v5n5p129

6. VON COSSEL, M., Lewandowski, I., Elbersen, B., Staritsky, I., Van Eupen, M., Iqbal, Y., Mantel, S., Scordia, D., Testa, G., Cosentino, S. L., Maliarenko, O., Eleftheriadis, I., Zanetti, F., Monti, A., Lazdina, D., Neimane, S., Lamy, I., Ciadamidaro, L., Sanz, M., Esteban Carrasco, J., Ciria, P., McCallum, I., Trindade, L. M., Van Loo, Eibertus N., Elbersen, W., Fernando, A. L., Papazoglou, E. G., Alexopoulou, E. Marginal Agricultural Land Low-Input Systems for Biomass Production. Energies, 2019, 12(16). Disponible en: https://doi.org/10.3390/en12163123

7. RUF, T., Audu, V., Holzhauser, K., Emmerling, C. Bioenergy from Periodically Waterlogged Cropland in Europe: A First Assessment of the Potential of Five Perennial Energy Crops to Provide Biomass and Their Interactions with Soil. Agronomy, 2019, 9(7) Disponible en: https://doi.org/10.3390/agronomy9070374

8. FERNANDO, A.L., Boleó, S., Barbosa, B., Costa, J., Duarte, M.P., Monti, A. Perennial grass production opportunities on marginal Mediterranean land. Bioenergy Reseach, 2015, 8(4), pp. 1523-1537. Disponible en: https://doi.org/10.1007/s12155-015-9692-0

9. MEHMOOD, M.A., Ibrahim, M., Rashid, U., Nawaz, M., Ali, S., Hussain, A., Gull, M. Biomass production for bioenergy using marginal lands. Sustainable Production and Consumption. 2017, 9, pp. 3-21. Disponible en: https://doi.org/10.1016/j.spc.2016.08.003

10. SOLDATOS, P. Economic Aspects of Bioenergy Production from Perennial Grasses in Marginal Lands of South Europe. Bioenergy Research. 2015, 8(4) pp. 1562-1573. Disponible en: https://doi.org/10.1007/s12155-015-9678-y

11. MAleTTA, E., Carrasco, J., Del Val, M. A., Pérez, J., Ciria, C.S., Ciria, P. Cultivos herbáceos perennes para la producción de biomasa en España, ed. Ciemat, 2016, Madrid, pp 86. ISBN: 978-84-7834-757-5 
12. BLANCO-CANQUI, H. Energy Crops and Their Implications on Soil and Environment. Agronomy-Journal, 2010, 102(2), pp. 403-419. Disponible en: https://doi.org/10.2134/agronj2009.0333

13. ZHANG, Y., Li, Y., Jiang, L., Tian, C., Li, J., Xiao, Z. Potential of Perennial Crop on Environmental Sustainability of Agriculture. 3rd International Conference on Environmental Science and Information Application Technology, 2011, Vol 10, pp. 1141-1147. Disponible en: https://doi.org/10.1016/j.proenv.2011.09.182

14. AGOSTINI, F., Gregory, A.S., Richter, G.M. Carbon Sequestration by Perennial Energy Crops: Is the Jury Still Out? Bioenergy Research. 2015, 8(3), pp. 10571080. Disponible en: https://doi.org/10.1007/s12155-014-9571-0

15. DUMITRU, M. The CAP towards 2020. Implementation of Rural Development Policy, 2015, pp. 19 [consulta: 27/01/2019]. Disponible en: https://enrd.ec.europa.eu/sites/enrd/files/rn-assembly2 state-ofplay dumitru.pdf

16. EUROSTAT. Agri-Environmental indicator: Irrigation, 2019 [consulta: 27/03/2019] Disponible en: https://ec.europa.eu/eurostat/statisticsexplained/index.php/Agri-environmental indicator irrigation\#Analysis at EU and country level

17. EUROPEAN COMMISSION. Report from the Commission to the Council and the European Parliament on the implementation of Council Directive 91/676/EEC concerning the protection of waters against pollution caused from agricultural sources based on Member State reports for the period 2012-2015, 2018, pp. 9

18. EUROPEAN ENVIRONMENTAL AGENCY (EEA). State of nature in the EU results from reporting under the nature directives 2007-2012, Luxenbourg, 2015.

19. KEENLEYSIDE, C., Beaufoy, G., Tucker, G., Jones, G. High Nature Value farming throughout EU-27 and its financial support under the CAP. Institute for European Environmental Policy: London, 2014, pp. 188

20. EUROPEAN ENVIRONMENTAL AGENCY (EEA). Pesticide sales, 2019 [consulta: 27/12/2019] Disponible en: https://www.eea.europa.eu/airs/2018/environment-and-health/pesticides-sales

21. EUROSTAT. Agri-environmental indicator- Consumption of pesticides, 2019, [consulta: 24/02/2020]. Disponible en: https://ec.europa.eu/eurostat/statisticsexplained/index.php/Agri-environmental indicator consumption of pesticides\#Categories and indicators

22. EUROSTAT. Greenhouse emissions statistics - emission inventories, 2019, [consulta: 24/02/2020]. Disponible en: https://ec.europa.eu/eurostat/statisticsexplained/index.php/Greenhouse gas emission statistics\#Trends in greenh ouse gas emissions

23. RICARDO, D. On the principles of political economy and taxation, $3^{\mathrm{a}} \mathrm{Ed}$, Dent and Sons Ltd, London, UK, 1817.

24. HOLLANDER, J.H. The concept of marginal rent. Q.J. Economy, 1895, 9, pp. 175-187.

25. PETERSON, G.M., Galbraith, J.K. The concept of marginal land. Journal of Farm Economics, 1932, 14 (2), pp. 295-310. Disponible en: https://doi.org/10.2307/1230112 
26. DAUBER, J., Miyake, S. To integrate or to segregate food crop and energy crop cultivation at the landscape scale? Perspectives on biodiversity conservation in agriculture in Europe. Energy, Sustainability and Society. 2016, 6 (25), pp. 11. Disponible en: https://doi.org/10.1186/s13705-016-0089-5

27. EUROPEAN ENVIRONMENTAL AGENCY (EEA). Marginal land concept. (GEMET) General Multilingual Environmental Thesaurus, 2018 [consulta: 30/04/2018]. Disponible en: http://www.eionet.europa.eu/gemet/concept/5023

28. LIU, TT., McConkey, B. G., Ma, Z. Y., Liu, Z. G., Li, X., Cheng, L. L. Strengths, Weaknessness, Opportunities and Threats Analysis of Bioenergy Production on Marginal Land. 2010 International Conference on Energy, Environment and Development (Iceed2010), 2011, 5, pp. 2378-2386. Disponible en: https://doi.org/10.1016/i.egypro.2011.03.409

29. SHORTALL, O.K. "Marginal land" for energy crops: Exploring definitions and embedded assumptions. Energy Policy, 2013, 62, pp. 19-27. Disponible en: https://doi.org/10.1016/j.enpol.2013.07.048

30. JAMES, L. Theory and identification of marginal land and factors determining land use change. Michigan State University: Graduate Research Masters Degree Plan B Papers, 2010

31. BARKLEY, P.W. Land Resource Economics - The Economics of Real-Estate. American Journal of Agricultural Economics, 1986, 68 (4), pp. 1030. https://doi.org/10.2307/1242159

32. DALE, V.H., Kline, K. L., Wiens, J., Fargione, J. Biofuels: implications for land use and biodiversity. Ecological Society of America, 2010.

33. STRIJKER, D., Marginal lands in Europe - causes of decline. Basic and Applied Ecology, 2005, 6(2), pp. 99-106. Disponible en: https://doi.org/10.1016/j.baae.2005.01.001

34. SCHROERS, J.O. Towards the development of marginal land use depending on the framework of agricultural market, policy and production techniques. University of Giessen, Germany, 2006.

35. SCHUBERT, R. Future bioenergy and sustainable land use. $1^{\text {a }}$ ed., Routledge, German Advisory Council on Global Change, 2009, pp. 365.

36. GALlAGHER, E., Berry, A., Archer, G., McDougall, S., Henderson, A. The Gallagher Review of the indirect effects of biofuels production. $4^{\mathrm{a}}$ ed., Renewable Fuels Agency, United Kingdom, 2008, pp. 92.

37. FAO. Annex 1. Crop salt tolerance data, 1999, [consulta: 25/05/2008] Disponible en: http://www.fao.org/docrep/005/y4263e/y4263e0e.htm

38. DAUBER, J., Brown, C., Fernando, A.L., Finnam, J., Krasuska, E., Ponitka, J., Styles, D., Thrän, D., Van Groenigen, K.J., Weih, M., Zah, R. Bioenergy from "surplus" land: environmental and socio-economic implications. Biorisk, 2012,

7, pp. 45. Disponible en: https://doi.org/10.3897/biorisk.7.3036

39. CAMPBELL, J.E., Lobell, D.B., Genova, R.C., Field, C.B. The global potential of bioenergy on abandoned agriculture lands. Environmental Science Technology, 2008, 42, pp. 5791-5794. Disponible en: https://doi.org/10.1021/es800052w

40. KEENLEYSIDE, C., Tucker, G.M. Farmland Abandonment in the EU: An Assessment of Trends and Prospects. Institute for European Environmental Policy, 2010, pp. 93. 
41. POINTEREAU, P. Coulon, F., Girard, P., Lambotte, M., Stuczynski, T., Sánchez Ortega, V., Del Rio, A. Analysis of Farmland Abandonment and the Extent and Location of Agricultural Areas that are Actually Abandoned or are in Risk to be Abandoned. Ed. E.Anguiano, C.Bamps, J-M.Terres. European Commission, Luxembourg, 2008, pp. 208. Disponible en https://doi.org/10.13140/RG.2.1.2467.7849

42. WIEGMANN, K., Hennenberg, K.J., Fritsche, U.R., Degraded land and sustainable bioenergy feedstock production, in Joint International Workshop on High Nature Value Criteria and Potential for Sustainable Use of Degraded Lands. Oko Institute, Paris, France, 2008.

43. NALEPA, R.A., Bauer, D.M. Marginal lands: the role of remote sensing in constructing landscapes for agrofuel development. Journal of Peasant Studies, 2012, 39(2), pp. 403-422. Disponible en: https:doi.org/10.1080/03066150.2012.665890

44. FAO. A framework for land evaluation. Soils Bulletin 32, Rome, Italy, 1976.

45. FISCHER, G. van Velthuizen, H., Shah, M., Nachtergaele, F. Global Agroecological Assessment for Agriculture in the 21st Century: Methodology and Results. International Institute for Applied Systems Analysis, Viena, Austria, 2002, pp. 156.

46. VAN ORSCHOVEN, J., Terres, J.M. Updated common bio-physical criteria to define natural constraints for agriculture in Europe. Definition and scientific justification for the common biophysical criteria. Ed. Jones, R. et al. JRC, 2014.

47. TERRES, J.M., Hagyo, A., Waina, A. Scientific contribution on combining biophysical criteria underpinning the delineation of agricultural areas affected by specific constraints. Methodology and factsheets for plausible criteria combinations. Ed. Confalonieri, R. et al., Vol. 92686, JRC, 2014. Disponible en https://doi.org/10.2788/844501

48. GERWIN, W., Repmann, F., Galatsidas, S., Vlachaki, D., Gounaris, N., Baumgarten, W., Volkmann, C., Keramitzis, D., Kiourtsis, F., Freese, D. Assessment and quantification of marginal lands for biomass production in Europe using soil-quality indicators. Soil, 2018, 4(4), pp. 267-290. Disponible en: https://doi.org/10.5194/soil-4-267-2018

49. GLOVER, J.D., Culman, S. W., DuPont, S. T., Broussard, W., Young, L., Mangan, M. E., Mai, J. G., Crews, T. E., DeHaan, L. R., Buckley, D. H., Ferris, H., Turner, R. E., Reynolds, H. L., Wyse, D. L. Harvested perennial grasslands provide ecological benchmarks for agricultural sustainability. Agriculture Ecosystems \& Environment, 2010. 137(1-2), pp. 3-12. Disponible en: https://doi.org/10.1016/j.agee.2009.11.001

50. PUlighE, G., Bonati, G., Fabiani, S., Barsali, T., Lupia, F., Vanino, S., Nino, P., Arca, P., Roggero, P. P. Assessment of the Agronomic Feasibility of Bioenergy Crop Cultivation on Marginal and Polluted Land: A GIS-Based Suitability Study from the Sulcis Area, Italy. Energies, 2016. 9(11) Disponible en: https://doi.org/10.3390/en9110895

51. PARACCHINI, M.L., Petersen, J.E., Hoogeveen, Y., Bamps, C., Burfield, I., Van Swaay, C. High Nature Value Farmland in Europe-An Estimate of the Distribution Patterns on the Basis of Land Cover and Biodiversity Data. Ed. JRC, 2008. Disponible en: https://doi.org/10.2788/8891 
52. DONALD, P.F., Green, R.E., Heath, M.F. Agricultural intesification and the collapse of Europe's farmland birds population. Document número 268, Royal Society of London: Proceedings of the Royal Society of London, 2001, pp. 2529. Disponible en: https://doi.org/10.1098/rspb2000.1325

53. VALIN, H., Sands, Ronald D., Van der Mensbrugghe, D., Nelson, G. C., Ahammad, H., Blanc, E., Bodirsky, B., Fujimori, S., Hasegawa, T., Havlik, P., Heyhoe, E., Kyle, P., Mason-D'Croz, D., Paltsev, S., Rolinski, S., Tabeau, A., Van Meijl, H., Von Lampe, M., Willenbockel, D. The future of food demand: understanding differences in global economic models. Agricultural Economics, 2014, 45(1) pp. 51-67. Disponible en: https://doi.org/10.1111/agec.12089

54. GIBBS, H.K., Salmon, J.M. Mapping the world's degraded lands. Applied Geography. 2015, 57 pp. 12-21. Disponible en: https://doi.org/10.1111/agec.12089

55. EITELBERG, D.A., Van Vliet, J., Verburg, P.H., A review of global potentially available cropland estimates and their consequences for model-based assessments. Global Change Biology. 2015, 21 (3) pp. 1236-1248. Disponible en: https://doi.org/10.1111/gcb.12733

56. OLDEMAN, L.R., Hakkeling, R.T.A., Sombroek, W.G. World map of the status of human-induced soil degradation. REP-12083. CIMMYT,1990.

57. BAI, Z.G., Dent, D. L., Olsson, L., Schaepman, M. E. Proxy global assessment of land degradation. Soil Use and Management. 2008, 24(3), pp. 223-234. Disponible en: https://doi.org/10.1111/j.1475-2743.2008.00169.x

58. CAI, X., Zhang, X., Wang, D. Land Availability for Biofuel Production. Environmental Science \& Technology. 2011, 45(1) pp. 334-339. Disponible en: https://doi.org/10.1021/es103338e

59. ALCANTARA, C., Kuemmerle, T., Prishchepov, A.V., Radeloff, V.C. Mapping abandoned agriculture with multi-temporal MODIS satellite data. Remote Sensing of Environment. 2012, 124, pp. 334-347. Disponible en: https://doi.org/10.1016/j.rse.2012.05.019

60. CEUASU, S., Hofmann, M., Navarro, L.M., Carver, S., Verburg, P.H., Pereira, H.M. Mapping opportunities and challenges for rewilding in Europe. Conservation Biology. 2015, 29(4), pp. 1017-1027. Disponible en: https://doi.org/10.1111/cobi.12533

61. LIU, T., Huffman, T., Kulshreshtha, S., McConkey, B., Du, Y., Green, M., Liu, J., Shang, J., Geng, X. Bioenergy production on marginal land in Canada: Potential, economic feasibility, and greenhouse gas emissions impacts. Applied Energy. 2017, 205, pp. 477-485. Disponible en: https://doi.org/10.1016/j.apenergy.2017.07.126

62. VAN EUPEN, M., Elbersen, B., Mantel, S. Marginal Land, Ed. Wageningen University and Research, 2018. [consulta 08/05/2018] Disponible en: http://iiasa-

spatial.maps.arcgis.com/apps/webappviewer/index.html?id=010a68ba425649 569a049d111b3dcbe7.

63. MC LAUGHLIN, S.B., Walsh, M.E. Evaluating environmental consequences of producing herbaceous crops for bioenergy. Biomass \& Bioenergy. 1998, 14(4), pp. 317-324. Disponible en: https://doi.org/10.1016/s0961-9534(97)10066-6

64. CURT, M.D. Cultivo energético del Switchgrass o panizo de pradera (Panicum virgatum L.). HD2134, 2009, MAPA, Madrid 
65. LEWANDOWSKI, I., Scurlock, J.M.O., Lindvall, E., Christou, M. The development and current status of perennial rhizomatous grasses as energy crops in the US and Europe. Biomass \& Bioenergy. 2003, 25(4), pp. 335-361. Disponible en: https://doi.org/10.1016/S0961-9534(03)00030-8

66. JUNG, J.Y., Lal, R. Impacts of nitrogen fertilization on biomass production of switchgrass (Panicum Virgatum L.) and changes in soil organic carbon in Ohio. Geoderma. 2011, 166(1), pp. 145-152. Disponible en https://doi.org/10.1016/j.geoderma.2011.07.023

67. FRANK, A.B., Berdahl, J.D., Hanson, J.D., Liebig, M.A., Johnson, H.A. Biomass and carbon partitioning in switchgrass. Crop Science. 2004, 44(4), pp. 13911396. Disponible en: https://doi.org/10.2135/cropsci2004.1391

68. ADERSON-TEIXEIRA, K.J., Davis, S.C., Masters, M.D., Delucia, E.H. Changes in soil organic carbon under biofuel crops. Global Change Biology Bioenergy. 2009, 1(1), pp. 75-96. Disponible en: https://doi.org/10.1111/j.17571707.2008.01001.x

69. GARTEN, C.T.Jr., Smith, J.L., Tyler, D.D., Amonette, J.E., Bailey, V.L., Brice, D.J., Castro, H.F., Graham, R.L., Gunderson, C.A., Izaurralde, R.C., Jardine, P.M., Jastrow, J.D., Kerley, M.K., Matamala, R., Mayes, M.A., Metting, F.B., Miller, R.M., Moran, K.K., Post, W.M., III, Sands, R.D., Schadt, C.W., Phillips, J.R., Thomson, A.M., Vugteveen, T., West, T.O., Wullschleger, S.D. Intraannual changes in biomass, carbon, and nitrogen dynamics at 4-year old switchgrass field trials in west Tennessee, USA. Agriculture Ecosystems \& Environment. 2010, 136(1-2), pp. 177-184. Disponible en: https://doi.org/10.1016/j.agee.2009.12.019

70. WIENHOLD, B.J., Varvel, G.E., Johnson, J.M.F., Wilhelm, W.W. Carbon Source Quality and Placement Effects on Soil Organic Carbon Status. Bioenergy Research. 2013, 6(2), pp. 786-796. Disponible en: https://doi.org/10.1007/s12155-013-9301-z

71. TUFEKCIOGLU, A., Raich, J.W., Isenhart, T.M., Schultz, R.C. Biomass, carbon and nitrogen dynamics of multi-species riparian buffers within an agricultural watershed in lowa, USA. Agroforestry Systems. 2003, 57(3), pp. 187-198. Disponible en: https://doi.org/10.1023/a:1024898615284

72. DOHLEMAN, F.G., Heaton, E.A., Arundale, R.A., Long, S.P. Seasonal dynamics of above- and below-ground biomass and nitrogen partitioning in Miscanthus $\mathrm{x}$ giganteus and Panicum virgatum across three growing seasons. Global Change Biology Bioenergy. 2012, 4(5), pp. 534-544. Disponible en: https://doi.org/10.1111/j.1757-1707.2011.01153.x

73. BRANSBY, D.L., McLaughlin, S.B., Parrish, D.J., A review of carbon and nitrogen balances in switchgrass grown for energy. Biomass \& Bioenergy. 1998, 14(4), pp. 379-384. Disponible en: https://doi.org/10.1016/s09619534(97)10074-5

74. COLLINS, H.P., Smith, J.L., Fransen, S., Alva, A.K., Kruger, C.E., Granatstein, D.M. Carbon Sequestration under Irrigated Switchgrass (Panicum virgatum L.) Production. Soil Science Society of America Journal. 2010, 74(6), pp. 20492058. Disponible en: https://doi.org/10.2136/sssaj2010.0020

75. WERLING, B.P., Dickson, T.L., Isaacs, R., Gaines, H., Gratton, C., Gross, K.L., Liere, H., Malmstrom, C.M., Meehan, T.D., Ruan, L., Robertson, B.A., Robertson, G. P., Schmidt, T.M., Schrotenboer, A.C., Teal, T.K., Wilson, J.K., 
Landis, D.A. Perennial grasslands enhance biodiversity and multiple ecosystem services in bioenergy landscapes. Proceedings of the National Academy of Sciences of the United States of America. 2014, 111(4), pp. 1652-1657. Disponible en: https://doi.org/10.1073/pnas.1309492111

76. ROTH, A.M., Sample, D.W., Ribic, C.A., Paine, L., Undersander, D.J., Bartelt, G.A. Grassland bird response to harvesting switchgrass as a biomass energy crop. Biomass \& Bioenergy. 2005, 28(5), pp. 490-498. Disponible en: https://doi.org/10.1016/j.biombioe.2004.11.001

77. SMEETS, E.M.W., Lewandoski, I.M., Faaij, A.P.C., The economical and environmental performance of miscanthus and switchgrass production and supply chains in a European setting. Renewable \& Sustainable Energy Reviews. 2009, 13(6-7), pp. 1230-1245. Disponible en: https://doi.org/10.1016/j.rser.2008.09.006

78. PALMER, L., Gehl, R.J., Ranney, T.G., Touchell, D., George, N. Biomass yield, nitrogen response, and nutrient uptake of perennial bioenergy grasses in North Carolina. Biomass \& Bioenergy. 2014, 63, pp. 218-228. Disponible en: https://doi.org/ 10.1016/j.biombioe.2014.02.016

79. ZILVERBERG, C.J., Johnson, W.C., Owens, V., Boe, A., Schumacher, T., Reitsma, K., Hong, C.O., Novotny, C., Volke, M., Werner, B. Biomass yield from planted mixtures and monocultures of native prairie vegetation across a heterogeneous farm landscape. Agriculture Ecosystems \& Environment. 2014, 186, pp. 148-159. Disponible en: https://doi.org/10.1016/j.agee.2014.01.027

80. KING, K.L., Homyack, J.A., Wigley, T.B., Miller, D.A., Kalcounis-Rueppell, M.C. Response of rodent community structure and population demographics to intercropping switchgrass within loblolly pine plantations in a forest-dominated landscape. Biomass \& Bioenergy. 2014, 69, pp. 255-264. Disponible en: https://doi.org/10.1016/j.biombioe.2014.07.006

81. HEATON, E.A., Dohleman, F.G., Minguez, A.F., Juvik, J.A., Lozovaya, V., Widholm, J., Zabotina, O.A., Mclsaac, G.F., David, M.B., Voigt, T.B., Boersma, N.N., Long, S.P. Miscanthus: A Promising Biomass Crop, en Advances in Botanical Research, Ed. Kader,J.C., Delseny, M. Vol. 56, Academic Press, 2010, pp. 75-137

82. CURT, M.D. Miscanto para producción de biomasa. HD2133, 2009, MAPA, Madrid

83. MALETTA, E., Lasorella, M.V. Lignocellulosic Crops, en Land use, crop management and their impacts on economic, environmental and social aspects of biofuel production. Ed. Langeveld et al. Capitulo 13, 2016, pp. 14.

84. CHRISTIAN, D.G., Poulton, P. R., Riche, A. B., Yates, N. E., Todd, A. D. The recovery over several seasons of $\mathrm{N}$-15-labelled fertilizer applied to Miscanthus $x$ giganteus ranging from 1 to 3 years old. Biomass \& Bioenergy. 2006, 30(2), pp. 125-133. Disponible en: https//doi.org/10.1016/j.biombioe.2005.11.002

85. BEUCH, S., Boelcke, B., Belau, L. Effect of the organic residues of Miscanthus $x$ giganteus on the soil organic matter level of arable soils. Journal of Agronomy and Crop Science. 2000, 184(2), pp. 111-119. Disponible en: https://doi.org/10.1046/j.1439-037x.2000.00367.x

86. DONDINI, M., Hastings, A., Saiz, G., Jones, M.B., Smith, P. The potential of Miscanthus to sequester carbon in soils: comparing field measurements in 
Carlow, Ireland to model predictions. Global Change Biology Bioenergy. 2009, 1(6), pp. 413-425. Disponible en: https://doi.org/10.1111/j.17571707.2010.01033.x

87. AMOUGOU, N., Bertrand, I., Machet, J.-M., Recous, S. Quality and decomposition in soil of rhizome, root and senescent leaf from Miscanthus $\mathrm{X}$ giganteus, as affected by harvest date and $\mathrm{N}$ fertilization. Plant and Soil. 2011, 338(1-2), pp. 83-97. Disponible en https://doi.org/10.1007/s11104-010-0443-x

88. HIMKEN, M., Lammel, J., Neukirchen, D., CzypionkaKrause, U., Olfs, H.W. Cultivation of Miscanthus under west European conditions: Seasonal changes in dry matter production, nutrient uptake and remobilization. Plant and Soil. 1997, 189(1), pp. 117-126. Disponible en https://doi.org/10.1023/a:1004244614537

89. RICHTER, G.M., Agostini, F., Redmile-Gordon, M., White, R., Goulding, K.W.T. Sequestration of $C$ in soils under Miscanthus can be marginal and is affected by genotype-specific root distribution. Agriculture Ecosystems \& Environment. 2015, 200, pp. 169-177. Disponible en: https://doi.org/10.1016/j.agee.2014.11.011

90. NEUKIRCHEN, D., Himken, M., Lammel, J., Czyionka-Krause, U., Olfs, H.W. Spatial and temporal distribution of the root system and root nutrient content of an established Miscanthus crop. European Journal of Agronomy. 1999, 11(34), pp. 301-309. Disponible en: https://doi.org/10.1016/s1161-0301(99)00031-3

91. HANSEN, E.M., Christensen, B.T., Jensen, L.S., Kristensen, K. Carbon sequestration in soil beneath long-term Miscanthus plantations as determined by C-13 abundance. Biomass \& Bioenergy. 2004, 26(2), pp. 97-105. Disponible en: https://doi.org/10.1016/s0961-9534(03)00102-8

92. HEDDE, M., van Oort, F., Boudon, E., Abonnel, F., Lamy, I. Responses of soil macroinvertebrate communities to Miscanthus cropping in different trace metal contaminated soils. Biomass \& Bioenergy. 2013, 55, pp. 122-129. Disponible en: https://doi.org/10.1016/j.biombioe.2013.01.016

93. HEDDE, M., van Oort, F., Renou, E., Thenard, J., Lamy, I. Dynamics of soil fauna after plantation of perennial energy crops on polluted soils. Applied Soil Ecology. 2013, 66, pp. 29-39. Disponible en: https://doi.org/10.1016/i.apsoil.2013.01.012

94. SEMERE, T., Slater, F.M., Invertebrate populations in miscanthus (Miscanthus $x$ giganteus) and reed canary-grass (Phalaris arundinacea) fields. Biomass \& Bioenergy, 2007, 31(1), pp. 30-39. Disponible en: https://doi.org/10.1016/j.biombioe.2006.07.002

95. CADOUX, S., Riche, A.B., Yates, N.E., Machet, J.-M. Nutrient requirements of Miscanthus $\mathrm{x}$ giganteus: Conclusions from a review of published studies. Biomass \& Bioenergy. 2012, 38, pp. 14-22. Disponible en: https://doi.org/10.1016/j.biombioe.2011.01.015

96. SEMERE, T., Slater, F.M., Ground flora, small mammal and bird species diversity in miscanthus (Miscanthus $x$ giganteus) and reed canary-grass (Phalaris arundinacea) fields. Biomass \& Bioenergy. 2007, 31(1), pp. 20-29. Disponible en: https://doi.org/10.1016/i.biombioe.2006.07.001

97. CURT, M.D. Cultivo de la caña común (Arundo donax L.) para producción de biomasa. HD2129, 2009, MAPA, Madrid. 
98. ANGELINI, L.G., Ceccarini, L., Bonari, E. Biomass yield and energy balance of giant reed (Arundo donax L.) cropped in central Italy as related to different management practices. European Journal of Agronomy, 2005, 22(4), pp. 375389. Disponible en: https://doi.org/10.1016/j.eja.2004.05.004

99. SARKHOT, D.V., Grunwald, S., Ge, Y., Morgan, C. L. S. Total and available soil carbon fractions under the perennial grass Cynodon dactylon (L.) Pers and the bioenergy crop Arundo donax L. Biomass \& Bioenergy. 2012, 41, pp. 122-130. Disponible en: https://doi.org/10.1016/j.biombioe.2012.02.015

100. CATTANEO, F., Di Gennaro, P., Barbanti, L., Giovannini, C., Labra, M., Moreno, B., Benitez, E., Marzadori, C. Perennial energy cropping systems affect soil enzyme activities and bacterial community structure in a South European agricultural area. Applied Soil Ecology. 2014, 84, pp. 213-222. Disponible en: https://doi.org/10.1016/j.apsoil.2014.08.003

101. SMITH, A.L., Klenk, N., Wood, S., Hewitt, N., Henriques, I., Yan, N., Bazely, D. R. Second generation biofuels and bioinvasions: An evaluation of invasive risks and policy responses in the United States and Canada. Renewable \& Sustainable Energy Reviews. 2013, 27, pp. 30-42. Disponible en: https://10.1016/j.rser.2013.06.013

102. LANDSTRÖM, S. Sustainability of reed canarygrass in cold climate., en Alternative crops for sustainable agriculture, Ed. Mela, T., et al. 1999, European Commision, Finland.

103. KATTERER, T., Andren, O. Growth dynamics of reed canarygrass (Phalaris arundinacea L.) and its allocation of biomass and nitrogen below ground in a field receiving daily irrigation and fertilisation. Nutrient Cycling in Agroecosystems. 1999, 54(1), pp. 21-29. Disponible en: https://doi.org/10.1023/a:1009701422394

104. BORJESSON, P. Environmental effects of energy crop cultivation in Sweden-I: Identification and quantification. Biomass \& Bioenergy. 1999, 16(2), pp. 137-154. Disponible en: https://doi.org/10.1016/s0961-9534(98)00080-4

105. GLOBAL BIODIVERSITY INFORMATION FACILITY. Free and open acces biodiversity data. [Consulta: 04/06/2020] Disponible en: https://www.gbif.org/

106. LIU, Z.W., Wang, R.C. TALL WHEATGRASS Thinopyrum ponticum (Podp.), Plant Guide. Ed. USDA-NRCS, Pamela Scheinost: Plant Materials Center. 2011, Pullman, Washington. pp. 5

107. SANDOR, C. Tall Wheatgrass Cultivar Szarvasi-1 Elymus elongatus subsp. ponticus cv. Szarvasi-1) as a Potential Energy Crop for Semi-Arid Lands of Eastern Europe, en Sustainable Growth and Applications in Renewable Energy Sources. Ed. Nayeripour, M, Intech Open. 2011, Hungary. pp. 269-294. ISBN: 978-953-307-408-5. Disponible en https://doi.org/10.5772/2433

108. MELDERIS, A. Flora Europaea. Alismataceae to Orchidaceae (Monocotyledones). Ed. Tutin, T.G., et al. Vol. 5, Cambridge University Press. 1980, Cambridge, England, pp:192-199. ISBN: 13:9780521153706

109. JAFARI, A.A., Elmi, A., Bakhtiari, M. Evaluation of yield and quality traits in 17 populations of tall wheatgrass (Agropyrum elongatum) grown in rainfed area of Iran, under two cutting management. Romanian Agricultural Research. 2014. 31, pp. 49-58. ISSN: 1222-4227. 
110. COX, G.W. And inventory and alaysis of the alien plant flora of New Mexico, en the New Mexico Botanist. Vol. 17, 2001, pp. 1-8

111. SEDIVEC, K.K., Tober, D.A., Duckwitz, W.L. Grasses for the Northern Plains: Growth patterns, forage characteristics and wildlife values. Volume I: Cool season grasses. Ed. North Dakota State University. 2009, Fargo, North Dakota. pp: 89.

112. OGLE, D. Crested wheatgrass. Agropyron cristatum (L.) Gaertn. Plant Guide. Ed. USDA-NRCS. 2006, Idaho. pp. 4

113. OGLE, D., St. John, L., Jensen, K.B. Siberian wheatgrass (Agropyron fragile). Plant Guide. Ed. USDA-NRCS. 2013, Aberdeen, Idaho. pp: 5

114. JENSEN, K.B., Bushman, B.S., Waldron, B.L., Robins, J.G., Johnson, D.A., Staub, J.E. 'Stabilizer', a New Low-Growing Siberian Wheatgrass Cultivar for Use on Semiarid Lands. Journal of Plants Registration. 2013, 7(1), pp: 8994. Disponible en: https://doi.org/10.3198/jpr2012.03.0193crc

115. SECCIÓN DE EVALUACIÓN DE RECURSOS AGRARIOS. Departamento de Desarrollo Rural y Medio Ambiente. Análisis de economía de los sistemas de producción. Ed. Gobierno de Navarra, 2008, Pamplona.

116. LLOVERAS, J., Cabases, M.A. Costes de producción de cultivos extensivos en secano y regadío. Ed. Eumedia. Vida Rural no 401 . 2015, Madrid, pp. 92.

117. EIRIZ-GERVAS, G., Orodea García, L.F., García Coiradas, L., Ramírez Carrasco, G., Simarro Bautista, J.C. MAPAMA (2017): Resultados técnicoeconómicos de Cultivos Herbáceos 2015, in Estudios de Costes y Rentas de las Explotaciones Agrarias. Ed. MAPA, 2017, Madrid.

118. NEMECEK, T., Kägi, T., Blaser, S. Life cycle inventories of agricultural production systems. Document no 15. 2a Ed. Ecoinvent, 2007

119. FINKBEINER, M. The International Standards as the Constitution of Life Cycle Assessment: The ISO 14040 Series and its Offspring. Background and Future Prospects in Life Cycle Assessment. 2014, pp. 85-106. Disponible en: https://doi.org/10.1007/978-94-017-8697-3 3

120. FRISCHKNECHT, R., Jungbluth, N., Althaus, H.-J., Hischier, R., Doka, G., Bauer, Ch., Dones, R., Nemecek, T., Hellweg, S., Humbert, S., Margni, M., Koellner, T., Loerincik, Y. Implementation of Life Cycle Impact Assessment Methods. Document no 3. Ed. 2.2 Ecoinvent, 2010.

121. MAPA, Evolución de la superficie y producción de cereales en España. Ed. Secretaría General de agricultura y Alimentación, MAPA. 2016, Madrid.

122. MAPA, Bienes y los rendimientos asegurables, las condiciones técnicas mínimas de cultivo, el ámbito de aplicación, los periodos de garantía, las fechas de suscripción y los precios unitarios del seguro de explotaciones de cultivos herbáceos extensivos, comprendido en el trigésimo noveno Plan de Seguros Agrarios Combinados. BOE no 11785, Orden APA/883/2018. Ed. Gobierno de España. 2018, Madrid, pp. 185.

123. MAPA, Hojas de cálculo de costes de la maquinaria. Ed. MAPA, 2018, Madrid. [Consulta 18/10/2018] Disponible en: https://www.mapa.gob.es/es/ministerio/servicios/informacion/plataforma-deconocimiento-para-el-medio-rural-y-pesquero/observatorio-de-tecnologiasprobadas/maquinaria-agricola/hojas-calculo-maqui.aspx. 
124. LOPEZ, L., Betran, J., Ramos, A., Lopez, H., Lopez, P., Bermejo, J.L., Urbano, P., Piñeiro, J., Castro, J., Blazquez, R., Ramos, C., Pomares, F., Quiñones, A., Martinez, B., Primo, E., Legaz, F., Espada, J.L., GarciaEscudero, E., Garcia, C., Perez, J. Guia práctica de la fertilización racional de los cultivos en España. Vol II, 1를. MAPA, 2009, pp: 144. ISBN: 978-84-4910997-3

125. FOMBELLIDA, A., Garijo, J. Manual para el cumplimiento de la condicionalidad. Cereales de invierno. Ed. MAPA, 2011. pp:34 NIPO: 770-11067-0

126. SISTEMA ESPAÑOL DE INFORMACIÓN SOBRE EL AGUA (HISPAGUA). Mapa de suelos. Ed: CEDEX. 2018. [Consulta: 27/09/2018] Disponible en: http://hispagua.cedex.es/en/datos/suelos

127. KING, J., Gay, A., Sylvester-Bradley, R., Bingham, I., Foulkes, J., Gregory, P., Robinson, D. Modelling cereal root systems for water and nitrogen capture: Towards an economic optimum. Annals of Botany. 2003, 91(3), pp. 383-390. Disponible en: https://doi.org/10.1093/aob/mcg033

128. JAHN, R., Blume, H.-P., Asio, V.B., Spaargaren, O., Schad, P. Guidelines For Soil Description. 4th ed. FAO. 2006, Rome, pp 109.

129. REEVES, D.W. The role of soil organic matter in maintaining soil quality in continuous cropping systems. Soil \& Tillage Research. 1997, 43(1-2), pp. 131-167. Disponible en: https://doi.org/10.1016/s0167-1987(97)00038-x

130. LYNCH, J. Spink, J., Doyle, D., Hackett, R., Phelan, S., Forristal, D., Kildea, S., Glynn, L., Plunkett, M., Wall, D., Hutton, F., Hennessy, M. The Winter Wheat Guide, enCrops, Environment and Land Use Program. Ed Agriculture and Food Authority. 2016, Ireland, pp. 40.

131. ARREGUI, L.M., Maetzu, I., Quemada, M. Estimación del drenaje y lavado de nitratos en un sistema de cultivo de cereal de invierno en condiciones de secano y clima Mediterráneo húmedo, en Estudios de la zona no saturada del suelo. Ed. Samper F.J., Paz, A. 7, 2005, pp. 137-143. ISBN: 84-9749-1718

132. VITOSH, H.L. Wheat fertility and fetilization, en Wheat Facts. Ed. Michigan University. 1998, Michigan State University, Michigan. p. 1-4.

133. Fleming, P., Perrier, A., Cavazza, L., Tombesi L., Feddes, R., Doorenbos, J., Pereira L.S., Monteith, J.L., Gunston H., Allen, R., Jensen M., Pruitt, W.O., Rijks, D. Evapotranspiración del cultivo. Guías para la determinación de los requerimientos de agua de los cultivos. Ed. FAO riego y drenaje, Vol. 54. FAO, 1990, Rome, pp 322. ISBN: 92-5-304219-2; ISSN 02545293

134. NINYEROLA, M., Pons, X., Roure, J.M. Atlas climático digital de la peninsula ibérica. Metodología y aplicaciones en bioclimatologia y geobotanica. Ed. Universidad Autonoma de Barcelona. 2005. [Consulta 28/09/2018] Disponible en: http://www.opengis.uab.es/wms/iberia/mms/index.htm

135. DARDEL, C., Kergoat, L., Hiernaux, P., Grippa, M., Mougin, E., Ciais, P., Nguyen, C.-C. Rain-Use-Efficiency: What it Tells us about the Conflicting Sahel Greening and Sahelian Paradox. Remote Sensing. 2014, 6(4), pp. 34463474. Disponible en: https://doi.org/10.3390/rs6043446

136. HENDRICKSON, J.R., Schemer, M.R., Sanderson, M.A. Water Use Efficiency by Switchgrass Compared to a Native Grass or a Native Grass Alfalfa 
Mixture. Bioenergy Research. 2013, 6(2), pp. 746-754. Disponible en: https://doi.org/10.1007/s12155-012-9290-3

137. FRANK, A.B., Bauer, A. Rooting activity and water use during vegetative development of crested wheatgrass and western wheatgrass. Agronomy Journal. 1991, 83(5), pp. 906-910. Disponible en: https://doi.org/10.2134/agronj1991.00021962008300050025x

138. MEYER, R. Diversity of European Farming Systems and Pathways to Sustainable Intensification en Technikfolgenabschätzung - Theorie und Praxis. 2014, 23(3), pp. 11

139. NEMECEK, T., Schnetzer, J. Methods of assessment of direct field emissions for LCls of agricultural production systems. Document $n^{0} 15$. $3^{\underline{a}}$ Ed. Ecoinvent. 2012, pp. 34.

140. BALESDENT, J., Chenu, C., Balabane, M. Relationship of soil organic matter dynamics to physical protection and tillage. Soil \& Tillage Research. 2000, 53(3-4), pp. 215-230. Disponible en: https://doi.org/10.1016/s01671987(99)00107-5

141. JARECKI, M.K., Lal, R. Crop management for soil carbon sequestration. Critical Reviews in Plant Sciences. 2003, 22(6), pp. 471-502. Disponible en: https://doi.org/10.1080/713608318

142. SIGNOR, D., Deon, M.D., de Camargo, P.B., Pellegrino Cerri, C.E. Quantity and quality of soil organic matter as a sustainability index under different land uses in Eastern Amazon. Scientia Agricola. 2018, 75(3), pp. 225232. Disponible en: https://doi.org/10.1590/1678-992x-2016-0089

143. SANCHEZ-GONZALEZ, A., Chapela-Lara, M., German-Venegas, E., Fuentes-Garcia, R., del Rio-Portilla, F., Siebe, C. Changes in quality and quantity of soil organic matter stocks resulting from wastewater irrigation in formerly forested land. Geoderma. 2017, 306, pp. 99-107. Disponible en: https://doi.org/10.1016/j.geoderma.2017.07.009

144. CIRIA, P., Perez, P., Maletta, E., Carrasco, J., Esteban, L.S. BIORAISECE. Aplicación SIG para la evaluación de cultivos energéticos en Europa. Ed. MINECO. CEDER-CIEMAT 2009 [consulta 25/10/2018]. Disponible en: http://bioraise.ciemat.es/BioraiseCE

145. SANZ, M., Mosquera, F., Sanchez, G., Barreiro, M., Aguado, P.L., Sanchez, J., Curt, M.D., Fernandez, J. Biomass potential of triticale and rye in two different phenological stages and energy characterization, en 19th European Biomass Conference., Ed. Faulstich, M., Ossenbrink, H., Dallemand, J.F., Baxter, D., Grassi, A., Helm, P. 2011, Berlin, Germany. pp. 591-595

146. CIRIA, P., Maletta, M., Del Val, M.A., Pérez, J., Pérez, P., Carrasco, J., Cultivos herbáceos anuales para producción de biomasa en España en el marco del Proyecto Singular Estratégico On- Cultivos. Ed. CIEMAT. 2015, Madrid, pp 116. ISBN: 978-84-7834-732-2

147. MEYER, A.K.P., Ehimen, E.A., Holm-Nielsen, J.B. Future European biogas: Animal manure, straw and grass potentials for a sustainable European biogas production. Biomass \& Bioenergy. 2018, 111, pp. 154-164. Disponible en: https://doi.org/10.1016/i.biombioe.2017.05.013

148. BOEHMEL, C., Lewandowski, I., Claupein, W. Comparing annual and perennial energy cropping systems with different management intensities. 
Agricultural Systems. 2008, 96(1-3), pp. 224-236. Disponible en: https://doi.org/10.1016/j.agsy.2007.08.004

149. PEARSON, C.H., Larson, S.R., Keske, C.M.H., Jensen, K.B. Native grasses for biomass production at high elevation, en Industrial Crops. Handbook of Plant Breeding, Ed. Cruz, V.M.V. and Dierig, D.A. Springer. 2014, New York. p. 101-132. Disponible en: https://doi.org/10.1007/978-1-4939-1447$\underline{06}$

150. PEDROSO, G.M., Hutmacher, R.B., Putnam, D., Six, J., van Kessel, C., Linquist, B.A. Biomass yield and nitrogen use of potential C-4 and C-3 dedicated energy crops in a Mediterranean climate. Field Crops Research. 2014, 161, pp. 149-157. Disponible en: https://doi.org/10.1016/i.fcr.2014.02.003

151. SUYAMA, H., Benes, S. E., Robinson, P. H., Getachew, G., Grattan, S. R., Grieve, C. M. Biomass yield and nutritional quality of forage species under long-term irrigation with saline-sodic drainage water: Field evaluation. Animal Feed Science and Technology. 2007, 135(3-4), pp. 329-345. Disponible en: https://doi.org/10.1016/j.anifeedsci.2006.08.010

152. LAURIAULT, L.M., Kirksey, R.E., Donart, G.B. Irrigation and nitrogen effects on tall wheatgrass yield in the Southern High Plains. Agronomy Journal. 2002, 94(4), pp. 792-797. ISSN: 0002-1962.

153. WANG, G.J., Nyren, P., Xue, Q. W., Aberle, E., Eriksmoen, E., Tjelde, T., Liebig, M., Nichols, K., Nyren, A. Establishment and Yield of Perennial Grass Monocultures and Binary Mixtures for Bioenergy in North Dakota. Agronomy Journal. 2014, 106(5), pp. 1605-1613. Disponible en: https://doi.org/10.2134/agronj14.0068

154. DICKEDUISBERG, M., Laser, H., Tonn, B., Isselstein, J. Tall wheatgrass (Agropyron elongatum) for biogas production: Crop management more important for biomass and methane yield than grass provenance. Industrial Crops and Products. 2017, 97, pp. 653-663. Disponible en: https://doi.org/10.1016/j.indcrop.2016.12.055

155. PODLASKI, S., Pietkiewicz, S., Choluj, D., Horaczek, T., Wisniewski, G., Gozdowski, D., Kalaji, H. M. The relationship between the soil water storage and water-use efficiency of seven energy crops. Photosynthetica. 2017, 55(2), pp. 210-218. Disponible en: https://doi.org/10.1007/s11099-017-0697-0

156. CABLE, D.R. Influence of precipitation on perennial grass production in semidesert Southwest. Ecology. 1975, 56(4), pp. 981-986. Disponible en: https://doi.org/10.2307/1936309

157. TELLO-GARCIA, E., Huber, L., Leitinger, G., Peters, A., Newesely, C., Ringler, M. E., Tasser, E. Drought- and heat-induced shifts in vegetation composition impact biomass production and water use of alpine grasslands. Environmental and Experimental Botany, 2020. 169. Disponible en: https://doi.org/10.1016/j.envexpbot.2019.103921

158. DI-NASSO, O., Angelini, L. G., Bonari, E. Influence of fertilisation and harvest time on fuel quality of giant reed (Arundo donax L.) in central Italy. European Journal of Agronomy. 2010, 32(3), pp. 219-227. Disponible en: https://doi.org/10.1016/j.eja.2009.12.001

159. PROCHNOW, A., Heiermann, M., Ploechl, M., Linke, B., Idler, C., Amon, T., Hobbs, P. J. Bioenergy from permanent grassland-A review: 1. Biogas. 
Bioresource Technology. 2009, 100(21), pp. 4931-4944. Disponible en: https://doi.org/10.1016/j.biortech.2009.05.070

160. OBERNBERGER, I., Brunner, T., Baernthaler, G. Chemical properties of solid biofuels - significance and impact. Biomass \& Bioenergy. 2006, 30(11), pp. 973-982. Disponible en: https://doi.org/10.1016/j.biombioe.2006.06.011

161. ISO, ISO 17225-1:2014 Solid biofuels- Fuel specifications and classes Part 1: General requirements. Ed. ISO. 2014, pp. 56

162. JENKINS, B.M., Bakker, R.R., Wei, J.B. On the properties of washed straw. Biomass \& Bioenergy. 1996, 10(4), pp. 177-200. Disponible en: https://doi.org/10.1016/0961-9534(95)00058-5

163. NAZLI, R.I., Tansi, V., Ozturk, H.H., Kusvuran, A. Miscanthus, switchgrass, giant reed, and bulbous canary grass as potential bioenergy crops in a semi-arid Mediterranean environment. Industrial Crops and Products. 2018, 125, pp. 9-23. Disponible en: https://doi.org/10.1016/j.indcrop.2018.08.090

164. MARTYNIAK, D., Zurek, G., Prokopiuk, K. Biomass yield and quality of wild populations of tall wheatgrass Elymus elongatus (Host.) Runemark. Biomass \& Bioenergy. 2017, 101, pp. 21-29. Disponible en: https://doi.org/ 10.1016/j.biombioe.2017.03.025

165. FLORINE, S.E., Moore, K.J., Fales, S.L., White, T.A., Burras, C.L. Yield and composition of herbaceous biomass harvested from naturalized grassland in southern lowa. Biomass \& Bioenergy. 2006, 30(6), pp. 522-528. Disponible en: https://doi.org/10.1016/j.biombioe.2005.12.007

166. EL-NASHAAR, H.M., Griffith, S.M., Steiner, J.J., Banowetz, G.M. Mineral concentration in selected native temperate grasses with potential use as biofuel feedstock. Bioresource Technology. 2009, 100(14), pp. 3526-3531. Disponible en: https://doi.org/10.1016/j.biortech.2009.02.051

167. NAZLI, R.I., Tansi, V. Influences of nitrogen fertilization and harvest time on combustion quality of four perennial grasses in a semi-arid Mediterranean climate. Industrial Crops and Products. 2019, 128, pp. 239-247. Disponible en: https://doi.org/10.1016/j.indcrop.2018.11.019

168. ISO, ISO 17225-6:2014 Solid biofuels- Fuel specifications and classesPart 6: Graded non woody pellets. Ed. ISO. 2014, pp. 7

169. FAO, FAOSTAT: Food and Agriculture Data. Ed. FAO. 2020 [Consulta 25/05/2020] Disponible en: http://www.fao.org/faostat/en/\#data/QC 
COLECCIÓN COMPLETA DE PUBLICACIONES 


\section{CAPÍTULO VIII: COLECCIÓN COMPLETA DE PUBLICACIONES}

\subsection{Congresos}

\subsubsection{Sustainable Biomass Feedstock Options for Advanced Biofuels}

Autores: Christou, M., Alexopoulou, E., Monti, A., Zegada-Lizarazu, W., Parenti, A., Carrasco, J., Ciria, C.S., Pari, L., Suardi, A.

Evento: 27th European Biomass Conference and Exhibition. Lisboa, 2019.

Sesión:1DV.3.1

Paginas:276 - 280

ISBN:978-88-89407-19-6

Paper DOI:10.5071/27thEUBCE2019-1DV.3.1

\subsubsection{Biomass Production and Feedstock Diversification for Advanced Biofuels: The} Becool Project

Autores: Christou, M., Alexopoulou, E., Monti, A., Zegada-Lizarazu, W., Parenti, A., Carrasco, J., Ciria, C.S., Pari, L., Suardi, A.

Evento: 26th European Biomass Conference and Exhibition. Copenhague, 2018.

Sesión: 1BV.8.26

Páginas: 207 - 208

ISBN: 978-88-89407-18-9

Paper DOI: 10.5071/26thEUBCE2018-1BV.8.26

\subsubsection{Perennial Grasses as feedstock for Bioenergy and Bio-Products}

Autores: Alexopoulou, E., Christou, M., Zegada-Lizarazu, W., Monti, A., Parenti, A., Carrasco, J., Ciria, C.S.

Evento: 26th European Biomass Conference and Exhibition. Copenhague, 2018.

Sesión: 1DV.5.21. Presentación realizada solo con póster.

ISBN: 978-88-89407-18-9

\subsubsection{Estimation and Geographic Distribution of Marginal Agricultural Lands in Spain with Bioenergy Potential}

Autores: Ciria, C.S., Carrasco, J., Sanz, M., Ciria, P.

Evento: 26th European Biomass Conference and Exhibition. Copenhague, 2018.

Sesión: 1AO.1.2. Presentación oral por el doctorando

Páginas: 16 - 20

ISBN: 978-88-89407-18-9

Paper DOI: 10.5071/26thEUBCE2018-1AO.1.2 


\subsubsection{Sunn Hemp, a Promising Leguminous Energy Crop as Inter-Cropping System:}

Preliminary Results for Spain

Autores: Sastre, C.M., Royano, L., Ciria, C.S., Parralejo, A.I., González, J., Ciria, P., Carrasco, J.

Evento: 26th European Biomass Conference and Exhibition. Copenhague, 2018.

Sesión: 1DV.5.10

Páginas: 362 - 365

ISBN: 978-88-89407-18-9

Paper DOI: 10.5071/26thEUBCE2018-1DV.5.10

\subsubsection{Effect of Harvest Time on the Composition of Tall Wheatgrass Biomass under Mediterranean Conditions}

Autores: Barro, R., Cortés, R., Pérez, J., Ciria, C.S., Ciria, P., Fernández, M., Carrasco, J.

Evento: 26th European Biomass Conference and Exhibition. Copenhague, 2018.

Sesión: 1BO.5.3

Páginas: 88 - 95

ISBN: 978-88-89407-18-9

Paper DOI: 10.5071/26thEUBCE2018-1BO.5.3

\subsubsection{Perennial Grasses: Biomass Quality and Yield Comparison of Different Species in the Northern Great Plains of the United States}

Autores: Ciria Ramos, C.S., Berti, M.T., Kazula, M., Peterson, A.

Evento: 25th European Biomass Conference and Exhibition. Estocolmo, 2017.

Sesión: 1DV.2.13

Páginas: 265 - 269

ISBN: 978-88-89407-17-2

Paper DOI: 10.5071/25thEUBCE2017-1DV.2.13

\subsubsection{Pure and Mixed Perennial Biomass Crops for a Constraint Marginal Land in North-Central Spain (a 6-Year Study)}

Autores: Ciria Ramos, C.S., Carrasco, J.E., Perez, J., Barro, R., Ciria, P. Evento: 25th European Biomass Conference and Exhibition. Estocolmo, 2017. Sesión: 1CO.5.3. Presentación oral por el doctorando

Páginas: $120-124$

ISBN: 978-88-89407-17-2

Paper DOI: 10.5071/25thEUBCE2017-1CO.5.3 


\subsubsection{Strategies for Marginal Lands Management in Rain-Fed Agricultural Farms in}

Spain: Economic and Energetic Analysis

Autores: Ciria, C.S., Carrasco, J.E., Pérez, J., Maletta, E., Ciria, P. Evento: 24th European Biomass Conference and Exhibition. Amsterdam, 2016.

Sesión: 1CO.1.2. Presentación oral por el doctorando

Páginas: 126 - 132

ISBN: 978-88-89407-165

Paper DOI: 10.5071/24thEUBCE2016-1CO.1.2

8.1.10 Varietal Response of Elytrigia Elongata under Semiarid Conditions in Spain: Establishment

Autores: Ciria, P., Ciria, C.S., Maletta, E., Pérez, J., Barro, R., Carrasco, J.

Evento: 23rd European Biomass Conference and Exhibition. Viena, 2015.

Sesión: 1 CV.1.8

Páginas: $139-146$

ISBN: 978-88-89407-516

Paper DOI: 10.5071/23rdEUBCE2015-1CV.1.8

8.1.11 Energy Analysis of Agricultural Exploitations under Rain-Fed Continental Conditions in Central-Northern Spain

Autores: Ciria, P., Ciria, C.S., Pérez, P., Carrasco, J.E.

Evento: 19th European Biomass Conference and Exhibition. Berlín, 2011.

Sesión: VP1.3.15

Páginas: 585 - 590

ISBN-13: 978-88-89407-55-4

ISBN-10: 88-89407-55-7

Paper DOI: 10.5071/19thEUBCE2011-VP1.3.15

8.1.12 Energy Balance for an Agricultural and Sheep Farming Exploitation under Extensive Conditions in a Semi-Arid Region of Spain

Autores: M.P. Ciria, C.S. Ciria, P. Pérez

Evento: 16th European Biomass Conference \& Exhibition from Research to Industry and Markets. Valencia, 2008.

Páginas: 322-326

ISBN: 978-88-89407-58-1 


\subsection{Revistas nacionales}

8.2.1 Gramíneas perennes C3 con fines energéticos en sustitución de cultivos tradicionales.

Autores: Carlos S. Ciria Ramos, Pilar Ciria.

Revista: Vida Rural, no 406. Año 2015.

Páginas: 52-56.

ISSN: $1133-8938$

\subsubsection{Gramíneas perennes destinadas a biomasa como alternativa en tierras marginales.}

Autores: Carlos S. Ciria Ramos, Pilar Ciria.

Revista: Vida Rural, no 405. Año 2015.

Páginas: $50-54$

ISSN: $1133-8938$

\subsubsection{Balance energético de siete explotaciones agrícolas de secano.}

Autores: Mํㅡ Pilar Ciria, Carlos S. Ciria, Paloma Pérez, Juan Carrasco.

Revista: Vida Rural. № 324, Suplemento de mecanización agraria. Año 2011.

Páginas: 30-34.

ISSN: $1133-8938$

\subsection{Libros}

\subsubsection{Cultivos herbáceos perennes para producción de biomasa en España.}

Autores: Emiliano Maletta, Juan Carrasco M. Aránzazu Del Val, Javier Pérez, Carlos S. Ciria y Pilar Ciria

Referencia libro: Colección documentos CIEMAT. Editorial Ciemat, Madrid. Año 2016. Páginas: 78

ISBN: 978-84-7834-757-5

\subsubsection{Análisis energético de explotaciones agrícolas de secano.}

Autores: Ma Pilar Ciria Ciria, Carlos S. Ciria Ramos, Paloma Pérez Ortiz, Juan Carrasco.

Referencia Libro: Colección documentos Ciemat. Editorial Ciemat, Madrid. Año 2010 Páginas: 99.

ISBN: 978-84-7834-645-5 
